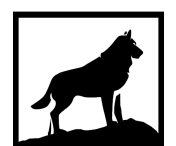

Michigan

Technological

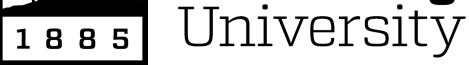

Michigan Technological University

Digital Commons @ Michigan Tech

INTEGRATED COMPUTATIONAL MATERIALS ENGINEERING (ICME) INVESTIGATION OF ELECTRICAL CONDUCTIVITY AND THERMODYNAMIC STABILITY FOR PRECIPITATION STRENGTHENED Al-Zn-Zr AND Al-Zn-Ni TERNARY ALLOYS

Oladeji Fadayomi

Michigan Technological University, otfadayo@mtu.edu

Copyright 2019 Oladeji Fadayomi

Recommended Citation

Fadayomi, Oladeji, "INTEGRATED COMPUTATIONAL MATERIALS ENGINEERING (ICME) INVESTIGATION OF ELECTRICAL CONDUCTIVITY AND THERMODYNAMIC STABILITY FOR PRECIPITATION STRENGTHENED AI-Zn-Zr AND AI-Zn-Ni TERNARY ALLOYS", Open Access Dissertation, Michigan Technological University, 2019.

https://doi.org/10.37099/mtu.dc.etdr/792

Follow this and additional works at: https://digitalcommons.mtu.edu/etdr

Part of the Computational Engineering Commons, and the Metallurgy Commons 


\title{
INTEGRATED COMPUTATIONAL MATERIALS ENGINEERING (ICME) INVESTIGATION OF ELECTRICAL CONDUCTIVITY AND THERMODYNAMIC STABILITY FOR PRECIPITATION STRENGTHENED Al-Zn-Zr AND Al-Zn-Ni TERNARY ALLOYS
}

By

Oladeji Fadayomi

\begin{abstract}
A DISSERTATION
Submitted in partial fulfillment of the requirements for the degree of DOCTOR OF PHILOSOPHY

In Materials Science and Engineering
\end{abstract}

MICHIGAN TECHNOLOGICAL UNIVERSITY

2019

(C) 2019 Oladeji Fadayomi 
This dissertation has been approved in partial fulfillment of the requirements for the Degree of DOCTOR OF PHILOSOPHY in Materials Science and Engineering.

Department of Materials Science and Engineering

\author{
Dissertation Co-Advisor: Gregory M. Odegard \\ Dissertation Co-Advisor: $\quad$ Paul G. Sanders
}

Committee Member: Stephen Hackney

Committee Member: $\quad$ S. Gowtham

Department Chair: Stephen Kampe 


\section{Contents}

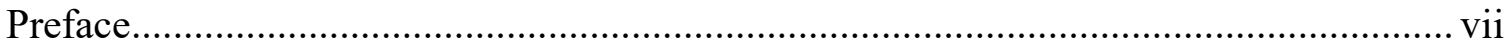

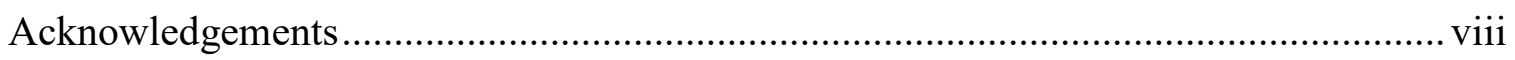

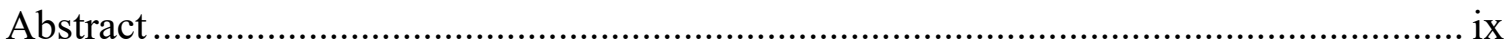

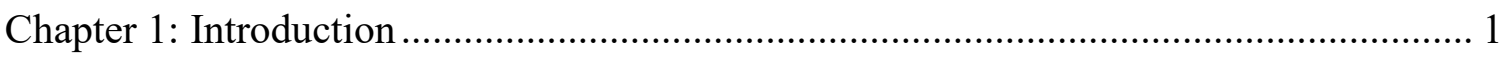

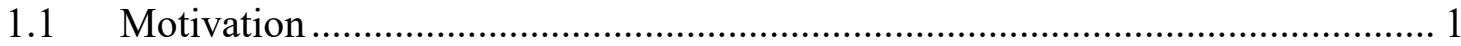

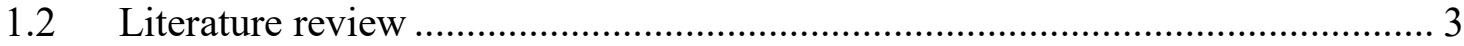

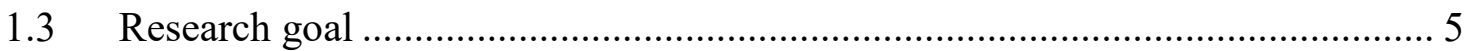

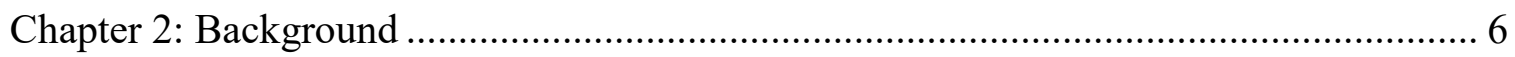

2.1 Vienna ab-initio simulation package - density functional theory...................... 6

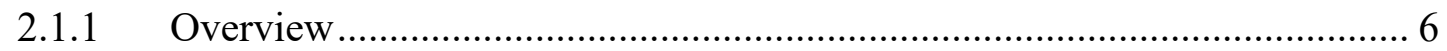

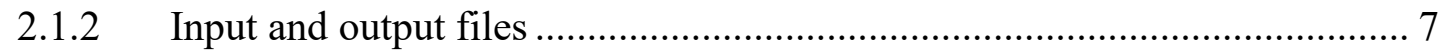

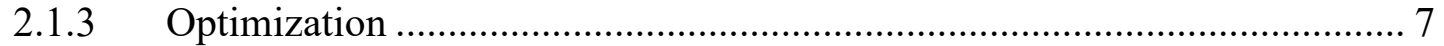

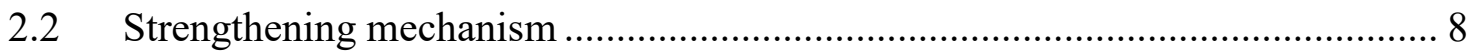

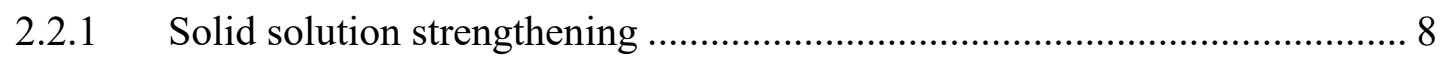

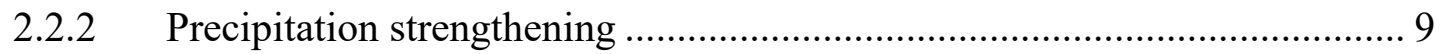

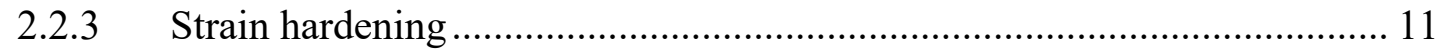

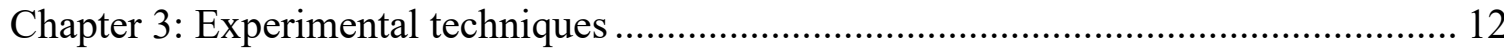

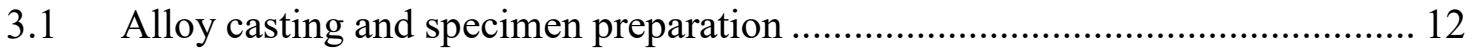

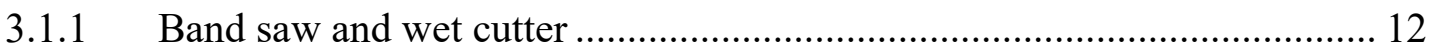

3.1.2 Vacuum induction melter................................................................... 13

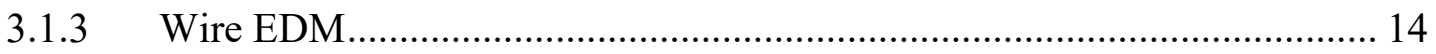

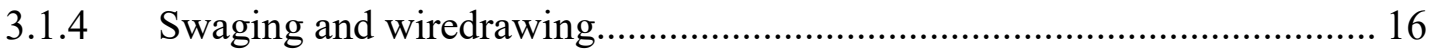

3.1.5 Grinding and auto-polishing specimens........................................... 17

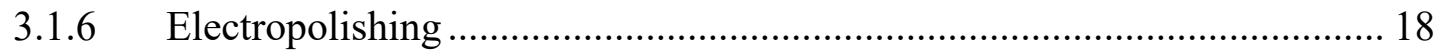

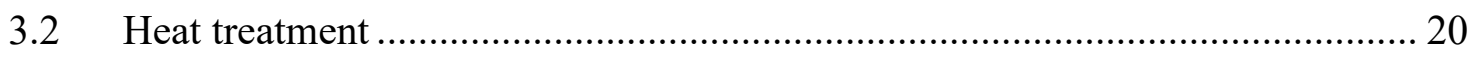

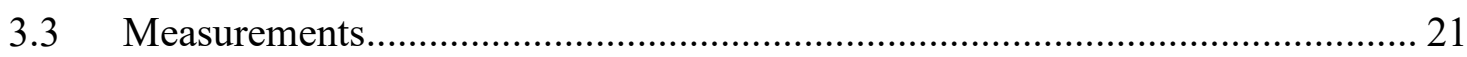

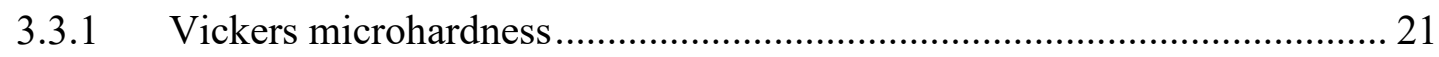

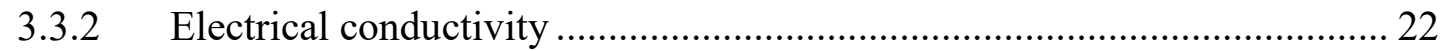




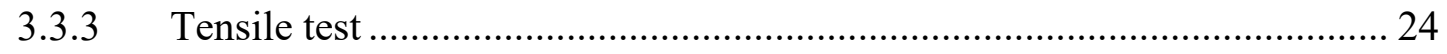

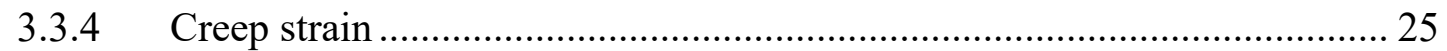

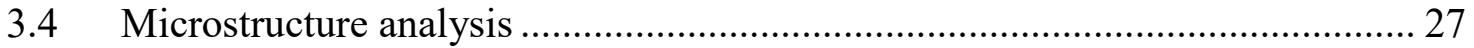

3.4.1 Scanning transmission electron microscope …………………................... 27

3.4.2 Environmental scanning electron microscope .......................................... 29

Chapter 4: Investigation of Al-Zn-Zr and Al-Zn-Ni alloys for high electrical conductivity

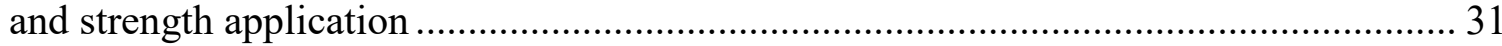

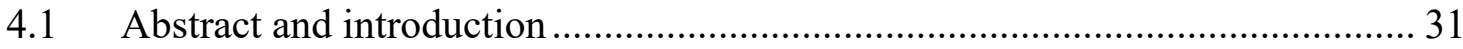

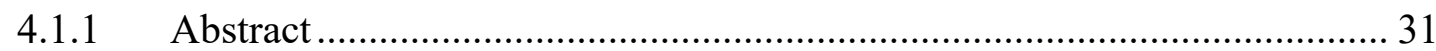

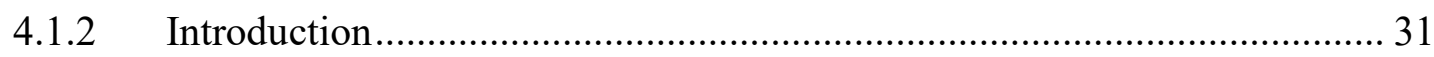

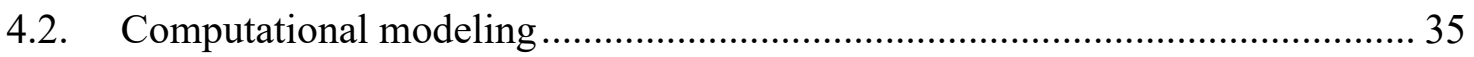

4.2.1 Method of electrical conductivity prediction............................................. 35

4.2.2 Effect of spatial arrangement on electrical conductivity ……..................... 37

4.2.3 Pattern of electrical conductivity across transition elements ...................... 40

4.2.4 Equilibrium precipitate phase of alloy systems ......................................... 45

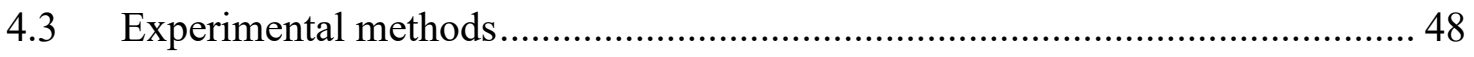

4.3.1 Fabrication and testing of Al-Zn-Ni and Al-Zn-Zr................................. 49

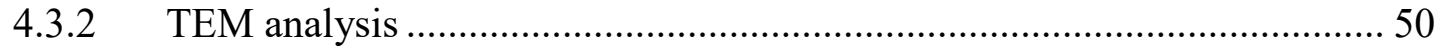

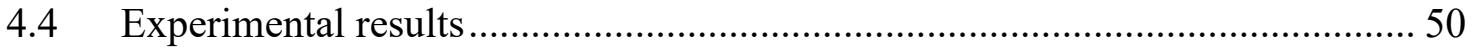

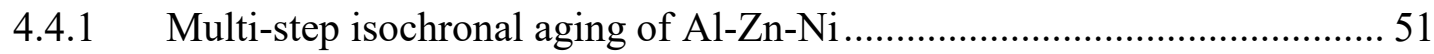

4.4.2 Multi-step isochronal aging of Al-Zn-Zr ............................................... 52

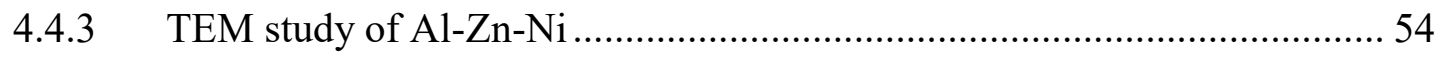

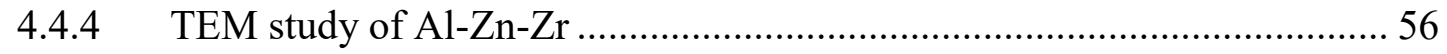

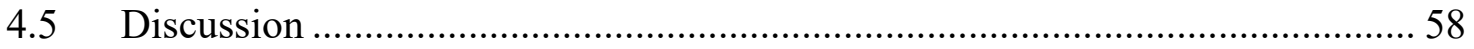

4.5.1 Comparing microhardness of Al-Zn-Ni and Al-Zn- $\mathrm{Zr}$.............................. 58

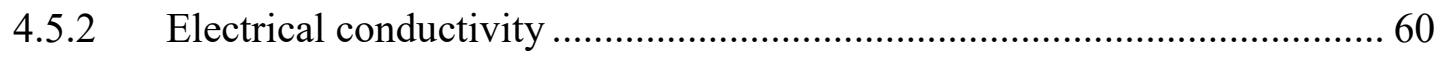

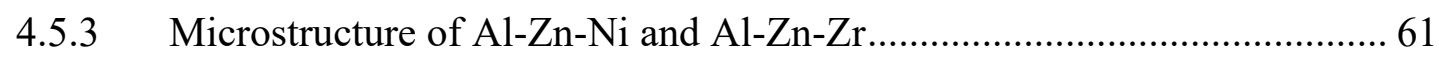

4.5.4 Estimation of yield strength at peak conditions ............................................. 63

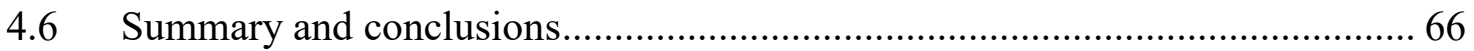

Chapter 5: Microstructure and properties of precipitation-hardened $\mathrm{Zr}$ and $\mathrm{Zn}-\mathrm{Zr}$ based

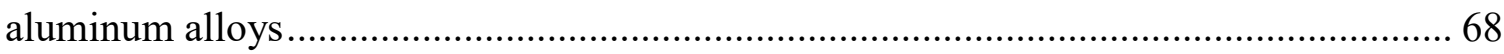

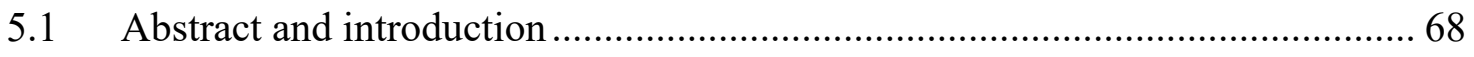




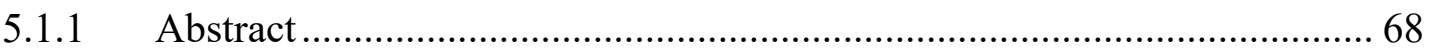

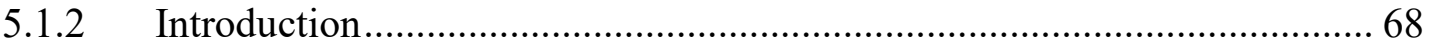

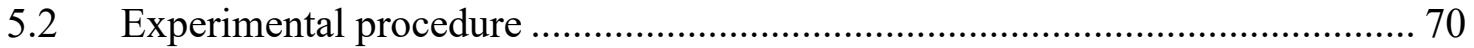

5.2.1 Fabrication and specimen preparation ................................................... 70

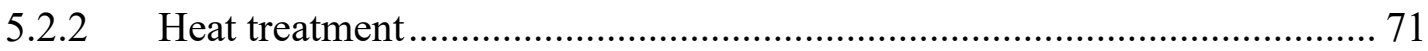

5.2.3 Deformation and thermal aging ……………….................................... 71

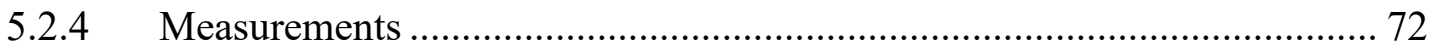

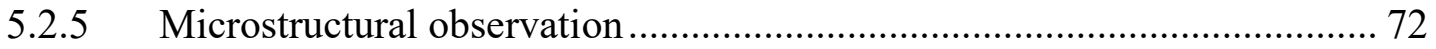

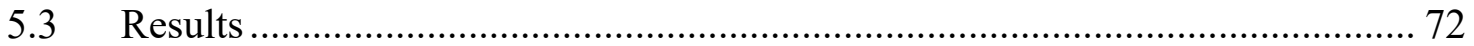

5.3.1 Vickers microhardness (Isochronal aging) …………………................... 73

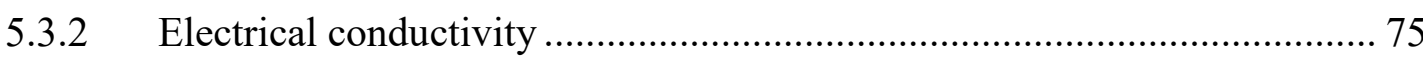

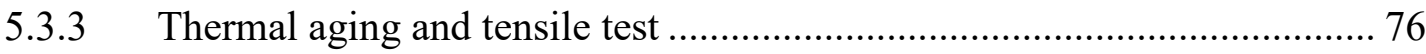

5.3.4 Dendritic/interdendritic microstructure ................................................... 80

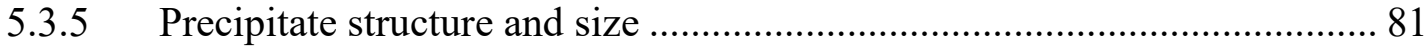

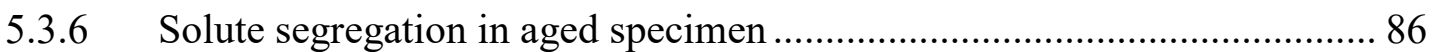

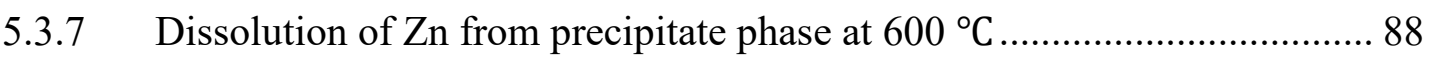

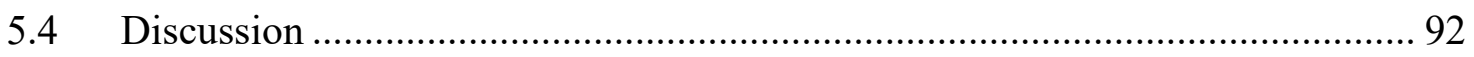

5.4.1 Effect of $\mathrm{Zn}$ addition on strengthening …………................................... 92

5.4.2 Stability of $\mathrm{L} 1_{2}$ precipitates with $\mathrm{Zn}$ addition............................................ 97

5.4.3 Effect of $\mathrm{Zn}$ on nucleation, growth, coarsening....................................... 99

5.4.4 Electrical conductivity ....................................................................... 100

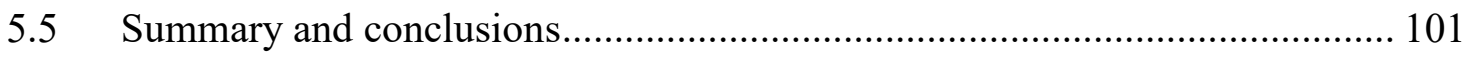

Chapter 6: Influence of $\mathrm{Zn}$ on ductility and creep rate of precipitation hardened Al alloys 103

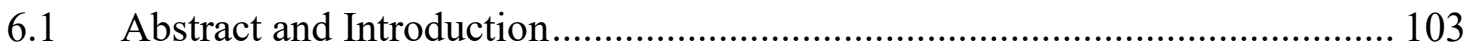

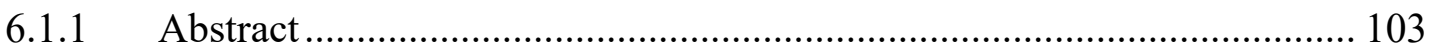

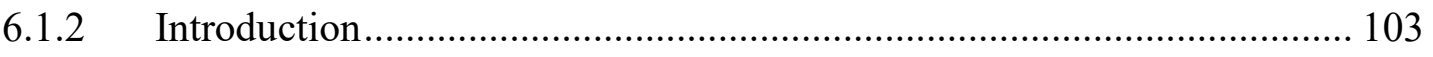

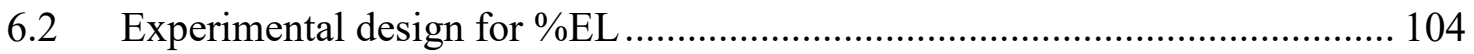

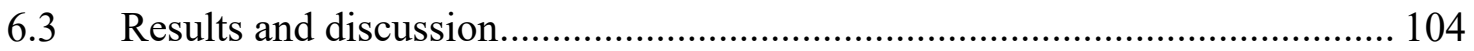

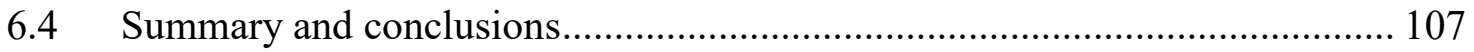

Chapter 7: Performance summary of Al-Zn-Zr and Al-Zn-Ni and AA1350 ................. 108 


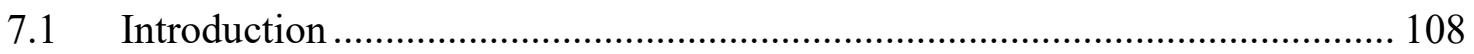

7.2 Mechanical and electrical properties............................................................. 108

7.2.1 Microhardness and eddy current ........................................................... 108

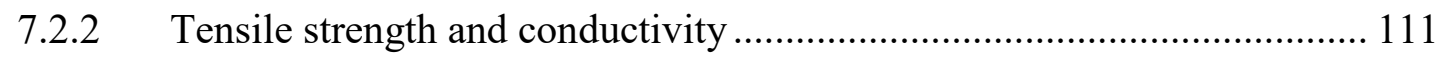

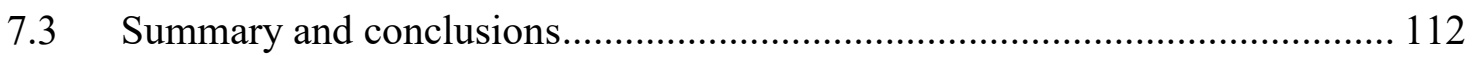

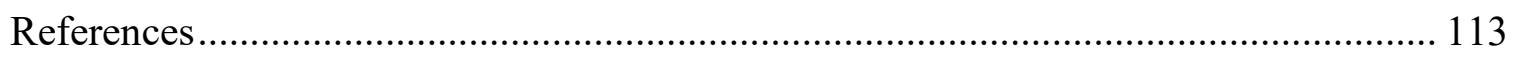

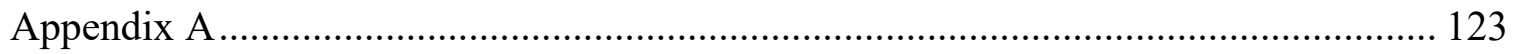

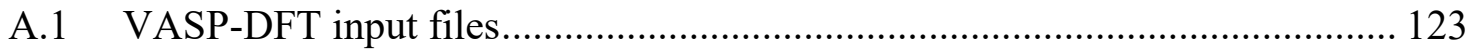

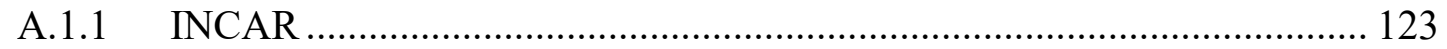

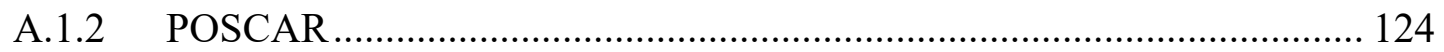

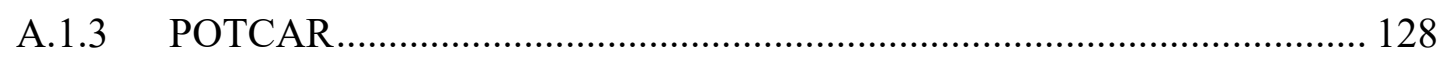

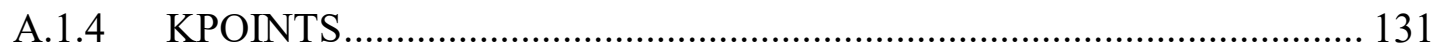

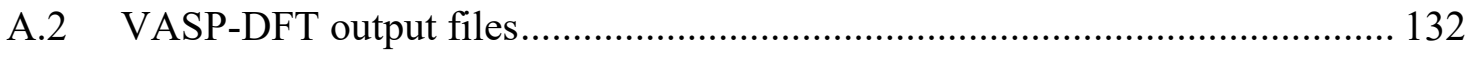

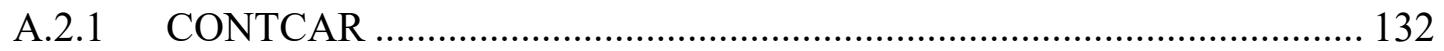

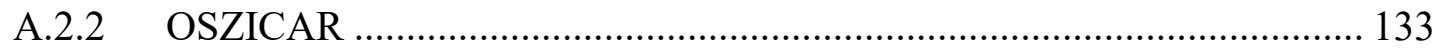

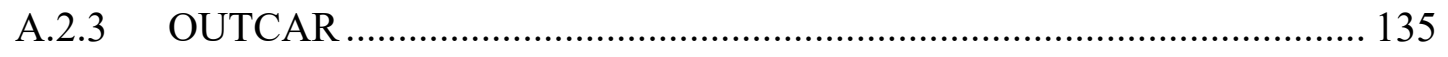

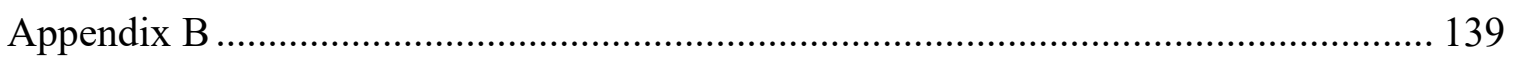

B.1 Automated bash submission (ABS) scripts ................................................. 139

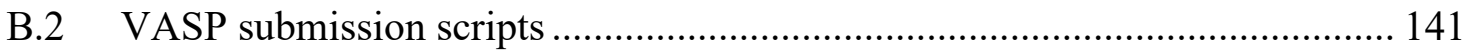

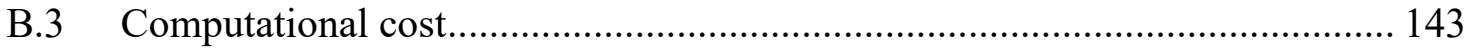

Appendix C: Reprint copyright permission .......................................................... 144 


\section{Preface}

This dissertation includes two chapters from my publication drafts. Chapter 4 has been accepted for publication at the Materials Science and Engineering: A journal (https://doi.org/10.1016/j.msea.2018.11.111), while chapter 5 is yet to be submitted to the Journal of Alloys and Compounds.

In terms of contributions to this work, Professor Gregory Odegard was very helpful with getting me up to speed with density functional theory simulation included in chapter 4 . He also gave me useful information that helped make my simulations data more accurate. Many useful recommendations for additional analysis and literature reviews were also given by Prof. Paul Sanders. Denise, Rachel and Violet are credited with the initial heat treatment of Al-Zn-Zr alloy. Prof. Hackney, Pinaki and Prof. Milligan assisted with transmission electron microscopy and scanning electron microscopy images, diffraction patterns and energy dispersive x-ray spectroscopy included in chapter 4 and 5. All other data in this study was collected and analyzed by the author. 


\section{Acknowledgements}

Most importantly, I will like to thank God Almighty for his many intervention, favor, mercy, guidance, love and compassion. I will not be where I am today without Him.

This work would not have been possible without the financial, moral and technical support from the following agencies, faculties, staff, graduate students, family and friends.

NSF I/UCRC on Novel High Voltage/Temperature Materials and Structures (Grant IIP1362040)

General Cable Corporation

SUPERIOR, a high-performance computing cluster at Michigan Technological University S/TEM - NSF MRI fund (Grant \#1429232)

Prof. Gregory Odegard, Prof. Paul Sanders, Prof. Stephen Hackney, Prof. S. Gowtham, Prof. Walt Milligan, Dr. Pinaki, Dr. Joe Licavoli and Dr. Dan Seguin

Tom Wood, Owen Mills, Jerry, Paul Fraley, Shenjia, CJ

Denise, Rachel, Violet, Akhila, Prasad, Ninad, Olumide Winjobi, Kyle Deane

Dad, Mum, siblings (Dele, Foluso, and Tosin Fadayomi), Ayotunde Fadayomi, Leke Adegbulugbe, Uncles and Aunts (Kola, Biodun and Oye Fadayomi, Lemmy Akintomide and Jumoke Bademosi), Onyeka Emili and family

Special thanks to my twin Kehinde Fadayomi

Edgar Kosgey, Lukmon Aminu, Ope Fatokun, LJ, Harry Orih, Wole Adebiyi, Jesse Balami, Dr. Tajuan Wilson, Ekong, Azih Onyeka, Oziegbe

Finally, Mr. Charles Anyansi, you have been heaven sent and I will never forget your act of kindness toward me. Continue to rest in peace (RIP) sir. 


\section{Abstract}

High electrical conductivity Al-Zn-TM (TM=Transition metals) alloys with improved mechanical properties and thermal resistance are developed with an integrated computational material engineering (ICME) strategy. From a series of ab initio density functional theory (DFT) simulations assessing combinations of ternary alloys, Al-Zn-Ni and $\mathrm{Al}-\mathrm{Zn}-\mathrm{Zr}$ are determined as alloys with relatively high electrical conductivity compared to several other ternary Al alloy combinations. The zero-temperature stable structure of precipitates formed in these alloys are determined from computed enthalpy of formation as $\mathrm{L}_{2}$, with particular focus of examining the influence of $\mathrm{Zn}$ on stabilizing the desired $\mathrm{L}_{2}$ precipitate phase.

Scanning transmission electron microscopy (STEM) is used to examine the role of $\mathrm{Zn}$ addition on the morphology and phase transformation of precipitates formed in the alloys. Elemental mapping and energy-dispersive X-ray spectroscopy (EDX) in STEM mode demonstrate the enrichment of $\mathrm{Zn}, \mathrm{Zr}$ and $\mathrm{Ni}$ in the precipitate phases. Moreover, mechanical and electrical properties of the alloys are determined. The results indicate that $\mathrm{Zn}$ addition improves microhardness and strength but reduces electrical conductivity, creep and thermal resistance of Al-Zr and Al-Ni alloys. Zn also has the potential to enhance the ductility of Al-Zr alloy by increasing work hardening through reduction of the alloy stacking fault energy. 


\section{Chapter 1: Introduction}

\subsection{Motivation}

The main motivation for this research is to develop Al-Zn-Zr and Al-Zn-Ni alloys that has a more balanced, electrical, thermal and mechanical properties for high strength and electrical applications such as overhead and underground power transmission.

The first generation of cables used for power transmission were developed from $\mathrm{Cu}$. However, due to its higher specific strength, high electrical conductivity, lighter weight and lower cost, $\mathrm{Al}$ has steadily phased out the use of $\mathrm{Cu}$ as the demand of electric power transmission increased[1,2].

After early 1960s, $1350 \mathrm{Al}$ alloy (containing 99.5\% Al) became widely used. For instance, aluminum conductor steel-reinforced cables (ACSR) is made from strands of Al 1350-H19 (strain hardened) with steel core, Figure 1. The 1350-H19 Al alloy has a high electrical conductivity of $34.9 \mathrm{MS} / \mathrm{m}$ but low strength. The tensile strength of the alloy ( 172 $\mathrm{MPa}$ ) is majorly derived from dislocation entanglement, as a result of extra-hard cold work. This limits its continuous operating temperature to $90^{\circ} \mathrm{C}\left(194^{\circ} \mathrm{F}\right)$, which is close to the temperature at which $\mathrm{Al}$ anneals. The low continuous operating temperature is due to dislocation recovery that occurs during extended use. The lack of dislocation pinning makes annihilation easier. This results in extensive softening and subsequent termination failure of the alloy[3]. One of the disadvantages of ACSR is the high sag during hot weather, due to the low thermal resistance and expansion of the 1350-H19 and steel core use.

To address the low continuous operating temperature observed in ACSR, aluminum conductor steel supported (ACSS) was developed with fully annealed 1350-O Al alloys. Annealing the alloy before using it for power line cable increases its continuous operating temperature to $250^{\circ} \mathrm{C}$, due to its enhanced thermal stability. However, the alloy becomes very soft ( $\sim 83 \mathrm{MPa}$ ), hence, the cable derives almost all its tensile strength from the steel 
reinforcement, Figure 1. It is therefore necessary to increase the number of steel strands used in the core to improve the overall tensile strength of the cable. This leads to increased cable weight (lbs/1000 ft) compared to ACSR[4, 5]. Similarly, ACSS experiences high sag at increased temperature, due to the high thermal expansion of aluminum and steel. The electrical conductivity of $1350-\mathrm{O} \mathrm{Al}$ alloy is $35.7 \mathrm{MS} / \mathrm{m}$, which is slightly higher than that of $1350-\mathrm{H} 19$.

Aluminum conductor composite core (ACCC) was developed as the solution to the combined challenge of high sag and low continuous operating temperature experienced by ACSR. This cable is made from a hybrid carbon and glass fiber core, wrapped by $1350-\mathrm{O}$ $\mathrm{Al}$ alloy. It has a much lower coefficient of thermal expansion $\left(1.6 \mathrm{ppm} /{ }^{\circ} \mathrm{C}\right)$ than $\mathrm{ACSR}$ $11.6 \mathrm{ppm} /{ }^{\circ} \mathrm{C}$, which reduces the thermal sag when operated at significantly higher temperature. However, it experiences ice loading sag due to the elastic nature of the composite core. Several other types of cable exist, however, none has a good balance between conductivity and mechanical properties.

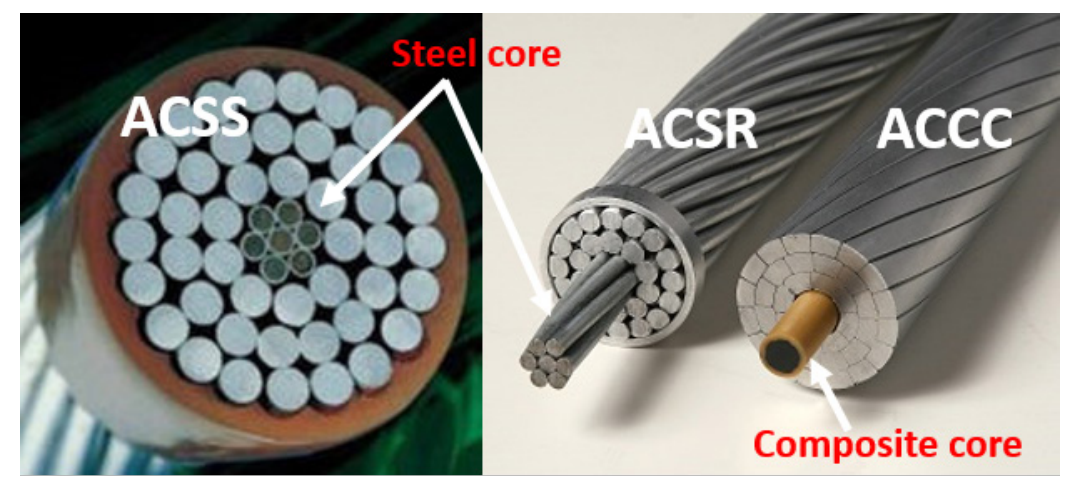

Figure 1. The steel core present in ACSR is wrapped by Al alloy 1350-H19, while ACSS and ACCC are surrounded by fully annealed Al alloy 1350-O. 


\subsection{Literature review}

As stated in the previous section, $\mathrm{Al}$ alloy 1350 (H19 or O) does not have a desirable combination of high thermal resistance, mechanical and electrical conductivity. Therefore, there is need to develop an aluminum alloy that have a better balance between mechanical and electrical properties at low cost. Precipitation strengthened Al-Zr-TM and Al-Sc-TM ( $\mathrm{TM}=$ transition metal) alloys have been studied over the years and shown to have potential for high electrical conductivity, thermal stability and enhanced strength. To achieve relatively higher electrical conductivity and enhanced strength compared to their as-cast conditions, precipitation technique was used to form secondary phases (dispersoids).

Knipling et al., studied the precipitation and high-temperature mechanical properties of isochronally aged $\mathrm{Al}-\mathrm{Sc}, \mathrm{Al}-\mathrm{Zr}, \mathrm{Al}-\mathrm{Zr}-\mathrm{Sc}$ and $\mathrm{Al}-\mathrm{Zr}-\mathrm{Ti}$ alloys. From their results, the addition of $0.1 \mathrm{Sc}(\mathrm{at} \%)$ to $\mathrm{Al}$ to form binary alloy yielded a higher peak microhardness of $668 \mathrm{MPa}$, relative to the peak microhardness achieved when $0.1 \mathrm{Zr}(410 \mathrm{MPa})$ was added. No microhardness data was found in the literature for Al-0.1Ti binary alloy, hence direct microhardness comparison could not be made with Al-0.1Sc and Al-0.1Zr. Though, Sc has a better strengthening potential than $\mathrm{Zr}$, it achieves peak aging at $350^{\circ} \mathrm{C}$, a lower temperature than $\mathrm{Zr}\left(450^{\circ} \mathrm{C}\right)$. Al-Sc starts experiences softening and overaging at a lower temperature, indicating that $\mathrm{Al}-\mathrm{Zr}$ has better thermal stability. Hence, $\mathrm{Zr}$ is an excellent candidate for thermal stability and coarsening resistance purpose[6-9].

Due to the excellent coarsening resistance potential of $\mathrm{Zr}$ in Al alloys, Knipling et al. studied Al-Sc-Zr ternary alloys with the aim of improving the microhardness and coarsening resistance of the alloy relative to binary Al-Sc. Similarly, Marsha et al. also improved the coarsening resistance of Al-Sc alloys by Ti addition. This is due to the slower diffusivities of $\mathrm{Ti}$ and $\mathrm{Zr}$, relative to $\mathrm{Sc}$ in $\mathrm{Al}[10]$.

Knipling was able to show that by increasing the combined solute concentration ( $\mathrm{Sc}, \mathrm{Zr}$, and Ti) in the cast alloys to within their individual maximum solubility limit, the volume fractions of the corresponding precipitates was enhanced, thereby, yielding higher peak strengths. For instance, by increasing the solute concentration from $0.06 \mathrm{Zr} 0.06 \mathrm{Sc}$ to 
$0.1 \mathrm{Zr} 0.1 \mathrm{Sc}$ (at.\%), the peak strength of the alloy increased from $610-782 \mathrm{MPa}$ after undergoing similar isochronal aging at $25^{\circ} \mathrm{C}$ temperature step size.

Naturally, the electrical conductivity of Al alloys reduces per at. \% (or wt. \%) solute added to the solution of the cast alloy. This indicates that increasing the solute concentration to achieve better strength would negatively affect the electrical conductivity of the alloy at as-cast. Even after precipitation of the solutes out of solution into the secondary phase, the negative effect of increased solute on electrical conductivity is still observed at peak conductivity condition. According to Knipling, the electrical conductivity measured for $0.06 \mathrm{Zr} 0.06 \mathrm{Sc}$ was 29.4 and 34.2 at as-cast and peak aged conditions, respectively. These values were 26.4 and $33.2 \mathrm{MS} / \mathrm{m}$ for $0.1 \mathrm{Zr} 0.1 \mathrm{Sc}$. The measured electrical conductivity of Al-0.1Zr-0.1Ti was 26.6 and $29.2 \mathrm{MS} / \mathrm{m}$ at as-cast and peak aged conditions. This indicates that $\mathrm{Sc}$ does not degrade the electrical conductivity as much as $\mathrm{Zr}$ and $\mathrm{Ti}$.

In summary, $\mathrm{Sc}$ is one of the most promising candidate for improving the combined mechanical and electrical properties of $\mathrm{Al}$ alloys, however, the high cost of Sc makes it less appealing for commercial production. $\mathrm{Zr}$ and $\mathrm{Ti}$ are also promising candidates but slightly expensive too. According to Chemicool, the approximate prices for pure Sc, Zr, and Ti are $\$ 1,400, \$ 157$ and $\$ 661$ per 100 grams[11].

In order to develop ternary alloys that have improved balance between mechanical and electrical properties, while maintaining a low-cost, Al-Zn-Zr and Al-Zn-Ni alloys were studied. These alloy combinations were selected as promising candidates because of the low impact of $\mathrm{Zn}, \mathrm{Ni}$ and $\mathrm{Zr}$ on electrical conductivity[12, 13] and their ability to form desirable coherent precipitate structure $\left(\mathrm{L1}_{2}\right)[12,14,15]$. According to Hatch, $\mathrm{Zn}, \mathrm{Ni}$ and $\mathrm{Zr}$ rank among the elements with the lowest impact on electrical conductivity when in or out of solution. $\mathrm{Zr}$ and $\mathrm{Ni}$ have low solid solution solubility and diffusivity in $\mathrm{Al}$, which helps to retard coarsening rate. In terms of cost, the approximate prices for pure $\mathrm{Zn}$ and $\mathrm{Ni}$ are $\$ 5.30$ and $\$ 7.70$ per 100 grams[11]. 


\subsection{Research goal}

The goal of this research study was to develop precipitation strengthened ternary Al-Zn-Zr and Al-Zn-Ni alloys that has improved balance between mechanical (tensile strength, coarsening resistance, microhardness and ductility) and electrical properties, relative to AA1350, while maintaining a lower cost than the currently studied Al-Zr-Sc, Al-Zr-Ti, AlSc-Ti alloys (Group IIIB, IVB and VB transition metals).

Second, the desired secondary phase structure, formed during precipitation is $\mathrm{Ll}_{2}$ (which is coherent with Al matrix), because it helps to reduce the precipitate/matrix mismatch. The reduced lattice mismatch is partially responsible for improved thermal/coarsening resistance and retention of strengthening phases. This reduces softening of the alloy after annealing at elevated temperature.

To achieve this, several ternary alloy combinations were first assessed for high electrical conductivity and thermodynamic phase stability using ICME, before fabrication and testing. Electrical conductivity screening was used to determine which alloy combinations have less impact on electrical conductivity of aluminum, while the thermodynamic phase stability assessment was used to determine the zero-temperature precipitate phase structures formed in the alloys. 


\section{Chapter 2: Background}

\subsection{Vienna ab-initio simulation package - density functional theory}

\subsubsection{Overview}

At the ICME stage, Vienna $A b$ initio Simulation Package - Density Functional Theory (VASP-DFT) was the preferred tool used to perform a quick screening of binary and ternary alloys for electrical conductivities and thermodynamic stability. The relevant output data to this study include electrical conductivity tensors, energy/atom, lattice parameters and unit cell volume. Though, due to no available experimental values in the literature, for the ternary alloys considered in this research, it is difficult to verify some of the predicted results.

In general, electrical conductivity is a complicated parameter to determine, since it is affected by temperature as well as impurities. The thorough approach is to use ab initio molecular dynamic simulations with the Kubo-Greenwood method[16, 17]. Because this approach simulates the effect of atomic movement directly, it provides for a good estimate of the temperature influence on the electrical conductivity. However, ab initio molecular dynamic simulation can be very time consuming, and a more efficient approach, such as DFT, is needed for material screening.

Ab-initio DFT computations can also be used to compute the enthalpy of formation $\Delta H_{f}$ $(\mathrm{kJ} / \mathrm{mol})$ from the total free energy per atom outputs. In this study the effect of $\mathrm{Zn}$ on the relative stability of $\mathrm{L}_{2}, \mathrm{D}_{11}, \mathrm{D} 0_{22}$ and $\mathrm{D}_{23}$ phase structures of $\mathrm{Al}_{3} \mathrm{TM}, \mathrm{Zn}_{3} \mathrm{TM}$ and intermediate compositions are examined. For each atomic fraction of $\mathrm{Zn}$ in the intermetallic, whichever phase structure has the lowest $\Delta H_{f}$, is considered to be the most stable structure for that particular composition[18]. 


\subsubsection{Input and output files}

To begin simulation, four (4) input files, named INCAR (simulation command codes), POSCAR (atomic positions), POTCAR (pseudo-potentials) and KPOINTS ( $k$-point spacings) - see appendix for details on all the file names mentioned - are developed before uploading to VASP. These files contain the VASP set of commands, atomic positions within the unit cell, exchange-correlation functionals and number of $k$-point spacing mesh ( $\Gamma$-centered Monkhorst-Pack grids) in the reciprocal space, respectively. The most relevant output files to this research study are the CONTCAR, OSZICAR and OUTCAR. They contain the final atomic positions after relaxation of the atoms from simulation, energies for every ionic step until convergence is achieved and detailed output of VASP run, respectively. Examples of the files can be found in appendix A section.

\subsubsection{Optimization}

Usually, the first step of the ICME process is to optimize POTCAR, $k$-point spacing and ENCUT (energy cut-off) for consistent free energy, lattice parameters and electrical conductivities computation for the individual elements (e.g. Al, Zr, Zn and Ni). Generally, optimization is performed using convergence test to see the minimum parameter required for consistent output data[19]. First, $k$-point spacing is optimized at a much higher ENCUT, before varying the energy cut-off using the optimized $k$-points. The optimized values are determined as k-point 70 and ENCUT $500 \mathrm{eV}$.

Once the ENCUT and $k$-point spacing are optimized using convergence test, these values are used with several pseudo-potential (POTCAR) files for a number of relevant elements to examine which file gives the most accurate free energy and lattice parameters data,

relative to experiment. During convergence test, only electrical conductivity displays a slightly higher degree of scatter of its data set. The optimized POTCAR is determined as Perdew-Burke-Ernzerhof exchange-correlation functionals (PAW-PBE_52). No spin orbital coupling is used during these simulations. 


\subsection{Strengthening mechanism}

Several strengthening mechanisms can be used to improve the strength of an alloy through restriction of dislocation motion. Only the various strengthening mechanisms employed in this study are discussed in this section.

\subsubsection{Solid solution strengthening}

For pure solid solution strengthening to occur, the solute concentration must not exceed its solubility limit in the solvent at a specific temperature. This mechanism occurs by solute atoms distorting the lattice structure of the solvent. The difference between the atomic size of solute and solvent atoms is responsible for the existing lattice distortion. These distortions generate several stress fields within the solvent, which impede dislocation motion. The stress fields imparted on lattice by the presence of the solute atoms can either be compressive or tensile, depending on the solute size (size effect).

According to Fleischer equation, the shear stress required to move dislocations past the solutes in a material is[20]:

$\Delta \tau=\frac{G \epsilon^{\frac{3}{2}} \sqrt{ } c}{700}$

$\epsilon$ can be defined as the total strain caused by lattice and modulus mismatch below:

$\epsilon=\left|\epsilon_{G}^{\prime}-\beta \epsilon_{a}\right|$

the lattice misfit strain is proportional to local change in lattice parameter:

$\epsilon_{a}=\frac{\Delta a}{a \Delta c}$

while the equation describing the modulus mismatch:

$\epsilon_{G}^{\prime}=\frac{\frac{\Delta G}{G \Delta c}}{1+\frac{1}{2}\left|\frac{\Delta G}{G \Delta c}\right|}$

where $c$ is concentration of solute atoms in atomic fraction, $G$ is shear modulus of the solute atom and $\epsilon$ is the lattice strain due to solute. The $\epsilon_{G}^{\prime}$ captures the local modulus change, $\epsilon_{a}$ 
is lattice distortion term, $a$ is lattice parameter of the material, $\beta$ is a solute atom dependent constant. To be able to use this model for solid solution strengthening prediction, the $\beta$ constant needs to be known.

In order to achieve significant material strengthening from solid solution strengthening, the solute atoms included in the alloy must have higher shear modulus, thereby, increasing the local shear modulus in the alloy. Another factor that could have major impact on solid solution strengthening of the alloy is the difference between the lattice parameters of solute and solvent atoms. This indicates that the bigger the lattice mismatch, the higher the local stress and lattice strain fields induced in the alloy. In summary, solid solution strengthening magnitude depends on concentration, shear modulus, size and vacancy of the solute atoms.

Solid solution strengthening negatively impacts the electrical conductivity of Al alloy, due to the induced strain fields from the solutes present in the alloy. The strain fields hinder the flow of electrons in the presence of electric field. Since electrical conductivity is directly proportional to the mobility of charge carriers (electrons or holes), adding more solutes to an alloy decreases the flow of electron and corresponding electrical conductivity.

\subsubsection{Precipitation strengthening}

Precipitation strengthening is one of the most effective methods for achieving increased mechanical and electrical properties of $\mathrm{Al}$ alloys[21]. This technique is essentially used to nucleate and grow nanosize precipitates that are effective in obstructing dislocation motion, thereby, improving the strength of the alloy. As the solutes come out of solution to form precipitate phase within the solvent, the lattice distortion of the solvent, due to the presence of the solutes is reduced. Thereby, increasing the electrical conductivity of the alloy. These precipitates are formed in the alloy by aging at a temperature within the two-phase region of the alloy phase diagram. This mechanism is diffusion dependent.

The size of the precipitates increases as the aging temperature and/or time increases. The degree of strengthening achieved from precipitation is determined by the volume fraction and particle-dislocation interaction. Whereby, the particle-dislocation interaction is 
dependent on particle size, crystal structure, shear modulus, precipitate-matrix lattice mismatch.

When a precipitation hardened metal alloy is stressed, each individual secondary phase precipitate has a force, $F$, that resists the movement of dislocation as shown in the schematic, Figure 2[22].

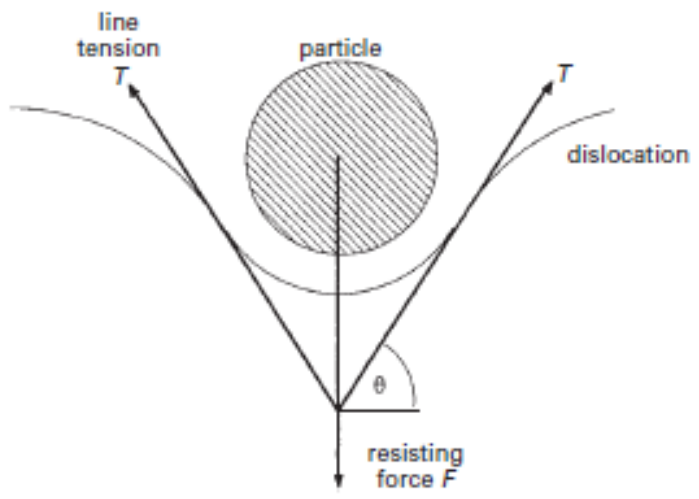

Figure 2. Interaction between spherical precipitate and dislocation line tension[23]. Depending on the magnitude of the resisting force, the dislocation decides to either loop or shear the precipitate.

The line of tension $\mathrm{T}$, of the dislocation, is proportional to the resisting force of the particle according to equation (5):

$F=2 T \sin \theta$

where $\theta$ is the angle of dislocation bowing. $F$, increases with precipitate size, indicating that as the precipitate size increases, it becomes harder for the dislocation to shear. The line of tension is maximum when $\theta=90^{\circ}$ and $\sin \theta$ is 1 . Therefore, when the maximum value of dislocation line of tension $2 T \sin \theta>$ particle resisting force $F$, where $F$ is proportional to the shear modulus of the precipitate, the particle will shear as a result of the dislocation cutting through. This indicates that the energy required to shear the particle is less than the 
energy required to loop through the dispersed precipitates. The higher the precipitate volume fraction the more difficult it is for dislocations to loop around due to small interparticle spacing. Hence, the strength of the alloy is dependent on the precipitate volume fraction and shear modulus, and is maximum when the particles are sheared by dislocation. If, however, $F>2 T \sin \theta$ (maximum line of tension), which usually occurs for bigger particles (with wider average interparticle spacing), dislocations will rather bypass the precipitates, either by Orowan looping or cross slip (equation for Orowan strengthening can be found in chapter 4 and 5)[22]. When this happens, it means that lower energy is required to bow the particles.

The preferred crystal structure of the precipitate formed in this study is coherent $\mathrm{L}_{2}$, due to its similarity to FCC aluminum matrix phase. The purpose of forming a precipitate phase that is coherent with the matrix is to reduce precipitate-matrix lattice mismatch and subsequently slow down coarsening rate. Coherent particles also generate surrounding strain fields associated with stretching bonds - these have the potential to impede dislocation motion through coherency strain strengthening.

\subsubsection{Strain hardening}

This strengthening mechanism is a process in which materials are made stronger by plastic deformation. When the material is plastically deformed, the number density of dislocations are multiplied, which leads to dislocation pile up and enhanced dislocation entanglement. Increasing the percentage reduction area $\left(\% R A=\frac{A_{o}-A_{i}}{A_{0}}\right)$ yields a corresponding higher dislocation density. Further permanent deformation is prevented after severe strain hardening due to possible brittleness of the alloy.

Strain hardening is divided into cold work and hot work. Hot working is a process whereby metals are plastically deformed above their recrystallization temperature, whereas, cold work occurs below the recrystallization temperature. From microstructural observation, the uniaxial grains in a cold worked metal are elongated in the direction of the work hardening. In this study, the alloys are cold worked using swaging and wire-drawing techniques. 


\section{Chapter 3: Experimental techniques}

\subsection{Alloy casting and specimen preparation}

The procedure of metal alloy fabricating involved, cutting the elements charge before melting and mixing in the chamber. After melting inside the graphite crucible placed in the vacuum chamber, the alloys were poured into the mold before allowing them to solidify and cool down. Before taking measurements, mechanical testing and acquisition of microstructure data, specimens were prepared. Specimen preparations used in this study could be divided into cutting, surface treatment and deformation. Band saw, wet cutter and wire EDM are classified into cutting, while surface treatment includes grinding, autopolishing and electropolishing. Swaging and wire drawing were used to deform the alloy rods for tensile experiments.

\subsubsection{Band saw and wet cutter}

After determining the mass quantity (in grams) of individual elements and master alloys in the alloy composition, the ingots were cut using a horizontal band saw with sufficient coolant. The band saw was first used due to the size of the initial cut out from the ingot; using the wet cutter would lead to breakage of the $\mathrm{SiC}$ abrasive cut-off disc.

The wet cutter was used to cut the larger pieces into smaller sections that could fit into the crucible. The wet cutter abrasive cut-off disc was also used to cut all the buttons and rod specimens in this research before polishing, swaging or wire-drawing. The disc (Allied High-Tech Products, $35.56 \mathrm{~cm}$ diameter, 80-10025) was bolted to a LECO CM-24 cut-off machine. While in operation, integrated coolant recirculation occurred. Figure 3 shows the image of the cutter used.

The cut-out pieces were all placed in ultrasonic acetone bath for at least 5 minutes to remove all burs and cutting fluid. The face of each piece was washed with soapy water and cotton ball before rinsing in running water and ethanol. 


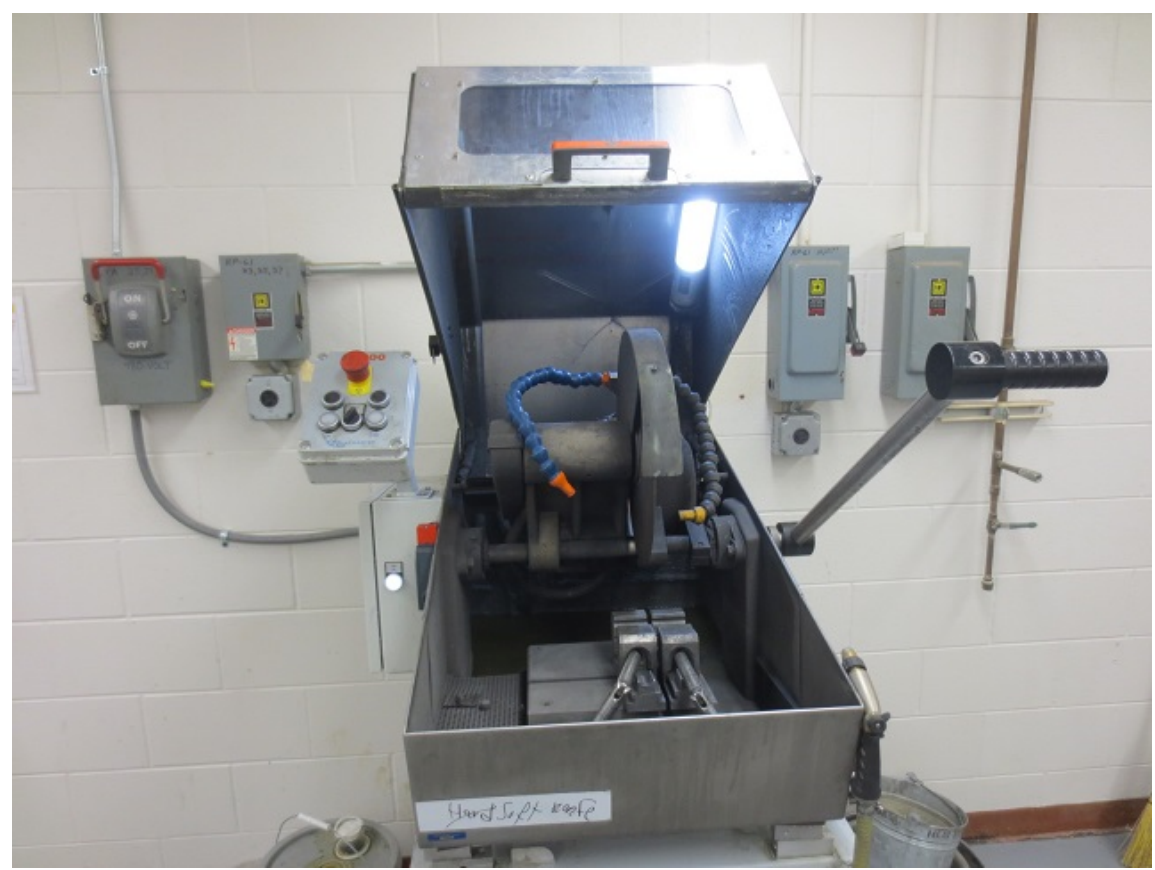

Figure 3. Wet cutter used to cut all ingot into rods and button specimens. The specimens were cut with 80-10025 abrasive cut-off disc (Allied High-Tech Products) screwed to the cutter.

\subsubsection{Vacuum induction melter}

This is a vacuum chamber used to fabricate cast alloys. This chamber has a coil that can hold the graphite crucible ( $60 \mathrm{~mm}$ dia. by $170 \mathrm{~mm}$ height) and can melt up to $600 \mathrm{~g}$ of alloying materials. A water chiller, rough mechanical and a diffusion pump are connected to the vacuum chamber to achieve a vacuum level of up to $1 \times 10^{-5}$ Torr. An argon tank connected to the chamber is used to backfill. This is mostly done to prevent a lot of elements with high vapor pressure from leaving the melt in the crucible. During melting, alternating current (AC) power was gradually ramped to increase the temperature inside the chamber. The temperature inside the chamber was measured with Accufiber HF-3 optical pyrometer. The VIM unit is shown in Figure 4. 

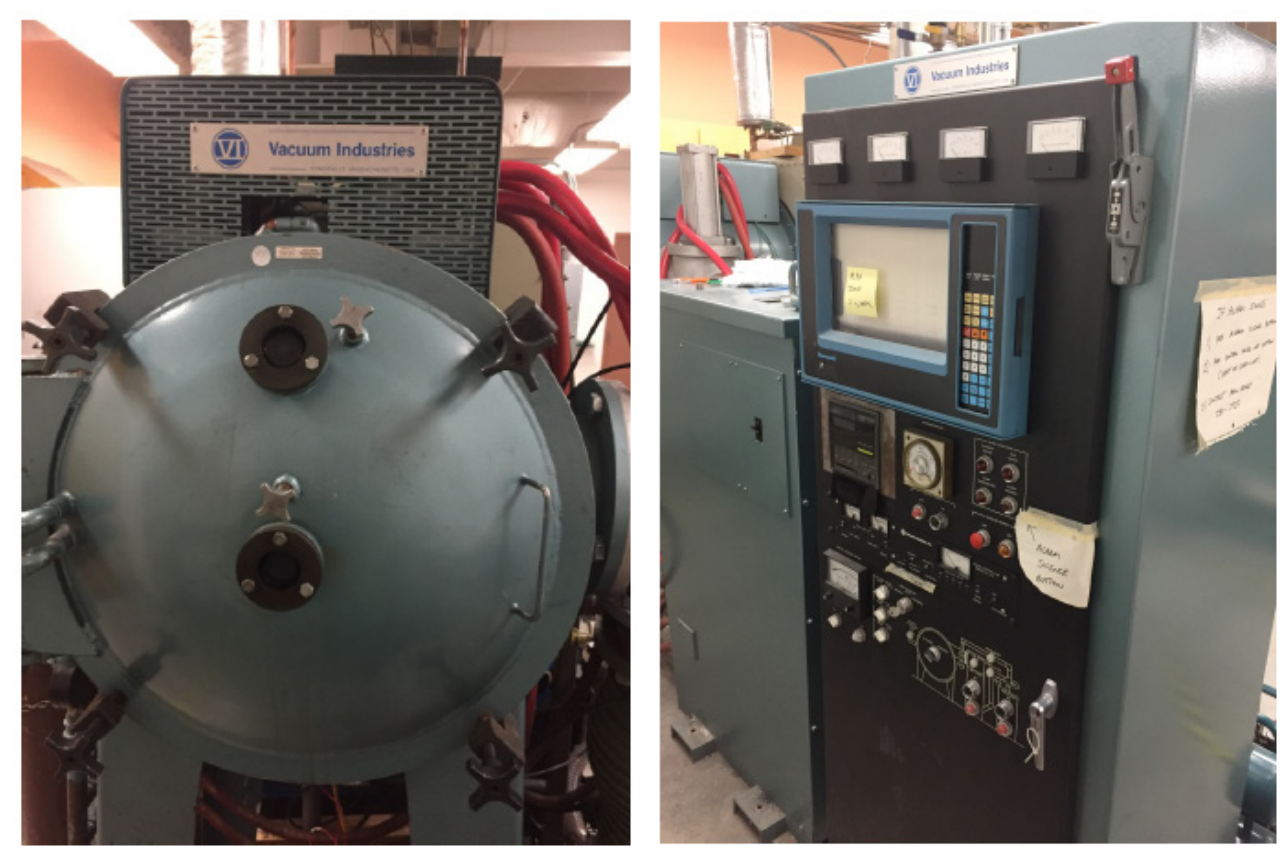

Figure 4. Vacuum induction meting unit, used to cast all alloy used in this study.

\subsubsection{Wire EDM}

The JAPAX LUX3 Wire Electrical Discharge Machining (Wire EDM) shown in Figure 5 uses spark erosion to cut through a specimen with bronze wire. EDM was used to cut thin cross-section of the specimen before grinding and electropolsihing for TEM experiment. 


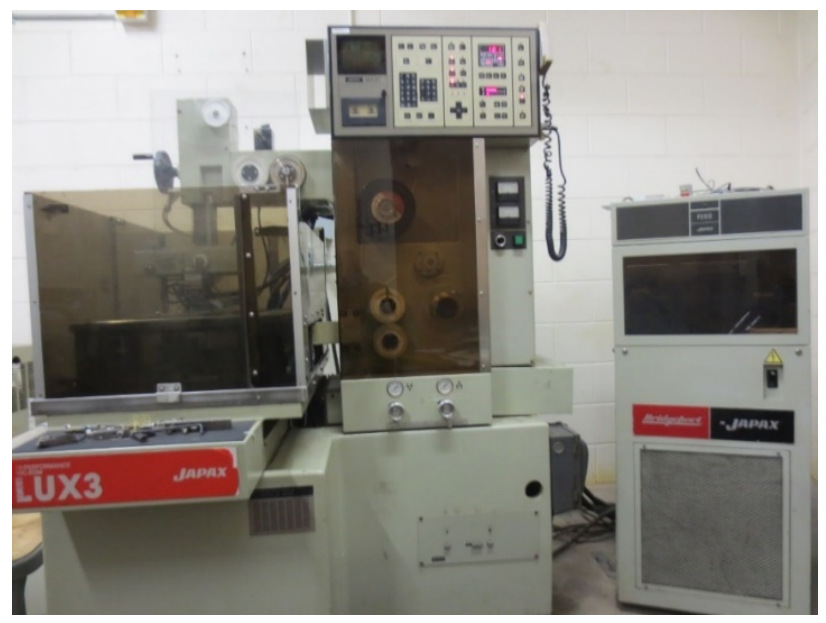

Figure 5. Wire EDM equipment for cutting thin alloy specimens. The thickness in the $\mathrm{X}$ direction was set to 500 on the machine. This corresponds to $\sim 250 \mathrm{~mm}$ specimen thickness before auto-polishing to $100 \mathrm{~mm}$.

To begin operation, the following settings were selected, and codes inserted:

- $T_{\text {off }}=10$

- $T_{\text {on }}=4$

- $I_{\mathrm{o}}=3$

- $V=4$

- $V_{\mathrm{s}}=4$

- $\%=100$
- Feed $=10$

- Tension $=6$

- $\mathrm{F}$ varies with thickness (sheeting $=$ $\sim 8)$

- Basc II for uniform thickness, Basc I for non-uniform

G-Code was set-up to define the cutting path and speed of the wire (details about the code can be found in the laboratory):

N01 G21 G91 X0.Y0.

N02 G01. Y-30.

N03 M02

/Store 
The conducting specimen is secured to the motorized stage in a way that it is grounded. The spook of Bedra Bercocut bronze wire is continuously unwound from the JAPAX JAPT $3 \mathrm{~F}$, as it gradually cuts through the specimen in the y-direction. Simultaneously, distilled water runs as the wire cuts through the specimen. This helps cool the specimen. The JAPAX \#PW20X wire EDM filtration unit is responsible for maintaining the conductivity of the distilled water.

\subsubsection{Swaging and wiredrawing}

Through swaging and wire drawing, the $19 \mathrm{~mm}$ diameter rod specimens were reduced to $4.6 \mathrm{~mm}$ diameter. This amounts for $94 \% \mathrm{CW}$. The cold work process was divided into two (2) stages:

- Swage specimens from 19 to $9.5 \mathrm{~mm}$ using the FENN 765 swager.

- Wire-draw from 9.5 to $4.6 \mathrm{~mm}$, while using the Swager to reduce the near end of the rods before each step of wire-drawing. Wire drawing was performed with the MEC MACBEE $(230 \mathrm{~V} ; 60 \mathrm{~Hz})$ machine.

Swaging the tip before wire drawing made it possible to pass the rods through the wiredrawing machine. As the rods got thinner in dimension, they became prone to breakage, especially the heat treated specimens. Most of the Al-Ni and Al-Zn-Ni alloys were able to go through the whole cold work process without experiencing breakage, relative to $\mathrm{Al}-\mathrm{Zr}$

and $\mathrm{Al}-\mathrm{Zn}-\mathrm{Zr}$, due to their higher ductility. To prevent breakage of the alloys with $\mathrm{Zr}$, the step size of the die was $10-15 \%$ reduction.

Another factor that could lead to specimens breaking is friction between the rod specimen and the die. Hence, during swaging and wire-drawing, proper lubrication of the dies was ensured so as to reduce the friction that occurred when passing the specimens through. The swaging and wire drawing equipment set up is shown in Figure 6. 

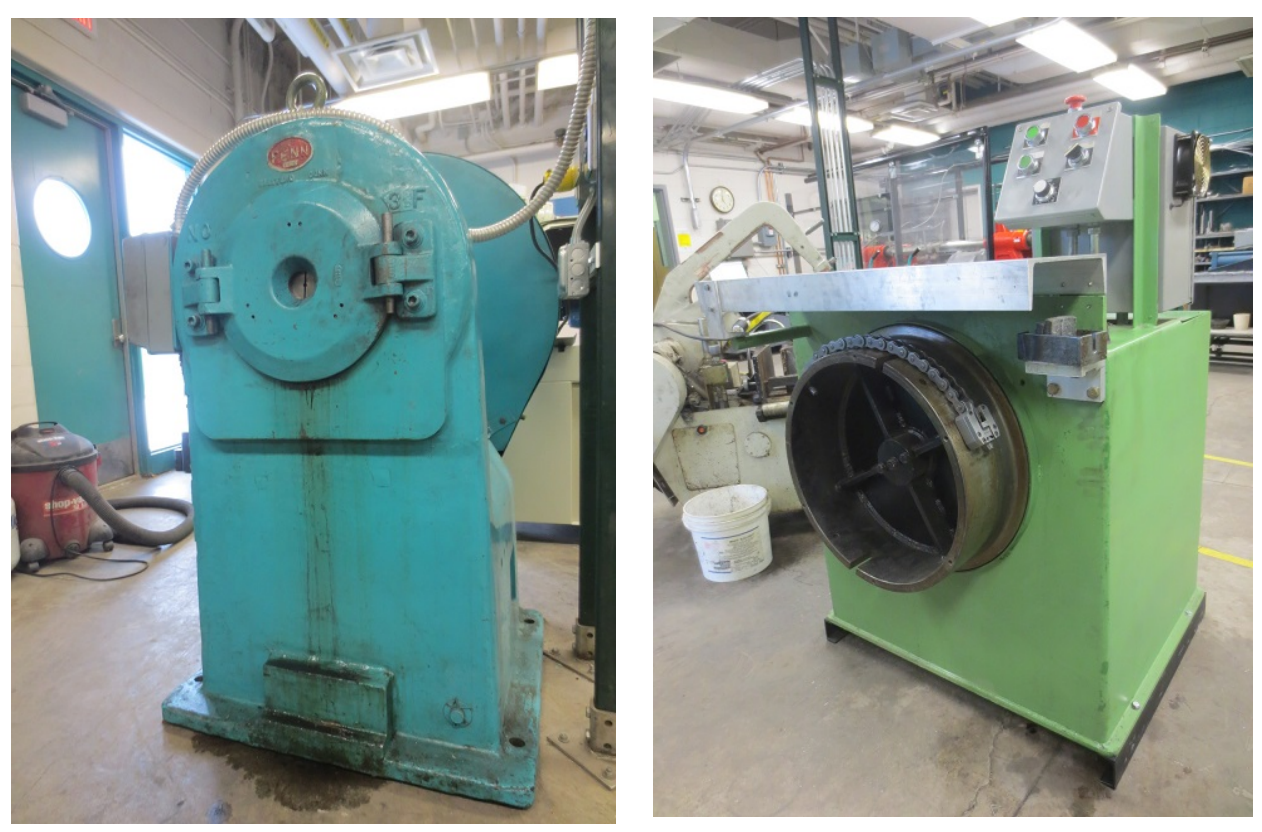

Figure 6. (Left) Swaging and (right) wire drawing unit. The swager was used for cold work of the rod specimens, thereby reducing their diameters from 19 to $9.5 \mathrm{~mm}$, before wiredrawing to a smaller diameter $(4.6 \mathrm{~mm})$. Before each die step of wire drawing process, the swager was used to first reduce the tip end of the rods to enable it pass through the wiredrawing die.

\subsubsection{Grinding and auto-polishing specimens}

Before proceeding to the grinding and polishing stage, the button specimens that were cut out of the ingots were placed inside several $3.175 \mathrm{~cm}$ diameter-mounting cups. The button specimens were mark-labelled with a Wen Power Tool electric engraver, so they could be distinguished after mounting. An epoxy containing 2:1 Quickset Acrylic Powder (\#18510005) to Acrylic Liquid Hardener (\#185-10010) volume ratio were thoroughly mixed, before pouring on top of the button specimen, placed in the mounting cup, ensuring that the specimen was covered. The epoxy was allowed to solidify after approximately 10 minutes.

After solidification the mounted specimens were removed from the mount cup. Hand grinding operation were performed on the specimens, with the following grinding steps: 
180, 320, 600 and $1500 \mathrm{SiC}$ paper grit. The samples were rinsed with cotton balls, soap and running water between each grinding step to remove any grit particles on the specimen surface.

The next step was to progress to the auto-polishing stage, with the use of Leco Polisher Grinder. The polishing steps included red or green lube with 6 and 1 micron diamond paste plus pads. Finally, the Allied 0.04 micron Colloidal Silica Suspension plus pad was used to get a mirror-like shiny surface. The specimens were washed with cotton balls, soap and running water before placing in ethanol solvent, in ultrasonic bath for approximately 5 minutes. See image in Figure 7 for autopolisher tool, button specimen and mounting cup.
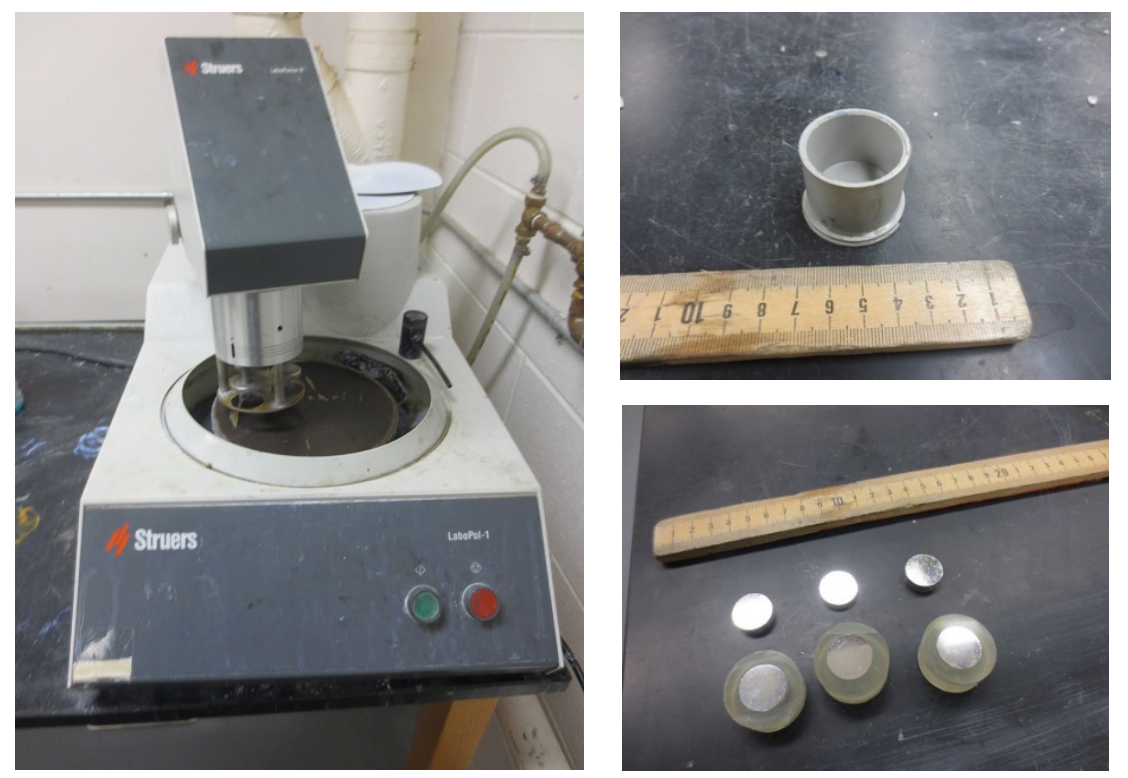

Figure 7. Auto-polishing equipment used to polish button specimens after mounting, using the mounting cup on the right.

\subsubsection{Electropolishing}

All specimens examined with S/TEM and SEM were electro-polished. The thin sheets ( $\sim 200$ micron thickness) cut-out from the button specimens, with Wire EDM, were first auto-polished to $\sim 100$ micron thickness sheet, using 400, 800 and $1200 \mathrm{SiC}$ grit papers. 
After, $\sim 3 \mathrm{~mm}$ diameter TEM foils were punched from the auto-polished sheets. The thin foils were carefully arranged in a labelled TEM grid storage box.

The actual electro-polishing process was done with an FTS System Multicool chiller connected to the Jet Electropolisher. The Jet polisher included a Metalthin digital instrument connected to the polishing cell, specimen holder and electrolytic solution tank. A thermometer was placed in the tank to read the temperature of the electrolyte. See Figure 8 for electropolisher set-up.

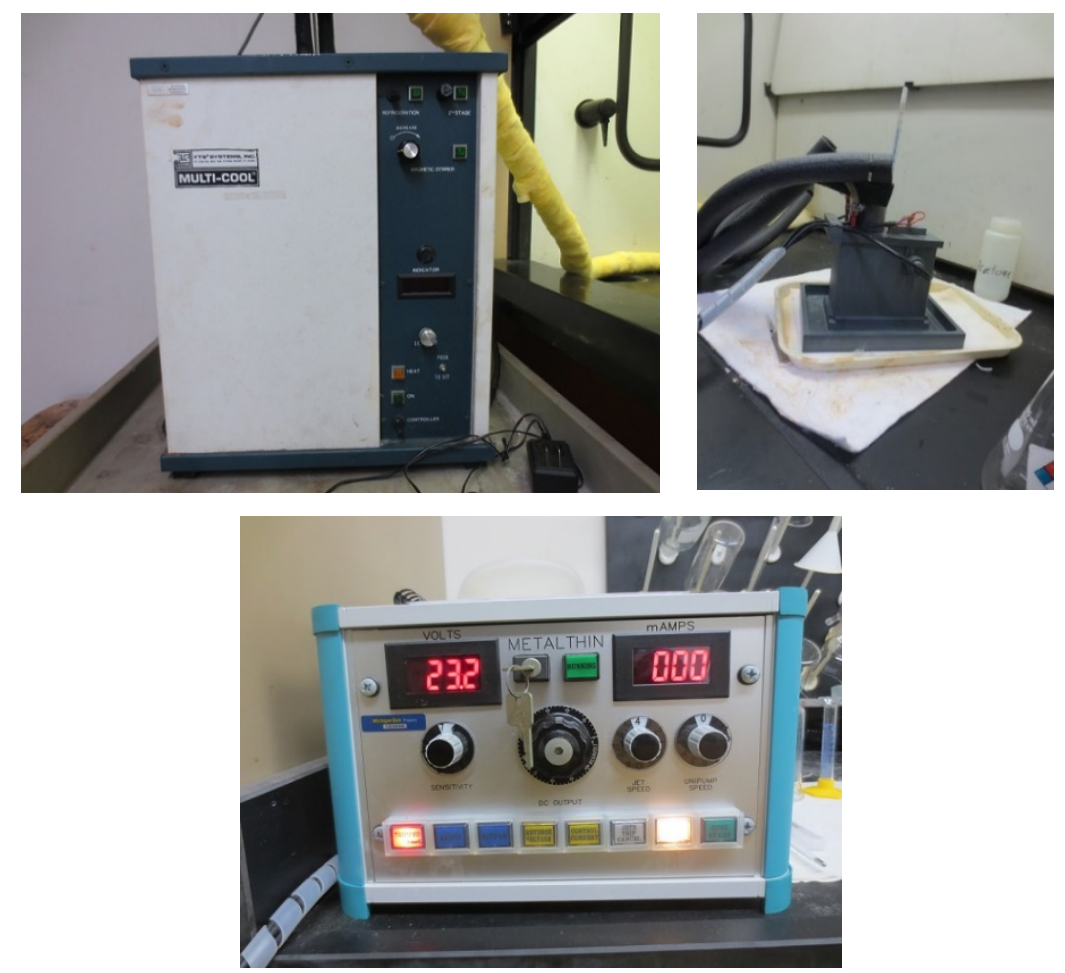

Figure 8. Electropolisher set-up used to polish the TEM specimens. (Top left) The FTS System Multicool chiller used to maintain the cold temperature of the electrolyte. (Top right) The tank that contains the mixture of nitric acid and methanol electrolyte, used to remove surface layer of the specimens during polishing. The polishing cell (including specimen holder) is placed on-top of the tank. (Bottom) Metalthin digital instrument used to control polishing parameters. 
The following operation settings were used for the Metalthin instrument:

- Sensitivity: 4-8

- Voltage: 12-20 V

- Current: Corresponds to the voltage used but varied from 65-200 mA, depending on how well polished the prior auto-polish was performed.

\subsection{Heat treatment}

All heat treatments of the specimens were performed in box furnaces. After setting the temperature on the PID controller, the furnace was gradually heated up to the set temperature. The temperature was allowed to stabilize at the set temperature before placing the specimens inside. The PID controller on the furnace reads the temperature from internal thermocouples mounted on the top of the furnace. The specimens were quenched in cold/room temperature water after each temperature and time step. The box furnace is shown in Figure 9.

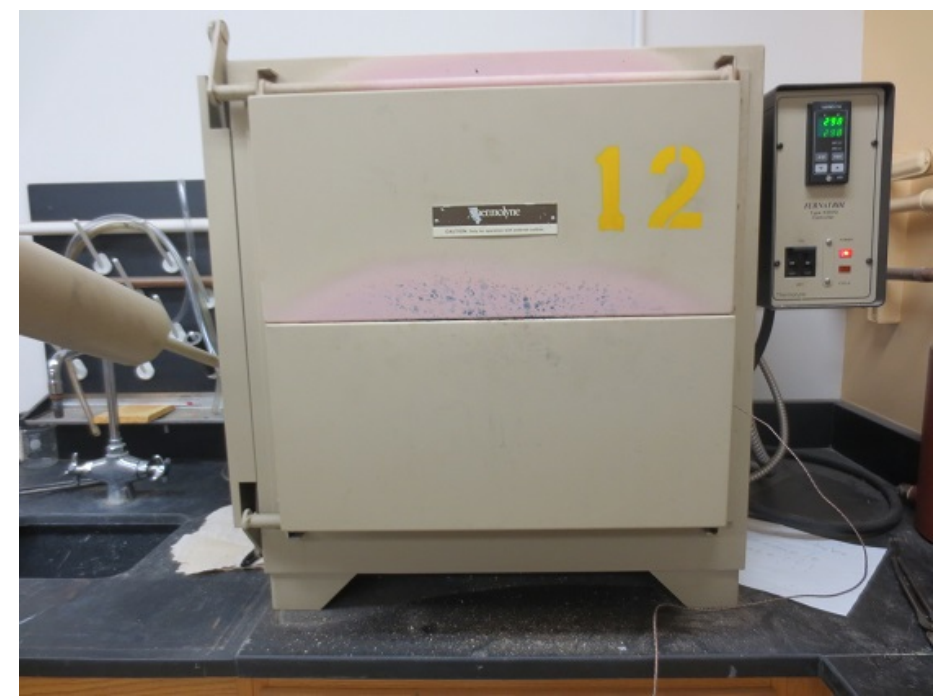

Figure 9. Box furnace used for isochronal and isothermal heat treatments of the specimens before water quenching. 


\subsection{Measurements}

\subsubsection{Vickers microhardness}

This experiment was performed using the LECO M-400-G1 instrument. To begin microhardness measurements, auto-polished button specimens were drilled out of the epoxy and secured to the specimen holder. A diamond (quadrilateral pyramidal) indenter was pressed on the polished surface of the specimen. The settings used for the experiments were:

- Load weight: $50-100 \mathrm{~g}$

- Dwell time: 15 seconds

- Objective lens: $50 \times$

The microhardness value is proportional to the size of the indent and displaced volume. The microhardness value recorded by the instrument was converted to microhardness in MPa by multiplying by $9.8 \mathrm{MPa}$. See Figure 10 for Vickers microhardness tester.

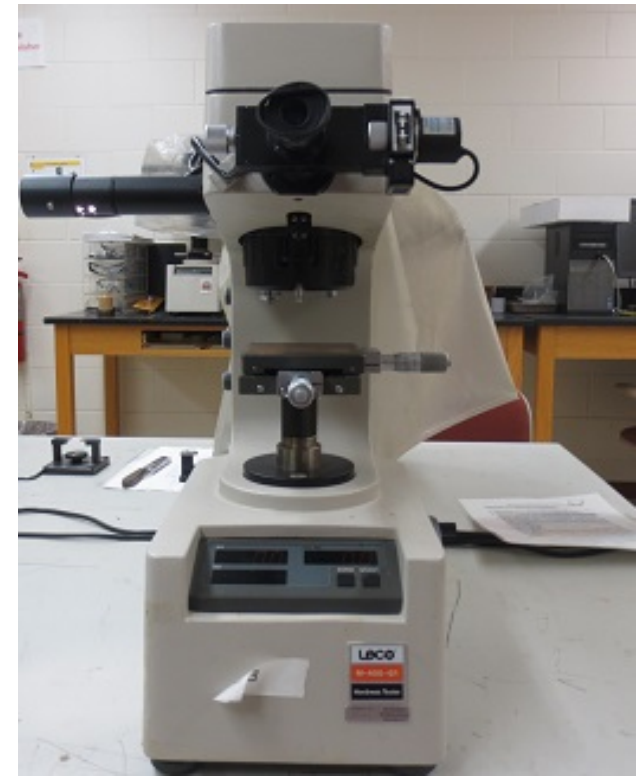

Figure 10. LECO M-400-G1 Vickers microhardness equipment. 


\subsubsection{Electrical conductivity}

Two different electrical conductivity setups were used throughout this research. For the polished buttons, measurements were taken with a Fisher Technologies Sigmascope SMP10 device and probe. While, the electrical conductivities of the wire drawn specimens were taken with a Keithley setup.

The Fisher SMP10 device has a surface contact probe with a probe size is $\sim 12.7 \mathrm{~mm}$ ( $0.5 \mathrm{inch}$ ) diameter. Therefore, the specimen to be tested have to be wider in surface area to fully accommodate the end of the probe. It is essential to have at least the first couple of grinding ( $>400 \mathrm{SiC}$ grit size) performed on the specimens to achieve flat surface. This is necessary so that the probe makes a complete contact with the specimen surface. Calibrations of the probe is performed before measurements are taking, by first inserting the accurate temperature of the specimens. Temperature calibrations (measured by an integrated thermocouple) are done by placing the probe on the specimen surface for at least 30 seconds, until the temperature reading stabilizes. Figure 11 shows the image of Fisher SMP10 tool used to measure the electrical conductivity of the button specimens.

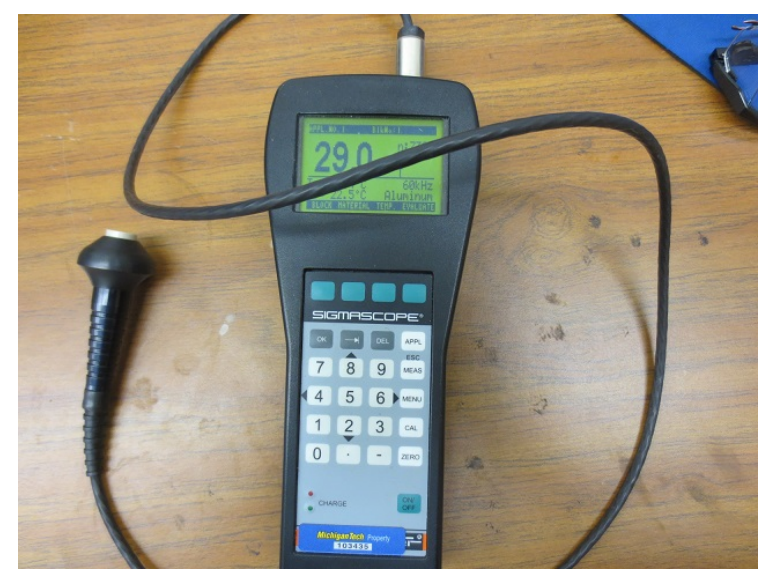

Figure 11. Fisher SMP10 device used to measure eddy current conductivity. The probe size $(\sim 12.7 \mathrm{~mm}$ diameter) is placed on the surface of the button specimen in order to take conductivity measurements. 
As for the Keithley setup, the current and 2182A nanovoltmeter (voltage) source are connected to the wire/rod specimens through a knife-edge voltage contact stage designed at the machine shop. It is important for the voltage contacts to be very sharp, so as to eliminate inaccuracies when measuring the voltage length $\left(\mathrm{V}_{\mathrm{L}}\right)$ between the contacts. $\mathrm{V}_{\mathrm{L}}$ is a very important parameter in calculating electrical conductivity. The average diameter of the specimens were taken with a digital micrometer Vernier caliper. The equation below was used to calculate the electrical conductivity.

$\sigma=\frac{V_{L}}{R A}$

where $\mathrm{R}$ is resistance and $\mathrm{A}$ is the cross-section area of the wire specimen. Figure 12 shows the Keithley set-up used to measure wire specimens.

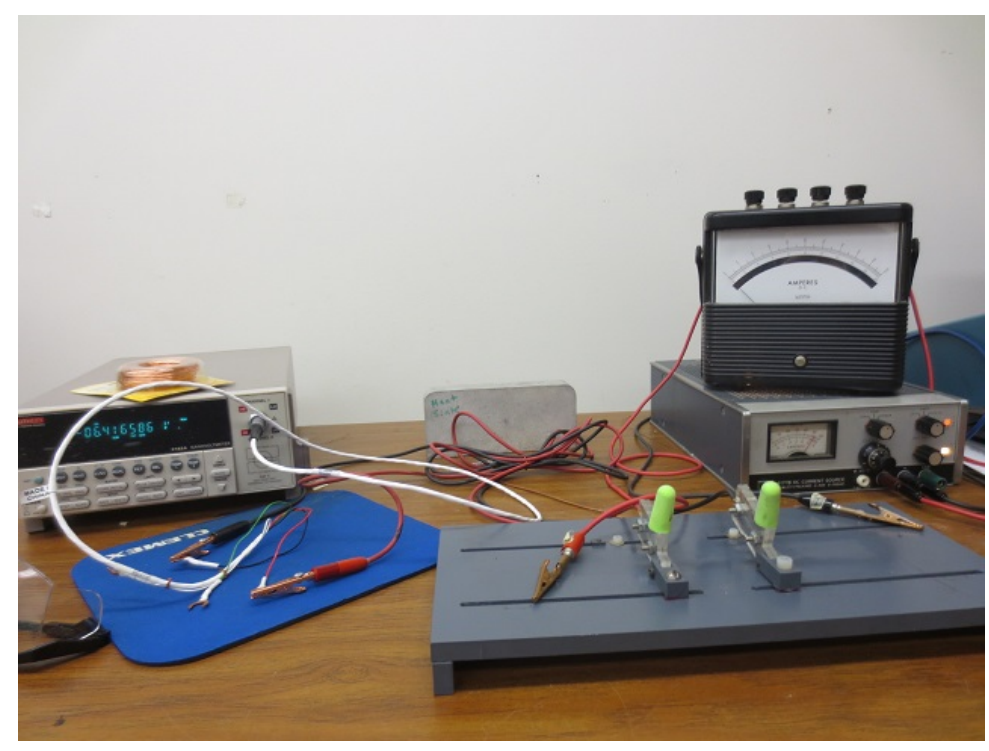

Figure 12. The Keithley conductivity set-up consist of $2182 \mathrm{~A}$ nanovoltmeter, current source, alligator clips and a knife edge contact stage, all connected to the wire specimens. Voltage readings were taken from the nanovoltmeter at a specific set current (500 mA). 


\subsubsection{Tensile test}

In this research, Instron tensile test equipment with Futek (Model \# LCF455) maximum load capacity of 10,000 lbs was used for all mechanical test experiments except creep test. The setup consisted of two radial grip fixtures connected to the base and the load cell, they were used to clamp the material that was tested. The radial diameter of the grip is between $3.2-8.4 \mathrm{~mm}(0.125-0.25 \mathrm{inch})$.

TestWork software on the computer connected to the system was used to configure the Epsilon 1" extensometer and 10,000 Futek tension load used. This is essential for accurate data output. The position and load on the grips was zeroed before placing the specimen and tightening the grips. The extensometer was zeroed after attaching it to the gage length of the specimen. Before starting the experiment, the diameter of the rod/wire specimen, test speed and strain rate were inserted. For a specific gage length of 2 inch, the test speed was set at $0.24 \mathrm{in} / \mathrm{min}$. This corresponds to a strain rate of $2 \times 10^{-3} \mathrm{~s}^{-1}$ used for all tensile tests performed.

Initially the specimen tested were $101 \mathrm{~mm}$ (4 inches) in length and uniform diameter of 4.6 $\mathrm{mm}(0.182 \mathrm{inch})$ - specimen tensile bar design A. A $50.8 \mathrm{~mm}$ (2 inch) gage length was used for all specimens, while an Epsilon extensometer (1 inch) attached to the equipment was clamped to the gage length. Most of the elongation test performed, using this design, broke inside the grid. Preventing the uniform diameter wire specimens from breaking near or inside the grip was one of the major challenges faced during tensile testing. Whenever the specimen break within the grip, it leads to error in the elongation data. However, the tensile and yield strength remain accurate. With a uniform wire specimen diameter, breakage inside the grip occurred when the force applied while tightening the two grips were unequal. Since it was impossible to measure the force applied on each grip during tightening, preventing such breaks became impossible.

To prevent specimen break, the diameter of the gage length region of the tensile specimen was lathed. The new diameter and length of the lathed region was approximately $3.8 \mathrm{~mm}$ (0.150 inch) and $38.1 \mathrm{~mm}$ (1.5 inch), respectively (specimen tensile bar design B). This 
new wire specimen design allowed the breakage to occur within the gage length and Epsilon extensometer. See Figure 13 for the tensile test grid set-up and tensile specimen.
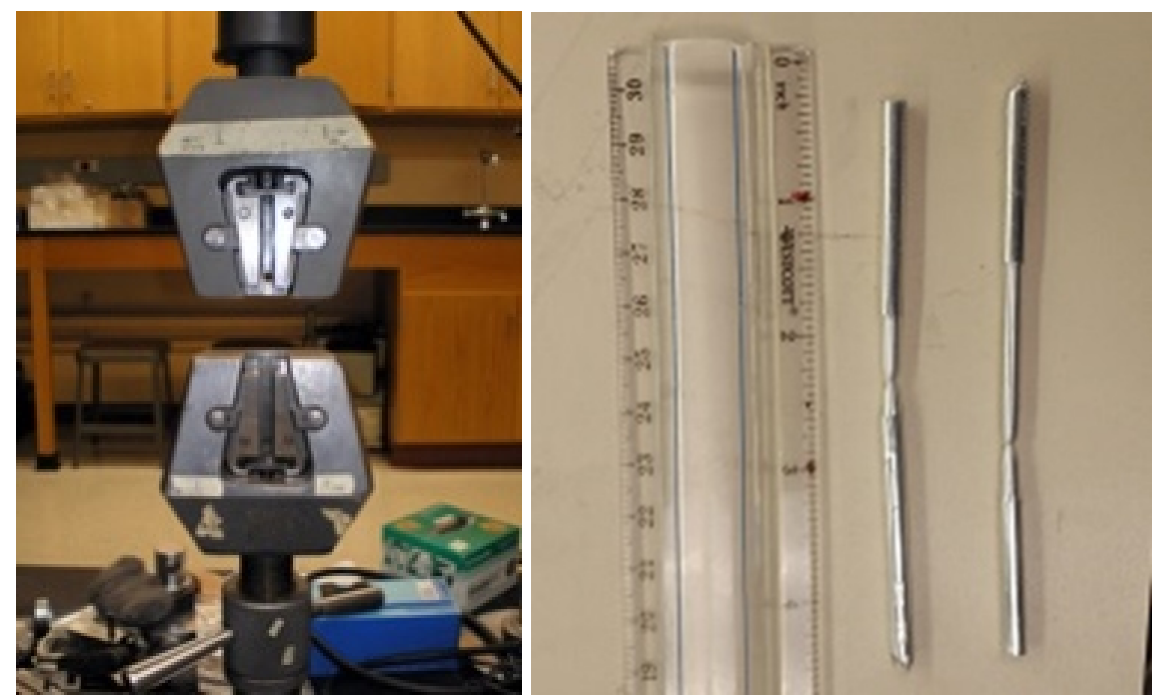

Figure 13. (Left) Tensile test grid set-up with wire specimen tensile bars, (shown on the right). The lathed gage length and diameter are $38.1 \mathrm{~mm}$ and $3.8 \mathrm{~mm}$ respectively.

\subsubsection{Creep strain}

Creep test was performed on as-wiredrawn and thermal aged wire specimens, using an Instron screw-driven tensile testing frame. A three-zone open-ended vertical tube furnace was used to maintain a constant temperature of $250^{\circ} \mathrm{C}$ over the entire length of test specimens. During creep test, stress was first ramped to the target stress of $40 \mathrm{MPa}$ within 15 seconds, held constant over the length $(2.5 \mathrm{hrs})$ of the creep test, and then dropped to zero. Figure 14 shows the creep test set-up. 

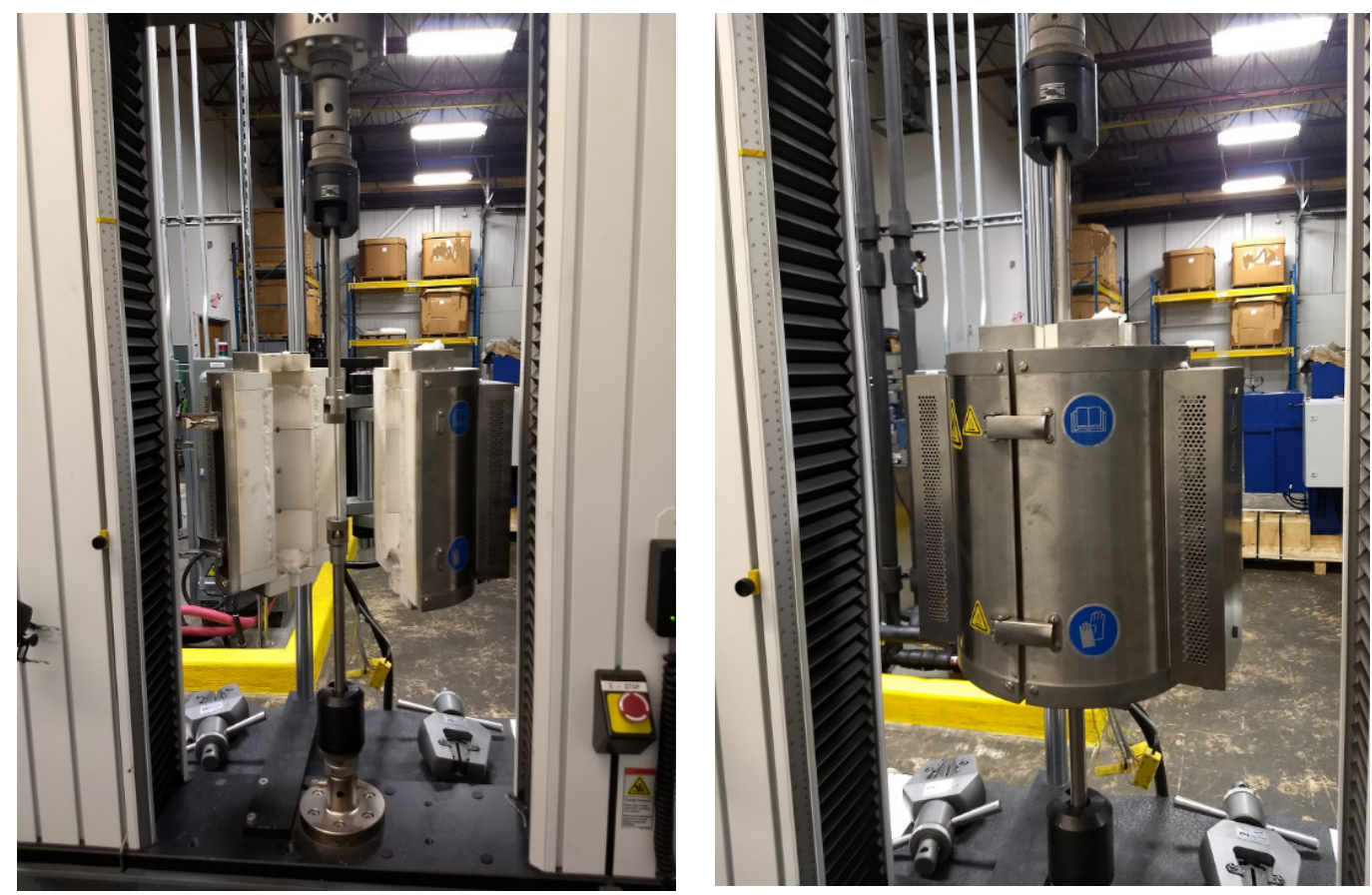

Figure 14. Instron screw-driven tensile testing frame was used to apply a constant stress of $40 \mathrm{MPa}$ on the specimens. The ambient temperature of the specimens was kept at $250^{\circ} \mathrm{C}$ using a three-zone open-ended vertical tube furnace.

Total strain at the end of the creep test $\left(\epsilon_{\text {total }}\right)$ and initial strain as stress ramping completes $\left(\epsilon_{\text {initial }}\right)$ were used to calculate creep strain:

$\epsilon_{\text {creep }}=\epsilon_{\text {total }}-\epsilon_{\text {initial }}$

Figure 15 shows an example of strain development of the duration of creep test. 


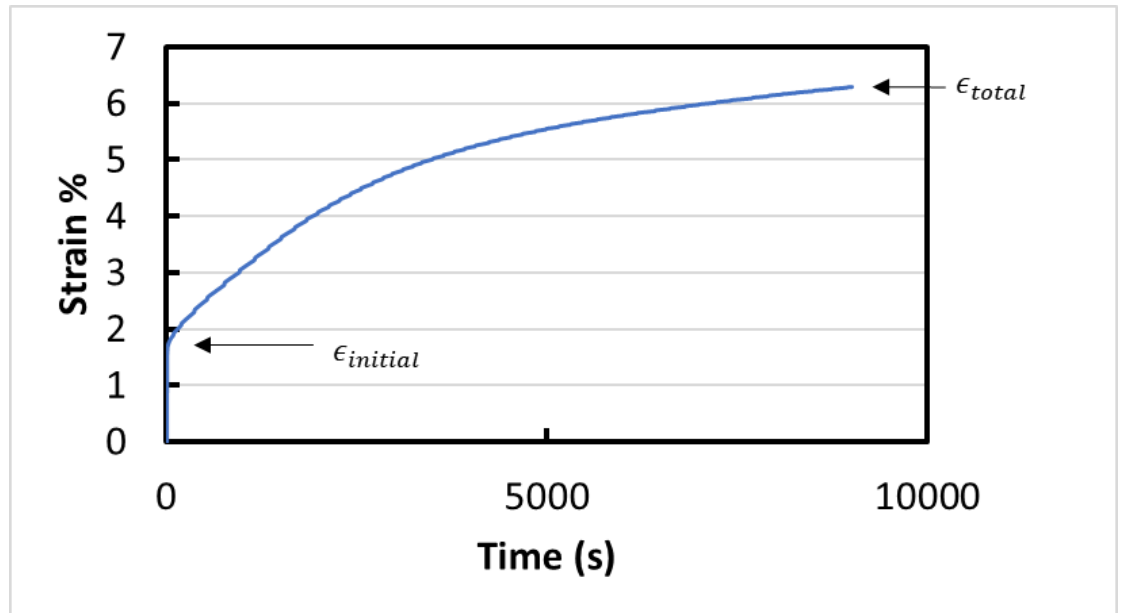

Figure 15. Sample strain over the duration of the load-controlled creep test.

Creep strain rate was calculated as:

$\epsilon_{\text {creep straln rate }}=\frac{\epsilon_{\text {creep }}}{2.5 h r}$

\subsection{Microstructure analysis}

\subsubsection{Scanning transmission electron microscope}

All transmission electron microscopy (TEM) imaging were performed with the FEI Titan Themis S-TEM, operating at $200 \mathrm{kV}$. The Themis has a full complement of state of the art accessories, including six (6) specialized specimen holders that extend the S-TEM utilities. Energy Dispersive X-ray Spectroscopy (EDX) analysis is performed on the elemental mapped specimens. Figure 16, shows the S-TEM set-up used for microstructure study. 


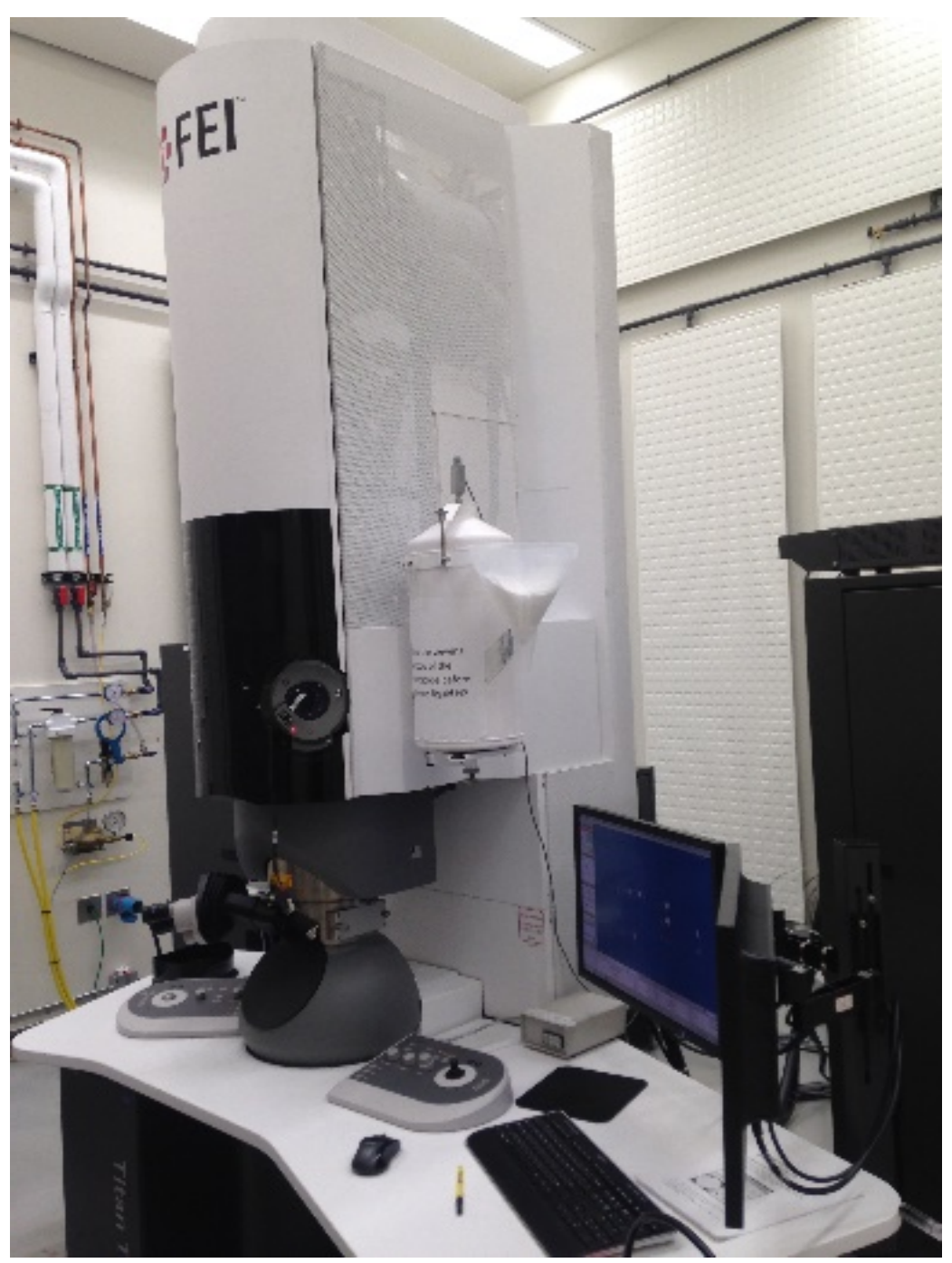

Figure 16. FEI Titan Themis Scanning Transmission Electron Microscope, operating at $200 \mathrm{kV}$, used for microstructural analysis. The double tilt holder was used while examining each specimen.

To begin, the electropolished thin foil specimen was placed on the double tilt holder and clamped gently to prevent a loose specimen falling off inside the chamber. The specimen holder including the specimen were cleaned under plasma plume to remove any form of oxide layers or contamination. Plasma cleaning took a minimum of 5 minutes before inserting the specimen holder inside the chamber. 
The startup setting included the following:

- Octagon pressure 16

- Gun was always set to 1 and on

- LN was $15-54 \%$

- Col Valve close $=$ yellow color: This meant there was a covering of the gun beam

- When the Col Valve was clicked, and the button turned grey: This meant the valve protecting the gun was open

- Under HT/FEG/Vacuum tab, FEG Registers was selected and the instrument setting was changed from S-TEM to TEM mode or vise-versa

- $200 \mathrm{kV}$ TEM - was selected and set button was clicked

- SA $72000 \times$ TEM: The magnification was reduced to $4000 \times$ to make the beam visible if it is not visible on the stage

The Z-height, beam tilt, beam shift and objective aperture alignments were performed to improve the quality of the image acquired. To examine the diffraction pattern of the matrix or precipitate phase, the magnification was set to $28000-36000 \times$ before the specimen was tilted by adjusting the $\alpha$ and $\beta$. The tilt was performed to find a specific zone axis of interest.

\subsubsection{Environmental scanning electron microscope}

The FEI Philips XL 40 Environmental Scanning Electron Microscope is a large chamber scanning electron microscope (SEM) with advanced accessories that include a thin window energy dispersive spectrometer (EDS). It was used to perform SEM experiments on electropolished thin foils.

To load the specimen, a double-sided carbon conducting sticky tape was laid down on the specimen pin mount. The edge of several specimens examined were placed on the sticky tape to hold and prevent it from falling inside the vacuum chamber during the experiment. The specimen pin mount has a big enough diameter to hold between 5 - 10 specimens, as long as they are labelled properly for identification purpose. After placing the specimens on the pin mount, it was placed on the mounting platform that slides onto the SEM stage. 
Generally, for SEM imaging, the specimen needs to be either conductive or coated with metal for grounding purpose. This is done to prevent electron beams from charging the specimen and distorting the images. After loading the specimen inside the chamber and the chamber door was closed, vacuum was created inside the chamber before running the experiment. The Scanning Electron Microscope used for this research is shown in Figure 17.

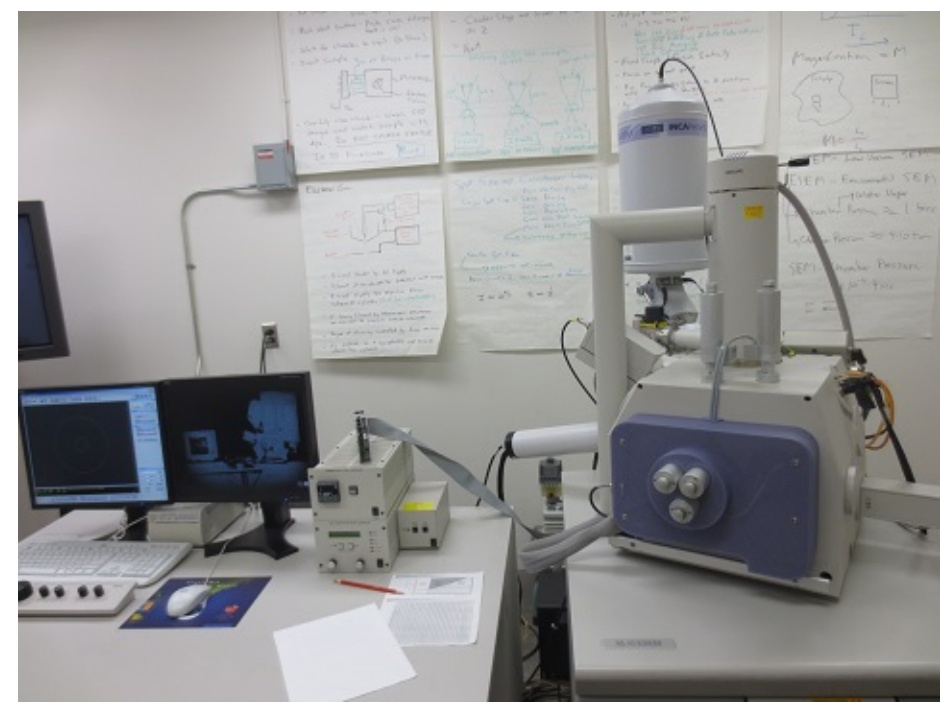

Figure 17. FEI Philips XL 40 Environmental Scanning Electron Microscope used for acquiring backscattered images of $\mathrm{Al}-\mathrm{Zr}$ and $\mathrm{Al}-\mathrm{Zn}-\mathrm{Zr}$ precipitate morphologies after aging at $600^{\circ} \mathrm{C}$.

The column valve was opened so the electron beam from the gun's tungsten filament could pass through the column. The image from the specimen was focused and aligned in secondary imaging mode, before capturing the microstructure features in backscatter electron imaging mode to enhance the visibility of the precipitates formed in the specimens. Backscatter electron imaging mode allows only elastically scattered, high energy electrons, reflected out of the specimen, after interaction with the atoms of the specimen, to be detected. On the other hand, secondary imaging is derived from secondary electrons emitted by excited atoms due to interaction with electron beam. 


\section{Chapter 4: Investigation of Al-Zn-Zr and Al- $\mathrm{Zn}-\mathrm{Ni}$ alloys for high electrical conductivity and strength application}

Accepted for publication in Materials Science and Engineering A

\subsection{Abstract and introduction}

\subsubsection{Abstract}

Al-Zn-TM (TM=Transition metals) alloys are developed with an integrated computational material engineering (ICME) strategy. Al-Zn-Ni and Al-Zn-Zr are determined to have promising electrical conductivities via a series of $a b$ initio density functional theory (DFT) simulations assessing combinations of Al-TM and Al-Zn-TM. The computed enthalpies of formation are used to identify the zero-temperature equilibrium precipitate phase in both alloys with increasing levels of $\mathrm{Zn}$ content, with a particular focus of finding $\mathrm{Zn}$ content levels that result in a precipitate $\mathrm{L}_{2}$ structure. The corresponding microhardness and electrical conductivity measurements of both alloys are evaluated. Transmission Electron Microscopy (TEM) is used to examine the morphology of the $\mathrm{Al}_{3-\mathrm{x}} \mathrm{Zn}_{\mathrm{x}} \mathrm{Ni}$ and $\mathrm{Al}_{3-\mathrm{x}} \mathrm{Zn} \mathrm{n}_{\mathrm{x}} \mathrm{Zr}$

precipitates formed in the respective alloys and their structures were confirmed as $\mathrm{L} 1_{2}$ by selected area electron diffraction (SAED). Through qualitative chemical analysis, it is demonstrated that $\mathrm{Ni}$ and $\mathrm{Zr}$ are not present in the matrix but are completely used up in forming the respective precipitate phases in both alloys.

\subsubsection{Introduction}

The Integrated Computational Materials Engineering (ICME) approach involves the use of computational simulation tools to facilitate the materials development process for targeted high strength and electrical conductivity engineering applications[24], thus reducing the number of design iterations and overall development time and cost. The ICME approach 
is well suited for the development of new aluminum alloy systems because of the presence of a well-defined metric (e.g. electrical conductivity and energy of formation) and a corresponding structure-property simulation tool for this purpose. For the ICME development of new metallic alloys, Density Functional Theory (DFT)[19] is a powerful computational tool for predicting stable crystal structures and estimating electrical conductivities for multi-element alloy systems. DFT has been used extensively for predicting structural, physical, and chemical properties of aluminum alloys and intermetallic compounds. Such properties include elastic constants[3, 4, 25], lattice parameters[26], stable microstructures, and density of states[15, 27, 28]. As the initial step in the ICME process, a broad range of $\mathrm{Al}$ alloys was selected for exploration of electrical conductivity and subsequent prediction of precipitate phase structure.

Precipitation strengthening utilized in this study is one of the most effective mechanism for enhancing alloy strength. For improved retention of precipitation hardened Al alloy strength, transition metal (TM) elements were specifically selected as solutes, because of their low rate of diffusivity and favorable solvus line with high solubility at solutionizing temperatures and low solubility at aging temperatures. The low rate of TM diffusivity in aluminum reduces the rate of precipitate coarsening, thus retaining the alloy strength at elevated service temperatures for longer periods of time. The low solubility at aging temperature increases the precipitate volume fraction and corresponding precipitation strengthening, because, majority of the solute atoms precipitate out of solid solution during aging. Low concentrations and solid solubility of alloying elements, especially in solution, are required to minimize their negative impact on the electrical conductivity. Another important benefit of using some transition metals includes resistance to corrosion[13].

Since aluminum has an fcc crystal structure, it is desirable to form precipitates with $\mathrm{L}_{2}$ crystal structure to minimize lattice mismatch and enhance precipitate/matrix lattice coherency. Coherency strains due to the minimal lattice mismatch is responsible for improved creep resistance and alloy strength through obstruction of dislocation motion by the strain fields surrounding the coherent precipitates[29]. A large lattice mismatch (observed in incoherent and semi-coherent precipitates) can be a driving force for 
precipitate coarsening. Therefore, it is expected that coherent $\mathrm{L}_{2}$ precipitates provide greater strengthening phases than precipitates of other crystal structures. Of all binary Al$\mathrm{TM}$ systems, only $\mathrm{Al}_{3} \mathrm{Sc}$ trialuminide has a thermodynamically stable $\mathrm{L}_{2}$ structure. Though, several studies have shown that metastable $\mathrm{L}_{2}-\mathrm{Al}_{3} \mathrm{Zr}$ precipitate structures form in $\mathrm{Al}-\mathrm{Zr}$ alloys during aging. However, some of these $\mathrm{L}_{2}$ precipitates transform back to their equilibrium $\mathrm{D}_{23}$ structure at high temperatures $\left(>475^{\circ} \mathrm{C}\right)[30,31]$. Precipitates formed in binary $\mathrm{Al}-\mathrm{Ni}$ alloys have a stable orthorhombic $\mathrm{D} 0_{11}-\mathrm{Al}_{3} \mathrm{Ni}$ phase[32], which is incoherent with the $\alpha-\mathrm{Al}$ matrix. Hence, the need for precipitate phase transformation from $\mathrm{D} 0_{11} \rightarrow \mathrm{L}_{2}$.

Most TMs have very low solid solubility limit $(<1$ at. \%) in the $\alpha$-Al matrix, which limits the volume fractions of the precipitate formed in binary Al-TM alloys to $\phi<1 \mathrm{vol} \%$ from aging, and their corresponding strengthening from precipitation hardening[29]. Hence, the need to develop ternary Al- $\mathrm{TM}_{1}-\mathrm{TM}_{2}$ alloys with stable $\mathrm{L}_{2}$ precipitate phase and increased precipitate volume fraction. Several studies of $\mathrm{Al}-\mathrm{Zr}-\mathrm{Ti}$ and $\mathrm{Al}-\mathrm{Zr}-\mathrm{Sc}$ ternary alloys have shown improved $\mathrm{L} 1_{2}$ precipitate volume fractions and corresponding microhardness values relative to $\mathrm{Al}-\mathrm{Zr}$, but their electrical conductivities are severely impacted[30, 31]. For instance, Knipling determined the electrical conductivities of Al-0.1Zr-0.1Ti and Al-0.1Zr$0.1 \mathrm{Sc}$ (at.\%) as 26.6 and $26.4 \mathrm{MS} / \mathrm{m}$ at as-cast and 29.2 and $32.8 \mathrm{MS} / \mathrm{m}$ at peak condition, respectively[30,33].

To form a suitable ternary aluminum alloy with high electrical conductivity, a natural choice of TM element is $\mathrm{Zn}$. As shown in Figure 18, $\mathrm{Zn}$ has a minimal impact on electrical conductivity of $\mathrm{Al}$, relative to other metals. However, it is generally more soluble in aluminum than other TM elements, hence, most of the added $\mathrm{Zn}$ remains in solid solution during the aging process[29]. It has been shown that the addition of $\mathrm{Zn}$ to aluminum results in minimal improvement of tensile strength through solid solution strengthening[29]. Thus, it follows that binary Al-Zn alloys are not suitable for achieving both high conductivity and strength. When in solid solution, solutes have significantly more negative impact on the electrical conductivity of the alloys (Figure 18) than when out of solution[13]. Taking advantage of $\mathrm{Zn}$ solute's minimal impact on the electrical conductivity of $\mathrm{Al}$, when in or 
out of solution, ternary Al-Zn-TM alloys with improved strength could therefore be developed, while still maintaining high electrical conductivity of the alloys[34].

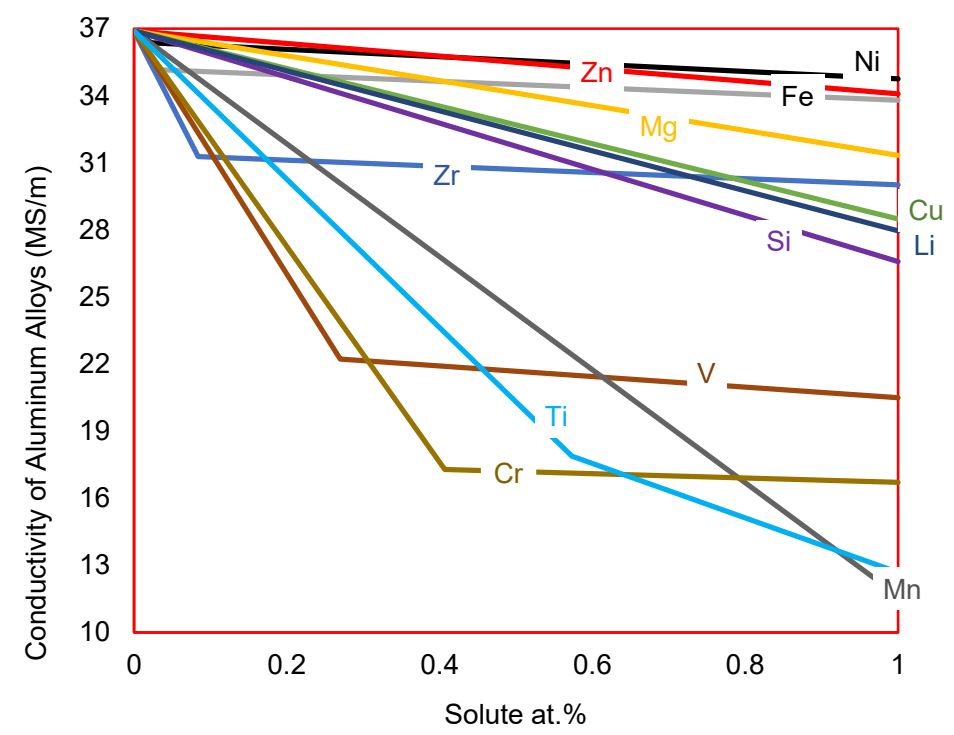

Figure 18. Experimental values of electrical conductivity drop, due to addition of $0-1 \mathrm{wt} . \%$ of each TM solute atom to form binary Al-TM alloy. Adapted from Hatch at room temperature $20^{\circ} \mathrm{C}[13]$. The change in slope occurs at the solvus line and corresponds to the composition beyond which excess solute precipitates out of solution.

Studies have also shown that adding $\mathrm{Zn}$ to certain binary Al-TM alloys to form $\mathrm{L}_{2}$ ternary Al-Zn-TM compounds are possible. The elements known to stabilize the ternary $\mathrm{L} 1_{2}$ crystal structure with respect to non-cubic $\mathrm{D}_{22}, \mathrm{D}_{23}$ and $\mathrm{D} 0_{11}$ all have atomic radii smaller than aluminum and contribute to the reduction of $\mathrm{c} / \mathrm{a}$ ratio of the $\mathrm{D} 0_{22}, \mathrm{D} 0_{23}$ and $\mathrm{D} 0_{11}$ phases[3537] or the number of d-shell electrons[35, 36]. For these reasons, the addition of $\mathrm{Zn}$ could be effective for transforming the non-cubic precipitate structures of $\mathrm{Al}_{3} \mathrm{Ni}$ to $\mathrm{L}_{2}$. According to Fine et al.[34], the use of ab-initio modeling predicts that adding $\mathrm{Zn}$ to $\mathrm{Al}_{3} \mathrm{Zr}$ improves the stability of metastable $\mathrm{L}_{2}$ precipitate phase. Which they verified by qualitative comparison of EDX data from the matrix and precipitate.

The objective of this study was to use ICME to facilitate the design, fabrication and testing of new aluminum alloy systems for high electrical conductivity applications, with 
improved mechanical properties, such as microhardness and yield strength. One application for these alloys is high-voltage electrical power transmission cables. DFT simulations were used to efficiently screen candidate alloy systems for subsequent experimental testing. Based on DFT results, Al-Zn-Zr and Al-Zn-Ni alloy systems were selected for experimental analysis because of their relatively high electrical conductivity and ability to form stable $\mathrm{L}_{2}$ precipitate phase required for improved alloy strengthening. In this paper, the computational effort is first described, followed by the experimental fabrication and characterization.

\subsection{Computational modeling}

This section describes the computational modeling methods and results that were used to efficiently down-select $\mathrm{Al}-\mathrm{Zn}-\mathrm{Zr}$ and $\mathrm{Al}-\mathrm{Zn}-\mathrm{Ni}$ as alloy candidates with optimal properties (electrical conductivity and precipitate phase stability). The pseudo-potential utilized for the simulation of each binary and ternary alloy system was a concatenation of the pseudopotential of the individual elements present in the specific alloy system simulated. These pseudo-potentials were selected from the PAW-PBE_52 category; they included zn_pv_GW, zr_sv_GW, Ni_sv_GW and Al_sv_GW. For every other transition elements, TM_sv_GW pseudo-potential was selected, because it generated physical properties (e.g. lattice parameter) that were consistent with experimental data of the elements.

\subsubsection{Method of electrical conductivity prediction}

For the DFT simulations, the generalized gradient approximation (GGA) with PerdewBurke-Ernzerhof (PBE) functional was used as implemented in the plane-wave Vienna Abinitio Simulation Package (VASP)[38]. The DFT approach was selected for this study because it efficiently provides a first-order prediction of the electrical conductivity and zero-temperature stability of the $\mathrm{L}_{2}$ precipitate phase for different alloy systems. In general, the electrical conductivity of metals is affected by the crystal structure, the presence of impurities, and temperature (which causes atomic vibrations that disrupt the transport and energetics of electrons near the Fermi surface). Although all these factors can be simulated using large ab initio Molecular Dynamics simulations (a series of DFT 
simulations that include thermal motion) and the Kubo-Greenwood formula[16, 17], this approach can be prohibitively time consuming for material screening efforts such as this. The electrical conductivity of metal alloys is also dependent on whether the alloying elements are in or out of solution (precipitation). The negative impact of alloying elements in solid solution on electrical conductivity is greater than when out of solid solution as secondary phase precipitates[13].

A more efficient approach is to use the semi-classical method[39], which predicts the electrical conductivity with a single DFT simulation at $0 \mathrm{~K}$. Although this approach does not consider the influence of thermal fluctuations on the scattering of electrons, precipitation of secondary phase from solid solution, and the presence of impurities (in this case $\mathrm{Zn}$ and TM); it does consider the density of state (DOS) predictions and the influence of temperature on the smoothed Fourier interpolation of the band. Density of state is a function $\rho_{\text {energy }}(E)$ that when multiplied by an interval of energy $\mathrm{dE}$ between energy states, $E$ and $E+d E$, provides the total concentration of the available states. It however does not provide any information about the number of states occupied by charge carries (e.g. electron). Therefore, the probability that an electron resides at a given energy is denoted by $\mathrm{P}(\mathrm{E})$, while the concentration of electrons at a given energy $\mathrm{E}$ is given as[19]:

$n_{e}(E)=P(E) \rho_{\text {energy }}(E) d E$

where $P(E)$ is the Fermi-Dirac distribution, $P(E) \rho_{\text {energy }}(E)$ implies that most of the electrons reside near the conduction band edge. Hence, the total concentration of electrons in the conduction band is given by:

$n_{c}=\int_{E_{C}}^{\infty} P(E) \rho_{\text {energy }}(E) d E$

$E_{C}$ is the starting energy of the conduction band. Generally, DFT utilizes the influence of the alloying elements included in Al matrix on the electron charge distribution and DOS of each $\mathrm{Al}$ alloy system to determine $n_{c}$.

This method has been used previously for prediction of electrical conductivity[40-43]. Though, it is however important to note that what DFT computes is the frequency 
dependent electrical conductivity tensor values. For any particular element, these tensor values vary with the number of atoms present in, or symmetry of the simulation cell. Hence, a direct comparison could not be made with experimental electrical conductivity. However, as long as the size of all the simulation cells (or number of atoms in simulation cell) are the same, the electrical conductivity fraction of each alloy system relative to that of pure Al can be plotted. Due to the multiple limitations of DFT, this approach was not used to predict the actual electrical conductivity of $\mathrm{Al}$ alloys, rather, it was only used as an efficient screening tool for exploring the electrical conductivity trends for binary and ternary Al alloys. The semi-classical approach calculates the electrical conductivity tensor using the Boltzmann transport equations.

$\sigma_{i j}(\varepsilon)=\frac{1}{N} \sum_{i, k} e^{2} \tau_{i, k} v_{\alpha}(i, k)\left(-\frac{\delta\left(\varepsilon-\varepsilon_{i, k}\right)}{d \varepsilon}\right)$

$\sigma_{i j}(T, \mu)=\int \sigma_{i j}(\varepsilon)\left(-\frac{\delta f_{\mu}(T, \varepsilon)}{\delta \varepsilon}\right) d \varepsilon$

where $f_{\mu}(T, \varepsilon)$ is the Fermi-Dirac distribution, $i$ and $j$ are tensor indices, $e$ is the electron charge, $N$ is the number of $k$-points sampled, $v$ is the band velocity, and $\tau$ is the relaxation time. VASP assumes a constant $\tau$ for charge carriers, which can be set using the RTIME command (in femtoseconds). The first equation is energy-dependent, while the second is a function of temperature $T$ and chemical potential $\mu$ [43]. In VASP, the chemical potential is considered to be the same as the Fermi level.

\subsubsection{Effect of spatial arrangement on electrical conductivity}

Before DFT simulations were performed to predict the electrical conductivity trends of AlZn-TM combinations, a sub-set of alloy supercells were modeled to establish the dependence of the placement of alloying elements within the supercell on electrical conductivity. The following face-centered cubic (FCC) supercells listed in Table 1, consisting of 108 atoms $(3 \times 3 \times 3$ unit cells) were constructed. For each alloy system (except pure Al) two supercells were constructed, one with clustered alloying elements, and another with dispersed alloying elements. For example, Figure 19 shows the cluster and disperse supercells for the $\mathrm{Al}_{106} \mathrm{ZnZr}$ alloy system. For the cluster configuration, the two 
atoms of the alloying elements were placed at the face center and corner lattice positions in a single FCC unit cell within the supercell (first neighbor positions). In the disperse configuration, an atom of the first alloying element was placed at the eight (8) corners of the super cell (amounting to 1 solute atom/supercell), while an atom of the second alloying element was placed within the supercell. These models represent $\sim 0.926$ at. $\%$ of each solute atom. This composition is well above practical solid solubility limit of most transition metals (Figure 18) which have solubility limits that are $\ll 1$ at. \% in aluminum. However, larger DFT supercells would need to be constructed to get lower concentration levels of solute atoms, which would become prohibitively time-consuming considering the large number of systems considered in this study.

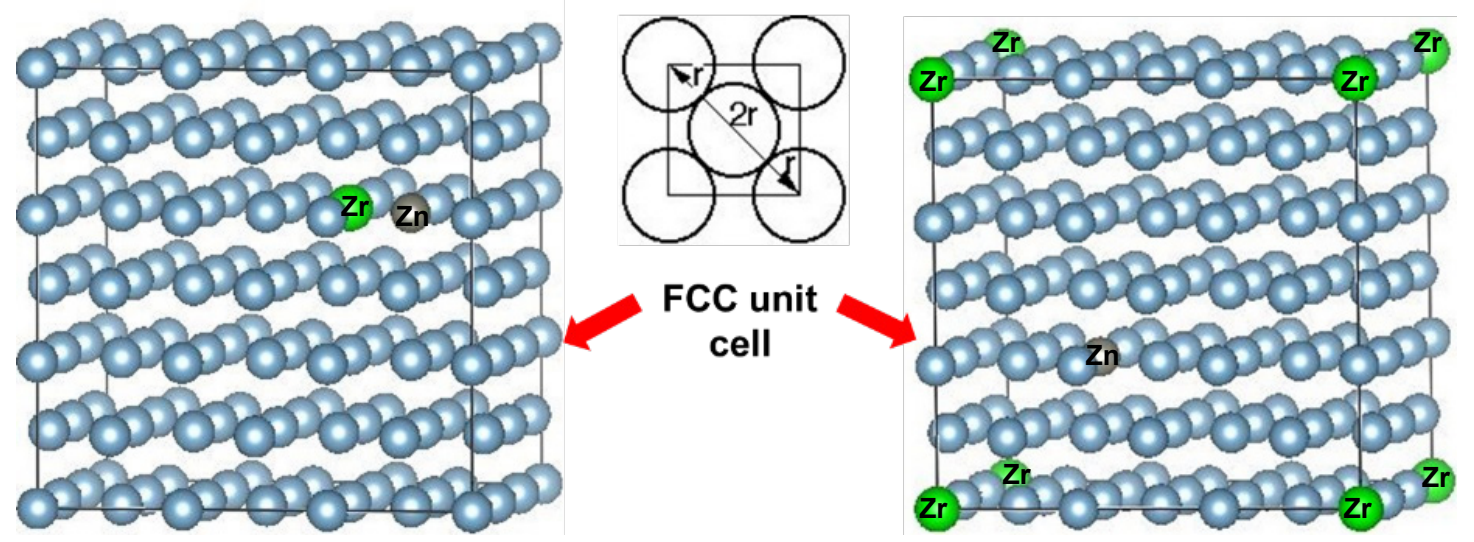

Figure 19. Clustered (left) vs disperse (right) supercell structures, consisting of aluminum (Blue atoms), $\mathrm{Zn}$ (grey atoms) and $\mathrm{Zr}$ (green atoms). Each supercell has a size of 3x3x3 FCC unit cells consisting of 108 atoms.

The electrical conductivity (MS/m) tensor was calculated for each alloy system using the VASP command "LOPTICS = .TRUE.". The Methfessel-Paxton method (of order 1) was used for smoothing of the energy bands. The energy cutoff was set to $550 \mathrm{eV}$, while the Brillouin zone sampling was performed using 6 × 6 × 6 k-point $\Gamma$-centered MonkhorstPack mesh. Table 1 shows the predicted electrical conductivities with respect to the $\mathrm{Al}_{108}$ 
system for each of the alloy system in the cluster and disperse configurations. In the table, the electrical conductivity of pure Al was normalized to 1. Electrical conductivities of the ternary alloy systems were also normalized as a fraction of the electrical conductivity of pure Al. Hence, $\sigma_{C}$ and $\sigma_{D}$ are the normalized values, with no unit. The lattice constant included in the Table 1 is the length of the simulation cell after relaxation.

From these data, it is clear that the clustered systems demonstrated a slightly higher electrical conductivity relative to the dispersed systems in all the alloy systems simulated. Due to the difference between the atomic radii of $\mathrm{Al}$ and the solute atoms, the distribution of alloying elements within the matrix generated multiple lattice strains and distortions that served as scattering sites for electrons. This was responsible for hindering electron mobility and reducing electrical conductivity. Therefore, when the alloying elements were clustered, the electron scattering sites were localized and thus reduced in number density relative to the disperse configuration. This could be responsible for their slightly higher electrical conductivities relative to their corresponding disperse systems. Since there was no significant change in free energy per atom, between both configurations in all alloy systems considered, the choice of using the clustered configurations for all remaining supercell calculations in this study was made for consistency purposes. 
Table 1. Comparison of electrical conductivity and energy per atom in dispersed and clustered Al alloy systems. The percent increase in conductivity is also listed.

\begin{tabular}{|c|c|c|c|c|c|c|c|}
\hline & $\begin{array}{c}\sigma_{D} \\
\text { fraction }\end{array}$ & $\begin{array}{c}\text { ED/atom } \\
\text { (Disperse) } \\
\text { (eV/atom) }\end{array}$ & $\begin{array}{c}\text { Lattice } \\
\text { constant } \\
\text { (Disperse) ( }(\AA)\end{array}$ & $\begin{array}{c}\sigma_{C} \\
\text { fraction }\end{array}$ & $\begin{array}{l}\text { Ec/atom } \\
\text { (Cluster) } \\
\text { (eV/atom) }\end{array}$ & $\begin{array}{c}\text { Lattice } \\
\text { constant } \\
\text { (Cluster) }(\AA)\end{array}$ & $\begin{array}{c}\% \sigma \\
\text { increase }\end{array}$ \\
\hline $\mathrm{Al}_{108}$ & 1.00 & -3.76 & 12.0637 & 1.00 & -3.76 & 12.0637 & - \\
\hline $\mathrm{Al}_{106} \mathrm{Ni}_{2}$ & 0.43 & -3.825 & 12.0062 & 0.50 & -3.825 & 12.0461 & 16.3 \\
\hline $\mathrm{Al}_{106} \mathrm{Zr}_{2}$ & 0.23 & -3.900 & 12.1042 & 0.25 & -3.897 & 12.0995 & 8.7 \\
\hline $\mathrm{Al}_{106} \mathrm{Zn}_{2}$ & 0.78 & -3.709 & 12.0786 & 0.86 & -3.709 & 12.0668 & 10.3 \\
\hline $\mathrm{Al}_{106} \mathrm{ZnZr}$ & 0.33 & -3.804 & 12.0761 & 0.34 & -3.804 & 12.1097 & 3.0 \\
\hline $\mathrm{Al}_{106} \mathrm{ZnTi}$ & 0.32 & -3.786 & 12.0549 & 0.33 & -3.785 & 12.0586 & 3.1 \\
\hline $\mathrm{Al}_{106} \mathrm{ZnHf}$ & 0.34 & -3.825 & 12.0764 & 0.36 & 3.825 & 12.0771 & 5.9 \\
\hline $\mathrm{Al}_{106} \mathrm{ZnV}$ & 0.27 & -3.772 & 12.0442 & 0.28 & -3.771 & 12.0462 & 3.7 \\
\hline $\mathrm{Al}_{106} \mathrm{ZnTa}$ & 0.30 & -3.828 & 12.0611 & 0.31 & -3.821 & 12.0534 & 3.3 \\
\hline $\mathrm{Al}_{106} \mathrm{ZnCr}$ & 0.26 & -3.789 & 12.0442 & 0.28 & -3.789 & 12.0483 & 7.7 \\
\hline $\mathrm{Al}_{106} \mathrm{ZnCo}$ & 0.40 & -3.765 & 12.012 & 0.43 & -3.765 & 12.0262 & 7.5 \\
\hline $\mathrm{Al}_{106} \mathrm{ZnNi}$ & 0.49 & -3.767 & 12.0331 & 0.55 & -3.767 & 12.0353 & 12.2 \\
\hline $\mathrm{Al}_{106} \mathrm{ZnCd}$ & 0.74 & 1.913 & 12.0431 & 0.78 & -1.913 & 12.0431 & 5.4 \\
\hline $\mathrm{Al}_{106} \mathrm{NiZr}$ & 0.23 & -3.861 & 12.0325 & 0.27 & -3.861 & 12.0664 & 17.4 \\
\hline $\mathrm{Al}_{106} \mathrm{MgSi}$ & 0.64 & -3.879 & 12.0624 & 0.65 & -3.879 & 12.0774 & 1.6 \\
\hline \multicolumn{8}{|c|}{ Conductivity of each configuration is a fraction of bulk aluminum supercell (108 atoms) } \\
\hline$\circ \sigma_{D}$ and $\sigma_{C}$ & & izod con & uctivities of $\mathrm{c}$ & & cluster & nfigurations, & espectively \\
\hline $\begin{array}{r}\mathrm{E}_{\mathrm{D}} / \text { atom } \\
\text { respectiv }\end{array}$ & $\mathrm{E}_{\mathrm{C}} / \mathrm{a}$ & , th & e energy & atom & dispers & dd cluster & figurations, \\
\hline
\end{tabular}

\subsubsection{Pattern of electrical conductivity across transition elements}

DFT simulations of FCC supercells of 108 atoms were constructed for a series of Al-TM binary systems to determine how the individual TMs affect the electrical conductivity in Al-TM binary systems. This information was important for validating the modeling with the experimental data[13]. Each system consisted of 107 atoms of aluminum and 1 atom (approx. 0.926 at. \%) of TM. The same simulation parameters as described in the previous sub-section were used to predict the electrical conductivities of each alloy system. In 
Figure 20, the electrical conductivities for a series of Al-TM systems are plotted with respect to pure aluminum (thus, the electrical conductivity of pure aluminum is normalized to 1, while those of Al-TM systems are expressed as fractions). Also shown in the figure are two sets of room temperature experimental values, based on the data in Figure 18. The series labeled as "expt-PPT" represents the true experimental result; it considers the effect of precipitation on conductivity once the maximum solubility limit of each transition metal in aluminum has been exceeded. The series "expt-SS" is the extrapolation of the data showing the decrease in conductivity per atomic percent of each transition metal in solid solution with aluminum according to Hatch[13]. The extrapolation of expt-SS ignores the solvus line (precipitation) effect on electrical conductivity, which is consistent with the execution of the DFT simulations. The trend of electrical conductivities computed using DFT agrees well with the experimental data (expt-SS) when precipitation is not considered, and all solutes are assumed to remain in solid solution. The same cannot be said about exptPPT. This is expected, because DFT simulations does not consider precipitation effects on electrical conductivity. However, similar to expt-SS and DFT curves, the expt-PPT data also shows an overall downward trend for the electrical conductivities of the Al-TM systems considered, though at a higher fraction of aluminum conductivity. Therefore, the overall electrical conductivity reduction observed for expt-PPT is lower than expt-SS. The lower conductivity reduction observed in expt-PPT is because once the composition of the solute atoms exceeds the solubility limit, the solute atoms that form precipitates do not degrade the conductivity as much as when in solution. Ni, Fe and Zr have a much higher electrical conductivity fraction for expt-PPT relative to expt-SS relative to $\mathrm{Zn}, \mathrm{Cu}, \mathrm{V}, \mathrm{Cr}$, Ti and Mn (Figure 20). This is because these elements have very small at.\% solid solubility limit in aluminum, Figure 18. Therefore, the precipitation effect on their electrical conductivity values is more dominant since the majority of these solutes will precipitate out of solution. 


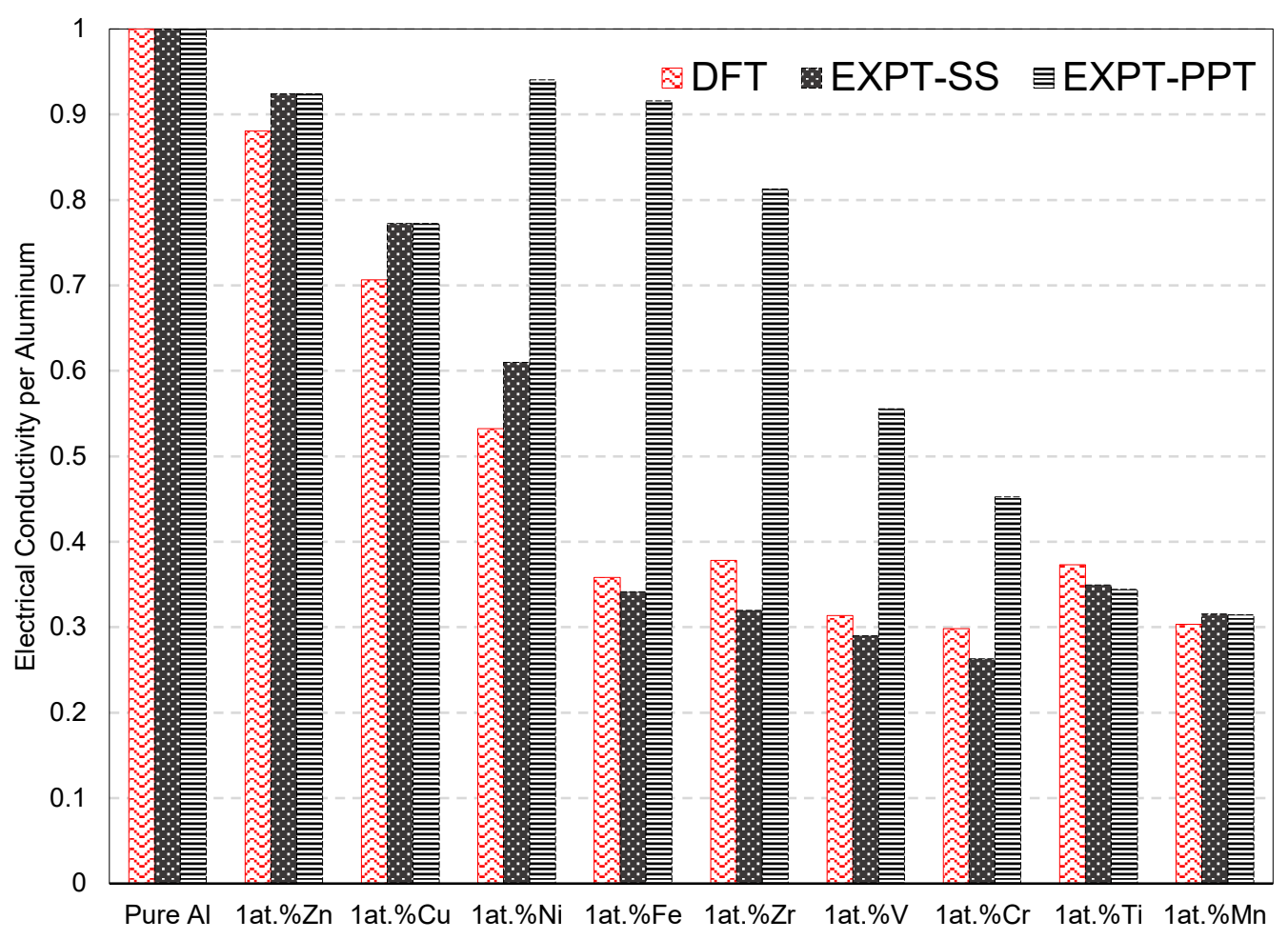

Figure 20. Comparison of electrical conductivity trends between experiment (precipitation and pure solid solution) and DFT. Except for pure Al, the alloy composition for each data point is $\mathrm{Al}-0.926$ at. \% TM.

After confirming modeling and experimental agreement in binary systems, fcc supercells (108 atoms) for a series of Al-Zn-TM ternary systems (TM = Sc, Y, Ti, Zr, Hf, V, Nb, Ta, $\mathrm{Cr}$, Mo, W, Mn, Tc, Re, Fe, Ru, Os, Co, Rh, Ir, Ni, Cu, Ag, Au, Zn, Cd, Hg) were constructed and their electrical conductivities were predicted (Figure 21). Each system consisted of 106 atoms of $\mathrm{Al}$ and 1 atom each (approx. 0.926 at. \%) of $\mathrm{Zn}$ and TM. The electrical conductivities are represented in bar chart format so that the overall trend of alloy conductivities within groups and across rows of the periodic table can be compared directly. According to the results shown in Figure 21, the predicted electrical conductivities show little change down each group from IIIB to VIIB, and a significant decrease down each of the groups VIII, IB, and IIB. 
The DFT electrical conductivity trend of selected ternary alloys was compared to that of previous binary alloy data in Figure 20, to examine how including a third element ( $\mathrm{Zn}$ ) would alter the electrical conductivity trend of the binary alloys. According to Figure 22, the addition of $\mathrm{Zn}$ to binary Al-TM alloys to form ternary Al-Zn-TM showed similar electrical conductivity trends with slightly lesser values. The similarity between electrical conductivity values of Al-TM and Al-Zn-TM indicates that the addition of 1 at.\% $\mathrm{Zn}$ to the binary Al-TM systems does not have significant negative impact on the electrical conductivities of the alloys. This agrees with the experimental observations shown in Figure 18.

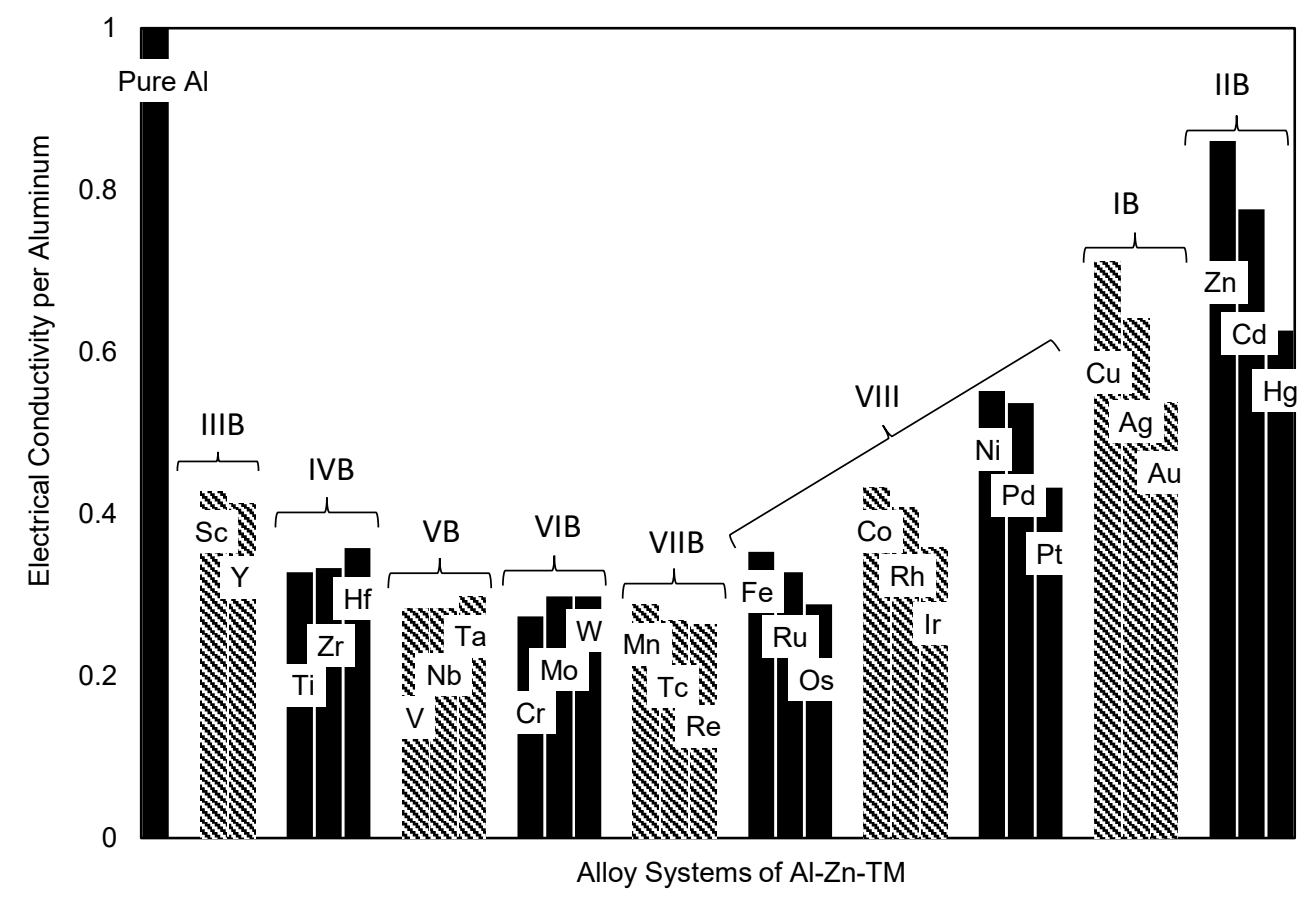

Figure 21. Electrical conductivity per aluminum of Al-Zn-TM formed across transition metals in the periodic table. Each block of solid and stripe pattern represents a group of transition metals. 


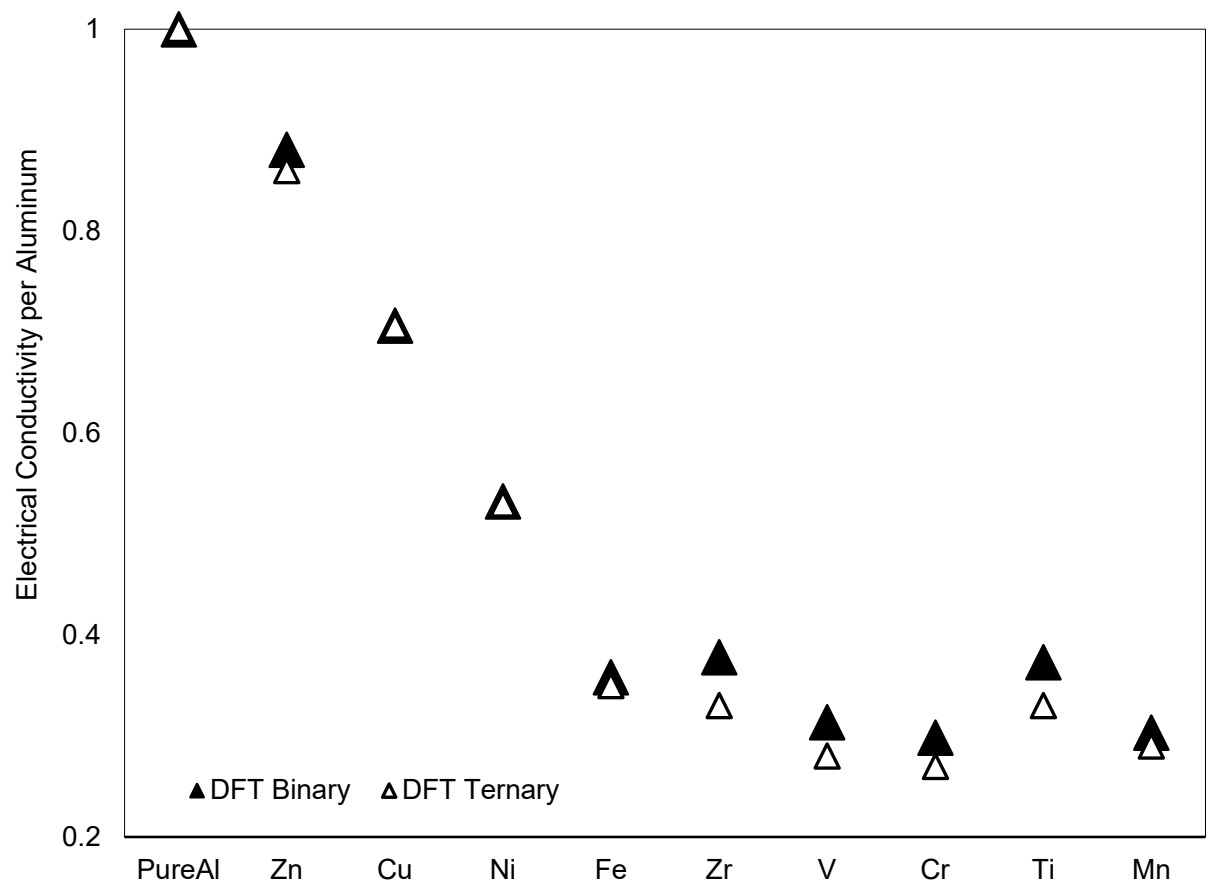

Figure 22. Comparison of the DFT electrical conductivity between binary Al-TM and ternary Al-Zn-TM. Except for pure Al, the alloy composition for each data point is Al0.926 at.\% TM for binary systems and $\mathrm{Al}-0.926$ at.\% Zn-0.926 at.\% TM for ternary.

From Figure 21, the conductivities can be ranked in order from the highest to lowest as TM $=\mathrm{Zn}, \mathrm{Cd}, \mathrm{Cu}, \mathrm{Ag}, \mathrm{Hg}, \mathrm{Ni}, \mathrm{Pd}, \mathrm{Au}, \mathrm{Co}, \mathrm{Pt}, \mathrm{Sc}, \mathrm{Y}, \mathrm{Rh}, \mathrm{Ir}, \mathrm{Hf}, \mathrm{Fe}$, and $\mathrm{Zr}$ (there are still more elements with lower conductivity in Figure 21). In order to down-select TM candidates for further industrial development and commercial use, several factors were considered. First, considering alloy costs in the Al-Zn-TM alloy, relatively expensive elements such as $\mathrm{Ag}$, $\mathrm{Pd}, \mathrm{Au}, \mathrm{Pt}, \mathrm{Sc}, \mathrm{Rh}$ and Ir were eliminated from consideration. Second, the avoidance of toxicity during fabrication is important, which eliminated $\mathrm{Cd}$ and $\mathrm{Hg}$ from consideration. Third, elements that do not aid the formation of $\mathrm{L}_{2}$ precipitate structure in Al-Zn-TM alloys, such as $\mathrm{Cu}$ and $\mathrm{Co}[44,45]$, were not considered. Finally, $\mathrm{TM}=\mathrm{Fe}$ usually does solutionize for subsequent precipitation, and was thus eliminated from consideration. Therefore, the only remaining transition metal candidates considered further were $\mathrm{TM}=$ 
$\mathrm{Ni}, \mathrm{Zr}, \mathrm{Y}$ and $\mathrm{Hf}$; and from these $\mathrm{Ni}$ and $\mathrm{Zr}$ were selected for this study because of their lower cost.

\subsubsection{Equilibrium precipitate phase of alloy systems}

The equilibrium phase structures of Al-Zn-Zr and Al-Zn-Ni aluminum alloy precipitates were investigated with DFT. The DFT approach was first used to simulate the most stable forms (unit cells) of pure $\mathrm{Al}, \mathrm{Zn}, \mathrm{Ni}$, and $\mathrm{Zr}$ to determine their free energy per atom values. The unit cells from these models are shown in Figure 23.
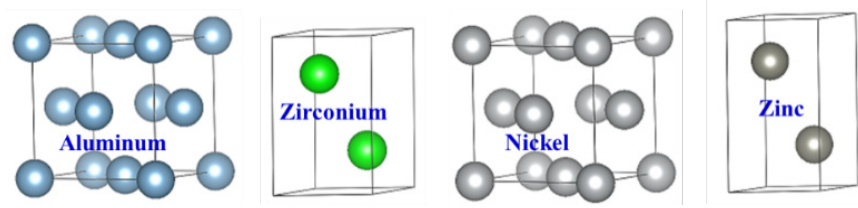

Figure 23. The most stable structures of pure $\mathrm{Al}$ (FCC), $\mathrm{Zr}$ (HCP), $\mathrm{Ni}$ (FCC), and $\mathrm{Zn}(\mathrm{HCP})$ from DFT simulation

Figure 24 shows the standard unit cells for the $\mathrm{L}_{2}, \mathrm{D} 0_{11}, \mathrm{D} 0_{22}$, and $\mathrm{D}_{23}$ structures. Because the $\mathrm{L}_{2}$ and $\mathrm{D} 0_{22}$ unit cells have fewer atoms than the $\mathrm{D}_{11}$ and $\mathrm{D} 0_{23}$ structures, they were scaled up to 16 atoms for direct comparison. Specifically, $1 \times 1 \times 4$ and $1 \times 1 \times 2$ arrays of $\mathrm{L}_{2}$ and $\mathrm{D}_{22}$ unit cells, respectively, were used to create supercells with 16 atoms each, to match the size of the $\mathrm{D}_{11}$ and $\mathrm{D} 0_{23}$ unit cells. For each simulation, an optimized plane-wave cutoff energy of $550 \mathrm{eV}$ was used. $\Gamma$-centered Monkhorst-Pack grids were generated and optimized for each structure using the automatic mesh generation scheme implemented in VASP. Partial occupancies for each wavefunction were set using the method of Methfessel-Paxton as implemented in VASP. $\mathrm{D}_{23}, \mathrm{D} 0_{22}$ and $\mathrm{L}_{2}$ crystal structures were considered for both $\mathrm{Al}-\mathrm{Zn}-\mathrm{Ni}$ and $\mathrm{Al}-\mathrm{Zn}-\mathrm{Zr}$ alloy systems while orthorhombic $\mathrm{D} 0_{11}$ (which is the initial stable crystal structure of $\mathrm{Al}_{3} \mathrm{Ni}$ prior to addition of $\mathrm{Zn}$ atoms) was considered only for the Al-Zn-Ni alloy. 


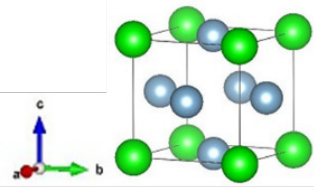

$\mathrm{L1}_{2}$ (4 atoms)

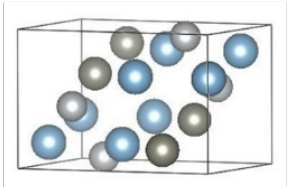

$\mathrm{DO}_{11}$ (16 atoms)

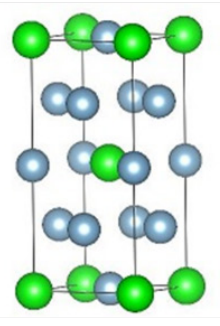

$\mathrm{DO}_{22}$ (8 atoms)

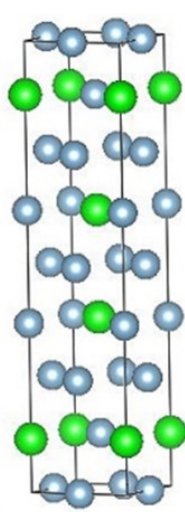

$\mathrm{DO}_{23}$ (16 atoms)

Figure 24. The unit cells of possible stable precipitates, consisting of aluminum (Blue atoms), $\mathrm{Zn}$ (grey atoms) and $\mathrm{Zr}$ (green atoms). $\mathrm{L} 1_{2}$ precipitate structure forms a coherent precipitate within the aluminum matrix, due to similarity in crystal structures and lattice parameters.

In order to determine the relative stability of the $\mathrm{L}_{2}, \mathrm{D}_{11}, \mathrm{D} 0_{22}$, and $\mathrm{D} 0_{23}$ phases for each $\mathrm{Zn}$ level in both systems, the enthalpy of formation at $0 \mathrm{~K}$ was determined from the energy per atom (energy/atom) values obtained from DFT simulations and the equation:

$\Delta H(A l-Z n-T M)=E(A l-Z n-T M)-a E(A l)-b E(Z n)-c E(T M)$

where $\Delta H$ is the enthalpy of formation; $E(A l-Z n-T M), E(A l), E(Z n)$ and $E(T M)$ are the energies per atom of the intermetallic compound, $\mathrm{Al}, \mathrm{Zn}$, and $\mathrm{TM}$, respectively; and $a, b$ and $c$ are mole fractions of the corresponding elements. Each species was relaxed to its equilibrium geometry at zero pressure in the DFT simulations. The enthalpy of formation values for the $\mathrm{Al}-\mathrm{Zn}-\mathrm{Ni}$ and $\mathrm{Al}-\mathrm{Zn}-\mathrm{Zr}$ alloy systems are shown in Figure 25 and Figure 26 respectively, wherein the structure with the lowest enthalpy of formation for a given concentration of $\mathrm{Zn}$ is the most stable.

From Figure 25 it is apparent that the lowest energy structure of the $\mathrm{Al}_{3} \mathrm{Ni}$ precipitate in the Al-Ni binary matrix is $\mathrm{D}_{11}$, which is incoherent with the matrix. However, there is a possibility of forming a $\mathrm{L}_{2}$ precipitate by replacing aluminum atoms in the precipitate 
structure with $\mathrm{Zn}$ atoms. Figure 25 shows that transformation of the $\mathrm{D} 0_{11}$ structure of $\mathrm{Al}_{3} \mathrm{Ni}$ trialuminide to $\mathrm{D}_{23}$ occurs for very low $\mathrm{Zn}$ concentrations, and the subsequent transformation to $\mathrm{L}_{2}$ occurs at approximately 0.17 atomic fraction of $\mathrm{Zn}$ (assuming a linear interpolation between data points). The $\mathrm{L}_{2}$ crystal structure continues to be most probable for $\mathrm{Zn}$ concentrations up to 0.5 , at which point the $\mathrm{D} 0_{22}$ phase has a nearly equal enthalpy of formation. Similarly, from Figure 26, the initial $\mathrm{Al}_{3} \mathrm{Zr}$ precipitate phase has a theoretical equilibrium $\mathrm{D}_{23}$ crystal structure even though experimentally it has been observed that during heat treatment, the $\mathrm{Al}_{3} \mathrm{Zr}$ precipitates formed assume a metastable $\mathrm{L}_{2}$ structure at temperature $<475^{\circ} \mathrm{C}[30]$. At a $\mathrm{Zn}$ concentration of about $\geq 0.04$, the lowest enthalpy of formation and crystal structure of the intermetallic becomes $\mathrm{L}_{2}$, which remains the most stable and equilibrium structure for higher $\mathrm{Zn}$ concentrations as shown in the graph[14]. Thus, it is evident from the simulations that the $\mathrm{Al}_{3-\mathrm{x}} \mathrm{Zn}_{\mathrm{x}} \mathrm{Ni}$ and $\mathrm{Al}_{3-\mathrm{x}} \mathrm{Zn} \times \mathrm{Zr}$ precipitates formed in $\mathrm{Al}-\mathrm{Zn}-\mathrm{Ni}$ and $\mathrm{Al}-\mathrm{Zn}-\mathrm{Zr}$ alloy systems respectively, have a coherent $\mathrm{L}_{2}$ structure, necessary for more effective material strengthening.

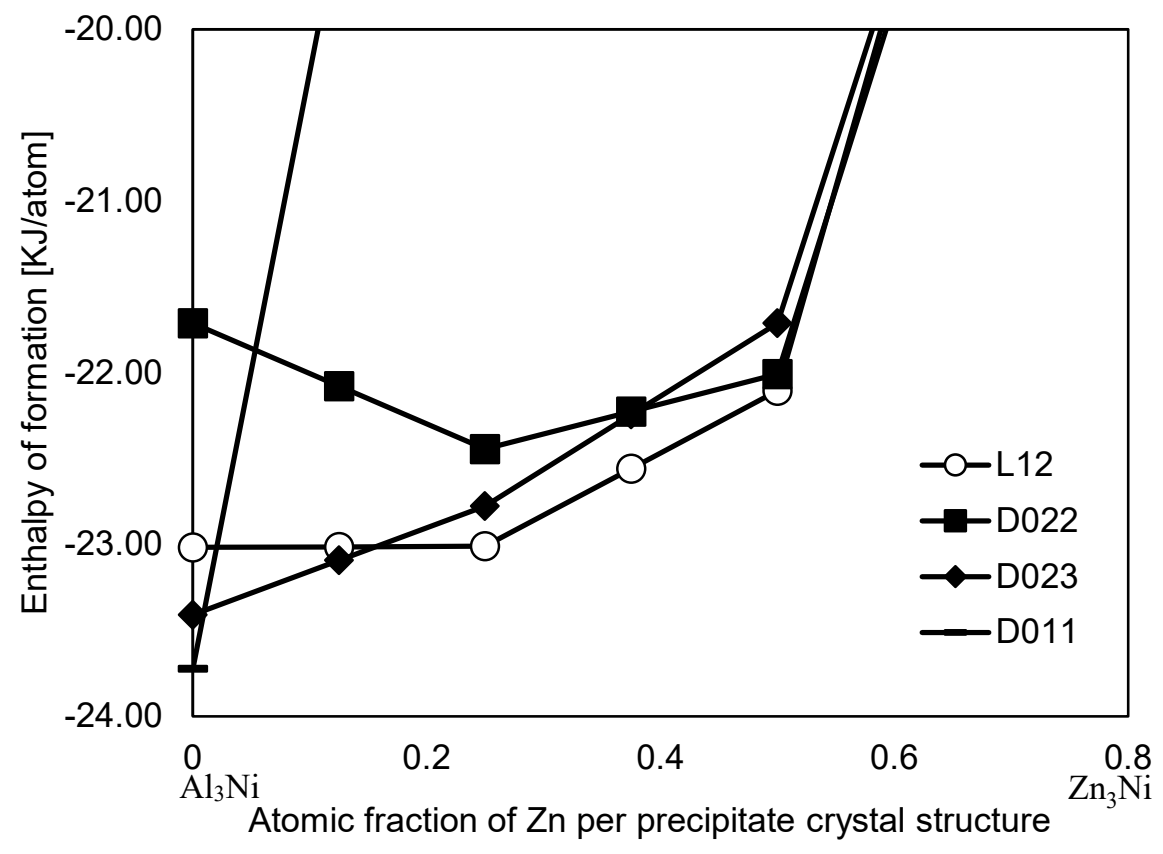

Figure 25. Enthalpy of formation of the Al-Zn-Ni alloy system. The $\mathrm{L}_{2}$ crystal structure becomes most stable at 0.17 atomic fraction of $\mathrm{Zn}$. 


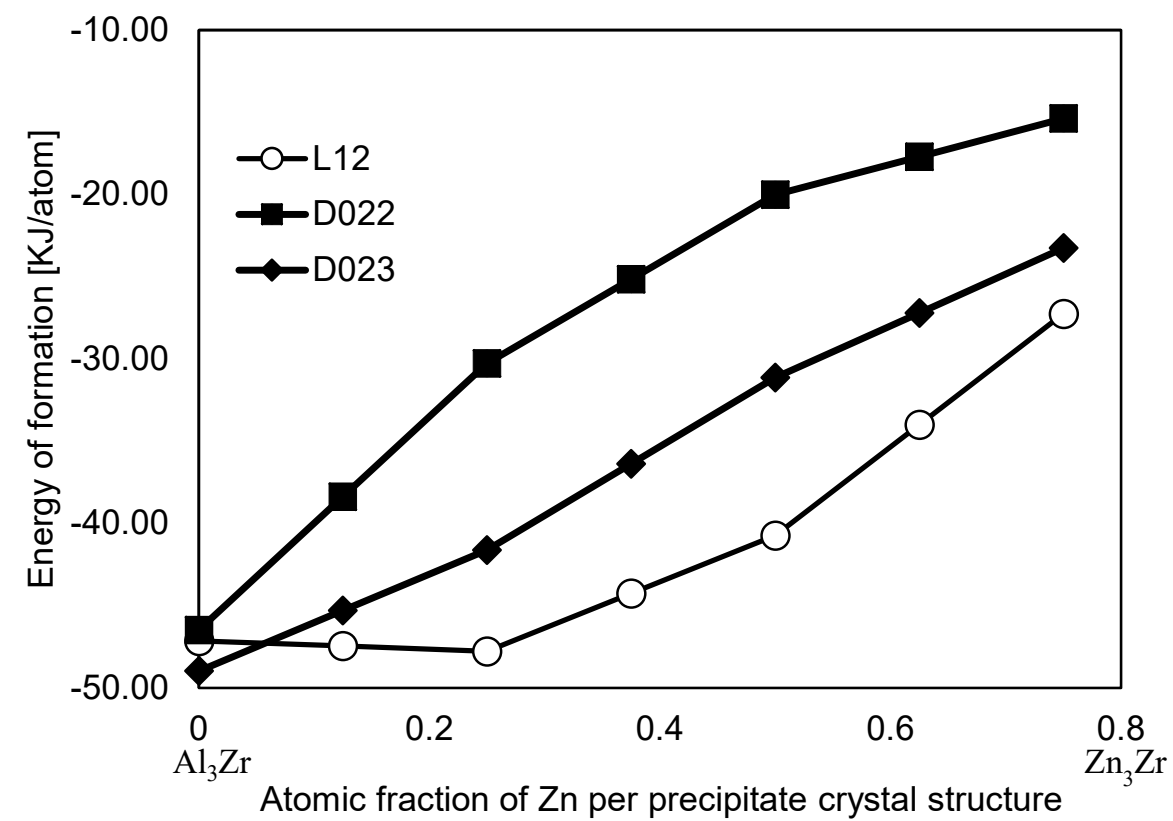

Figure 26. Enthalpy of formation of the $\mathrm{Al}-\mathrm{Zn}-\mathrm{Zr}$ alloy system. The $\mathrm{L} 1_{2}$ crystal structure becomes most stable at a 0.04 atomic fraction of $\mathrm{Zn}$.

\subsection{Experimental methods}

Based on the electrical conductivity and thermodynamic phase stability results from DFT computational simulation discussed above, Al-Zn-Ni and Al-Zn-Zr alloys were identified as having moderate to high conductivities and the ability to form $\mathrm{L}_{2}$ precipitate structure necessary for improved strength. Additionally, compared to other Al-Zn-TM alloys, Ni and $\mathrm{Zr}$ were expected to be inexpensive, not involve any toxic metals, have low diffusivity, and be highly castable. The next step in the ICME process was to fabricate samples of the Al$\mathrm{Zn}-\mathrm{Ni}$ and $\mathrm{Al}-\mathrm{Zn}-\mathrm{Zr}$ systems for characterization and mechanical and electrical testing. In this section, the fabrication and testing procedures are described, and the test results for Al$\mathrm{Zn}-\mathrm{Ni}$ and $\mathrm{Al}-\mathrm{Zn}-\mathrm{Zr}$ are compared. 


\subsubsection{Fabrication and testing of Al-Zn-Ni and Al-Zn-Zr}

Four different 600-gram ingots of $\mathrm{Al}-\mathrm{Zn}-\mathrm{Ni}$ and two 600-gram ingots of $\mathrm{Al}-\mathrm{Zn}-\mathrm{Zr}$ alloys were fabricated from 99.99 wt.\% purity aluminum, Al-20 wt.\% Ni and Al-5 wt.\% Zr master alloys, and 99.99 wt.\% purity $\mathrm{Zn}$ ingots in a vacuum induction melter (VIM). Measured quantities of each component were arranged inside a graphite crucible within the VIM chamber. A vacuum pressure of $7.8 \times 10^{-5}$ Torr was obtained inside the chamber through the use of a diffusion pump to minimize reactive gases before partially backfilling to 558 Torr with 99.999 wt.\% Ar gas. The temperature (measured by an optical pyrometer above the crucible) was gradually ramped to $710^{\circ} \mathrm{C}$, thereby melting the components inside the crucible. The target and nominal compositions of the alloys are listed in Table 2. Small size buttons were cut out of the $19 \mathrm{~mm}$ diameter rods of each ingot and their compositions measured using Inductively Coupled Plasma Optical Emission Spectroscopy (ICP-OES). The small buttons from the ingots were polished for optical metallography using 180, 320, 600 and 1500 silicon carbide paper grit followed by $6 \mu \mathrm{m}$ diamond, $1 \mu \mathrm{m}$ diamond, and a $0.04 \mu \mathrm{m}$ silica solutions polishing pads.

Solid solution heat treatments were performed on the Al-Zn-Ni samples for 4 hours at 620 ${ }^{\circ} \mathrm{C}$, within the single phase region so as to homogenize the Ni solute, before quenching in cold water. Without prior homogenization of $\mathrm{Al}-\mathrm{Zn}-\mathrm{Ni}$ specimens, a microhardness increase was not observed during aging. The Al-Zn-Zr alloys were not homogenized because prior homogenization of $\mathrm{Al}-\mathrm{Zr}$ alloy first nucleates primary $\mathrm{Al}_{3} \mathrm{Zr}$ precipitates. This reduces the amount of $\mathrm{Zr}$ solute left in solid solution for subsequent aging, thereby leading to a corresponding lower peak microhardness from precipitation hardening[33]. A series of multi-step isochronal aging experiments were carried out on the alloy buttons from 150 to $400^{\circ} \mathrm{C}$ at $50^{\circ} \mathrm{C}$ temperature steps and 150 to $600^{\circ} \mathrm{C}$ at $50{ }^{\circ} \mathrm{C}$ temperature steps for $\mathrm{Al}-\mathrm{Zn}-\mathrm{Ni}$ and $\mathrm{Al}-\mathrm{Zn}-\mathrm{Zr}$, respectively. The duration for each temperature step was $3 \mathrm{~h}$ in the furnace before quenching in water.

Vickers microhardness measurements were performed on the mechanically polished surface at every temperature step, with a load of $50 \mathrm{~g}$ and dwell time of $15 \mathrm{~s}$. A calibrated 
Sigmascope SMP10 probe was used for electrical conductivity measurements of each button specimen.

\subsubsection{TEM analysis}

For TEM analysis, thin foils ( $200 \mu \mathrm{m}$ thickness) were cut out from samples of $0.5 \mathrm{Zn} 0.05 \mathrm{Ni}$, $1.0 \mathrm{Zn} 0.05 \mathrm{Ni}, 1.8 \mathrm{Zn} 0.05 \mathrm{Ni}$ and $1.7 \mathrm{Zn} 0.07 \mathrm{Zr}$. These foils were then mechanically polished down to $<100 \mu \mathrm{m}$. An FTS System Multicool chiller connected to the Jet Electropolisher was used to maintain the temperature of $150 \mathrm{ml}$ methanol and $60 \mathrm{ml}$ nitric acid mixture (electrolyte) at $-35^{\circ} \mathrm{C}$ before electropolishing was performed on the samples at $10 \mathrm{~V}$ ( 70 $\mathrm{mA})$. The TEM imaging used an FEI Titan Themis Scanning-Transmission Electron Microscopy (S-TEM) operating at $200 \mathrm{kV}$. Energy Dispersive X-ray Spectroscopy (EDX) analysis was performed on the samples with the use of Bruker software.

Table 2. Sample labels and composition in at.\% (ICP OES)

\begin{tabular}{cccccccc}
\hline $\begin{array}{c}\text { Sample } \\
\text { Label }\end{array}$ & $\mathrm{Al}$ & $\begin{array}{c}\text { Target } \\
\mathrm{Zn}\end{array}$ & $\begin{array}{c}\text { Actual } \\
\mathrm{Zn}\end{array}$ & $\begin{array}{c}\text { Target } \\
\mathrm{Ni}\end{array}$ & $\begin{array}{c}\text { Actual } \\
\mathrm{Ni}\end{array}$ & $\begin{array}{c}\text { Target } \\
\mathrm{Zr}\end{array}$ & $\begin{array}{c}\text { Actual } \\
\mathrm{Zr}\end{array}$ \\
\hline $0.5 \mathrm{Zn} 0.05 \mathrm{Ni}$ & $\mathrm{Bal}$ & 0.5 & 0.51 & 0.05 & 0.05 & - & - \\
$1.0 \mathrm{Zn} 0.05 \mathrm{Ni}$ & $\mathrm{Bal}$ & 1.0 & 1.02 & 0.05 & 0.04 & - & - \\
$1.8 \mathrm{Zn} 0.05 \mathrm{Ni}$ & $\mathrm{Bal}$ & 1.5 & 1.80 & 0.05 & 0.07 & - & - \\
$0.5 \mathrm{Zn} 0.10 \mathrm{Ni}$ & $\mathrm{Bal}$ & 0.5 & 0.50 & 0.1 & 0.08 & - & - \\
$1.0 \mathrm{Zn} 0.07 \mathrm{Zr}$ & $\mathrm{Bal}$ & 1.0 & 1.00 & - & - & 0.075 & 0.06 \\
$1.7 \mathrm{Zn} 0.07 \mathrm{Zr}$ & $\mathrm{Bal}$ & 1.5 & 1.70 & - & - & 0.075 & 0.06 \\
\hline
\end{tabular}

\subsection{Experimental results}

The results obtained from the experiments described in Section 4 for the two material systems identified in Section 3 are presented below. The Al-Zn-Ni system is reported first followed by the Al-Zn-Zr system. 


\subsubsection{Multi-step isochronal aging of Al-Zn-Ni}

Figure 27 shows the conductivity and microhardness of multi-step isochronally aged Al$\mathrm{Zn}-\mathrm{Ni}$ with $50{ }^{\circ} \mathrm{C}$ temperature steps. The peak microhardness values of all the $\mathrm{Al}-\mathrm{Zn}-\mathrm{Ni}$ alloys were observed at an aging temperature of $250{ }^{\circ} \mathrm{C}$. Alloys $0.5 \mathrm{Zn} 0.05 \mathrm{Ni}$ and 1.8Zn0.05Ni have similar Ni compositions but different $\mathrm{Zn}$ levels (see Table 2 for exact composition). An increase of $\mathrm{Zn}$ composition from 0.5 to 1.8 at.\% improved the alloy microhardness at all aging temperatures. The peak microhardness achieved for $0.5 \mathrm{Zn} 0.05 \mathrm{Ni}, 1.0 \mathrm{Zn} 0.05 \mathrm{Ni}, 1.8 \mathrm{Zn} 0.05 \mathrm{Ni}$, and $0.5 \mathrm{Zn} 0.1 \mathrm{Ni}$ were $337,341,376$ and $328 \mathrm{MPa}$ respectively. The average increase in microhardness due to precipitation of $\mathrm{Al}-\mathrm{Zn}-\mathrm{Ni}$ system is approx. $28 \%$. Comparison of $0.5 \mathrm{Zn} 0.05 \mathrm{Ni}$ and $0.5 \mathrm{Zn} 0.1 \mathrm{Ni}$, which have the same $\mathrm{Zn}$ level but different Ni content (Table 2), indicates that increasing Ni from 0.05 to 0.08 at.\% yields a slightly higher microhardness in the as-solutionized state but reduces the peak microhardness at $250{ }^{\circ} \mathrm{C}$. Beyond $250{ }^{\circ} \mathrm{C}$, the microhardness of all $\mathrm{Al}-\mathrm{Zn}-\mathrm{Ni}$ samples continued to drop until they reached their as-cast/pre-aging microhardness due to overaging and precipitate dissolution. During over-aging, precipitate mean size increases as a result of growth and subsequent coarsening also known as Ostwald Ripening. This increases the edge-to-edge precipitate spacing, thereby allowing dislocations to move more freely between precipitates.

An increase in $\mathrm{Zn}$ level reduced the conductivity from $35.1(0.5 \mathrm{Zn} 0.05 \mathrm{Ni})$ to $32.3 \mathrm{MS} / \mathrm{m}$ $(1.8 \mathrm{Zn} 0.05 \mathrm{Ni})$ mostly due to the presence of more $\mathrm{Zn}$ solute in solid solution. The effect

of increasing $\mathrm{Ni}$ composition from 0.05 at.\% $(0.5 \mathrm{Zn} 0.05 \mathrm{Ni})$ to 0.08 at.\% $(0.5 \mathrm{Zn} 0.1 \mathrm{Ni})$ on conductivity is negligible (they are both approximately $35.1 \mathrm{MS} / \mathrm{m}$ ) because $\mathrm{Ni}$ has a very minimal negative effect on conductivity of aluminum alloys when precipitated out of solution[13]. For all aging temperatures, the conductivities of Al-Zn-Ni alloys remained almost constant. 


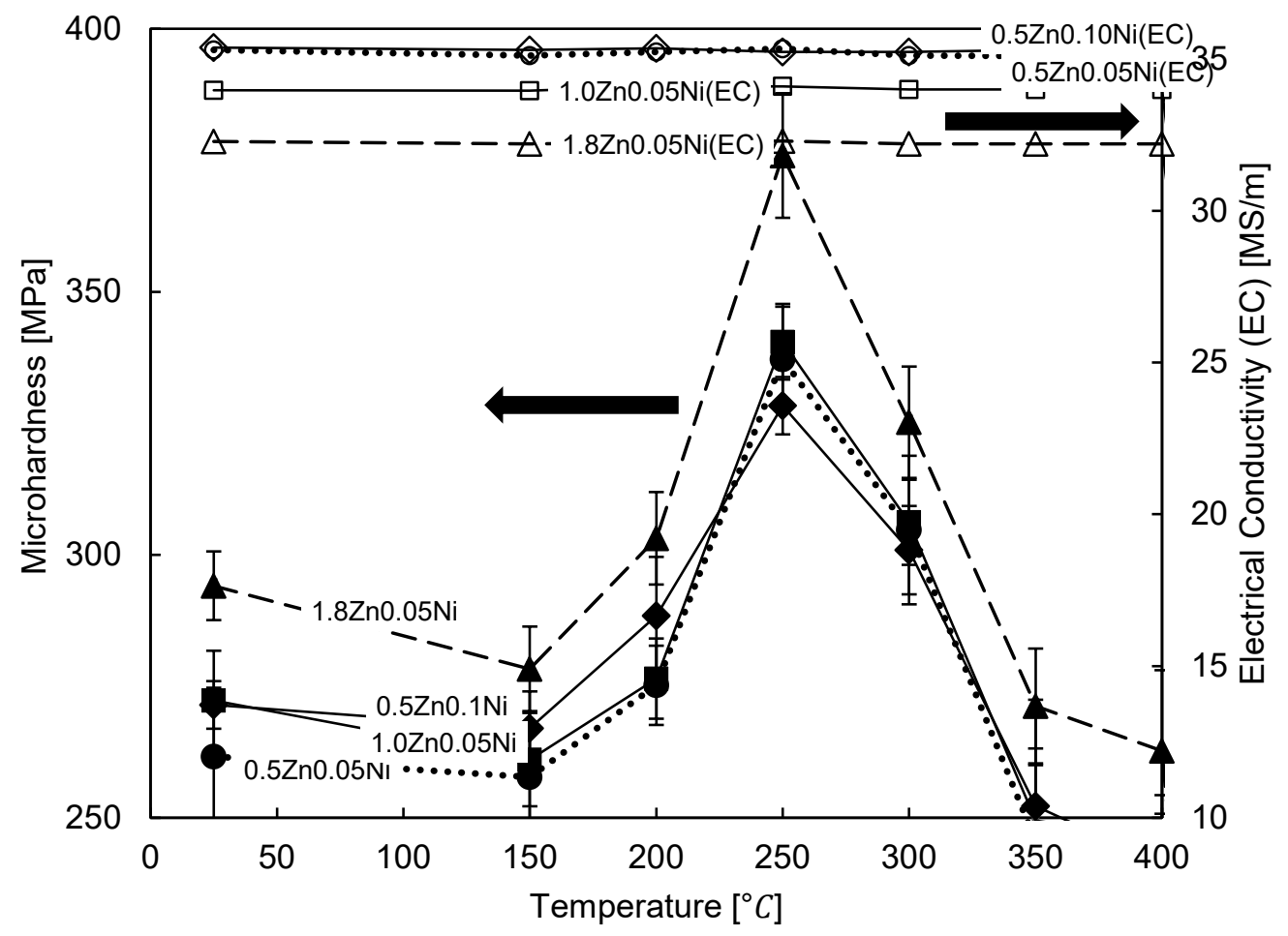

Figure 27. Conductivity and microhardness of $\mathrm{Al}-\mathrm{Zn}-\mathrm{Ni}$ as a function of aging temperature for a $3 \mathrm{~h}$ multi-step isochronal annealing with temperature increments of $50^{\circ} \mathrm{C}$.

\subsubsection{Multi-step isochronal aging of Al-Zn-Zr}

Results from isochronal aging of homogenized Al-Zn-Zr samples are shown in Figure 28. The purpose was to observe the peak microhardness, the aging temperature at which peak microhardness occurs, and the conductivity of the Al-Zn-Zr alloys; and to compare these values to those of the Al-Zn-Ni alloys. In this alloy system, peak microhardness occurs at $450{ }^{\circ} \mathrm{C}$, which is $200{ }^{\circ} \mathrm{C}$ higher than that of Al-Zn-Ni. The increase in $\mathrm{Zn}$ composition increased the peak microhardness while reducing the electrical conductivity. The $1.0 \mathrm{Zn} 0.07 \mathrm{Zr}$ and $1.7 \mathrm{Zn} 0.07 \mathrm{Zr}$ systems have peak microhardness values of 441 and 458 $\mathrm{MPa}$, while their conductivities are $31.8 \mathrm{MS} / \mathrm{m}$ and $30.1 \mathrm{MS} / \mathrm{m}$, respectively. The similar microhardness difference between both alloys at as-cast (14 MPa) and peak-aged condition (17 MPa) indicates mostly solid solution strengthening from the excess $\mathrm{Zn}$ between them. Hence, increasing $\mathrm{Zn}$ composition does not increase precipitate volume fraction. The 
microhardness values of Al- $\mathrm{Zn}-\mathrm{Zr}$ are much higher than the equivalent composition of Al$\mathrm{Zn}-\mathrm{Ni}$ alloys. However, they have lower electrical conductivities than Al-Zn-Ni. For instance, $1.7 \mathrm{Zn} 0.07 \mathrm{Zr}$ (Al-1.7 at.\% Zn-0.06 at.\% Zr) has a peak microhardness of 458 $\mathrm{MPa}$ and conductivity of $30.1 \mathrm{MS} / \mathrm{m}$ at approximately $450{ }^{\circ} \mathrm{C}$ (Figure 28), compared to $376 \mathrm{MPa}$ and $32.2 \mathrm{MS} / \mathrm{m}$ in $1.8 \mathrm{Zn} 0.05 \mathrm{Ni}\left(\mathrm{Al}-1.8\right.$ at.\% $\mathrm{Zn}-0.07$ at.\% Ni) at $250{ }^{\circ} \mathrm{C}$ (Figure 27). Even though $1.7 \mathrm{Zn} 0.07 \mathrm{Zr}$ has similar at.\% of $\mathrm{Zn}$ and $\mathrm{Zr}$ to the compositions of $\mathrm{Zn}$ and $\mathrm{Ni}$ in $1.8 \mathrm{Zn} 0.05 \mathrm{Ni}$. The peak conductivity occurred at $\sim 475^{\circ} \mathrm{C}$ due to the precipitation of solutes out of solution. The subsequent reduction in conductivity after the peak condition is due to the precipitate coarsening and dissolution as the aging temperature continued to increase. Similarly, over-aging leads to the strength reduction of Al-Zn-Zr alloys to their as-cast microhardness due to coarsening.

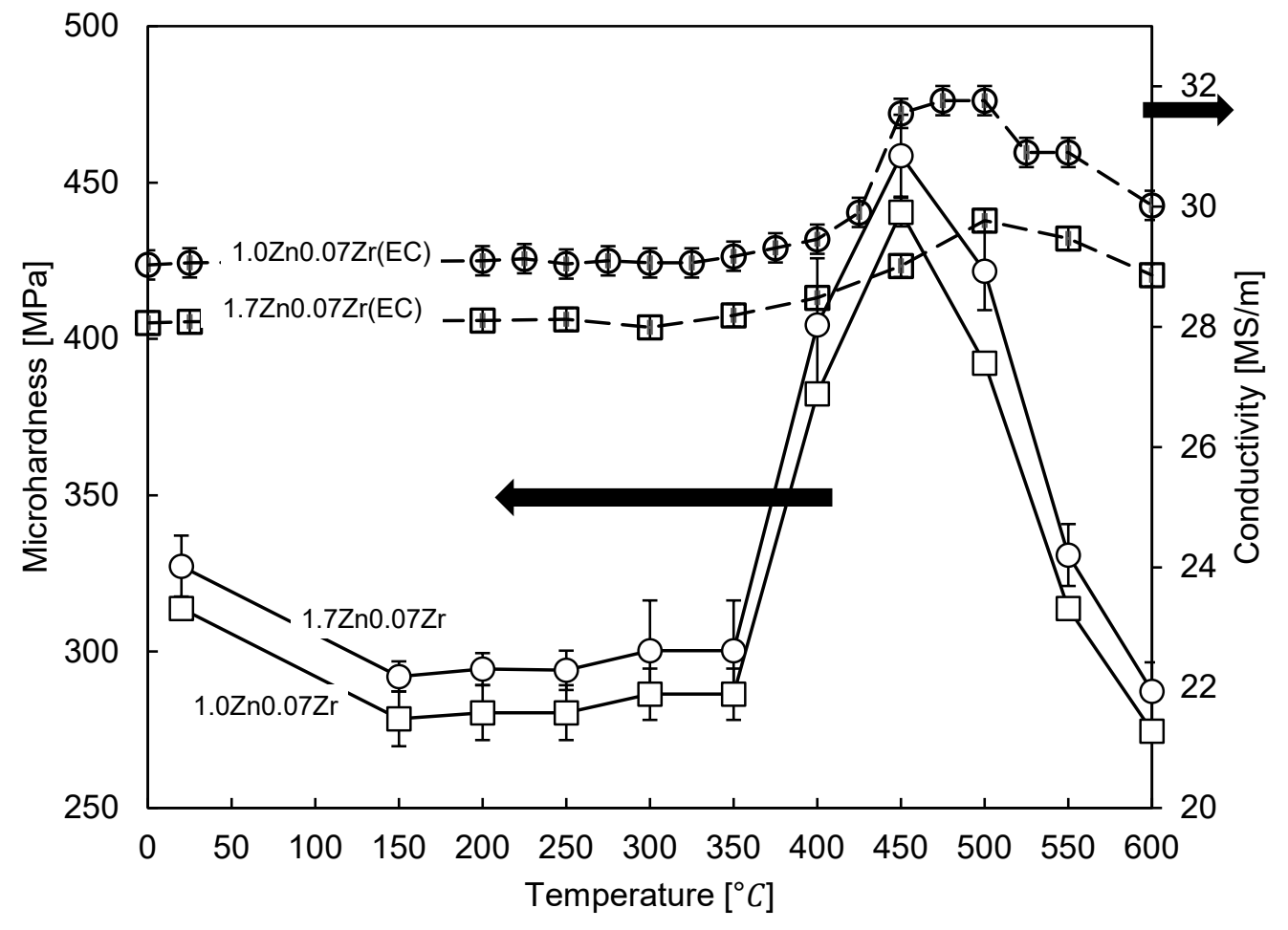

Figure 28. Conductivity and microhardness of $\mathrm{Al}-\mathrm{Zn}-\mathrm{Zr}$ as a function of aging temperature (3 h multi-step isochronal). 


\subsubsection{TEM study of Al-Zn-Ni}

The small precipitates formed in $0.5 \mathrm{Zn} 0.05 \mathrm{Ni}, 1.0 \mathrm{Zn} 0.05 \mathrm{Ni}$ and $1.8 \mathrm{Zn} 0.05 \mathrm{Ni}$ specimens after aging at $250^{\circ} \mathrm{C}$ have a mean size of $\leq 10 \mathrm{~nm}$. The orientation of these uniformly distributed particles, present in $0.5 \mathrm{Zn} 0.05 \mathrm{Ni}$ and $1.0 \mathrm{Zn} 0.05 \mathrm{Ni}$ is along the longitudinal section (needle-like), Figure 29[a] \& [b]. However, coherent spheroidal particles, (Figure $29[\mathrm{c}]$ ), were present in the $1.8 \mathrm{Zn} 0.05 \mathrm{Ni}$ specimen, which has higher $\mathrm{Zn}$ solute. The precipitate/matrix coherency in $1.8 \mathrm{Zn} 0.05 \mathrm{Ni}$ is indicated by the Ashby-Brown strain contrast. The diffraction patterns acquired from the $\mathrm{Al}-\mathrm{Zn}-\mathrm{Ni}$ specimens at $250^{\circ} \mathrm{C}$ showed no ordered superlattice spots that could be attributed to the precipitate phase. Only fcc planes were observed. Since the miscibility gap where 2-FCC phases coexists only occurs at $>14$ at. $\% \mathrm{Zn}$ and $>280^{\circ} \mathrm{C}$ in the $\mathrm{Al}-\mathrm{Zn}$ binary phase diagram, the precipitates can not be said to have FCC structure. Hence, the reason for the invisible superlattice spots could be attributed to a combination of the small size and volume fraction of the precipitates. It was difficult to acquire the lattice image of the needle-like and spheroidal-like precipitates formed in $\mathrm{Al}-\mathrm{Zn}-\mathrm{Ni}$ at $250^{\circ} \mathrm{C}$. Hence, the structure of the precipitates could also not be determined by observing the atomic positions and lattice parameter.

To increase the likelihood of detecting the precipitate phase structure from the diffraction pattern, the beam was converged on the large precipitate formed in the overaged specimens after aging at $400{ }^{\circ} \mathrm{C}$. Specifically, needle-like precipitates were found in the $0.5 \mathrm{Zn} 0.05 \mathrm{Ni}$ and $1.0 \mathrm{Zn} 0.05 \mathrm{Ni}$ specimens (Figure 29[d] \& [e]). The diffraction pattern along the $\mathrm{z}[100]$ indicates that these precipitates have a $\mathrm{D} 0_{11}$ structure, which is the typical crystal structure of $\mathrm{Al}_{3} \mathrm{Ni}$. Precipitates formed in $1.8 \mathrm{Zn} 0.05 \mathrm{Ni}$ maintained spheroidal morphology at an overaged temperature, Figure 29[f], with a slightly visible line of no contrast. The $(00 \overline{1})$ and $(01 \overline{1})$ superlattice spots present in the SAED acquired along $z[100]$ show that these spheroidal particles most likely have $\mathrm{L}_{2}$ precipitate structure. The precipitate volume fraction could be said to be responsible for the low intensity of the superlattice spot.

EDX chemical composition analysis indicates that the $0.5 \mathrm{Zn} 0.05 \mathrm{Ni}$ and $1.0 \mathrm{Zn} 0.05 \mathrm{Ni}$ specimens have no $\mathrm{Zn}$ species present in their precipitate phases, while the spheroidal particles in $1.8 \mathrm{Zn} 0.05 \mathrm{Ni}$ are rich in $\mathrm{Zn}$. When the electron beam was converged on just the 
matrix region versus a single precipitate, the EDX data showed that all the Ni species were contained in the precipitate phase; no Ni was present in the matrix. Quantitatively, $0.5 \mathrm{Zn} 0.05 \mathrm{Ni}$ and $1.0 \mathrm{Zn} 0.05 \mathrm{Ni}$ alloys are likely to have a precipitate stoichiometry of $\mathrm{Al}_{3} \mathrm{Ni}$. However, since there was a measurable amount of $\mathrm{Zn}$ present in the precipitates formed in $1.8 \mathrm{Zn} 0.05 \mathrm{Ni}$, they are presumed to have the form $\mathrm{Al}_{3-\mathrm{x}} \mathrm{Zn}_{\mathrm{x}} \mathrm{Ni}$ [34]. The composition of the precipitates and matrix of Al-Zn-Ni alloys are summarized in Table 3.

At $400{ }^{\circ} \mathrm{C}$, the average length of the needlelike particles in $0.5 \mathrm{Zn} 0.05 \mathrm{Ni}$ and $1.0 \mathrm{Zn} 0.05 \mathrm{Ni}$ is between 60 and $250 \mathrm{~nm}$, while the average interparticle spacing for both alloys varies from 80 to $400 \mathrm{~nm}$, Figure 29[d] \& [e]. From observation, increasing the composition of $\mathrm{Zn}$ from 0.5 to 1.0 at.\% translated into bigger mean precipitate size in $1.0 \mathrm{Zn} 0.05 \mathrm{Ni}$ relative to $0.5 \mathrm{Zn} 0.05 \mathrm{Ni}$. The overaged spheroidal precipitates formed in $1.8 \mathrm{Zn} 0.05 \mathrm{Ni}$ have a mean particle diameter of $25 \mathrm{~nm}$ as shown in Figure 29[f]. 

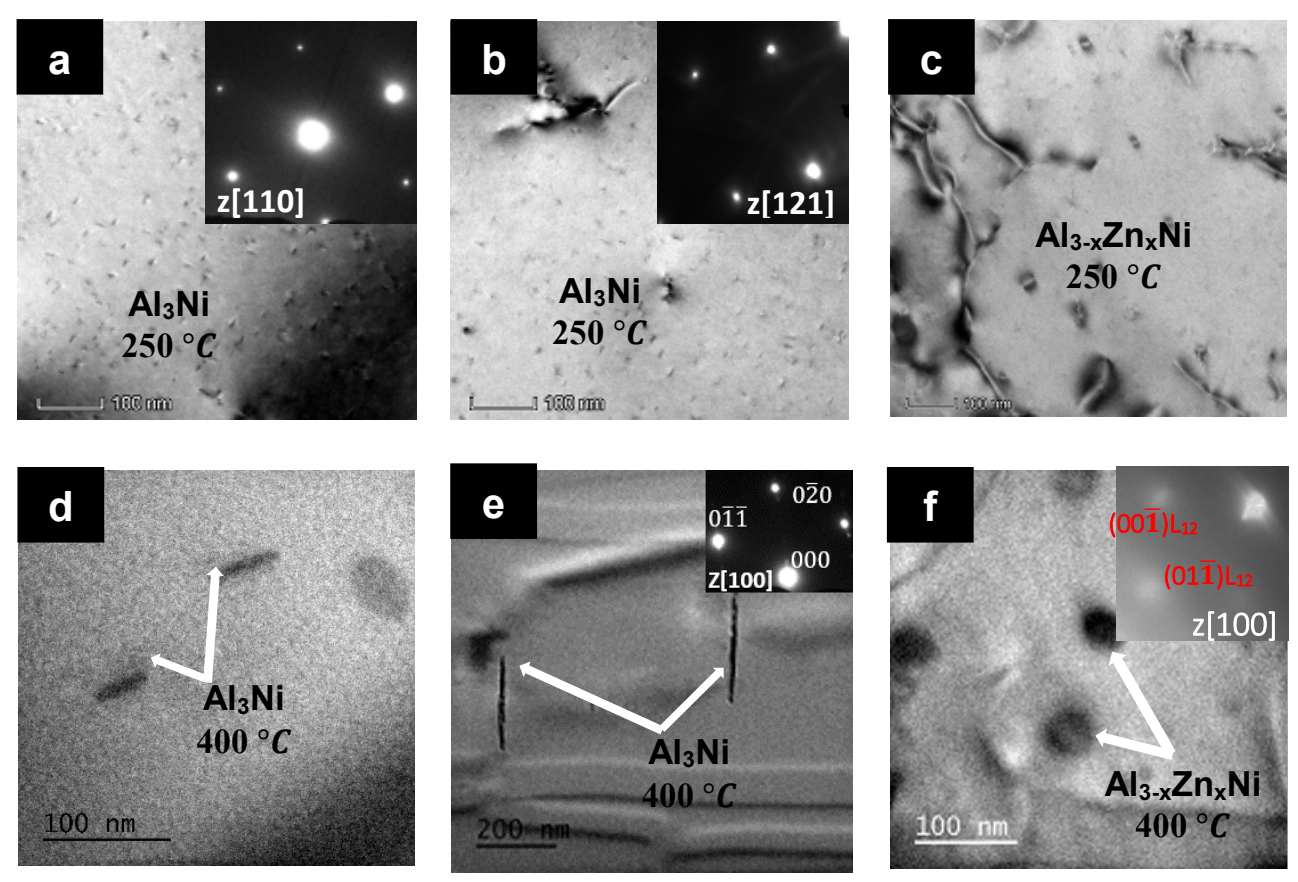

Figure 29. TEM images showing the microstructures of precipitates formed in $\mathrm{Al}-\mathrm{Zn}-\mathrm{Ni}$ alloy specimens at 250 and $400{ }^{\circ} \mathrm{C}$, (a \& d) 0.51 at. \% Zn, (b \& e) 1.02 at. \% $\mathrm{Zn}$ and (c \& f) 1.8 at.\% Zn. TEM images of the overaged specimens were observed along the [100] zone axis. The observed phase structures of the precipitates are $\mathrm{D} 0_{11}$ for $0.5 \mathrm{Zn} 0.05 \mathrm{Ni}$ and $1.0 \mathrm{Zn} 0.05 \mathrm{Ni}$, and possibly coherent $\mathrm{L} 1_{2}$ for $1.8 \mathrm{Zn} 0.05 \mathrm{Ni}$, however, the very low intensity of the superlattice spot due to precipitate volume fraction makes this inconclusive.

\subsubsection{TEM study of Al-Zn-Zr}

The microstructure and diffraction patterns (matrix and precipitate) of the $1.7 \mathrm{Zn} 0.07 \mathrm{Zr} \mathrm{Al}$ alloy isochronally peak-aged at $450^{\circ} \mathrm{C}$ were observed under TEM. Figure 30 [a \& b] shows a high and low number density of precipitates with spheroidal morphology dispersed in the dendritic center and interdendritic channel, respectively. There was a lateral gradient of precipitate sizes from the dendritic center toward the interdendritic channel of the specimen. A similar mean size gradient has been reported for Al-Zr alloys[30]. The particles present in the dendritic center have a mean diameter of $<5 \mathrm{~nm}$, while those in the interdendritic channels are bigger in size, with a mean diameter of $\sim 17 \mathrm{~nm}$ and interparticle spacing of $80-100 \mathrm{~nm}$. The Ashby-Brown strain contrast in Figure 30[c] indicates precipitate/matrix coherency. From the SAED, it was observed that in addition to the 56 
expected fcc planes such as $(\overline{2} 20)$ and $(\overline{3} 13)$, there are other smaller superlattice spots that are attributed to the presence of $\mathrm{L1}_{2}-\{110\}$ planes. These indicate that the precipitates formed in $\mathrm{Al}-\mathrm{Zn}-\mathrm{Zr}$ have $\mathrm{L1}_{2}$ crystal structure. The TEM images of this specimen were collected along [332] zone axis. Other diffraction patterns along low index zone axes [111] and [110] (not included in this paper) were collected, further showing that the $\mathrm{Al}_{3-\mathrm{x}} \mathrm{Zn} \times \mathrm{Zr}$ precipitate phase is $\mathrm{L} 1_{2}$.

EDX data obtained when the beam was converged on the matrix or spheroidal precipitate regions of the $1.7 \mathrm{Zn} 0.07 \mathrm{Zr}$ system shows that there is a high concentration of $\mathrm{Zr}$ in the precipitates phase relative to the matrix. The compositions of the precipitates and matrix are summarized in Table 3. As with the Ni alloy, the matrix had no $\mathrm{Zr}$ atoms present.
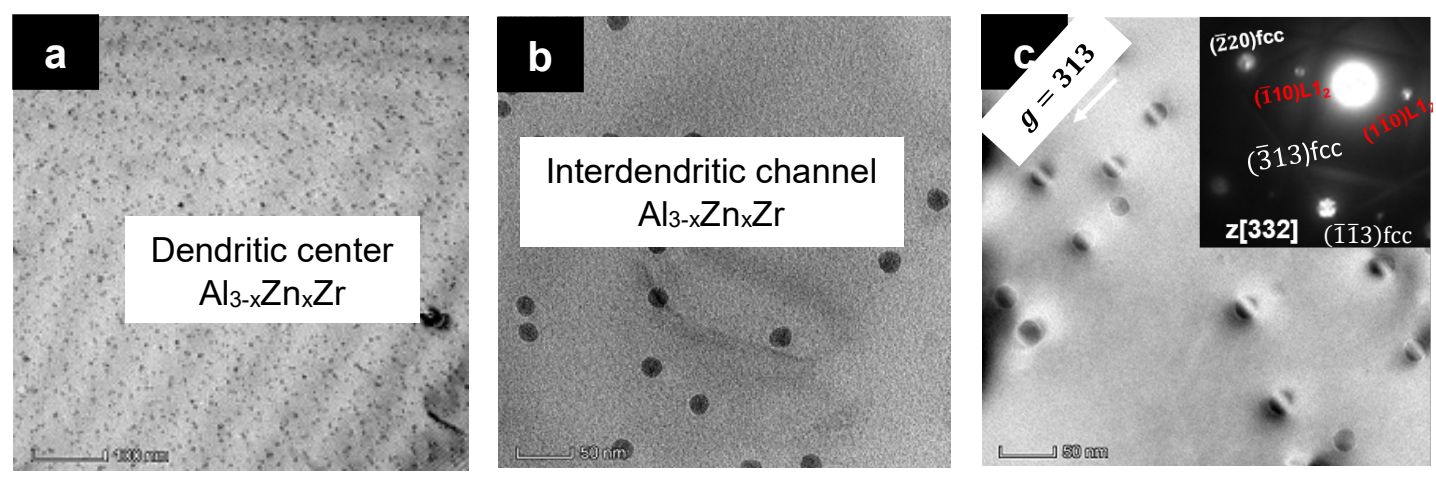

Figure 30. TEM images showing the microstructures and diffraction patterns of 1.7Zn0.07Zr alloys: (a) Small spheroidal $\mathrm{Al}_{3-\mathrm{x}} \mathrm{Zn}_{\mathrm{x}} \mathrm{Zr}$ precipitates of $<5 \mathrm{~nm}$ diameter formed at the center of the dendrites. (b) At the interdendritic channels, bigger $\mathrm{L}_{2}-\mathrm{Al}_{3}$ ${ }_{x} \mathrm{Zn}_{\mathrm{x}} \mathrm{Zr}$ precipitates of $17 \mathrm{~nm}$ diameter were present. (c) Shows the corresponding AshbyBrown strain contrast of the coherent $\mathrm{Al}_{3-\mathrm{x}} \mathrm{Zn}_{\mathrm{x}} \mathrm{Zr}$ precipitates within the same interdendritic channel, with the diffraction pattern obtained along [332] zone axis showing the $\{110\}$ plane. This indicates that the precipitate phase has an $\mathrm{L}_{2}$ ordered lattice structure. 
Table 3. Summary of EDX data of Al-Zn-Ni and Al-Zn-Zr (at. \%) at peak aged conditions

\begin{tabular}{cccccc}
\hline Specimens & & $\mathrm{Al}$ & $\mathrm{Zn}$ & $\mathrm{Ni}$ & $\mathrm{Zr}$ \\
\hline $0.5 \mathrm{Zn} 0.05 \mathrm{Ni}$ & Precipitate & 75.1 & - & 24.9 & - \\
& Matrix & 99.5 & 0.5 & - & - \\
$1.0 \mathrm{Z} \mathrm{n0.05Ni}$ & Precipitate & 75.0 & - & 25.0 & - \\
& Matrix & 99.0 & 1.0 & - & - \\
$1.8 \mathrm{Zn} 0.05 \mathrm{Ni}$ & Precipitate & 69.3 & 5.9 & 24.8 & - \\
& Matrix & 98.3 & 1.7 & - & - \\
$1.7 \mathrm{Zn0.07Zr}$ & Precipitate & 70.1 & 5.1 & - & 24.8 \\
& Matrix & 99.1 & 1.6 & - & - \\
& & & & & \\
\hline
\end{tabular}

\subsection{Discussion}

\subsubsection{Comparing microhardness of Al-Zn-Ni and Al-Zn-Zr}

From Figure 27 and Figure 28, the first sign of nucleation occurs after 150 and $350{ }^{\circ} \mathrm{C}$ for $\mathrm{Al}-\mathrm{Zn}-\mathrm{Ni}$ and Al-Zn-Zr, respectively. This indicates that the presence of $\mathrm{Ni}$ in the Al-ZnTM alloy decreased the incubation time for precipitate nucleation compared to Zr. As precipitates formed in $\mathrm{Al}-\mathrm{Zn}-\mathrm{Ni}$ nucleate at $>150{ }^{\circ} \mathrm{C}$, continued increase of aging temperature led to precipitate growth. At $250{ }^{\circ} \mathrm{C}$, a critical precipitate diameter was reached, and peak microhardness was observed. Between 150 and $250{ }^{\circ} \mathrm{C}$, there was no sign of nucleation in the Al-Zn-Zr alloy. The peak microhardness for this alloy was attained after aging up to $450^{\circ} \mathrm{C}$. The lower peak microhardness temperature observed in Al-Zn$\mathrm{Ni}$ relative to $\mathrm{Al}-\mathrm{Zn}-\mathrm{Zr}$ suggests that the precipitates formed in $\mathrm{Al}-\mathrm{Zn}-\mathrm{Zr}$ are more stable to higher temperatures compared to Al-Zn-Ni. The difference between their peak microhardness temperatures can be attributed to the higher diffusivity of $\mathrm{Ni}$ in Al relative to that of $\mathrm{Zr}$ in $\mathrm{Al}$ at every aging temperature, as shown in Table 4. Precipitation growth is controlled by the diffusion of solute atoms in the solvent at specific aging temperatures. At any particular aging temperature, the diffusivity of the solute atoms in the solvent has a direct influence on the distance covered by the solute from its supersaturated position to 
the nearby nucleation site. The higher the diffusivity, the faster the precipitates grow. The diffusivity and diffusion distance of various elements (used in this study) at 250 and $450{ }^{\circ} \mathrm{C}$ were estimated by an Arhenius relationship, $D=D_{o} \exp \left(-Q / R_{g} T\right)$, using their respective activation enthalpy $Q$ and pre-exponential $D_{o}$ values[29, 33, 46, 47]. For precipitate growth to occur at specific aging temperatures, the solutes would require sufficient heat energy to migrate from their supersaturation position to a nearby nucleation site. In general, the distance traveled by the solutes should be reasonably close to the average interparticle spacing at that aging temperature.

Table 4. Diffusion and distance data for selected transition metal (3d and 4d) solutes in aluminum at 250 and $450^{\circ} \mathrm{C}[29]$.

\begin{tabular}{|c|c|c|c|c|c|}
\hline & $\begin{array}{l}\text { Pre-exponential } \mathrm{D}_{\mathrm{o}} \\
\qquad\left(\mathrm{m}^{2} \mathrm{~s}^{-1}\right)\end{array}$ & $\begin{array}{l}\text { Activation } \\
\text { Enthalpy, } \\
\mathrm{Q}(\mathrm{KJ} / \mathrm{mol})\end{array}$ & $\begin{array}{c}\text { D at } 250^{\circ} \mathrm{C} \\
\left(\mathrm{m}^{2} \mathrm{~s}^{-1}\right)\end{array}$ & $\begin{array}{l}\text { Diffusion distance (nm) } \\
\text { at } 250^{\circ} \mathrm{C} \text { after } 3 \mathrm{hrs}\end{array}$ & References \\
\hline \multicolumn{6}{|c|}{ Self-Diffusion } \\
\hline $\mathrm{Al}$ & $1.37 \times 10^{-5}$ & 124 & $5.64 \times 10^{-18}$ & 349 & [48] \\
\hline \multicolumn{6}{|c|}{$3 \mathrm{~d}$ and $4 \mathrm{~d}-$-Transition metals } \\
\hline $\mathrm{Ni}$ & $4.4 \times 10^{-4}$ & 146 & $7.27 \times 10^{-19}$ & 125 & [49] \\
\hline $\mathrm{Zn}$ & $2.59 \times 10^{-5}$ & 121 & $2.13 \times 10^{-17}$ & 678 & {$[50]$} \\
\hline $\mathrm{Zr}$ & $7.28 \times 10^{-2}$ & 242 & $4.92 \times 10^{-26}$ & 0.0325 & {$[47]$} \\
\hline & $\begin{array}{l}\text { Pre-exponential } \mathrm{D}_{\mathrm{o}} \\
\qquad\left(\mathrm{m}^{2} \mathrm{~s}^{-1}\right)\end{array}$ & $\begin{array}{c}\text { Activation } \\
\text { Enthalpy, Q } \\
(\mathrm{KJ} / \mathrm{mol})\end{array}$ & $\begin{array}{c}\text { D at } 450^{\circ} \mathrm{C} \\
\left(\mathrm{m}^{2} \mathrm{~s}^{-1}\right)\end{array}$ & $\begin{array}{l}\text { Diffusion distance }(\mathrm{nm}) \\
\text { at } 450^{\circ} \mathrm{C} \text { after } 3 \mathrm{hrs}\end{array}$ & References \\
\hline $\mathrm{Zr}$ & $7.28 \times 10^{-2}$ & 242 & $2.38 \times 10^{-19}$ & $72 \mathrm{~nm}$ & {$[47]$} \\
\hline
\end{tabular}

After aging at $250{ }^{\circ} \mathrm{C}$ for $3 \mathrm{~h}$, only $\mathrm{Al}, \mathrm{Zn}$, and Ni solute species would cover distances > $120 \mathrm{~nm}$, while Zr would cover only $0.0325 \mathrm{~nm}$. Considering that the average interparticle spacing for $1.8 \mathrm{Zn} 0.05 \mathrm{Ni}$ is $80-200 \mathrm{~nm}$, the $\mathrm{Zn}$ and Ni solutes have sufficient driving force to reach a nearby nucleation site, which leads to precipitate growth. The distance covered by $\mathrm{Zr}$ at this temperature makes it unlikely that any $\mathrm{Al}_{3-\mathrm{x}} \mathrm{Zn}_{\mathrm{x}} \mathrm{Zr}$ precipitate growth would 
happen. It also explains why $\mathrm{Zr}$ alloys require a higher temperature for the formation and growth of its strengthening phase. $\mathrm{Zr}$ atoms move $72 \mathrm{~nm}$ after aging at $450^{\circ} \mathrm{C}$ for $3 \mathrm{~h}$ (Table 4), which is far enough to reach the nearby precipitate phase, since the interparticle spacing for $1.7 \mathrm{Zn} 0.07 \mathrm{Zr}$ is between $10-15 \mathrm{~nm}$ (dendritic center) and $20-80 \mathrm{~nm}$ (interdendritic channel). Beyond the peak microhardness conditions for both alloys, the precipitates continue to grow and become bigger than the critical size, as more solutes migrate into the precipitate phase. As a result, the precipitates become harder, thereby, requiring more force for dislocations to shear instead of bowing through. The early stage of overaging, at approximately between $250-300{ }^{\circ} \mathrm{C}(1.8 \mathrm{Zn} 0.05 \mathrm{Ni})$ and $450-500{ }^{\circ} \mathrm{C}(1.7 \mathrm{Zn} 0.07 \mathrm{Zr})$, is controlled by dislocation bowing (Orowan strengthening). This is followed by precipitate coarsening and dissolution of solutes from the precipitate phase into the matrix at the latter stage of overaging. Here the bigger precipitates grow at the expense of smaller ones. The influence of precipitation on the microhardness of the alloys becomes insignificant at this stage as the hardness of the alloy mostly depends on solid solution strengthening from the dissolved solutes[23]. Hence, the microhardness values of the specimens return to the ascast microhardness state at 400 and $600{ }^{\circ} \mathrm{C}$ for $1.8 \mathrm{Zn} 0.05 \mathrm{Ni}$ and $1.7 \mathrm{Zn} 0.07 \mathrm{Zr}$ respectively.

\subsubsection{Electrical conductivity}

The heat treatment results presented in Figure 27 and Figure 28 also show a consistent reduction in conductivity as $\mathrm{Zn}$ composition increases. Since most of the $\mathrm{Zn}$ remains in solid solution, the trend of reduced conductivity is due to the increase in local electron scattering sites as a result of the presence of $\mathrm{Zn}$ solute atoms within the $\mathrm{Al}$ matrix. The increase in conductivity of the $\mathrm{Al}-\mathrm{Zn}-\mathrm{Zr}$ alloys $(1.7 \mathrm{Zn} 0.07 \mathrm{Zr}$ and $1.0 \mathrm{Zn} 0.07 \mathrm{Zr}$ ) observed at $475{ }^{\circ} \mathrm{C}$ in Figure 28 is due to the precipitation of the solute atoms out of solution (especially Zr; Figure 18). When in solid solution, alloying elements contribute to the lattice distortion of the matrix and generation of local electron scattering sites, which reduce the mobility of free electrons in the system[51]. The creation of lattice distortion by the solutes in solid solution is driven by the dissimilar atomic radii of the solute and solvent atoms[51]. However, during precipitation, the solute atoms form a secondary phase with a different composition and structure from the matrix, thus reducing their contribution to the 
lattice distortion and local electron scattering. Hence, the mobility of free electrons within the system is less hindered, leading to the increased conductivity observed. A similar increase in conductivity was not observed in Al-Zn-Ni alloys as shown in Figure 27. The lower electrical conductivity observed in $\mathrm{Al}-\mathrm{Zn}-\mathrm{Zr}(1.0 \mathrm{Zn} 0.07 \mathrm{Zr}$ and $1.7 \mathrm{Zn} 0.07 \mathrm{Zr})$ relative to $\mathrm{Al}-\mathrm{Zn}-\mathrm{Ni}(1.0 \mathrm{Zn} 0.05 \mathrm{Ni}$ and $1.8 \mathrm{Zn} 0.05 \mathrm{Ni})$ is due in large part to the role of $\mathrm{Zr}$ in electrical conductivity degradation relative to $\mathrm{Ni}$ (Figure 18). Unlike $\mathrm{Zr}, \mathrm{Zn}$ and $\mathrm{Ni}$ do not have a severe impact on the electrical conductivity of aluminum alloy. The more damaging impact of $\mathrm{Zr}$ on the electrical conductivity of aluminum, relative to $\mathrm{Zn}$ and $\mathrm{Ni}$, was already predicted by the DFT simulation results for Al-TM and Al-Zn-TM shown in Figure 20 and Figure 21.

\subsubsection{Microstructure of Al-Zn-Ni and Al-Zn-Zr}

For the precipitates of the aged $\mathrm{Al}-\mathrm{Zn}-\mathrm{Ni}$ alloys to transform into the $\mathrm{L}_{2}$ structure of spheroidal morphology, a critical quantity of $\mathrm{Zn}$ must be present in the precipitate phase according to DFT simulation results (Figure 25 and Figure 26). The needle-like morphology of the particles observed in $0.5 \mathrm{Zn} 0.05 \mathrm{Ni}$ and $1.0 \mathrm{Zn} 0.05 \mathrm{Ni}$, Figure 29, represents the formation of an $\mathrm{Al}_{3} \mathrm{Ni}$ intermetallic. This is supported by EDX chemical composition analysis, which shows that there is no $\mathrm{Zn}$ present in the precipitate phase of $0.5 \mathrm{Zn} 0.05 \mathrm{Ni}$ and $1.0 \mathrm{Zn} 0.05 \mathrm{Ni}$. The diffraction patterns shown in Figure 29[d] and [e] confirm their precipitate structures as orthorhombic $\mathrm{D} 0_{11}$. $\mathrm{Al}_{3} \mathrm{Ni}$ has a $\mathrm{D} 0_{11}, \mathrm{Fe}_{3} \mathrm{C}$-type cementite structure that has a needlelike particle shape, indicating an orthorhombic crystal structure $[52,53]$. From the ternary phase diagram of $\mathrm{Al}-\mathrm{Zn}-\mathrm{Ni}$, the maximum solubility limits of $\mathrm{Zn}$ in aluminum at room temperature and $250{ }^{\circ} \mathrm{C}$ (peak aging) are 0.69 and 10 at. $\%$, respectively[44]. Considering that $0.5 \mathrm{Zn} 0.05 \mathrm{Ni}$ and $1.0 \mathrm{Zn} 0.05 \mathrm{Ni}$ alloys have 0.51 and 1.02 at. $\% \mathrm{Zn}$ respectively, these solubility limits are significantly high. Therefore, it is possible that most of the $\mathrm{Zn}$ remained in solution after quenching the alloys to room temperature and during subsequent aging. This could explain why the precipitate morphologies were non- $\mathrm{L}_{2}\left(\mathrm{D} 0_{11}\right)$ with no $\mathrm{Zn}$ present in the precipitate phase. It is also possible that the excess $\mathrm{Zn}$ that precipitated out of solution while aging $1.0 \mathrm{Zn} 0.05 \mathrm{Ni}$ diffused into the precipitate phase but was insufficient to transform the precipitate structure 
from $\mathrm{D}_{11}$ to coherent $\mathrm{L} 1_{2}$, Figure 25 . The spheroidal particles shown in Figure 29[c] and [f] for $1.8 \mathrm{Zn} 0.05 \mathrm{Ni}$ indicate that there is a sufficient amount of $\mathrm{Zn}$ atoms entering the precipitate phase from the saturated solid solution. The presence of these $\mathrm{Zn}$ atoms allows for the transformation of the precipitate morphology from $\mathrm{Al}_{3} \mathrm{Ni}$, which has the needlelike - orthorhombic $\mathrm{D}_{11}$ structure[29, 52-54] to $\mathrm{Al}_{3-\mathrm{x}} \mathrm{Zn}_{\mathrm{x}} \mathrm{Ni}$ (likely spheroidal $\mathrm{L}_{2}$ phase). However, the structure of $\mathrm{Al}_{3-\mathrm{x}} \mathrm{Zn}_{\mathrm{x}} \mathrm{Ni}$ present in $1.8 \mathrm{Zn} 0.05 \mathrm{Ni}$ could not be confirmed as $\mathrm{L}_{2}$ by the diffraction pattern shown in Figure 29 [c and f] inset, especially at $250^{\circ} \mathrm{C}[55]$, due to the invisible or low intensity superlattice spot.

As shown in Figure 30, there is a precipitate size gradient observed in $1.7 \mathrm{Zn} 0.07 \mathrm{Zr}$. This size gradient is as a result of the microsegregation of $\mathrm{Zr}$ solute in the alloy while solidifying during casting. The $\mathrm{Zr}$ solutes segregate into dendritic centers and interdendritic channels[30]. The high concentration of $\mathrm{Zr}$ in the dendritic center increases the chemical driving force for precipitate nucleation. Therefore, the critical mean radius for nucleation to occur is reduced and smaller precipitates are formed. For the interdendritic channels, Figure $30[\mathrm{~b}]$, the mean precipitate size is bigger due to low $\mathrm{Zr}$ solute concentration and lower chemical driving force for nucleation. Similar to the morphology of $\mathrm{Al}_{3} \mathrm{Zr}$ precipitates reported in several studies[30,31], $\mathrm{Al}_{3-\mathrm{x}} \mathrm{Zn}_{\mathrm{x}} \mathrm{Zr}$ precipitates have a spheroidal form with lines of no contrast perpendicular to $g=313$ vector, Figure 30[c]. The SAED information obtained along the [332] zone axis shows additional weak $\{110\}$ superlattice spots, which confirms that the $\mathrm{Al}_{3-\mathrm{x}} \mathrm{Zn}_{\mathrm{x}} \mathrm{Zr}$ precipitate has an ordered lattice structure corresponding to the $\mathrm{L}_{2}$ phase. This demonstrates that including $\mathrm{Zn}$ into the precipitate phase structure does not alter the metastable $\mathrm{L}_{2}$ phase structure previously reported for $\mathrm{Al}_{3} \mathrm{Zr}$. Therefore, while attempting to improve the alloy strength with $\mathrm{Zn}$, the $\mathrm{L1}_{2}$ precipitate phase structure and high electrical conductivity were maintained. According to EDX chemical composition analyses, Table 3, the absence of $\mathrm{Zr}$ in the matrix indicates that $\mathrm{Zr}$ solute atoms precipitated out of solid solution to form coherent $\mathrm{Al}_{3-\mathrm{x}} \mathrm{Zn}_{\mathrm{x}} \mathrm{Zr}$ precipitates. It also shows that a small fraction of $\mathrm{Zn}$ was used up in the precipitate phase. 


\subsubsection{Estimation of yield strength at peak conditions}

According to Figure 27 and Figure 28, the observed maximum yield strength for $1.8 \mathrm{Zn} 0.05 \mathrm{Ni}$ and $1.7 \mathrm{Zn} 0.07 \mathrm{Zr}$ are $\sim 125\left(250^{\circ} \mathrm{C}\right)$ and $\sim 156 \mathrm{MPa}\left(450^{\circ} \mathrm{C}\right)$, respectively,

using a conversion factor of $\frac{1}{3}$ between Vickers microhardness and yield strength[56]. These observed strengths are due to solid solution and precipitation strengthening mechanisms. Grain size reduction and strain hardening of the specimens were not considered since aging is not expected to have any significant effect on grain size and the specimens were not deformed. The yield strengths of the specimens have contributions from modulus mismatch, order, Orowan, and coherency strengthening mechanisms due to the spheroidal coherent precipitates formed during aging. The relative contributions of these mechanisms can be quantified as follows.

Modulus mismatch strengthening, $\Delta \sigma_{m s}$, results from the difference between the shear moduli of the precipitate and matrix phases. It can be estimated by using [33, 57]:

$\Delta \sigma_{m s}=0.0055 M(\Delta G)^{3 / 2}\left(\frac{2 \phi}{G_{A l}}\right)^{1 / 2}\left(\frac{\langle R\rangle}{\mathrm{b}}\right)^{3 m / 2^{-1}}$

where the Taylor factor[58] $M=3.06$ and $\Delta G$ is the difference in the shear modulus between the precipitate and matrix, which are approximated as 30.6 and $40 \mathrm{GPa}$ for $\mathrm{Al}_{3-}$ ${ }_{x} \mathrm{Zn}_{x} \mathrm{Ni}$ and $\mathrm{Al}_{3-\mathrm{x}} \mathrm{Zn}_{\mathrm{x}} \mathrm{Zr}$, respectively. The shear moduli of $\mathrm{L1}_{2}$-type $\mathrm{Al}_{3-\mathrm{x}} \mathrm{Zn}_{\mathrm{x}} \mathrm{Ni}, \mathrm{Al}_{3-\mathrm{x}} \mathrm{Zn} \mathrm{n}_{\mathrm{x}} \mathrm{Zr}$ and the matrix are taken as $G_{\mathrm{Al} 3-\mathrm{xZnxNi}}=56 \mathrm{GPa}$ (same as the value for $\mathrm{Al}_{3} \mathrm{Ni}[59,60]$ ), $G_{\mathrm{Al} 3-\mathrm{xZnxZr}}=67.4 \mathrm{GPa}$ (same as the value for $\mathrm{Al}_{3} \mathrm{Zr}[61-63]$ ), and $G_{A l}=25.4 \mathrm{GPa}$, respectively. The volume fraction was approximated as $\phi \cong 0.003$ (estimated from the tie line of the $\mathrm{Al}_{3} \mathrm{Zr}$ phase diagram) for $\mathrm{Al}_{(3-\mathrm{x})} \mathrm{Zn}_{\mathrm{x}} \mathrm{Zr}$. Since the added $\mathrm{Zn}$ is assumed to replace the $\mathrm{Al}$ site, it is expected that $\mathrm{Al}_{3} \mathrm{Zr}$ and $\mathrm{Al}_{(3-\mathrm{x})} \mathrm{Zn}_{\mathrm{x}} \mathrm{Zr}$ have similar volume fractions[12]. This assumption is also confirmed by the heat treatment curves. Using the same approach, $\phi \cong 0.002$ for $\mathrm{Al}_{(3-\mathrm{x})} \mathrm{Zn}_{\mathrm{x}} \mathrm{Ni}$. $\langle R\rangle$ is the average particle radius of the specimens. Due to their large number density and small interparticle spacing, most of the precipitation strengthening of $1.7 \mathrm{Zn} 0.07 \mathrm{Zr}$ comes from the small size particles segregated in the dendritic centers. Hence, the values of $\langle R\rangle$ used for the yield strength estimates were 
$2.5 \mathrm{~nm}$ (dendrite core) and $4.0 \mathrm{~nm}$ for the precipitates present in $1.7 \mathrm{Zn} 0.07 \mathrm{Zr}$ and $1.8 \mathrm{Zn} 0.05 \mathrm{Ni}$, respectively (Table 5). The Burgers vector magnitude of the matrix was[64, $65] b=0.286 \mathrm{~nm}$, and $\mathrm{m}=0.85$ is a constant.

At peak strength, order strengthening $\Delta \sigma_{o s}$ (which is due to the formation of antiphase boundaries (APBs) as matrix dislocations shear ordered particles) is given by[33, 57, 64]:

$\Delta \sigma_{o S}=0.81 M \frac{\gamma_{A P B}}{2 b}\left(\frac{3 \pi \phi}{8}\right)^{1 / 2}$

where $\gamma_{A P B} \sim 0.48$ and $0.445 \mathrm{Jm}^{-2}$ are taken as the average APB energies for $\mathrm{Al}_{3-\mathrm{x}} \mathrm{Zn}_{\mathrm{x}} \mathrm{Ni}$ and $\mathrm{Al}_{3-\mathrm{x}} \mathrm{Zn}_{\mathrm{x}} \mathrm{Zr}$ alloys based on several reported values for $\mathrm{Al}_{3} \mathrm{Ni}$ and $\mathrm{Al}_{3} \mathrm{Zr}$ for the (111) plane[66-68]. APB energies are difficult to determine, and different methods tend to give varying values for the same intermetallic compound. Therefore, APB energies have only been reported for a limited number of compounds[69-71]. Recently, Rudy and Sauthoff reported a APB energy of $\sim 0.4 \mathrm{Jm}^{-2}$ for NiAl[72]. A study has already reported the APB energy for $\mathrm{Ni}_{3} \mathrm{Al} \sim 0.195 \mathrm{Jm}^{-2}[73]$.

During the over-aging, Orowan strengthening $\Delta \sigma_{o r}$ is given by[33, 57, 64]:

$\Delta \sigma_{o r}=0.4 M \frac{G_{A l} b}{\pi \sqrt{ }(1-v)} \frac{\ln \left(\frac{2 R}{b}\right)}{\lambda_{e-e}}$

where the mean planar radius[64] is given by $R=\frac{\pi}{4}\langle R\rangle, v=0.354$ is the Poisson's ratio for $\mathrm{Al}$, and the inter-precipitate distance[64] $\lambda_{e-e}=\left(\sqrt{\frac{2 \pi}{3 \phi}}-\frac{\pi}{2}\right)\langle R\rangle$.

Coherency strengthening, $\Delta \sigma_{c s}$, can be estimated using[33, 57, 64]:

$\Delta \sigma_{c s}=M \chi\left(\epsilon G_{A l}\right)^{3 / 2}\left(\frac{\langle R\rangle \phi b}{\Gamma}\right)^{1 / 2}$

where $\chi=2.6$ for fcc metals[64], $\epsilon$ is the mismatch parameter approximated by $\frac{2}{3} \delta$; $\delta=$ $1.23 \%$ and $0.75 \%$ is taken as the lattice parameter mismatch for the $\mathrm{Al}_{3-\mathrm{x}} \mathrm{Zn}_{\mathrm{x}} \mathrm{Ni}$ and $\mathrm{Al}_{3-}$ ${ }_{x} \mathrm{Zn} \times \mathrm{Zr}$ precipitates estimated from the composition-dependent lattice parameter[30-32, 74], and $\Gamma=\frac{1}{2} G_{A l} b^{2}$ is the line tension of dislocations in Al. 
Generally, precipitation hardening is governed by either the dislocation by-pass (Orowantype) or dislocation shearing mechanisms. At peak strength, only the shearing mechanism was considered and the contributing factors in this mechanism are coherency strengthening $\left(\Delta \sigma_{c s}\right)$, modulus mismatch strengthening $\left(\Delta \sigma_{m s}\right)$, and order strengthening $\left(\Delta \sigma_{o r}\right)[33,57]$. Regardless of the unavailability of exact data and approximations made for some of the parameters used in the equations above, these models successfully predicted the maximum yield strength observed experimentally. Using equations 14-17 and the data in Table 5, the contribution of each strengthening mechanism to the yield strength of $1.7 \mathrm{Zn} 0.07 \mathrm{Zr}$, was estimated as $\Delta \sigma_{o r} \approx 148 \mathrm{MPa}, \Delta \sigma_{o s} \approx 114 \mathrm{MPa}, \Delta \sigma_{c s} \approx 18 \mathrm{MPa}$ and $\Delta \sigma_{m s} \approx$ $118 \mathrm{MPa}$ for Orowan, order, coherency strain, and modulus mismatch strengthening, respectively. The larger value between $\Delta \sigma_{c s}+\Delta \sigma_{m s}(\sim 136 \mathrm{MPa})$ and $\Delta \sigma_{o s}(\sim 114 \mathrm{MPa})$ determines the resultant yield strength increment due to the shearing mechanism[33, 57]. As a result, the yield strength $\left(\Delta \sigma_{p p t}\right)$ of $1.7 \mathrm{Zn} 0.07 \mathrm{Zr}$ at $450{ }^{\circ} \mathrm{C}$, due to precipitation hardening was estimated as $136 \mathrm{MPa}$ from $\Delta \sigma_{c s}+\Delta \sigma_{m s}$ (ignoring Orowan strengthening). Therefore, the significant difference between the estimated and measured yield strength of $1.7 \mathrm{Zn} 0.07 \mathrm{Zr}$ is $20 \mathrm{MPa}$, which could be attributed to the solid solution strengthening (not considered in the estimate) from the remaining $\mathrm{Zn}$ in the matrix. The difference between estimated and measured strength values could also be a result of some of the approximated parameters used in the estimation, due to a lack of exact theoretical or experimental data for the $\mathrm{Al}_{3-\mathrm{x}} \mathrm{Zn}_{\mathrm{x}} \mathrm{Zr}$ precipitate.

Table 5. Measured precipitate mean radii, $\langle R\rangle$, of $\mathrm{L}_{2} 2$ precipitates located at the dendritic centers of $1.8 \mathrm{Zn} 0.05 \mathrm{Ni}$ and $1.7 \mathrm{Zn} 0.07 \mathrm{Zr}$, after isochronal aging at 250 and $450{ }^{\circ} \mathrm{C}$ respectively.

\begin{tabular}{lccc}
\hline Specimen & Aging Temperature ${ }^{\circ} \mathrm{C}$ & $\begin{array}{c}\text { Mean precipitate } \\
\text { radius }\langle R\rangle n m\end{array}$ & $\begin{array}{c}\text { Number of counted } \\
\text { precipitates }\end{array}$ \\
\hline $1.8 \mathrm{Zn} 0.05 \mathrm{Ni}$ & 250 & 4.0 & 285 \\
$1.7 \mathrm{Zn} 0.07 \mathrm{Zr}$ & 450 & 2.5 & 201 \\
\hline
\end{tabular}


Similar to the estimation made for the $1.7 \mathrm{Zn} 0.07 \mathrm{Zr}$ alloy, the yield strength due to precipitation $\left(\Delta \sigma_{p p t}\right)$ of the $1.8 \mathrm{Zn} 0.05 \mathrm{Ni}$ alloy at peak strength was estimated as $108 \mathrm{MPa}$ from $\Delta \sigma_{c s}+\Delta \sigma_{m s}$. The measured peak strength for this specimen was $125 \mathrm{MPa}$. The observed difference between the estimated and measured strength values is $17 \mathrm{MPa}$, which could also be attributed to the solid solution strengthening due to the remaining $\mathrm{Zn}$ left in the matrix and the gross approximation made for some of the parameters used.

\subsection{Summary and conclusions}

When the solubility limits of the solutes in $\mathrm{Al}$ are not considered and all the solute atoms are assumed to remain in solid solution (no precipitation effect), the electrical conductivity predictions from DFT simulations agree well with experiment (expt-SS). According to Figure 22, the addition of $\mathrm{Zn}$ to binary Al-TM alloys only slightly reduced the electrical conductivity. This demonstrates that $\mathrm{Zn}$ has a minimal impact on electrical conductivity when in- and out-of solid solution. The experimental electrical conductivity data in Figure 27 and Figure 28 show that at equivalent atomic percentage of alloying elements, Al-ZnNi has a higher electrical conductivity than Al-Zn-Zr, as predicted by DFT.

Using enthalpy of formation, the predicted zero-temperature stabilities of $\mathrm{Al}-\mathrm{Zn}-\mathrm{Ni}$ and $\mathrm{Al}-\mathrm{Zn}-\mathrm{Zr}$ precipitate phase structures revealed the equilibrium crystal structures of $\mathrm{Al}_{3} \mathrm{Ni}$ and $\mathrm{Al}_{3} \mathrm{Zr}$ as $\mathrm{D}_{11}$ and $\mathrm{D}_{23}$, respectively. The step-by-step inclusion of $\mathrm{Zn}$ into the precipitate phase demonstrated that the resulting $\mathrm{Al}_{3-\mathrm{x}} \mathrm{Zn}_{\mathrm{x}} \mathrm{Ni}$ and $\mathrm{Al}_{3-\mathrm{x}} \mathrm{Zn}_{\mathrm{x}} \mathrm{Zr}$ precipitates have stable $\mathrm{L}_{2}$ structures, which was confirmed by experiment. These simulations were performed at $0 \mathrm{~K}$, hence, the influence of temperature on the stability of the $\mathrm{L}_{2}$ structures was not computationally determined in this study.

Heat treatment experiments showed that the difference in peak microhardness temperatures of $\mathrm{Al}-\mathrm{Zn}-\mathrm{Ni}$ and $\mathrm{Al}-\mathrm{Zn}-\mathrm{Zr}$ alloys is due to the difference in nucleation and growth rates of $\mathrm{Ni}$ and $\mathrm{Zr}$ precipitates in aluminum. Peak microhardness values of both alloys increase with Zn loading, whereas conductivity drops slightly. This study also showed that increase in electrical conductivity of $\mathrm{Al}-\mathrm{Zn}-\mathrm{Zr}$ was achieved at peak strength due to precipitation of 
the solute atoms from matrix, although this was not observed in the Al-Zn-Ni samples due to the much smaller impact of $\mathrm{Ni}$ on conductivity.

A microstructural study of $\mathrm{Al}-\mathrm{Zn}-\mathrm{Ni}$ revealed that for alloys with lower $\mathrm{Zn}$ composition $(0.5 \mathrm{Zn} 0.05 \mathrm{Ni}$ and $1.0 \mathrm{Zn} 0.05 \mathrm{Ni})$, the precipitates retained their orthorhombic $\mathrm{D} 0{ }_{11}-\mathrm{Al}{ }_{3} \mathrm{Ni}$ structure, because there was insignificant amount of $\mathrm{Zn}$ atom in their precipitate phases. For higher $\mathrm{Zn}$ compositions, the precipitate morphology transformed to $\mathrm{Al}_{3-\mathrm{x}} \mathrm{Zn} \times \mathrm{Ni}$ precipitate as shown in Figure 29[c] and [f]. This indicates that the inclusion of $\mathrm{Zn}$ is likely responsible for the possible $\mathrm{D} 0_{11} \rightarrow \mathrm{L} 1_{2}$ precipitate transformation. Since $\mathrm{Al}_{3} \mathrm{Zr}$ already has a metastable $\mathrm{L}_{2}$ structure during aging, there was no precipitate transformation required at $450{ }^{\circ} \mathrm{C}$. The crystal structure of $\mathrm{Al}_{3-\mathrm{x}} \mathrm{Zn}_{\mathrm{x}} \mathrm{Zr}$ precipitates formed in $1.7 \mathrm{Zn} 0.07 \mathrm{Zr}$ remained as $\mathrm{L1}_{2}$. Hence, the addition of $\mathrm{Zn}$ into the $\mathrm{Al}_{3} \mathrm{Zr}$ precipitate phase did not alter the $\mathrm{L} 1_{2}$ phase structure.

In summary, these alloys have demonstrated a good balance between electrical conductivity and microhardness, relative to several other electrical conductors used for high conducting applications. Examples of such alloys are 1350 aluminum alloy (AA) and Al-Mg-Si (AA6101) commonly used as electrical conductors for overhead power lines. The laboratory fabricated AA1350 has high electrical conductivity (35.7 MS/m) but very low ultimate tensile strength, while Al-Mg-Si (AA6101) has very high strength but lower electrical conductivity, depending on the amount of $\mathrm{Mg}_{2} \mathrm{Si}$ solute present[75, 76]. 


\section{Chapter 5: Microstructure and properties of precipitation-hardened $\mathrm{Zr}$ and $\mathrm{Zn}-\mathrm{Zr}$ based aluminum alloys}

Submitted for publication in Journal of Alloys and Compounds

\subsection{Abstract and introduction}

\subsubsection{Abstract}

New aluminum alloys with improved durability and thermal resistance are desired to improve the performance of high-voltage power transmission lines. These improvements must not significantly reduce the electrical conductivity of the Al alloys currently used for this application to maintain current levels of power transmission efficiency. Precipitationhardened binary Al-Zr alloy has been shown to have promising electrical conductivity and strength. However, there is room for improving the alloy strength, while maintaining a relatively high electrical conductivity by controlled additions of $\mathrm{Zn}$. The objective of this study is to experimentally examine the addition of $\mathrm{Zn}$ to Al-Zr alloys with subsequent heat treatment to improve mechanical properties via controlled precipitation hardening. Vickers microhardness measurements, scanning transmission electron microscopy, energydispersive X-ray spectroscopy, and selected area electron diffraction are used to measure the properties and determine the microstructure of Al-Zr-Zn alloys for a wide range of aging conditions. As expected, the results indicate that Al-Zr-Zn alloys have improved mechanical properties and slightly reduced electrical conductivity relative to Al alloys currently used for power transmission. However, it is determined that the addition of $\mathrm{Zn}$ is unable to improve the heat resistance of Al-Zr alloys.

\subsubsection{Introduction}

The development of new aluminum alloys with improved strength, electrical conductivity, and thermal resistance can improve the efficiency and durability of high-voltage power 
transmission lines. Current aluminum alloys used for this application are nearly pure $\mathrm{Al}$, which provides excellent electrical conductivity with relatively poor mechanical durability. Thus, the challenge is to develop new allows with improved strength and thermal resistance without significant degradation of the electrical conductivity.

Improved strengthening of $\mathrm{Al}$ alloys can be achieved with the formation of intermetallic precipitates[23, 77]. Precipitates formed from transition metals are particularly stable for long periods of exposure to elevated temperatures, because of low solubility and diffusivity in $\alpha$-Al. Of all alloying transition elements, $\mathrm{Zr}$ offers one of the greatest potentials for forming $\mathrm{Al}$ alloys with high strength, creep resistance, and thermal resistance at elevated temperatures[30, 33]. The $\mathrm{Zr}$ solute, like many transition elements, is more effective in improving the yield strength of Al-Zr alloy, when out of solution (through the formation of $\mathrm{Al}_{3} \mathrm{Zr}$ precipitates), relative to when in solid solution. These precipitates improve strengthening by impeding the movement of dislocations[23]. The observed increase in electrical conductivity during aging is also due to the precipitation $\mathrm{Zr}$ solute atoms out of solid solution. As solutes precipitate out of solution, the number density of electron scattering sites is reduced, leading to increase in conductivity[51].

Many intermetallic precipitates formed in $\mathrm{Al}$ alloys are non-cubic tri-aluminide compounds $\left(\mathrm{D}_{11}, \mathrm{D}_{22}\right.$, and $\left.\mathrm{D}_{23}\right)[78]$. The tri-aluminides of group IV and $\mathrm{V}$ (Ti, Hf, $\mathrm{V}$ etc.), crystallize in the tetragonal $\mathrm{D}_{22}$ or $\mathrm{D} 0_{23}$ form, which are incoherent with $\alpha$-Al and promote precipitate coarsening. Of all $\mathrm{Al}_{3} \mathrm{TM}(\mathrm{TM}=$ transition metals) intermetallic compounds, only $\mathrm{Al}_{3} \mathrm{Sc}$ has a thermodynamically stable cubic $\mathrm{L}_{2}$ structure. However, $\mathrm{Al}_{3} \mathrm{Zr}$ forms metastable $\mathrm{L}_{2}$ precipitate structure at temperatures $\cong 475^{\circ} \mathrm{C}$, and transforms to its more stable $\mathrm{D} 0_{23}$ structure when exposed to higher temperature for several hours[30, 78]. Cubic $\mathrm{L}_{2}$ precipitate phase is desired because it provides better precipitate/ $\alpha$-Al matrix lattice coherency, creep resistance, and retention of strength at higher temperatures than the noncubic phases[29, 33].

Several studies have focused on developing ternary alloys with improved strength and more stable $\mathrm{L}_{2}$ precipitate structures at elevated aging temperatures[30, 36, 78, 79]. Zerotemperature density functional theory (DFT) simulations predict that adding $\mathrm{Zn}$ to $\mathrm{Al}_{3} \mathrm{Zr}$ 
to form $\mathrm{Al}_{(3-\mathrm{x})} \mathrm{Zn}_{\mathrm{x}} \mathrm{Zr}$, stabilizes the resulting $\mathrm{L1}_{2} \mathrm{Al}_{(3-\mathrm{x})} \mathrm{Zn}_{\mathrm{x}} \mathrm{Zr}$ precipitates with respect to $\mathrm{D}_{23}$ through enthalpy of formation computations[12, 14, 34]. This prediction is made with the use of electronic structure calculations of competing fcc-based ordered structures. Ghosh et al. experimentally confirmed the enrichment of $\mathrm{Zn}$ in the resulting $\mathrm{Al}_{(3-\mathrm{x})} \mathrm{Zn}_{\mathrm{x}} \mathrm{Zr}$ precipitate phase, by comparing the relative heights (intensity counts) of $\mathrm{Zn}-\mathrm{K}$ or $\mathrm{Zn}-\mathrm{L}$ peaks in the EDX spectra acquired from $\alpha$-Al matrix and $\mathrm{L}_{2}$ precipitate[34]. Theoretically, $\mathrm{Zn}$ stabilizes the $\mathrm{L} 1_{2}$ structure by reducing the $c / a$ ratio $(\mathrm{z}-\mathrm{axis})$ or the number of $\mathrm{d}$-shell electrons of $\mathrm{D}_{23}$ with respect to $\mathrm{L}_{2}$ phase[12, 35, 37].

There is no study that has been able to effectively demonstrate the prevention of $\mathrm{L}_{2} \rightarrow \mathrm{D} 0_{23}$ precipitate transformation in binary Al-Zr or ternary Al-Zr-TM alloys at temperatures > $500^{\circ} \mathrm{C}$. This work focuses on the role of $\mathrm{Zn}$ addition to $\mathrm{Al}-\mathrm{Zr}$ in stabilizing the $\mathrm{L}_{2}$ phase relative to $\mathrm{D}_{23}$, at elevated temperatures $\geq 500^{\circ} \mathrm{C}$ (if any). It also examines how $\mathrm{Zn}$ impacts the mechanical properties, thermal resistance and electrical conductivity of Al-Zr at peak and overaged conditions.

\subsection{Experimental procedure}

\subsubsection{Fabrication and specimen preparation}

Additional $600 \mathrm{~g}$ ingots of $0.2 \mathrm{Zr}$ and $3.5 \mathrm{Zn} 0.2 \mathrm{Zr}$ (wt.\%) were fabricated from the aluminum, zinc and Al-5.0Zr master alloys in VIM. The alloys were melted in graphite crucible placed in the VIM chamber to form ingots; small buttons were cut from the ingots, mechanically polished and their compositions measured using the same procedure discussed in sub-section 4.3. The measured compositions of the alloys used in this study are listed in Table 6.

Table 6. Specimen labels and compositions in wt.\% as measured by ICP-OES.

\begin{tabular}{cccc}
\hline Specimen Label & $\mathrm{Al}$ & Actual $\mathrm{Zn}$ & Actual Zr \\
\hline $0.2 \mathrm{Zr}$ & $\mathrm{Bal}$ & 0.0 & 0.20 \\
$3.5 \mathrm{Zn} 0.2 \mathrm{Zr}$ & $\mathrm{Bal}$ & 3.5 & 0.22 \\
\hline
\end{tabular}




\subsubsection{Heat treatment}

A series of the polished button specimens cut from as-cast $0.2 \mathrm{Zr}$ and $3.6 \mathrm{Zn} 0.2 \mathrm{Zr}$ ingots, fabricated with VIM were isochronally aged without prior solution heat treatment. The multi-step isochronal aging was carried out on both alloys from 150 to $450{ }^{\circ} \mathrm{C}, 150$ to 500 ${ }^{\circ} \mathrm{C}$ and 150 to $600{ }^{\circ} \mathrm{C}$ - at $50^{\circ} \mathrm{C}$ temperature step. The duration at each temperature step was $3 \mathrm{~h}$ in the furnace before quenching in water. Finally, isochronal heat treatment from 150 to $600{ }^{\circ} \mathrm{C}$ - at $50^{\circ} \mathrm{C}$ temperature step $(3 \mathrm{~h}$ duration per temperature step) was performed on $3.6 \mathrm{Zn} 0.2 \mathrm{Zr}$ button specimen, after prior homogenization at $620^{\circ} \mathrm{C}$ (within the singlephase region of the phase diagram) for $24 \mathrm{~h}$. This was done to observe the effect of prior solutionizing on peak microhardness.

\subsubsection{Deformation and thermal aging}

Two $76 \mathrm{~mm}$ long and $19 \mathrm{~mm}$ diameter as-cast rod specimens were cut out from the $0.2 \mathrm{Zr}$ and $3.5 \mathrm{Zn} 0.2 \mathrm{Zr}$ ingots. One specimen of each alloy was isochronally heat treated from 150 to $450{ }^{\circ} \mathrm{C}$ (at $50{ }^{\circ} \mathrm{C}$ temperature step - each step lasting $3 \mathrm{~h}$ in the furnace) to attain peak strength, while the second specimen remained in as-cast state. All specimens were then swaged down to $9.5 \mathrm{~mm}$ rods before drawing to wires with a diameter of $4.6 \mathrm{~mm}$ for heat resistance and tensile testing. This stage was labelled as-wiredrawn, Figure 33. The diameter reduction of the rods from $19-4.6 \mathrm{~mm}$ represents $94 \% \mathrm{CW}$ (percent cold work).

Each heat treated - wiredrawn specimen was cut into several $102 \mathrm{~mm}$ long wire specimens for subsequent thermal aging experiment. Thermal aging experiment was performed on some of these $102 \mathrm{~mm}$ long wire specimens at $300{ }^{\circ} \mathrm{C}$ for $5 \mathrm{~h}$ and $15 \mathrm{~h}$, while others were left in their as-wiredrawn state. According to the Arrhenius plot in the IEC international standard for "Thermal resistant aluminum alloy wire for overhead line conductor" (IEC 62004), the accelerated thermal aging of these alloys at $300{ }^{\circ} \mathrm{C}$ for $5 \mathrm{~h}$ corresponds to a continuous operation temperature for 40 years when used as power line conductors[80]. The purpose of thermal aging experiment was to observe the thermal resistance of the alloys. A thermally resistant alloy is defined as an alloy that has the ability to retain $\sim 90$ $\%$ of its strength after undergoing long-term exposure to high temperatures[80]. 


\subsubsection{Measurements}

Vickers microhardness measurements were taken from the mechanically polished surfaces

of all specimens at every temperature step and time interval. A $100 \mathrm{~g}$ load was used with a dwell time of $15 \mathrm{~s}$. A calibrated Sigmascope SMP10 probe was used to measure electrical conductivity (in $\mathrm{MS} / \mathrm{m}$ ) of the button specimens. The electrical conductivity values of all the drawn wires used in this study were measured by a Keithly setup, consisting of a $2182 \mathrm{~A}$ nanovoltmeter, current source, and alligator clips. Tensile tests were performed on the asdrawn and heat aged wires with an Instron 8920. A Futek (Model \# LCF455) device with maximum load capacity rating of 10,000 lbs attached to the crosshead, a two-inch gauge length, and a $2 \times 10^{-3} \mathrm{~s}^{-1}$ strain rate were used for the tensile tests.

\subsubsection{Microstructural observation}

For TEM analysis, thin sheets ( $200 \mu \mathrm{m}$ thickness) were cut out of isochronally aged $0.2 \mathrm{Zr}$ and $3.5 \mathrm{Zn} 0.2 \mathrm{Zr}$ specimens $\left(450,500\right.$ and $\left.600^{\circ} \mathrm{C}\right)$ using wire electrical discharge machining (EDM). These thin sheets were mechanically polished down to $<100 \mu \mathrm{m}$ thickness and $\sim 3 \mathrm{~mm}$ diameter foils were punched from the auto-polished sheets for TEM experiments. An FTS System Multicool chiller connected to the Jet Electropolisher was used to maintain the temperature of a mixture of $150 \mathrm{ml}$ methanol and $60 \mathrm{ml}$ nitric acid (electrolyte) at $35^{\circ} \mathrm{C}$ before electropolishing was performed on the foil specimens at $10 \mathrm{~V}(\sim 70 \mathrm{~mA})$. The TEM imaging used an FEI Titan Themis scanning transmission electron microscope (STEM) operating at $200 \mathrm{kV}$. Energy Dispersive X-ray Spectroscopy (EDX) analysis was performed after elemental mapping of the specimens in STEM mode. The electropolished TEM foils were examined using environmental scanning electron microscopy (ESEM), operated at $5 \mathrm{kV}$ with a short working distance.

\subsection{Results}

The results from the microhardness tests, electrical conductivity tests, and tensile tests, and STEM/SEM microscopy are detailed in this section. 


\subsubsection{Vickers microhardness (Isochronal aging)}

The microhardness values of $0.2 \mathrm{Zr}$ and $3.5 \mathrm{Zn} 0.2 \mathrm{Zr}$ were measured to determine the influence of $\mathrm{Zn}$ addition on the peak microhardness of Al-Zr. The results shown in Figure 31 indicate that adding 3.5wt.\% $\mathrm{Zn}$ to Al-Zr enhanced the peak microhardness attained from 403 to $459 \mathrm{MPa}$. During isochronal aging, $0.2 \mathrm{Zr}$ and $3.5 \mathrm{Zn} 0.2 \mathrm{Zr}$ specimens gained 140 (amounting to 53\% microhardness gain) and $132 \mathrm{MPa}(40 \%)$, respectively, from precipitation strengthening. However, most of the observed difference in microhardness between $0.2 \mathrm{Zr}$ and $3.5 \mathrm{Zn} 0.2 \mathrm{Zr}$ at as-cast $(\triangle$ microhardness $\cong 64 \mathrm{MPa}$ ) and peak-aged conditions ( $\triangle$ microhardness $\cong 56 \mathrm{MPa})$ is likely due to solid solution strengthening from the added $\mathrm{Zn}$.

The microhardness of the homogenized $3.5 \mathrm{Zn} 0.2 \mathrm{Zr}$ specimen dropped instantly from 347 to $253 \mathrm{MPa}$ due to annealing (release of residual stress accumulated during solidification while casting) from solution heat treatment, before isochronal aging (Figure 31). In addition, a much lower peak microhardness (324 MPa) was attained when the homogenized $3.5 \mathrm{Zn} 0.2 \mathrm{Zr}$ was aged, because prior homogenization of the Al-Zr alloy first nucleated $\mathrm{Al}_{3} \mathrm{Zr}$ precipitates. This reduced the amount of $\mathrm{Zr}$ solute left in solid solution for subsequent aging and led to a corresponding lower peak microhardness from precipitation hardening[33]. The subsequent percent increase in the microhardness due to aging of the homogenized $3.5 \mathrm{Zn} 0.2 \mathrm{Zr}$ was $19 \%$.

For all aging conditions used for $0.2 \mathrm{Zr}$ and $3.5 \mathrm{Zn} 0.2 \mathrm{Zr}$, the peak microhardness occurred at $\sim 450^{\circ} \mathrm{C}$. This shows that the addition of $\mathrm{Zn}$ to $\mathrm{Al}-\mathrm{Zr}$ alloy did not cause any significant shift in the peak microhardness temperature during isochronal aging. The first sign of nucleation and precipitate growth was observed after $350^{\circ} \mathrm{C}$ for both alloys. Hence, $\mathrm{Zn}$ did not have any significant impact on the incubation time for nucleation under the aging conditions studied.

Between $450-600^{\circ} \mathrm{C}$, the microhardness values of $0.2 \mathrm{Zr}$ and $3.5 \mathrm{Zn} 0.2 \mathrm{Zr}$ reversed and continued to decrease due to Orowan strengthening, subsequent precipitate coarsening and dissolution[81]. Clearly, there was a steeper decline in the microhardness of $3.5 \mathrm{Zn} 0.2 \mathrm{Zr}$ 
observed between 450 and $550{ }^{\circ} \mathrm{C}$, relative to $0.2 \mathrm{Zr}$. The microhardness of $3.5 \mathrm{Zn} 0.2 \mathrm{Zr}$ converged toward $0.2 \mathrm{Zr}$ as the two alloys overaged. Similar convergence was not observed between $1.0 \mathrm{Zn} 0.07 \mathrm{Zr}$ and $1.7 \mathrm{Zn} 0.07 \mathrm{Zr}$ (at. \%) alloys in a previous study[12] when both alloys had $\mathrm{Zn}$ solute. This convergence could initially be due to the combined effect of enhanced precipitate coarsening rate of and/or dissolution of $\mathrm{Zn}$ from the $\mathrm{Al}_{(3-\mathrm{x})} \mathrm{Zn}_{\mathrm{x}} \mathrm{Zr}$ precipitate phase. The dissolution of $\mathrm{Zn}$ from the precipitate phase is discussed in more detail below. The initially lost microhardness of $3.5 \mathrm{Zn} 0.2 \mathrm{Zr}$ relative to $0.2 \mathrm{Zr}$, due to its microhardness convergence between 450 and $550^{\circ} \mathrm{C}$, was restored after isochronal aging at $600{ }^{\circ} \mathrm{C}$. This microhardness behavior is likely due to $\mathrm{Zn}$ addition and is discussed in detail below.

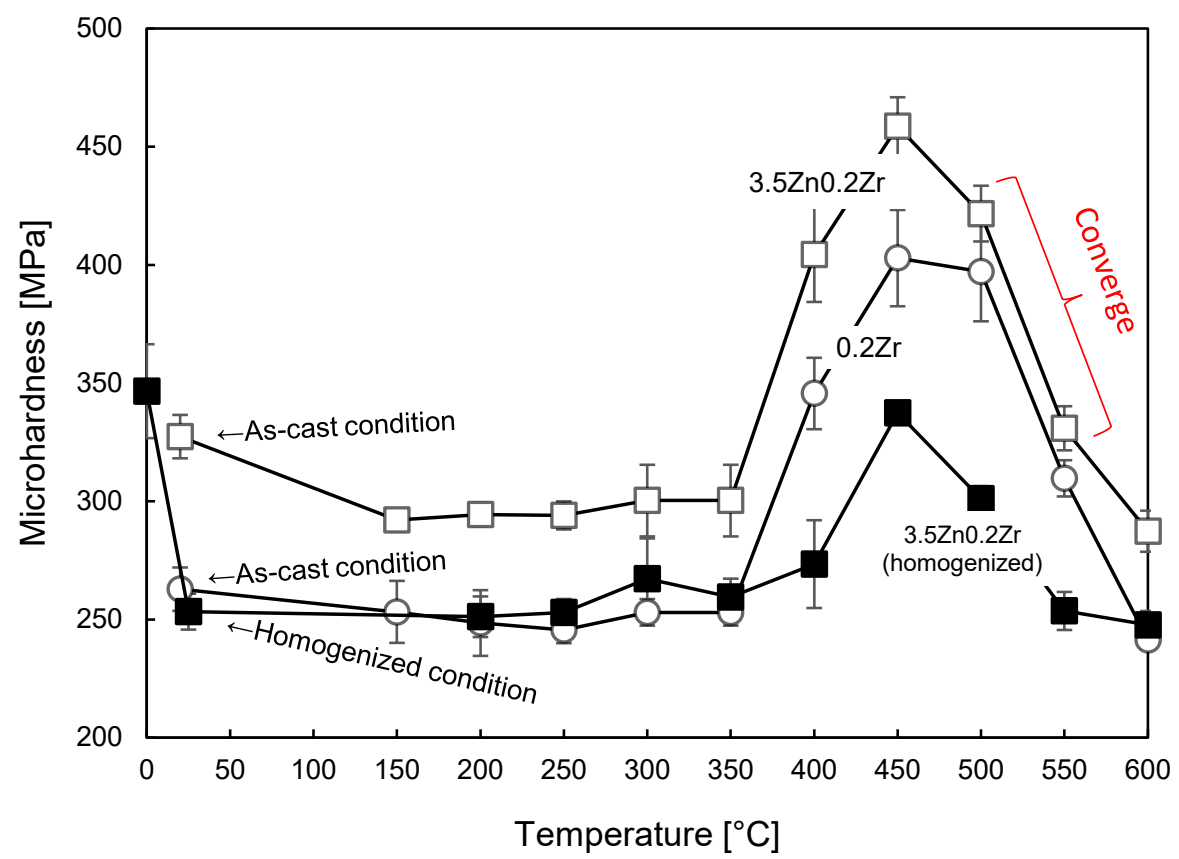

Figure 31. Evolution of Vickers microhardness during isochronal aging of as-cast $0.2 \mathrm{Zr}$, $3.5 \mathrm{Zn} 0.2 \mathrm{Zr}$, and homogenized $3.5 \mathrm{Zn} 0.2 \mathrm{Zr}$ specimens. During the early overage stage, the microhardness of $3.5 \mathrm{Zn} 0.2 \mathrm{Zr}$ converges toward $0.2 \mathrm{Zr}$ as a result of the possible enhanced coarsening rate and $\mathrm{Zn}$ dissolution from the precipitate phase. 


\subsubsection{Electrical conductivity}

The as-cast electrical conductivities of $0.2 \mathrm{Zr}$ and $3.5 \mathrm{Zn} 0.2 \mathrm{Zr}$ were measured as 32.6 and 28.1 MS/m, respectively (Figure 32). The $3.5 \mathrm{Zn} 0.2 \mathrm{Zr}$ alloy demonstrated a lower as-cast electrical conductivity compared to $0.2 \mathrm{Zr}$ due to a large amount of $\mathrm{Zn}$ in solid solution. Similar to the Vickers microhardness measurement (Figure 31), the first evidence of nucleation and growth of precipitates in the alloys was observed after $350{ }^{\circ} \mathrm{C}$, as the conductivity increased.

Upon continued aging, the peak strengthened specimens recorded maximum electrical conductivities at $\sim 475^{\circ} \mathrm{C}$; this is about the same temperature at which peak microhardness was attained in the specimens. This indicates that the presence of $\mathrm{Zn}$ in $\mathrm{Al}-\mathrm{Zr}$ did not change the temperature of peak electrical conductivity during multistep isochronal aging, as demonstrated in Figure 32. The observed increase in electrical conductivity was as a result of the precipitation of the solute species out of the solid solution. There was a 1.9 $\mathrm{MS} / \mathrm{m}$ increase in the electrical conductivity of $0.2 \mathrm{Zr}$ to $34.6 \mathrm{MS} / \mathrm{m}$ due to aging, while $3.5 \mathrm{Zn} 0.2 \mathrm{Zr}$ increased by $1.7 \mathrm{MS} / \mathrm{m}$ (peak electrical conductivity is $29.8 \mathrm{MS} / \mathrm{m}$ ).

The difference between the electrical conductivity values of $0.2 \mathrm{Zr}$ and $3.5 \mathrm{Zn} 0.2 \mathrm{Zr}$, at ascast and peak aged conditions were similar, $\sim 4.6 \mathrm{MS} / \mathrm{m}$. This difference was mostly because of the quantity of $\mathrm{Zn}$ remaining in solid solution. Due to the high solid solubility of $\mathrm{Zn}$ in $\mathrm{Al}[13]$, most of the zinc remained in solid solution at the peak-aged condition. Beyond $500{ }^{\circ} \mathrm{C}$, their electrical conductivities began to drop until they almost reached their as-cast values. Throughout the as-cast, peak-aged, and overaged conditions, the electrical conductivity trend remained consistent. As expected, the electrical conductivity reduced with the addition of $\mathrm{Zn}$ at all aging temperatures. 


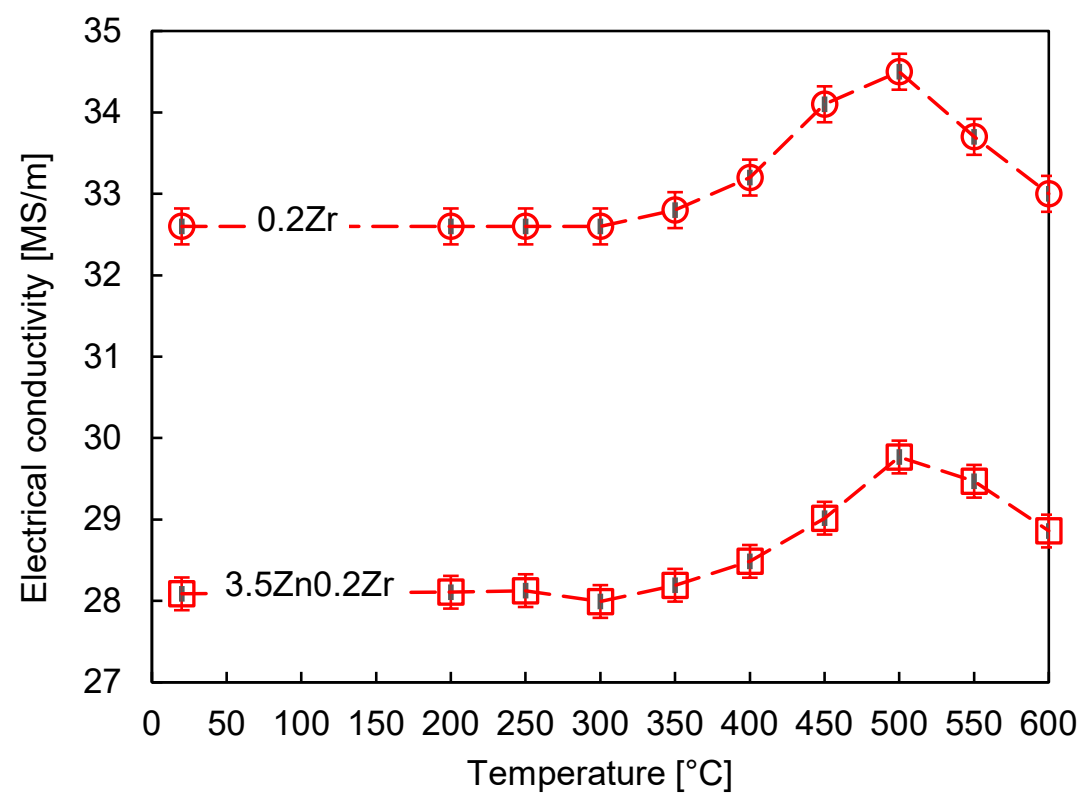

Figure 32. Electrical conductivity of isochronally aged Al-Zr and Al-Zn-Zr specimens. The as-cast and peak conductivities reduced as a result of the addition of $\mathrm{Zn}$.

\subsubsection{Thermal aging and tensile test}

In Figure 33, "AA+CW" and "CW" denote $94 \% \mathrm{CW}$ of isochronally peak-aged and ascast alloys $(0.2 \mathrm{Zr}$ and $3.5 \mathrm{Zn} 0.2 \mathrm{Zr})$, respectively. Afterwards, thermal aging experiments were performed on the as-wiredrawn " $\mathrm{AA}+\mathrm{CW}$ " and "CW" alloys at $300{ }^{\circ} \mathrm{C}$ for 5 and 15 $h$ to compare the heat resistance of the alloys.

For $\mathrm{CW}$ (as-wiredrawn), the tensile strengths of $0.2 \mathrm{Zr}$ and $3.5 \mathrm{Zn} 0.2 \mathrm{Zr}$ were determined to be 122 and $148 \mathrm{MPa}$, respectively - not represented on the Figure 33(a). According to this plot, the tensile strengths of the alloys were 192 and $233 \mathrm{MPa}$ for $0.2 \mathrm{Zr}$ and $3.5 \mathrm{Zn} 0.2 \mathrm{Zr}$, respectively, at the $\mathrm{AA}+\mathrm{CW}$ (as-wiredrawn) condition. This means that $0.2 \mathrm{Zr}$ gained 70 MPa from prior isochronal peak aging of the cast rods before wiredrawing, while 3.5Zn0.2Zr gained $85 \mathrm{MPa}$. The difference between the tensile strengths of $0.2 \mathrm{Zr}$ and $3.5 \mathrm{Zn} 0.2 \mathrm{Zr}$ wires at as-wiredrawn state, before thermal aging, was $26 \mathrm{MPa}$ for $\mathrm{CW}$, compared to $41 \mathrm{MPa}$ for $\mathrm{AA}+\mathrm{CW}$ condition. This indicates an excess of $15 \mathrm{MPa}$ strength difference was gained in $3.5 \mathrm{Zn} 0.2 \mathrm{Zr}$ relative to $0.2 \mathrm{Zr}$ from prior heat treatment $-\mathrm{AA}+\mathrm{CW}$. 
The difference between the tensile strengths of the alloys in the CW condition is mostly due to solid solution strengthening from the added $\mathrm{Zn}$ solute.

Because $\mathrm{Zn}$ addition is not expected to change the precipitate volume fraction, the excess strength difference of $15 \mathrm{MPa}$ observed between $0.2 \mathrm{Zr}$ and $3.5 \mathrm{Zn} 0.2 \mathrm{Zr}$ wires, as a result of prior heat treatment of the alloy rods before cold work, could be attributed to the higher strengthening potential of $\mathrm{Al}_{(3-\mathrm{x})} \mathrm{Zn}_{\mathrm{x}} \mathrm{Zr}$ relative to $\mathrm{Al}_{3} \mathrm{Zr}$. Assuming the number density of dislocations generated from cold work is approximately the same in both alloys, having gone through similar deformation processes. This would indicate that the strengthening magnitude from dislocation- $\mathrm{Al}_{(3-\mathrm{x})} \mathrm{Zn}_{\mathrm{x}} \mathrm{Zr}$ precipitate interaction is slightly higher than that of dislocation- $\mathrm{Al}_{3} \mathrm{Zr}$ interaction. This could be as a result of the higher precipitate/matrix lattice mismatch and corresponding coherency strain fields generated by $\mathrm{Al}_{(3-\mathrm{x})} \mathrm{Zn}_{\mathrm{x}} \mathrm{Zr}$ precipitates.

After thermal aging of $\mathrm{AA}+\mathrm{CW}$ wires at $300{ }^{\circ} \mathrm{C}$ for $5 \mathrm{~h}, 95 \%$ of the as-wiredrawn tensile strength of $0.2 \mathrm{Zr}$ specimen was retained, while $3.5 \mathrm{Zn} 0.2 \mathrm{Zr}$ retained $84 \%$ of its aswiredrawn strength. The rapid decline of tensile strength after thermal aging for $5 \mathrm{~h}$ was mostly due to the recovery process (reduction in the number density of dislocations at elevated temperature due to atomic diffusion). During this process, some of the stored internal strain energies were released by virtue of dislocation motion as a result of enhanced atomic diffusion motion at elevated temperature. It is worth noting that $3.5 \mathrm{Zn} 0.2 \mathrm{Zr}$ experienced $16 \%$ softening, which is more than the $5 \%$ softening for $0.2 \mathrm{Zr}$. This is just a reflection of both alloys losing some of the strengthening potential from their respective dislocation-precipitate and dislocation-solid solution interactions due to the recovery process. Since, the strengthening magnitude derived from the dislocation-precipitate interaction is higher for $3.5 \mathrm{Zn} 0.2 \mathrm{Zr}$ relative to $0.2 \mathrm{Zr}$, a greater softening was observed after the dislocation density significantly reduced.

After $15 \mathrm{~h}$ of thermal aging, $0.2 \mathrm{Zr}$ and $3.5 \mathrm{Zn} 0.2 \mathrm{Zr}$ retained 94 and $83 \%$ of their aswiredrawn tensile strengths (similar strength retention to $5 \mathrm{~h}$ thermal aging), respectively. The insignificant softening difference between the 5 and $15 \mathrm{~h}$ annealed wires showed that 
the recovery process was complete in $\leq 5 \mathrm{~h}$. Thus, the inclusion of $\mathrm{Zn}$ increased the tensile strength and slightly reduced the thermal resistance of the alloy.

The electrical conductivities of the $\mathrm{AA}+\mathrm{CW}$ wires before and after thermal aging for 5 and $15 \mathrm{~h}$ were measured (Figure 3(b)). The data indicates that there was a slight increase in electrical conductivities of the wires as a result of annealing for 5 and $15 \mathrm{~h}$. After $5 \mathrm{~h}$ of thermal aging, the electrical conductivity of $0.2 \mathrm{Zr}$ increased from 34.9 to $35.3 \mathrm{MS} / \mathrm{m}$ (35.7 MS/m after $15 \mathrm{~h}$ ), while $3.5 \mathrm{Zn} 0.2 \mathrm{Zr}$ increased from 29 to $29.5 \mathrm{MS} / \mathrm{m}$ (30 MS/m after $15 \mathrm{~h}$ ). The observed increase in electrical conductivity after annealing (recovery process) was due to annihilation of dislocations. 

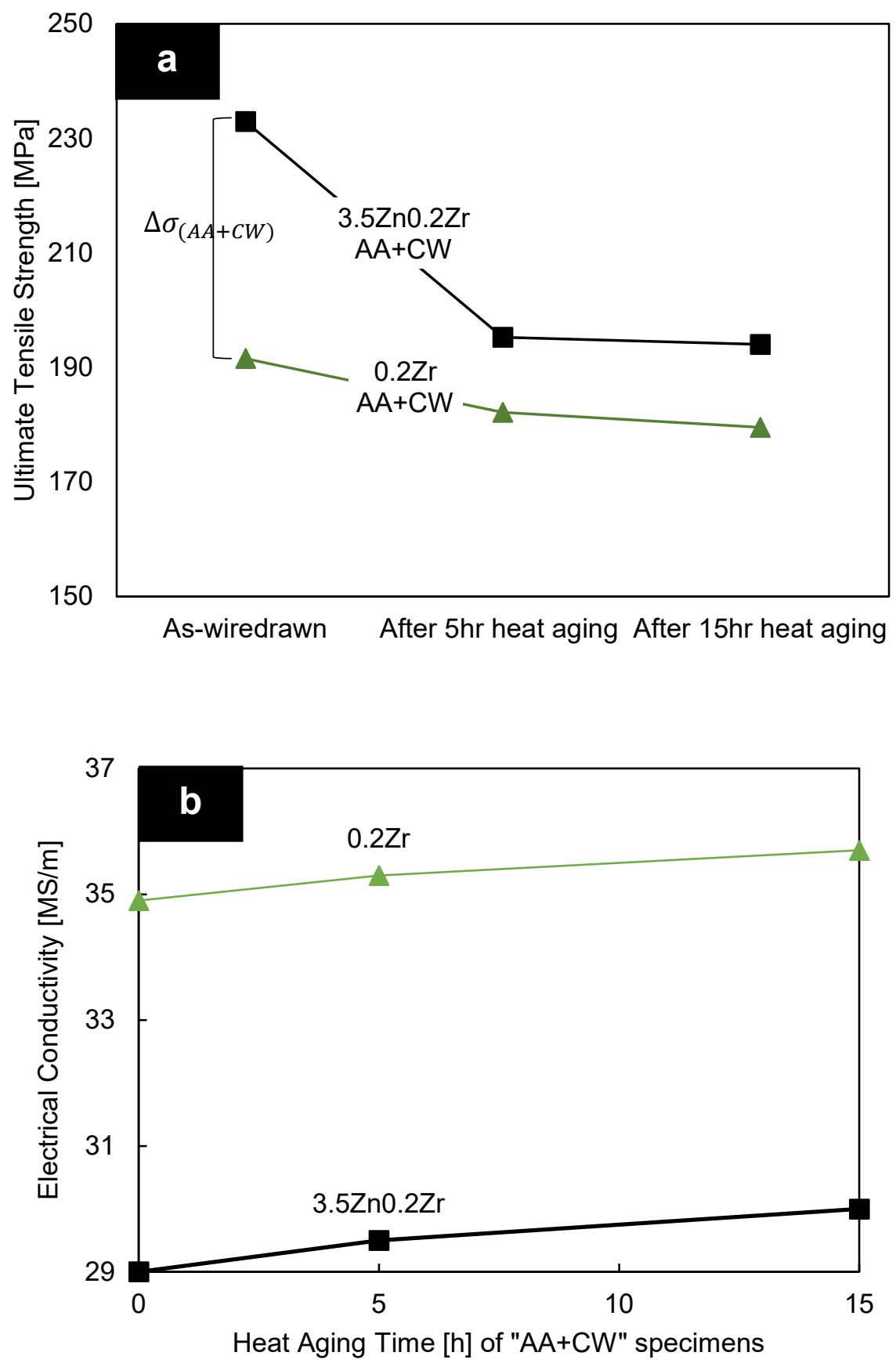

Figure 33. Results of thermal aging test performed on post peak aged - cold worked (AA+CW) $0.2 \mathrm{Zr}$ and $3.5 \mathrm{Zn} 0.2 \mathrm{Zr}$ at $300{ }^{\circ} \mathrm{C}$ for 5 and $15 \mathrm{~h}$. (a) The tensile strengths of both specimens were measured before and after thermal aging. (b) The corresponding electrical conductivity measurements. 


\subsubsection{Dendritic/interdendritic microstructure}

Several studies have shown that during casting, some peritectic Al-Zr and Al-Zr-TM alloys form dendritic/interdendritic microstructures as they solidify. Smaller precipitates occupy the precipitate-rich dendritic center, whereas the interdendritic channels are occupied by low number densities of larger precipitates[30,31]. The larger precipitates in the interdendritic channels are possible because they can nucleate and grow before their diffusion fields begin to overlap[30]. Figure 34 reveals the precipitate gradient across the $3.5 \mathrm{Zn} 0.2 \mathrm{Zr}$ specimen. From observation, the dendritic center was characterized by a high number density of smaller precipitates (mean radius $\langle R\rangle=2.45 \mathrm{~nm}$ ) compared to those present in the interdendritic channel, $\langle R\rangle=6.5 \mathrm{~nm}$, Figure 34(a) and (c).

The high concentration of segregated $\mathrm{Zr}$ solute (due to solidification during alloy casting) in the dendritic center was responsible for the high number density and small size of the precipitates during aging, because the chemical driving force for nucleation increases with supersaturation of $\mathrm{Zr}$ solutes. As a result, the critical mean radius required for nucleation to occur was reduced and smaller precipitates were formed (Figure 34(c)). From previous study, the mean precipitate size of aged $\mathrm{Al}-\mathrm{Zr}$ or $\mathrm{Al}-\mathrm{Zr}-\mathrm{TM}$ alloy increases progressively along a lateral position from the dendritic center toward the interdendritic channel[30, 31]. This is because the supersaturation of $\mathrm{Zr}$ solute decays along this direction[30, 31]. In the interdendritic channels, $\mathrm{Zr}$ solute was depleted as the chemical driving force for nucleation was reduced. The critical mean radius for nucleation increased, causing a low volume fraction of bigger precipitates to be formed (Figure 34(a)). One disadvantage of the interdendritic channels is that they are usually weaker and more susceptible to failure relative to other regions because of the fewer and bigger precipitates present. This leads to deleterious effects on the mechanical properties[30, 31, 82].

Precipitate-rich dendritic edges that boarder the interdendritic channel were characterized by precipitate free zones (Figure 34(b)) which were about $0.5 \mu m$ wide[30, 31]. The bigger precipitates were located within the interdendritic channels, after crossing over the precipitate free zone (PFZ). Because $\mathrm{Zr}$ has a very low diffusivity in $\alpha-\mathrm{Al}$, it is almost impossible to homogenize $\mathrm{Al}-\mathrm{Zr}$ or $\mathrm{Al}-\mathrm{Zn}-\mathrm{Zr}$ alloys, except alloys that are solutionized at 
high temperatures below the liquidus line but within the single-phase region $\sim 620^{\circ} \mathrm{C}$ for an extensively long time[12,44]. This is why the dendritic/interdendritic microconstituents observed in (Al,TM)-Zr alloys are difficult to eliminate. Table 7 summarizes the sizes of the precipitates positioned in the interdendritic channels.
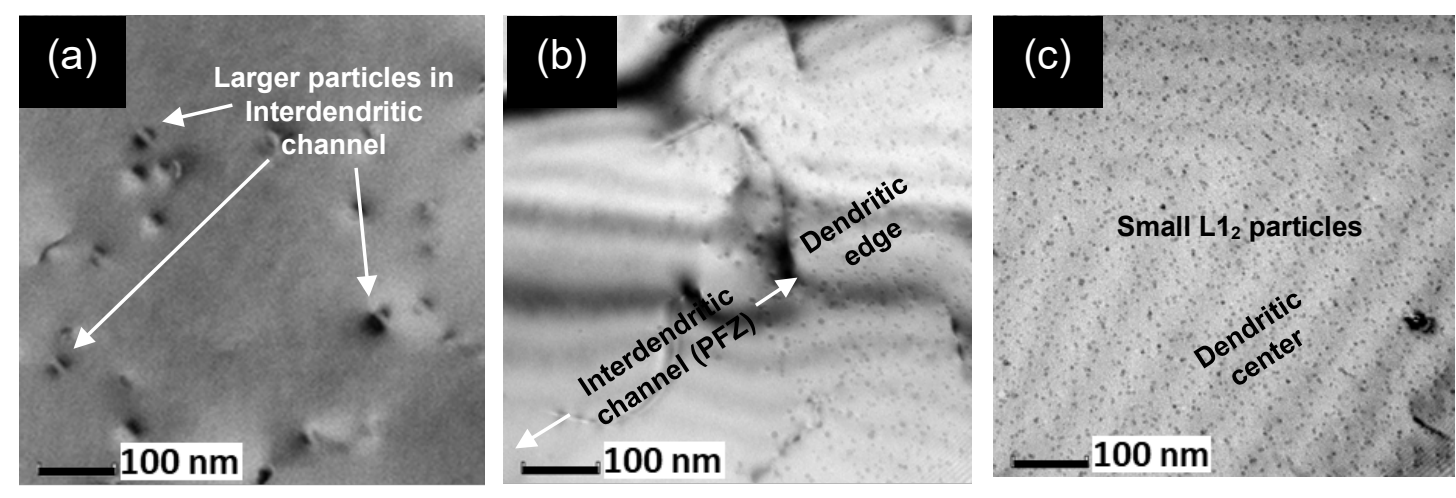

Figure 34. Distribution and mean sizes of precipitates in the dendritic center, edge, and interdendritic channel corresponding to the microsegregation of $\mathrm{Zr}$ solute in the $3.5 \mathrm{Zn} 0.2 \mathrm{Zr}$ specimen. (a) Precipitates formed in interdendritic channels have a bigger mean size but smaller number density, (b) precipitate free zone (PFZ) along the boundary between a dendritic edge/interdendritic channel, (c) Dendritic center with smaller-size precipitates.

\subsubsection{Precipitate structure and size}

It is expected that the precipitates formed when as-cast Al-Zr is peak aged have metastable $\mathrm{L}_{2}-\mathrm{Al}_{3} \mathrm{Zr}$ phases that are coherent with $\alpha$ - $\mathrm{Al}$ matrix. The precipitate/matrix coherency is confirmed by the precipitates' Ashby-brown strain contrast reported in several studies[12, $30,31,34,79]$. Similar Ashby-brown strain contrasts were also observed for coherent $\mathrm{Al}_{(3-}$ х) $\mathrm{Zn} \times \mathrm{Zr}$ precipitates formed in the interdendritic channels of $3.5 \mathrm{Zn} 0.2 \mathrm{Zr}$ system (Figure 35 (b)) after isochronal aging at $450^{\circ} \mathrm{C}$. Comparison of precipitates revealed that the mean precipitate size of $\mathrm{Al}_{(3-\mathrm{x})} \mathrm{Zn}_{\mathrm{x}} \mathrm{Zr}$ is slightly bigger than that of $\mathrm{Al}_{3} \mathrm{Zr}$. The mean radii of these precipitates formed in the interdendritic channels are $6.5 \pm 1.2 \mathrm{~nm}$ for $\mathrm{Al}_{(3-\mathrm{x})} \mathrm{Zn} \times \mathrm{Zr}$ (Figure 
35(a)) and approximately $5.5 \pm 1.5 \mathrm{~nm}$ for $\mathrm{Al}_{3} \mathrm{Zr}$ (Figure 35(c)). This indicates that adding $\mathrm{Zn}$ increased the average precipitate growth.

After isochronal aging at $600{ }^{\circ} \mathrm{C}$, some of the precipitates formed in the alloys remained in the $\mathrm{L}_{2}$ structure. Pronounced coarsening of the precipitates led to significant increases of their mean radii, as summarized in Table 7 . The $\mathrm{Al}_{(3-\mathrm{x})} \mathrm{Zn}_{\mathrm{x}} \mathrm{Zr}$ interdendritic precipitate mean size increased significantly to $\langle R\rangle \cong 30 \mathrm{~nm}$ from $6.5 \mathrm{~nm}$ (Figure 36). On the other hand, $\mathrm{Al}_{3} \mathrm{Zr}$ increased from $\langle R\rangle \cong 5.5 \mathrm{~nm}$ to $23 \mathrm{~nm}$. Thus, $\mathrm{Ll}_{2}-\mathrm{Al}_{3} \mathrm{Zr}$ and $\mathrm{Al}_{(3-\mathrm{x})} \mathrm{Zn}_{\mathrm{x}} \mathrm{Zr}$ precipitate mean sizes increased by a factor of four after aging from 450 to $600{ }^{\circ} \mathrm{C}$. The gain in precipitate size of $\mathrm{Al}_{(3-\mathrm{x})} \mathrm{Zn} \times \mathrm{Zr}(\sim 23.5 \mathrm{~nm})$ is larger relative to $\mathrm{Al}_{3} \mathrm{Zr}(\sim 17.5 \mathrm{~nm})$. This observation indicates that the inclusion of $\mathrm{Zn}$ increased the precipitate coarsening rate. This is in part due to the higher diffusivity of $\mathrm{Zn}$ in $\mathrm{Al}$ relative to that of $\mathrm{Zr}$.

At $600{ }^{\circ} \mathrm{C}$, the transformation of some of the heterogeneously nucleated particles in $0.2 \mathrm{Zr}$ and $3.5 \mathrm{Zn} 0.2 \mathrm{Zr}$ from $\mathrm{L}_{2}$ to $\mathrm{D}_{23}$ was observed along the interdendritic channels and on dislocations (Figure 36 (c), (e) \& (f)). The $\mathrm{D}_{23}$ disk-like precipitates in the alloys are $\sim 400-500 \mathrm{~nm}$ in length. During overaging, the $\mathrm{L}_{2}$ to $\mathrm{D}_{23}$ transition is not direct; rather, it occurs in two stages[30, 31]: Dissolution of solutes from metastable $\mathrm{L}_{2}$ phase and formation of new equilibrium $\mathrm{D} 0_{23}$ by re-precipitation from the dissolved solutes.

TEM images acquired from the peak-aged specimens (Figure 35) were collected along a low index [111] zone axis. Their selected area electron diffraction (SAED) patterns show cubic $\{101\}$ superlattice spots forming hexagonal patterns around each fcc spot (Figure $35(\mathrm{a}) \&(\mathrm{c}))$. These indicate the presence of an ordered lattice structure attributed to the $\mathrm{L}_{2}$ phase. Therefore, the structures of coherent $\mathrm{Al}_{3} \mathrm{Zr}$ and $\mathrm{Al}_{(3-\mathrm{x})} \mathrm{Zn}_{\mathrm{x}} \mathrm{Zr}$ precipitates were confirmed as $\mathrm{L}_{2}$ at a $450{ }^{\circ} \mathrm{C}$ aging temperature. 

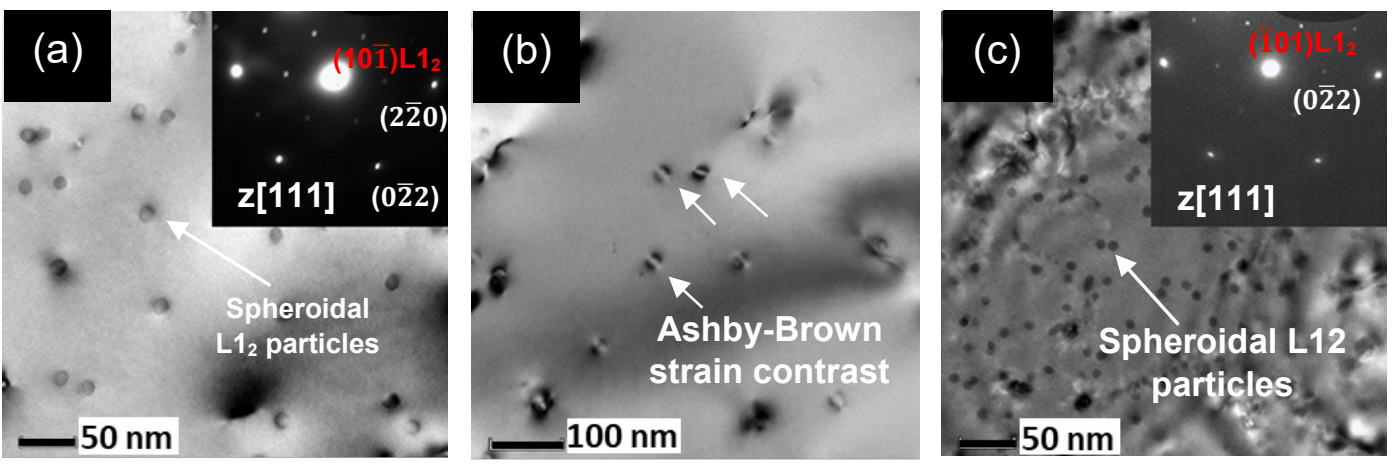

Figure 35. Coherent $\mathrm{L}_{2}$ precipitates formed in $0.2 \mathrm{Zr}$ and $3.5 \mathrm{Zn} 0.2 \mathrm{Zr}$ at $450{ }^{\circ} \mathrm{C}$, as indicated by the line of no contrast and $\{110\}$ superlattice spots in the diffraction patterns (inset), (a) Spheroidal- $\mathrm{L1}_{2} \mathrm{Al}_{(3-\mathrm{x})} \mathrm{Zn}_{\mathrm{x}} \mathrm{Zr}$ precipitates, which are coherent with the matrix as evident by their Ashby-Brown strain contrasts, shown in (b), (c) Coherent $\mathrm{L}_{2} \mathrm{Al}_{3} \mathrm{Zr}$ spherical particles were also formed in $0.2 \mathrm{Zr}$.

Table 7. Measured precipitate mean radii, $\langle R\rangle$, of $\mathrm{L}_{2}$ precipitates located in the interdendritic channels of $0.2 \mathrm{Zr}$ and $3.5 \mathrm{Zn} 0.2 \mathrm{Zr}$, after isochronal aging at 450,500 , and $600{ }^{\circ} \mathrm{C}$.

\begin{tabular}{cccc}
\hline Specimen & Aging Temperature ${ }^{\circ} \mathrm{C}$ & $\begin{array}{c}\text { Mean precipitate } \\
\text { radius }\langle R\rangle n m\end{array}$ & $\begin{array}{c}\text { Number of counted } \\
\text { precipitates }\end{array}$ \\
\hline $3.5 \mathrm{Zn} 0.2 \mathrm{Zr}$ & 450 & 6.5 & 152 \\
& 500 & 10.0 & 56 \\
$0.2 \mathrm{Zr}$ & 600 & 30.0 & 84 \\
& 450 & 5.5 & 92 \\
& 500 & 8.5 & 124 \\
& 600 & 23.0 & 134 \\
\hline
\end{tabular}

The diffraction pattern of the overaged spheroidal $\mathrm{Al}_{(3-\mathrm{x})} \mathrm{Zn}_{\mathrm{x}} \mathrm{Zr}$ showed $\{100\}$ and $\{110\}$ superlattice spots along [110] zone axis, which corresponds to the $\mathrm{L}_{2}$ structure (Figure 36(a)). There were planar faults parallel to (001)-L12. High-resolution TEM (HREM), Figure 36(b) inset, confirms that the planar faults is parallel to $\{100\}$ planes of the $\mathrm{L}_{2}$ $\mathrm{Al}_{(3-\mathrm{x})} \mathrm{Zn}_{\mathrm{x}} \mathrm{Zr}$ phase, with $d_{100}=0.41 \mathrm{~nm}$. The planar faults are always parallel to the $\{100\}$ 
planes in the $\mathrm{L}_{2}$ phase (Figure 36(b)) and are identified as antiphase boundaries (APB) with a dislocation vector $a_{p} / 2\langle 110\rangle$ in the $\{100\}$ plane, where $a_{p}$ is the lattice parameter of the $\mathrm{L}_{2}$ unit cell. Generally, the formation of these planar faults is the first step in the transformation to stable tetragonal $\mathrm{D}_{22}$ or $\mathrm{D}_{23}$ structures[83]. Similar planar faults were also detected in Al-Zr, Al-Ti-V-Zr, and Al-Ti-Zr alloys using TEM (Tsau \& Chen, 2002)[83, 84]. There were also disk-like $\mathrm{Al}_{(3-\mathrm{x})} \mathrm{Zn}_{\mathrm{x}} \mathrm{Zr}$ precipitates identified by SAED patterns as fully transformed $\mathrm{D}_{23}$ (Figure 36(c)). Therefore, spheroidal $\mathrm{L}_{2}$ and disk-like $\mathrm{D}_{23}$ precipitate structures were confirmed in the $3.5 \mathrm{Zn} 0.2 \mathrm{Zr}$ alloy at $600{ }^{\circ} \mathrm{C}$. As expected, spheroidal $\mathrm{L}_{2}$ and disk-like $\mathrm{D}_{23}$ precipitates were also present in $0.2 \mathrm{Zr}$ (Figure $36(\mathrm{~d}-\mathrm{f}$ )). 

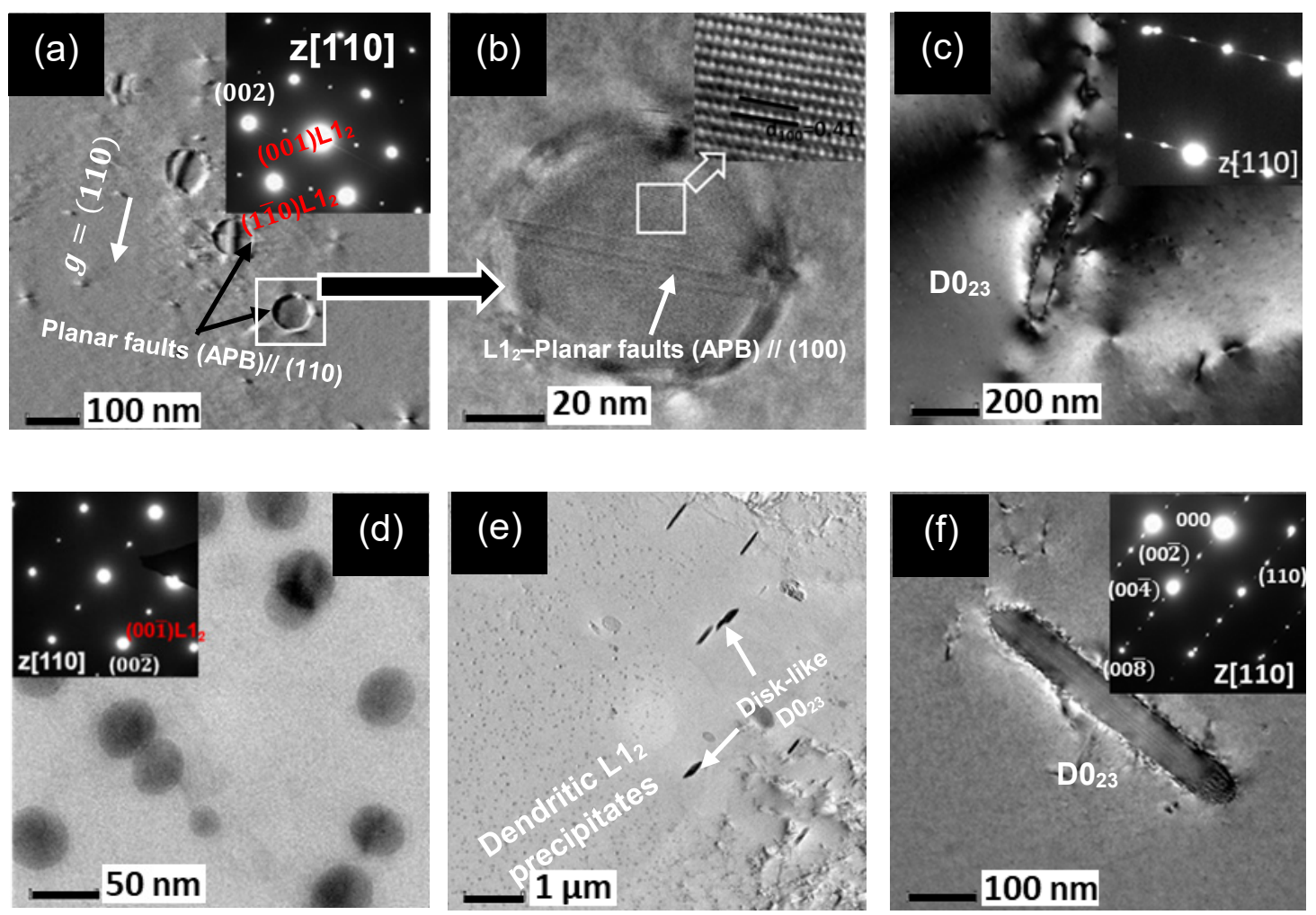

Figure 36. Coarsened interdendritic $\mathrm{Al}_{3} \mathrm{Zr}$ and $\mathrm{Al}_{(3-x)} \mathrm{Zn}_{x} \mathrm{Zr}$ precipitates aged at $600{ }^{\circ} \mathrm{C}$. The precipitate mean size increased significantly to $\langle R\rangle=23 \mathrm{~nm}$ and $30 \mathrm{~nm}$ for spheroidal $\mathrm{Al}_{3} \mathrm{Zr}$ and $\mathrm{Al}_{(3-x)} \mathrm{Zn}_{\times} \mathrm{Zr}$, respectively. (a) The planar faults observed when the beam was tilted along the [110] zone axis showed that the $\mathrm{L1}_{2}-\mathrm{Al}_{(3-x)} \mathrm{Zn}_{\mathrm{x}} \mathrm{Zr}$ precipitates were semicoherent with the matrix. (001) and (1 $\overline{1} 0)$ superlattice spots indicate the $\mathrm{L}_{2}$ structure for the $\mathrm{Al}_{(3-x)} \mathrm{Zn}_{\times} \mathrm{Zr}$ phase, (b) HREM image of the spheroidal $\mathrm{L1}_{2}-\mathrm{Al}_{(3-x)} \mathrm{Zn} \times \mathrm{Zr}$ particle highlighted in 6(a), showed planar faults parallel to the (100) lattice plane, (c) Completely transformed disk-like $\mathrm{D}_{23}-\mathrm{Al}_{(3-x)} \mathrm{Zn} \times \mathrm{Zr}$, (d) Some $\mathrm{Al}_{3} \mathrm{Zr}$ precipitates maintained their $\mathrm{L}_{2}$ form, (e and f) Disk-like $\mathrm{D}_{23}-\mathrm{Al}_{3} \mathrm{Zr}$ precipitates were formed heterogeneously on dislocations and along the interdendritic channel at $600^{\circ} \mathrm{C}$.

In order to examine the broader distribution and number density of the $\mathrm{D}_{23}$ precipitate phase, low magnification SEM images were taken from isochronally aged $0.2 \mathrm{Zr}$ and $3.5 \mathrm{Zn} 0.2 \mathrm{Zr}$ specimens after aging at $600{ }^{\circ} \mathrm{C}$. Due to the combination of the smaller precipitate sizes and the SEM resolution, the overaged $\mathrm{L}_{2}$ precipitates are barely 85 
noticeable in the images. Figure 37 shows that both specimens have very similar number densities of transformed $\mathrm{D}_{23}$ precipitates. In summary, the inclusion of $\mathrm{Zn}$ into the $\mathrm{Al}_{3} \mathrm{Zr}$ precipitate phase did not prevent the eventual $\mathrm{L}_{2} \rightarrow \mathrm{D}_{23}$ transformation from taking place at $600{ }^{\circ} \mathrm{C}$. Hence, the stability of the $\mathrm{L}_{2}$ precipitate phase with $\mathrm{Zn}$ addition was not established in this study.
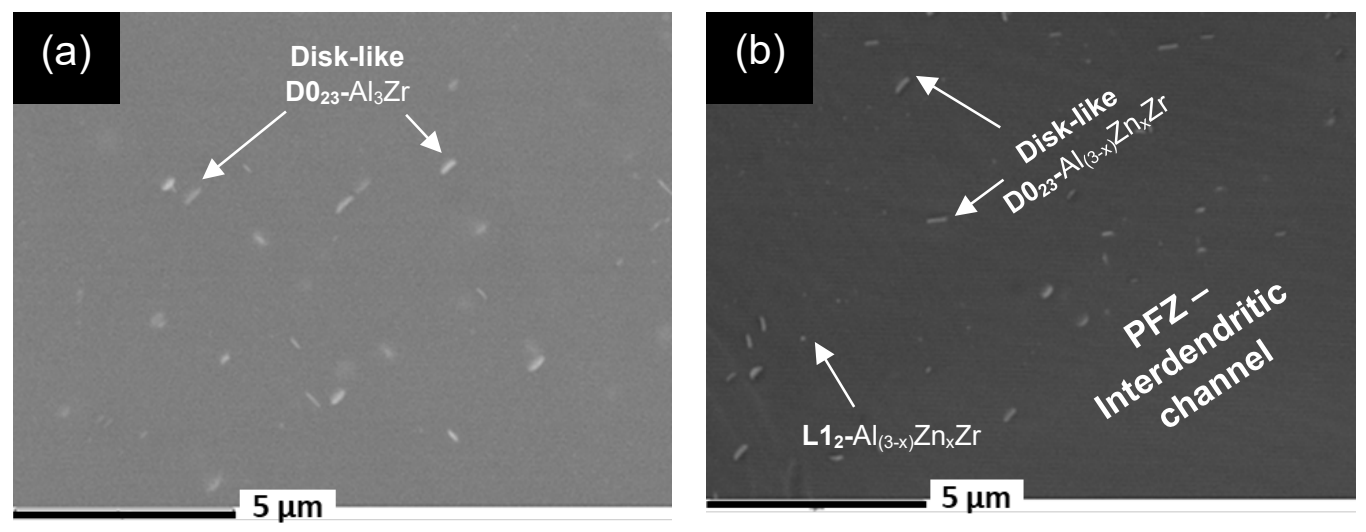

Figure 37. SEM images showing the distribution of $\mathrm{L}_{2}$ and $\mathrm{D} 0_{23}$ precipitates across both specimens after isochronal aging at $600^{\circ} \mathrm{C}$, (a) $0.2 \mathrm{Zr}$ and (b) $3.5 \mathrm{Zn} 0.2 \mathrm{Zr}$.

\subsubsection{Solute segregation in aged specimen}

In order to observe the nanoscale distribution of $\mathrm{Zn}$ and $\mathrm{Zr}$ solutes in isochronally aged $3.5 \mathrm{Zn} 0.2 \mathrm{Zr}$ specimens, elemental maps of the matrix and precipitates were obtained in aberration-corrected STEM. High-angle annular dark field (HAADF) and STEM map images were acquired under magnification of $1300 \mathrm{KX}$ and high voltage: $200 \mathrm{kV}$. After isochronal aging at $450{ }^{\circ} \mathrm{C}$, the particles examined by EDX mapping had a mean particle radius $\langle R\rangle=6.0 \mathrm{~nm}$, interparticle spacing of $15-20 \mathrm{~nm}$ and were located in the interdendritic channel (Figure 38 (a)). As seen in Figure 38 (b and c), Al is the matrix, while $\mathrm{Zn}$ is uniformly distributed in the matrix. However, EDX data showed a very slight $\mathrm{Zn}$ enrichment of the precipitate phase. Almost all the $\mathrm{Zr}$ species were concentrated in the $\mathrm{Al}_{(3-\mathrm{x})} \mathrm{Zn}_{\mathrm{x}} \mathrm{Zr}$ precipitates (Figure 38 (d)). This concentration of $\mathrm{Zr}$ solute in the precipitate phase is also reflected in Table 8 and indicates that $\mathrm{Zr}$ solutes migrated from their 86 
supersaturated position in the dendritic region or depleted interdendritic channel into nearby precipitate phases, leaving the surrounding matrix with no Zr.

Similar $\mathrm{Zr}$ solute concentrations were observed in coarsened $\mathrm{L}_{2}$ - and $\mathrm{D}_{23}-\mathrm{Al}_{3} \mathrm{Zr}$ precipitate phases after isochronally aging $0.2 \mathrm{Zr}$ at $600{ }^{\circ} \mathrm{C}$ (Figure 39). This observed concentration of $\mathrm{Zr}$ solute in the precipitate phase is confirmed by the chemical composition data shown in Table 8 . The coarsened spheroidal- $\mathrm{Al}_{3} \mathrm{Zr}$ precipitate observed, $\langle R\rangle \cong 30.0 \mathrm{~nm}$, shows planar faults signaling a potential $\mathrm{L}_{2} \rightarrow \mathrm{D} 0_{23}$ transformation. The $\mathrm{D} 0_{23}$ precipitate had a length of $\cong 480.0 \mathrm{~nm}$.
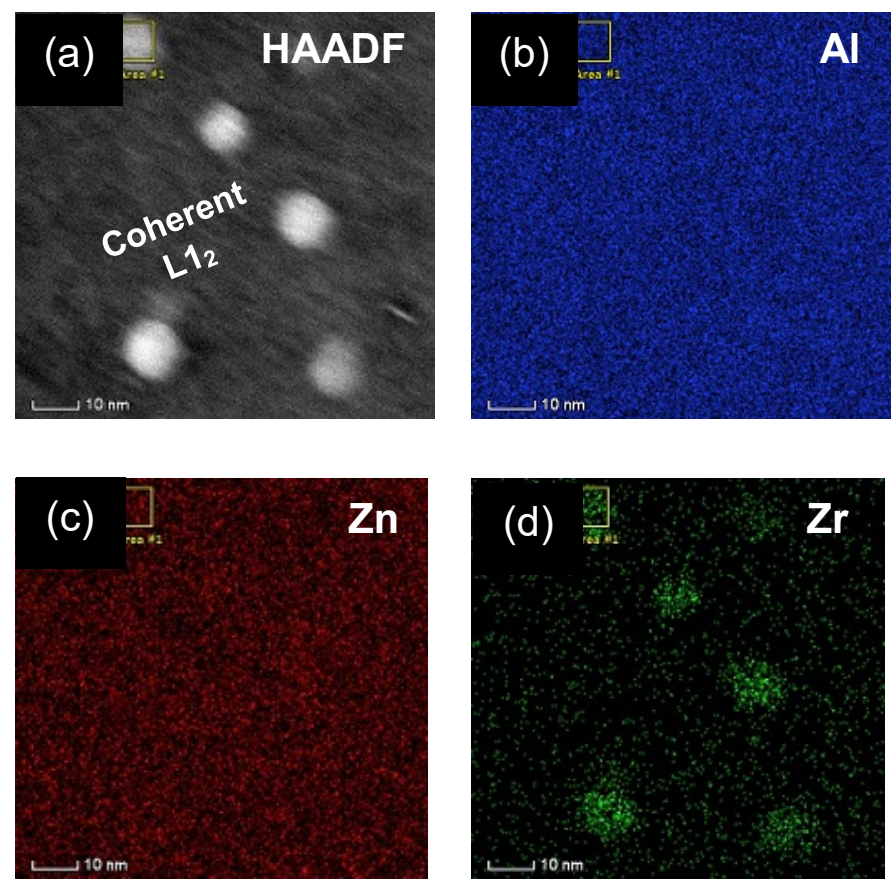

Figure 38. HAADF STEM mapping of $\mathrm{Al}, \mathrm{Zn}$ and $\mathrm{Zr}$ in $3.5 \mathrm{Zn} 0.2 \mathrm{Zr}$ at peak aged temperature, including the $\mathrm{Al}_{(3-\mathrm{x})} \mathrm{Zn}_{\mathrm{x}} \mathrm{Zr}$ precipitates located at the interdendritic channel. (a) The particles separated by $\sim 15-20 \mathrm{~nm}$ spacing were mapped in order to observe the distribution of the elements, (b and c) Al (blue) and $\mathrm{Zn}$ (red) were uniformly distributed across the specimen, although EDX data showed slight enrichment of $\mathrm{Zn}$ in the precipitate phase relative to the matrix, (d) $\mathrm{Zr}$ atoms (green) were concentrated inside the $\mathrm{Ll}_{2}$ precipitate phase, while the surrounding matrix region was deficient in $\mathrm{Zr}$ solute. 

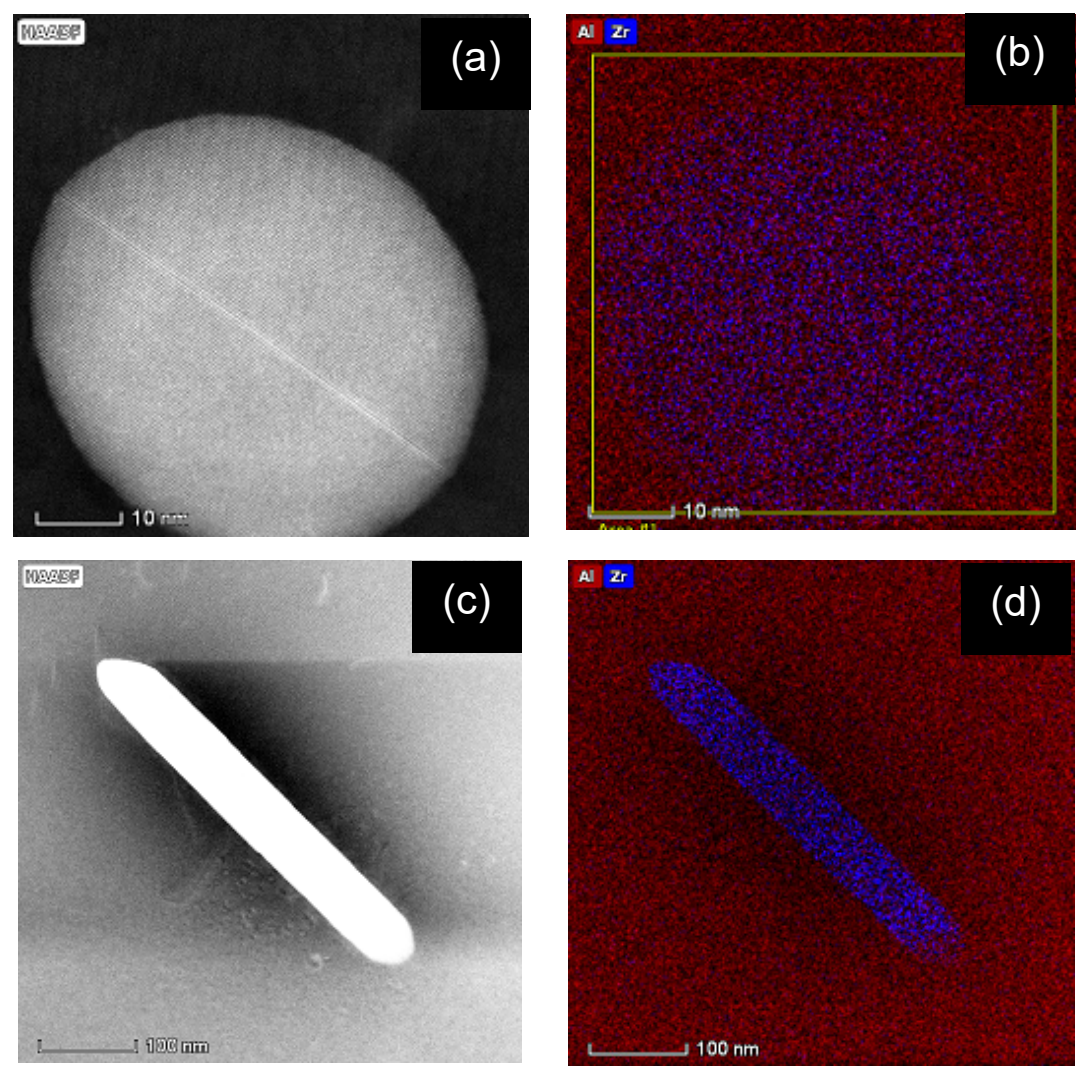

Figure 39. HAADF STEM mapping of $\mathrm{Al}$ and $\mathrm{Zr}$ in $0.2 \mathrm{Zr}$ after overaging at $600{ }^{\circ} \mathrm{C}$. The interdendritic particles have significantly coarsened, (a \& c) HAADF of $\mathrm{L1}_{2}-\mathrm{Al}_{3} \mathrm{Zr}$ (spheroidal) and $\mathrm{D}_{23}-\mathrm{Al}_{3} \mathrm{Zr}$ (disk-like) precipitates. Planar faults are seen in the $\mathrm{L}_{2}$ precipitate before complete transformation into $\mathrm{D}_{23}$. Their corresponding mappings are also shown in (b and d) $\mathrm{Al}$ (red) is the matrix, while $\mathrm{Zr}$ (blue) is concentrated in the precipitate phase.

\subsubsection{Dissolution of $\mathrm{Zn}$ from precipitate phase at $600{ }^{\circ} \mathrm{C}$}

As the $3.5 \mathrm{Zn} 0.2 \mathrm{Zr}$ specimen overaged at $600{ }^{\circ} \mathrm{C}$, its particles increased in size (Figure 40(a)), as $\mathrm{Zn}$ gradually dissolved from the $\mathrm{Al}_{(3-\mathrm{x})} \mathrm{Zn}_{\mathrm{x}} \mathrm{Zr}$ precipitates back into the matrix phase. This explains why the $\mathrm{Al}_{(3-\mathrm{x})} \mathrm{Zn}_{\mathrm{x}} \mathrm{Zr}$ precipitate phase had a higher $\mathrm{Zn}$ composition of 8.0 wt. $\%$ at $450{ }^{\circ} \mathrm{C}$ than 5.5 wt. $\%$ at $600{ }^{\circ} \mathrm{C}$. The dissolved $\mathrm{Zn}$ formed several solid solution clusters within the matrix, as shown in Figure 40 (b) and (c). These $\mathrm{Zn}$ cluster features were not found in $3.5 \mathrm{Zn} 0.2 \mathrm{Zr}$ at $450{ }^{\circ} \mathrm{C}$. They appear on the micrograph as small pseudo- 
particles $\langle R\rangle<3 \mathrm{~nm}$, with no particular morphologic form (HAADF: white contrast in Figure 40 (c)). However, SAED collected from this region along the [110] zone did not reveal superlattice spots that could be associated with any precipitate ordered lattice structure (Figure 40(b)). Only fcc plane spots were present.

EDX data summarized in Table 8 shows that these particle-like features only contained Al and $\mathrm{Zn}$, with no $\mathrm{Zr}$ present. Based on the diffraction pattern and the inability of $\mathrm{Al}$ and $\mathrm{Zn}$ to form an intermetallic compound[13] (Al-Zn binary phase diagram), the particle-like features were determined to be solid solution clusters of $\mathrm{Zn}$ within the $\alpha$-Al matrix and not actual precipitates. EDX chemical composition analysis performed on the $\mathrm{Zn}$ clusters identified as $\mathrm{A}, \mathrm{B}$ and $\mathrm{C}$ in the figure revealed that the composition of $\mathrm{Zn}$ in the clusters are inconsistent; as A, B and $\mathrm{C}$ have $65.4,35.5$ and 72.3 at\% $\mathrm{Zn}$, respectively. The $\mathrm{Zn}: \mathrm{Al}$ wt. \% ratio is the highest in the $\mathrm{Zn}$ cluster feature $(0.6-2.6)$ compared to the $\alpha$-Al matrix and precipitate phase $(0.13)$ at $600^{\circ} \mathrm{C}$.
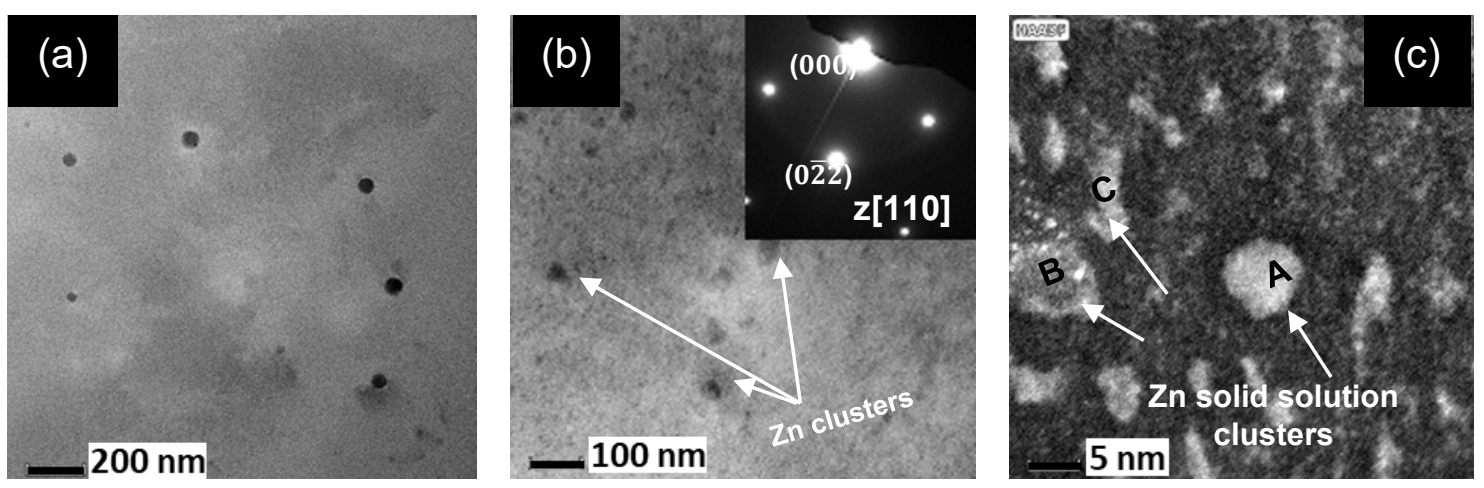

Figure 40. Overaged $\mathrm{Al}_{(3-x)} \mathrm{Zn}_{\mathrm{x}} \mathrm{Zr}$ precipitates and $\mathrm{Zn}$ clusters formed in $3.5 \mathrm{Zn} 0.2 \mathrm{Zr}$ at 600 ${ }^{\circ} \mathrm{C}$. (a) $\mathrm{The} \mathrm{L1}_{2}-\mathrm{Al}_{(3-\mathrm{x})} \mathrm{Zn}_{\mathrm{x}} \mathrm{Zr}$ precipitates observed were coarsened with a mean particle radius of $\sim 30 \mathrm{~nm}$ (b) Particle-like Zn clusters formed within the matrix, (c) HAADF image of $\mathrm{Zn}$ clusters (white contrast) with no specific form, distributed across the matrix. Cluster $\mathrm{A}, \mathrm{B}$ and $\mathrm{C}$ have varying $\mathrm{Zn}$ composition. 
Table 8. EDX of isochronally aged $0.2 \mathrm{Zn}$ and $3.5 \mathrm{Zn} 0.2 \mathrm{Zr}$ (wt.\%) at 450,500 and $600{ }^{\circ} \mathrm{C}$

\begin{tabular}{|c|c|c|c|c|c|c|c|c|}
\hline \multirow[t]{2}{*}{ Specimen name } & \multirow{2}{*}{$\begin{array}{c}\text { Aging } \\
\text { temperature }{ }^{\circ} \mathrm{C}\end{array}$} & \multicolumn{3}{|c|}{ Surrounding Matrix } & \multicolumn{3}{|c|}{ Precipitate } & $\mathrm{Zn}$ in \\
\hline & & $\mathrm{Al}$ & $\mathrm{Zn}$ & $\mathrm{Zr}$ & $\mathrm{Al}$ & $\mathrm{Zn}$ & $\mathrm{Zr}$ & $\mathrm{Zn}: \mathrm{Al}$ \\
\hline \multirow{3}{*}{$3.5 \mathrm{Zn} 0.2 \mathrm{Zr}$} & 450 & 96.5 & 3.5 & 0.0 & 41.5 & 8.0 & 50.5 & 0.20 \\
\hline & 500 & 96.6 & 3.5 & 0.0 & 42.2 & 7.0 & 50.8 & 0.17 \\
\hline & 600 & 96.6 & 3.4 & 0.0 & 43.2 & 5.5 & 51.3 & 0.13 \\
\hline \multirow{3}{*}{$0.2 \mathrm{Zr}$} & 450 & 100 & - & 0.0 & 47.0 & - & 53.0 & - \\
\hline & 500 & 100 & - & 0.0 & 47.0 & - & 53.0 & - \\
\hline & 600 & 100 & - & 0.0 & 47.0 & - & 53.0 & - \\
\hline Features in & Aging & \multicolumn{3}{|c|}{ Surrounding Matrix } & \multicolumn{3}{|c|}{ Zn cluster } & Fraction of \\
\hline & & $\mathrm{Al}$ & $\mathrm{Zn}$ & $\mathrm{Zr}$ & $\mathrm{Al}$ & $\mathrm{Zn}$ & $\mathrm{Zr}$ & $\mathrm{Zn}: \mathrm{Al}$ \\
\hline Zn cluster A & 600 & 96.4 & 3.6 & 0.0 & 34.6 & 65.4 & 0.0 & 1.9 \\
\hline Zn cluster B & 600 & 96.4 & 3.6 & 0.0 & 64.5 & 35.5 & 0.0 & 0.6 \\
\hline Zn cluster C & 600 & 95.7 & 4.3 & 0.0 & 27.7 & 72.3 & 0.0 & 2.6 \\
\hline
\end{tabular}

Additionally, ternary phase diagram was used to determine whether the dissolution of $\mathrm{Zn}$ observed in the $3.5 \mathrm{Zn} 0.2 \mathrm{Zr}$ at $600^{\circ} \mathrm{C}$ was due to formation of liquid phase from melting. From Figure 41 (top), it is clear that for $3.5 \mathrm{Zn} 0.2 \mathrm{Zr}$ alloy, no liquid phase from melting occurs at temperature $\leq 630^{\circ} \mathrm{C}$. According to the isothermal ternary phase diagram, at $630^{\circ} \mathrm{C}$, the first liquid phase starts forming at $\sim 8 \mathrm{wt} . \% \mathrm{Zn}$, if the amount of $\mathrm{Zr}$ is kept at 0.2 wt.\%. To melt $3.5 \mathrm{Zn} 0.2 \mathrm{Zr}$, the aging temperature has to be increased to $650{ }^{\circ} \mathrm{C}$, as shown in Figure 41 (bottom). Therefore, since the maximum temperature attained during the heat treatment experiment was $600^{\circ} \mathrm{C}, \mathrm{Zn}$ must have dissolved from the precipitates to form solid solution cluster at this temperature. 

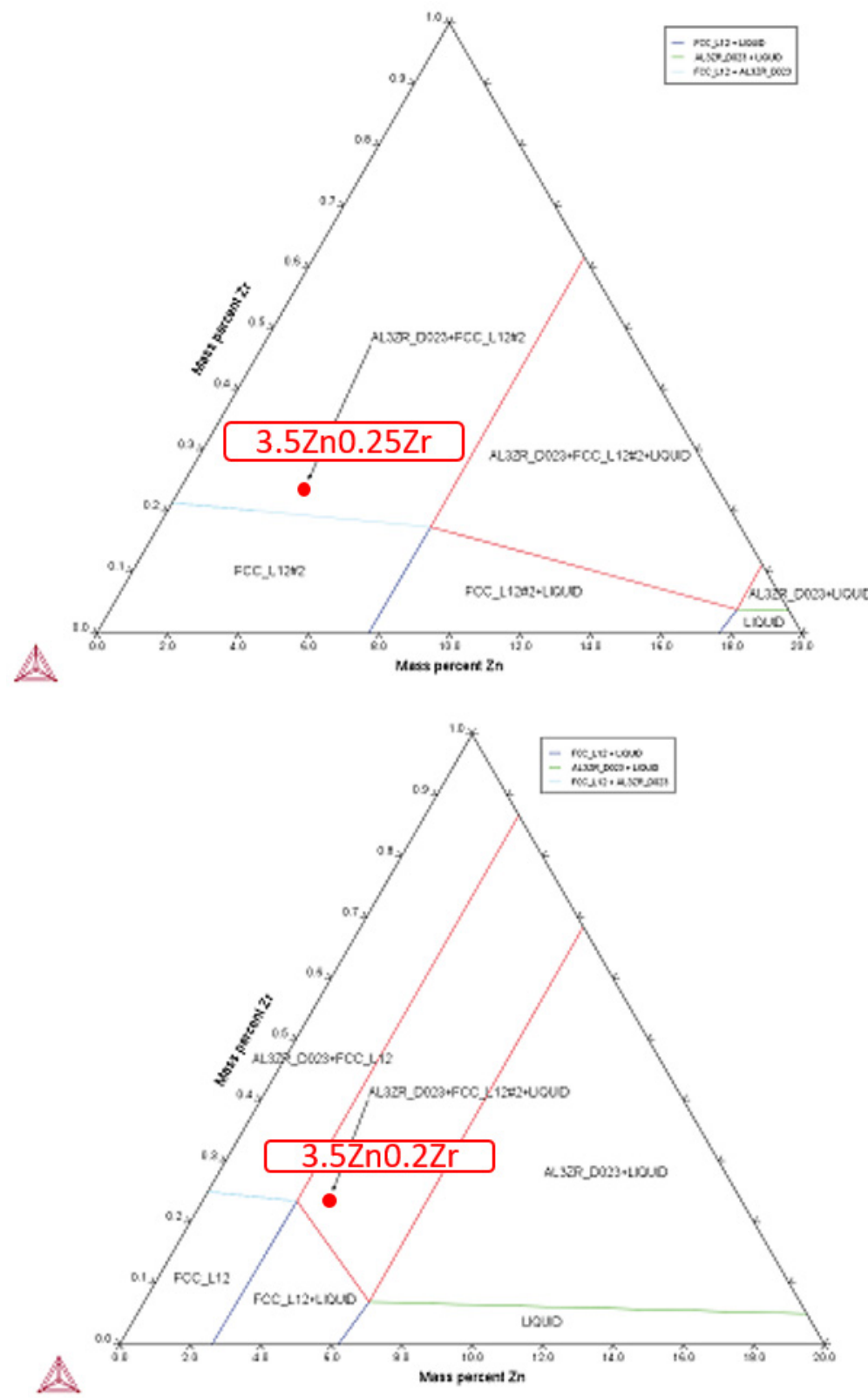

Figure 41. Isothermal ternary phase diagram of $\mathrm{Al}-\mathrm{Zn}-\mathrm{Zr}$ at $630^{\circ} \mathrm{C}$ (top) and $650^{\circ} \mathrm{C}$ (bottom), shows that liquid phase does not form for $3.6 \mathrm{Zn} 0.2 \mathrm{Zr}$ at temperatures $\leq 630^{\circ} \mathrm{C}$. At the same composition, liquid phase is present at $650^{\circ} \mathrm{C}$. 


\subsection{Discussion}

Based on the results presented above, this section discusses the effect of $\mathrm{Zn}$ on strengthening, $\mathrm{L}_{2}$ stability, precipitate growth, and electrical conductivity.

\subsubsection{Effect of $\mathrm{Zn}$ addition on strengthening}

The addition of $\mathrm{Zn}$ to Al-Zr alloy improved the microhardness by two main mechanisms: solid solution and precipitation strengthening. Of all elements, $\mathrm{Zn}$ has the highest solubility in $\mathrm{Al}$, showing a maximum of 67 at. $\%$ at $381{ }^{\circ} \mathrm{C}$ in binary $\mathrm{Al}-\mathrm{Zn}$ alloys[85]. Therefore, only a very small fraction of $\mathrm{Zn}$ goes into the precipitate phase during aging, while the remaining stays in solid solution[12, 13]. The role of $\mathrm{Zn}$ addition in improving the $\mathrm{Al}-\mathrm{Zr}$ strength was investigated by:

(1) Observing the microhardness difference between $0.2 \mathrm{Zr}$ and $3.5 \mathrm{Zn} 0.2 \mathrm{Zr}$ in as-cast and peak-aged conditions. Since the maximum increase in microhardness attainable from precipitation hardening is dependent on the root square of volume fraction, $\phi$, the similarity in microhardness values gained between as-cast and peak-aged $\left(\Delta M H=M H_{\text {peak-aged }}-M H_{\text {as-cast }}\right)$ conditions of $3.5 \mathrm{Zn} 0.2 \mathrm{Zr}(132 \mathrm{MPa})$ and $0.2 \mathrm{Zr}(140 \mathrm{MPa})$ alloys indicates that the addition of zinc to $\mathrm{Al}-\mathrm{Zr}$ did not significantly increase the volume fraction of the precipitates formed. This is also supported by the similar microhardness difference between $0.2 \mathrm{Zr}$ and $3.5 \mathrm{Zn} 0.2 \mathrm{Zr}$ at as-cast (64 MPa) and peak aged (56 MPa) conditions (Figure 31). Therefore, as long as the $\phi$ values of precipitates formed in both alloys are similar, the difference between the microhardness of $0.2 \mathrm{Zr}$ and $3.5 \mathrm{Zn} 0.2 \mathrm{Zr}$ at maximum strength was mostly due to solid solution strengthening from the $\mathrm{Zn}$ solute present in the $\alpha-\mathrm{Al}$ matrix.

(2) Estimating the precipitate mean size based on multiple TEM micrographs. The size of the precipitates influenced the magnitude of modulus mismatch, coherency, and Orowan strengthening. 
(3) Estimating how the effect of $\mathrm{Zn}$ on the parameters used in the various precipitation strengthening equations affected their magnitudes. This estimation was used to determine how the strengthening potential of $\mathrm{Al}_{3} \mathrm{Zr}$ differs from $\mathrm{Al}_{(3-\mathrm{x})} \mathrm{Zn}_{\mathrm{x}} \mathrm{Zr}$.

(4) Comparing $\mathrm{Zn}$ composition in precipitate and matrix phases, based on EDX chemical composition analysis. This confirmed the enrichment of $\mathrm{Zn}$ in the precipitate phase, leading to the formation of $\mathrm{Al}_{(3-\mathrm{x})} \mathrm{Zn}_{\mathrm{x}} \mathrm{Zr}$.

At various stages of aging temperatures $\leq 450{ }^{\circ} \mathrm{C}$, precipitation hardening is generally governed by dislocation shearing. The contributing factors to this mechanism are modulus mismatch, order, and coherency strengthening[12, 33]:

Modulus mismatch strengthening $\Delta \sigma_{m s}$, is as a result of the difference between the shear moduli of precipitates and matrix phases, and it is estimated by[57]:

$\Delta \sigma_{m s}=0.0055 M(\Delta G)^{3 / 2}\left(\frac{2 \phi}{G_{A l}}\right)^{1 / 2}\left(\frac{\langle R\rangle}{\mathrm{b}}\right)^{3 m / 2-1}$

where $\langle R\rangle$ is the average particle radius of the specimens, the Burgers vector magnitude of the Al matrix $[64,65] b=0.286 \mathrm{~nm}, \mathrm{~m}=0.85$. the Taylor factor[58] $M=3.06$, and $\Delta G$ is the difference in the shear modulus between the precipitate and matrix. The $\mathrm{L}_{2}$ shear moduli of $\mathrm{Al}_{3} \mathrm{Zr}, \mathrm{Al}_{(3-\mathrm{x})} \mathrm{Zn} \mathrm{n}_{\mathrm{x}} \mathrm{Zr}$, and the $\mathrm{Al}$ matrix are taken as $G_{\mathrm{Al} 3 \mathrm{Zr}}=G_{\mathrm{Al} 3-\mathrm{xZnxZr}} \cong$ 68.3 GPa[26, 62] and $G_{A l}=25.4 G P a$, respectively. First principle predictions by Zhenyi Wei et al. determined the shear modulus of $\mathrm{Al}_{2} \mathrm{ZnZr}$ (which has 25 at.\% $\mathrm{Zn}$ present in the precipitate phase) as $G_{\mathrm{Al2ZnZr}}=83.4 \mathrm{GPa}[63]$. However, they did not confirm this experimentally. Since, according to EDX data in Table 8, the fraction of $\mathrm{Zn}$ present in the $\mathrm{Al}_{(3-\mathrm{x})} \mathrm{Zn}_{\mathrm{x}} \mathrm{Zr}$ precipitate phase was $\sim 5.5$ at. $\%$ at $450^{\circ} \mathrm{C}$, the true shear modulus of $G_{\mathrm{Al} 3-x Z n x Z r}$ would be between the shear modulus of $\mathrm{Al}_{3} \mathrm{Zr}$ and $\mathrm{Al}_{2} \mathrm{ZnZr}, 68.3 \mathrm{GPa} \leq x \leq$ 83.4 GPa. Moreover, it would be expected to be much closer to $68.3 \mathrm{GPa}$. The volume fraction $\phi=0.003$ (estimated from the tie line of $\mathrm{Al}_{3} \mathrm{Zr}$ phase diagram) for both precipitate compositions, because it is expected that $\mathrm{Al}_{3} \mathrm{Zr}$ and $\mathrm{Al}_{(3-\mathrm{x})} \mathrm{Zn}_{\mathrm{x}} \mathrm{Zr}$ have similar volume fractions based on the microhardness and electrical conductivity results. 
Order strengthening, $\Delta \sigma_{o s}$, is due to the formation of APB as dislocations cut through ordered particles. It is maximum when the particles are completely sheared, yielding peak microhardness, and it is given by[57, 74$]$ :

$\Delta \sigma_{o S}=0.81 M \frac{\gamma_{A P B}}{2 b}\left(\frac{3 \pi \phi}{8}\right)^{1 / 2}$

where $\gamma_{A P B} \sim 0.445 \mathrm{Jm}^{-2}$ is taken as the average APB energy for $\mathrm{Al}_{(3-\mathrm{x})} \mathrm{Zn}_{\mathrm{x}} \mathrm{Zr}$ alloys based on several reported values for the (111) plane of $\mathrm{Al}_{3} \mathrm{Zr}[67,68]$.

Coherency strengthening, $\Delta \sigma_{c s}$, is estimated by using $[57,74]$ :

$\Delta \sigma_{c s}=M \chi\left(\epsilon G_{A l}\right)^{3 / 2}\left(\frac{\langle R\rangle \phi b}{\Gamma}\right)^{1 / 2}$

where $\chi=2.6$ for fcc metals, $\epsilon$ is the mismatch parameter approximated by $\frac{2}{3} \delta$; $\delta$ is the lattice mismatch and $\Gamma=\frac{1}{2} G_{A l} b^{2}$ is the line tension of dislocations in Al.

At temperatures $>450^{\circ} \mathrm{C}$, the particles begin to overage as the strengthening is governed by Orowan strengthening, $\Delta \sigma_{o r}$, which is given by[57, 74]:

$\Delta \sigma_{o r}=M \frac{0.4 G_{A l} b}{\pi \sqrt{ }(1-\nu)} \frac{\ln \left(\frac{2 R}{b}\right)}{\lambda_{e-e}}$

where the mean planar radius[86] $\mathrm{R}=\frac{\pi}{4}\langle R\rangle, v=0.354$ is the Poisson's ratio for $\mathrm{Al}[58]$, and the inter-precipitate distance[86] is $\lambda_{e-e}=\left(\sqrt{\frac{2 \pi}{3 \phi}}-\frac{\pi}{2}\right)\langle R\rangle$.

From all the parameters required in the strengthening equations listed above, only the $\Delta G$, $\epsilon$, and $\langle R\rangle$ terms are significantly affected by the conversion of the precipitate phase from $\mathrm{Al}_{3} \mathrm{Zr}$ to $\mathrm{Al}_{(3-\mathrm{x})} \mathrm{Zn}_{\mathrm{x}} \mathrm{Zr}$. The following parameters: $M, G_{A l}, b, m, \pi, \Gamma, v$ and $\chi$ are constants, while $\lambda_{e-e}$ (depends on volume fraction), $\gamma$, and $\phi$ remain approximately similar for both precipitate phases. Below is a description of how increasing $\Delta G, \epsilon$, and $\langle R\rangle$ independently influenced the precipitation strengthening derived from $\mathrm{Al}_{(3-\mathrm{x})} \mathrm{Zn}_{\mathrm{x}} \mathrm{Zr}$ relative to $\mathrm{Al}_{3} \mathrm{Zr}$.

(a) $\Delta G$ : Since $\mathrm{Al}_{(3-\mathrm{x})} \mathrm{Zn}_{\mathrm{x}} \mathrm{Zr}$ precipitates have about $\sim 5.5$ at. $\%$, the shear modulus $G_{\mathrm{Al} 3-\mathrm{xZnxZr}}$ could be assumed to be relatively low, $68.3 \mathrm{GPa}$, which is the value for $G_{\mathrm{Al} 3 \mathrm{Zr}}$ rather than the higher value of $G_{\mathrm{Al} 2 \mathrm{ZnZr}}=83.4 \mathrm{GPa}$, corresponding to 
25 at. $\% \mathrm{Zn}$. Therefore, only a slight increase in the corresponding $\Delta \sigma_{m s}$ is expected as a result of the change in precipitate phase from $\mathrm{Al}_{3} \mathrm{Zr}_{\mathrm{r}}$ to $\mathrm{Al}_{(3-\mathrm{x})} \mathrm{Zn}_{\mathrm{x}}$.

(b) $\epsilon$ : Given that the lattice parameters of $\alpha-\mathrm{Al}$ and $\mathrm{L}_{2}-\mathrm{Al}_{3} \mathrm{Zr}$ are $a=0.40496$ and $a_{p}=0.408 \mathrm{~nm}$ respectively at room temperature, the lattice mismatch of coherent $\mathrm{L}_{2}-\mathrm{Al}_{3} \mathrm{Zr}$ with $\alpha-\mathrm{Al}$ is $\delta=+0.75 \%[31,68]$. There are no consistent experimental or theoretical data for $a_{p}$ of $\mathrm{Al}_{(3-\mathrm{x})} \mathrm{Zn}_{\mathrm{x}} \mathrm{Zr}$ intermetallic compounds. Zhenyi Wei et al. reported the lattice parameter of $\mathrm{L}_{2}-\mathrm{Al}_{2} \mathrm{ZnZr}$ as $0.4099 \mathrm{~nm}[63]$ at $0 \mathrm{~K}$ from the quasi-harmonic approximation method, but did not provide the value for $\mathrm{L}_{2}-\mathrm{Al}_{3} \mathrm{Zr}$. Comparison of their reported value to that of Knipling or Lefebvre for $\mathrm{L}_{2}-\mathrm{Al}_{3} \mathrm{Zr}$ $(a=0.408 \mathrm{~nm})[31,68]$ reveals that the addition of $\mathrm{Zn}$ to the precipitate phase increased the precipitate/matrix lattice mismatch from $+0.75 \%$ for $\mathrm{Al}_{3} \mathrm{Zr}$ to $+1.22 \%$ for $\mathrm{Al}_{2} \mathrm{ZnZr}$. Therefore, using the same logic, the $a_{p}$ of $\mathrm{Al}_{(3-\mathrm{x})} \mathrm{Zn}_{\mathrm{x}} \mathrm{Zr}$ is $0.408<a_{p}<0.4099 \mathrm{~nm}$, depending on the atomic fraction of $\mathrm{Zn}$ present in the precipitate phase (where $x \ll 1$ ). This suggests that adding $\mathrm{Zn}$ slightly increased the lattice mismatch of $\mathrm{Al}_{(3-\mathrm{x})} \mathrm{Zn}_{\mathrm{x}} \mathrm{Zr} / \alpha-\mathrm{Al}$ to $+0.75<\delta<+1.22$. Hence, the $\mathrm{Al}_{(3-}$ ${ }_{\mathrm{x})} \mathrm{Zn}_{\mathrm{x}} \mathrm{Zr}$ precipitate phase yielded a higher $\epsilon$ and corresponding coherency strengthening than $\mathrm{Al}_{3} \mathrm{Zr}$.

(c) $\langle R\rangle$ : According to Table 7, the precipitate mean radius of $\mathrm{Al}_{(3-\mathrm{x})} \mathrm{Zn}_{\mathrm{x}} \mathrm{Zr}$ is slightly higher than that of $\mathrm{Al}_{3} \mathrm{Zr}$, which certainly enhanced $\Delta \sigma_{m s}, \Delta \sigma_{c s}$, and $\Delta \sigma_{o r}$.

In summary, the very small fraction of $\mathrm{Zn}$ present in the precipitate phase increased $\Delta G, \epsilon$, $\langle R\rangle$, and the corresponding $\Delta \sigma_{m s}, \Delta \sigma_{c s}$, and $\Delta \sigma_{o r}$ strengthening mechanisms. However, based on the heat treatment curve in Figure 31, the additional precipitation strengthening gained from $\mathrm{Al}_{(3-\mathrm{x})} \mathrm{Zn}_{\mathrm{x}} \mathrm{Zr}$ relative to the $\mathrm{Al}_{3} \mathrm{Zr}$ must be minimal. $\mathrm{Zn}$ solute remaining in solid solution was responsible for the majority of the microhardness difference between both specimens, through solid solution strengthening. With this understanding, the microhardness behavior of $3.5 \mathrm{Zn} 0.2 \mathrm{Zr}$ relative to $0.2 \mathrm{Zr}$, Figure 31 , due to $\mathrm{Zn}$ addition was qualitatively interpreted in three (3) stages: Pre-peak, overage, and dissolution, Table 9. At the pre-peak stage (between as-cast and peak age conditions), both alloys maintained a uniform microhardness difference. Their microhardness values followed parallel paths 
from as-cast to $450^{\circ} \mathrm{C}$. This indicates that most of the microhardness difference came from solid solution strengthening, as a result of adding $\mathrm{Zn}$. As the precipitates grew in $3.5 \mathrm{Zn} 0.2 \mathrm{Zr}$, very few $\mathrm{Zn}$ atoms migrated into the precipitate phase as indicated in Table 8 . Naturally, the solid solution strengthening from the remaining $\mathrm{Zn}$ solute in solution slightly reduced. This lost strength was compensated for by the slightly increased precipitation strengthening from the $\mathrm{Al}_{(3-\mathrm{x})} \mathrm{Zn}_{\mathrm{x}} \mathrm{Zr}$ precipitates relative to $\mathrm{Al}_{3} \mathrm{Zr}$. Thereby maintaining a fairly constant microhardness difference between $3.5 \mathrm{Zn} 0.2 \mathrm{Zr}$ and $0.2 \mathrm{Zr}$ from as-cast to peak age temperatures.

During the overage stage, some of the $\mathrm{Zn}$ dissolved from the precipitate phase back into the matrix as a result of increasing diffusivity and solid solubility of $\mathrm{Zn}$ in Al. This is confirmed by the lower $\mathrm{Zn}$ concentration in the precipitate phase at 500 and $600^{\circ} \mathrm{C}$ relative to $450^{\circ} \mathrm{C}$ (Table 8 ). The gradual dissolution of $\mathrm{Zn}$ from the precipitate phase directly led to a reduced $\epsilon, \Delta G$, and corresponding precipitation strengthening from the $\mathrm{Al}_{(3-\mathrm{x})} \mathrm{Zn}_{\mathrm{x}} \mathrm{Zr}$ precipitate relative to $\mathrm{Al}_{3} \mathrm{Zr}$. Therefore, the microhardness of $3.5 \mathrm{Zn} 0.2 \mathrm{Zr}$ converged towards $0.2 Z$ r. This could explain why a steeper microhardness drop was observed for $3.5 \mathrm{Zn} 0.2 \mathrm{Zr}$ immediately after the peak age condition. Hence, in addition to the gradual $\mathrm{Zn}$ dissolution, the higher coarsening rate of precipitates formed in $3.5 \mathrm{Zn} 0.2 \mathrm{Zr}$ relative to $0.2 \mathrm{Zr}$ could be simultaneously responsible for the faster strength reduction observed during the early overaging convergence stage.

At the later stage of heat treatment (significant dissolution), the precipitates had experienced pronounced coarsening. At this stage, the magnitude of microhardness derived from precipitation is expected to be insignificant, as most of the microhardness of the alloys depended on solid solution, similar to the as-cast condition. Therefore, the microhardness difference between $3.5 \mathrm{Zn} 0.2 \mathrm{Zr}$ and $0.2 \mathrm{Zr}$ was gradually restored due to solid solution strengthening from the $\mathrm{Zn}$ already dissolved into the matrix. These stages are summarized in Table 9. 
Table 9. Qualitative interpretation of the influence of $\mathrm{Zn}$ addition on the isochronal aging behavior of $3.5 \mathrm{Zn} 0.2 \mathrm{Zr}$ with respect to $0.2 \mathrm{Zr}$.

\begin{tabular}{|c|c|c|c|c|c|c|}
\hline $\begin{array}{l}\text { Aging } \\
\text { stage }\end{array}$ & $\begin{array}{c}\text { Zn in } \\
\text { solid } \\
\text { solution }\end{array}$ & $\begin{array}{c}\text { Solid } \\
\text { solution } \\
\text { strength }\end{array}$ & $\epsilon$ and $\Delta G$ & $\begin{array}{l}\text { Precipitation } \\
\text { strength }\end{array}$ & $\begin{array}{l}\text { Dominant } \\
\text { mechanism }\end{array}$ & $\begin{array}{c}\text { Behavior } \\
\text { relative to } \\
\mathrm{Al}_{3} \mathrm{Zr}\end{array}$ \\
\hline Pre-peak & $\downarrow$ & $\downarrow$ & $\uparrow$ & $\uparrow$ & Solid solution & Uniform \\
\hline $\begin{array}{c}\text { Early } \\
\text { overage }\end{array}$ & $\uparrow$ & $\uparrow$ & $\downarrow$ & $\downarrow$ & Precipitation & Converge \\
\hline Dissolution & $\uparrow$ & $\uparrow$ & $\downarrow$ & $\downarrow$ (Insignificant) & Solid solution & Diverge \\
\hline
\end{tabular}

$\uparrow:$ Increasing trend of composition or magnitude; $\downarrow$ : Decreasing trend of composition or magnitude

Theoretically, it can be confirmed that majority of the microhardness gained from $\mathrm{Zn}$ addition to Al-Zr alloy comes from solid solution strengthening. Using equations (1-4), we estimated the microhardness of $3.5 \mathrm{Zn} 0.2 \mathrm{Zr}$ derived from solid solution strengthening, as a result of adding $3.5 \mathrm{wt} . \% \mathrm{Zn}$ to $\mathrm{Al}-\mathrm{Zr}$ alloy as $71.4 \mathrm{MPa}$. This is slightly higher than the observed microhardness difference between as-cast $0.2 \mathrm{Zr}$ and $3.5 \mathrm{Zn} 0.2 \mathrm{Zr}, 64 \mathrm{MPa}$. The values used in this estimation are, $G_{A l \text { matrix }}=25.4 \mathrm{GPa}, G_{Z n \text { solute }}=39.5 \mathrm{GPa}$,

$c_{Z n \text { solute }}=1.5$ at. $\%, a_{A l \text { matrix }}=0.572 \mathrm{~nm}$ and $a_{Z n \text { solute }}=0.495 \mathrm{~nm}$. Because, both atoms have similar closed packed structures, the (111) and z-axis lattice constant of Al and $\mathrm{Zn}$ were used, respectively. It is however important to note that the estimate could vary over a large range based on minor changes in the values of the parameters used, especially

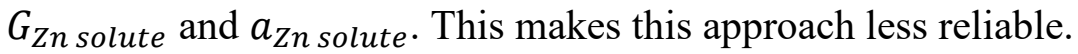

\subsubsection{Stability of $\mathrm{L1}_{2}$ precipitates with $\mathrm{Zn}$ addition}

As expected, equilibrium $\mathrm{D}_{23}$ precipitates were not observed in the specimens after isochronal aging at $450{ }^{\circ} \mathrm{C}$ (Figure 35). Such transitions usually take place at higher temperatures[30, 31]. However, other factors, including aging time and dislocation density present in the specimen, could also impact the temperature of transformation and kinetics. Zedalis and Fine[87] observed the $\mathrm{L1}_{2} \rightarrow \mathrm{D}_{23}$ transformation in $95 \% \mathrm{CW}$ Al- $0.24 \mathrm{Zr}$ (at. $\%$ ) after aging at $450{ }^{\circ} \mathrm{C}$. The relatively lower transformation temperature at which they 
observed this transformation was due to the high dislocation density from initial cold rolling, which served as heterogeneous sites for such transformation to take place more easily.

At $600{ }^{\circ} \mathrm{C}$, significant precipitate coarsening and overaging occurred in $0.2 \mathrm{Zr}$ and $3.5 \mathrm{Zn} 0.2 \mathrm{Zr}$ specimens as represented by the Vickers microhardness results shown in Figure 31. The specimens were examined under the SEM and TEM microscope to study the influence of $\mathrm{Zn}$ on stabilizing the $\mathrm{L} 1_{2}$ precipitate structure at higher aging temperatures. At this temperature, the $\mathrm{L}_{2} \rightarrow \mathrm{D} 0_{23}$ transformation observed in overaged $0.2 \mathrm{Zr}$ was extensive along the dendritic border, interdendritic channels, and on dislocation sites, as shown in Figure 36(e) and Figure 37(a). However, many precipitates maintained their $\mathrm{L}_{2}$ structure, especially in the dendritic center (Figure 36(e)). A similar transformation was observed for $\mathrm{Al}_{(3-\mathrm{x})} \mathrm{Zn} \mathrm{x} \mathrm{Zr}$ in the $3.5 \mathrm{Zn} 0.2 \mathrm{Zr}$ alloy after undergoing the same aging procedure, Figure 36(c) and Figure 37(b). This confirms that the presence of $\mathrm{Zn}$ in the precipitate phase did not prevent the eventual transformation from occurring.

The specimens were examined after an intermediate overaging temperature $\left(500^{\circ} \mathrm{C}\right)$ to determine if $\mathrm{Zn}$ addition has any influence on delaying the isochronal aging temperature of the $\mathrm{L}_{2} \rightarrow \mathrm{D} 0_{23}$ transition. Few disk-like $\mathrm{D}_{23}$ precipitates were spotted in both specimens after thorough examination. Therefore, $\mathrm{Zn}$ did not delay the precipitate phase transformation. The only minor claim that can be made is that the presence of $\mathrm{Zn}$ in the precipitate phase reduced the number of visible disk-like $\mathrm{D} 0_{23}$ precipitates present after aging at $500^{\circ} \mathrm{C}$. This was evident because after examining three $0.2 \mathrm{Zr}$ specimens, the average number of $\mathrm{D}_{23}-\mathrm{Al}_{3} \mathrm{Zr}$ precipitates found was 13 , which is about 3 times as much as the four (4) $\mathrm{D} 0_{23}-\mathrm{Al}_{(3-\mathrm{x})} \mathrm{Zn} \times \mathrm{Zr}$ found in $3.5 \mathrm{Zn} 0.2 \mathrm{Zr}$ specimens. 

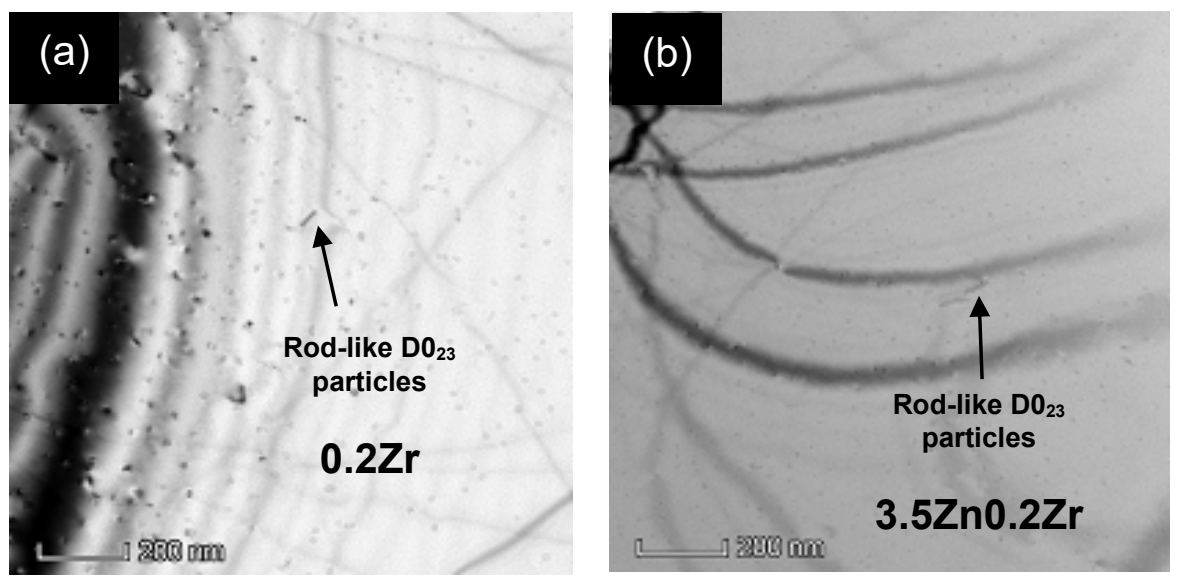

Figure 42 . TEM showing some of the few spotted $\mathrm{D}_{23}$ precipitates embedded in the midst of several $\mathrm{L}_{2}$ phases, after isochronal aging at $500^{\circ} \mathrm{C}$, (a) $0.2 \mathrm{Zr}$ and (b) $3.5 \mathrm{Zn} 0.2 \mathrm{Zr}$.

\subsubsection{Effect of $\mathrm{Zn}$ on nucleation, growth, coarsening}

In both specimens, the first sign of nucleation occurred after isochronal aging at $350^{\circ} \mathrm{C}$. This implies that the inclusion of $\mathrm{Zn}$ did not have any influence on the incubation time required for nucleation under this aging condition. This is probably because $\mathrm{Zr}$ solute first precipitated out of solid solution before $\mathrm{Zn}$, due to its much lower solid solubility in Al. Hence, $\mathrm{Zr}$ served as heterogeneous sites for nucleation to occur. Similar to $0.2 \mathrm{Zr}$, the $3.5 \mathrm{Zn} 0.2 \mathrm{Zr}$ alloy reached peak microhardness at $\sim 450^{\circ} \mathrm{C}$, after undergoing the same isochronal aging procedure. Therefore, the addition of $\mathrm{Zn}$ into the precipitate phase did not cause any significant shift in the peak microhardness temperature.

The particle growth occurred by long-range solute atomic diffusion through the matrix phase across the phase boundary and into the nucleus. The diffusivities of $\mathrm{Zn}$ and $\mathrm{Zr}$ in $\mathrm{Al}$ are estimated by an Arhenius relationship, $D=D_{o} \exp \left(-Q / R_{g} T\right)$, where $Q=121$ and $242 \mathrm{~kJ} \mathrm{~mol}^{-1}$ and $D_{o}=2.59 \times 10^{-5}$ and $7.28 \times 10^{-2} \mathrm{~m}^{2} \mathrm{~s}^{-1}$ for $\mathrm{Zn}$ and $\mathrm{Zr}$, respectively[12, 29, 46, 47]. At $450^{\circ} \mathrm{C}$, where peak microhardness occurred for both alloys, the diffusivities of $\mathrm{Zn}$ and $\mathrm{Zr}$ in $\alpha-\mathrm{Al}$ are $4.69 \times 10^{-11}$ and $2.38 \times 10^{-19} \mathrm{~m}^{2} / \mathrm{s}$, respectively. Clearly, since $\mathrm{Zn}$ has a higher diffusivity in $\alpha-\mathrm{Al}$ than $\mathrm{Zr}$, it would be expected that precipitates in $3.5 \mathrm{Zn} 0.2 \mathrm{Zr}$ would grow and coarsen at a much faster rate than $0.2 \mathrm{Zr}$. From observation, the average precipitate size of $\mathrm{Al}_{(3-\mathrm{x})} \mathrm{Zn}_{\mathrm{x}} \mathrm{Zr}$ was slightly bigger than 
$\mathrm{Al}_{3} \mathrm{Zr}$ at the various aging temperature levels examined. At $450^{\circ} \mathrm{C}$, the mean size $\langle R\rangle$ of $\mathrm{Al}_{(3-\mathrm{x})} \mathrm{Zn} \times \mathrm{Zr}$ precipitates located in the interdendritic channel and dendritic centers were $2.45 \mathrm{~nm}$ and $6.5 \mathrm{~nm}$, while those of $\mathrm{Al}_{3} \mathrm{Zr}$ were approximately $2.2 \mathrm{~nm}$ and $5.5 \mathrm{~nm}$, respectively. The $\mathrm{Al}_{(3-\mathrm{x})} \mathrm{Zn}_{\mathrm{x}} \mathrm{Zr}$ precipitates present in the interdendritic channels have a mean size of $10.0 \mathrm{~nm}$ and $30.0 \mathrm{~nm}$ at $500^{\circ} \mathrm{C}$ and $600^{\circ} \mathrm{C}$, respectively, while $\mathrm{Al}_{3} \mathrm{Zr}$ increased to $8.5 \mathrm{~nm}$ and $23.0 \mathrm{~nm}$, respectively. These precipitate sizes show that the inclusion of $\mathrm{Zn}$ in the $\mathrm{Al}_{3} \mathrm{Zr}$ precipitate phase slightly increased the precipitate growth and coarsening rate.

\subsubsection{Electrical conductivity}

The solute atoms ( $\mathrm{Zr}$ and/or $\mathrm{Zn}$ ) within the matrix distort the lattice parameter of $\alpha$ - $\mathrm{Al}$ and serve as local electron scattering lattice sites[51]. The source of distortion is the difference between the atomic radii of $\mathrm{Al}$ and the solute species ( $\mathrm{Zn}$ and $\mathrm{Zr}$ ). Lattice distortion hinders the motion of electrons carrying current when an electric field is passed through the specimen. Due to its high solid solubility in Al, only a small at. \% of Zn (together with majority of $\mathrm{Zr}$ atoms) precipitated out of solid solution during aging. The remaining $\mathrm{Zn}$ in solid solution is responsible for the electrical conductivity difference $(+4.6 \mathrm{MS} / \mathrm{m})$ between $0.2 \mathrm{Zr}$ and $3.5 \mathrm{Zn} 0.2 \mathrm{Zr}$. At the peak-aged condition, the contribution of the remaining $\mathrm{Zn}$ solute to the lattice distortion and number of local electron scattering sites within the matrix is slightly reduced (but still significant), since only a few $\mathrm{Zn}$ atoms migrated into the precipitate phase.

At temperatures $\geq 500^{\circ} \mathrm{C}$, the steady decrease of electrical conductivity was due to overaging and the subsequent dissolution of the precipitate phase back into the matrix. The electrical conductivities gained as a result of precipitation hardening are similar; +1.9 $\mathrm{MS} / \mathrm{m}$ for $0.2 \mathrm{Zr}$ and $+1.7 \mathrm{MS} / \mathrm{m}$ for $3.5 \mathrm{Zn} 0.2 \mathrm{Zr}$. This suggests that similar volume fractions of precipitates were formed in both alloys. In summary, the addition of $\mathrm{Zn}$ to $\mathrm{Al}-\mathrm{Zr}$ did not increase the precipitate volume fraction. The uniform conductivity difference between $0.2 \mathrm{Zr}$ and $3.5 \mathrm{Zn} 0.2 \mathrm{Zr}$ at as-cast and peak-aged states also supports this suggestion. 


\subsection{Summary and conclusions}

This study focused on the effect of $\mathrm{Zn}$ on electrical conductivity, mechanical properties, and potential $\mathrm{L}_{2}$ phase stability of $\mathrm{Al}-\mathrm{Zr}$ alloy by comparing precipitation of $\mathrm{Al}_{3} \mathrm{Zr}$ in $0.2 \mathrm{Zr}$ to $\mathrm{Al}_{(3-\mathrm{x})} \mathrm{Zn} \mathrm{n}_{\mathrm{x}} \mathrm{Zr}$ in $3.5 \mathrm{Zn} 0.2 \mathrm{Zr}$ after isochronal aging from $150-600{ }^{\circ} \mathrm{C}$.

The addition of $3.5 \mathrm{wt} \% \mathrm{of} \mathrm{Zn}$ to $\mathrm{Al}-\mathrm{Zr}$ has been shown to increase the peak microhardness of the alloy. However, the majority of the gained microhardness is due to solid solution strengthening from the remaining $\mathrm{Zn}$ in the matrix. The conversion of the precipitate phase from $\mathrm{Al}_{3} \mathrm{Zr}$ to $\mathrm{Al}_{(3-\mathrm{x})} \mathrm{Zn}_{\mathrm{x}} \mathrm{Zr}$ by $\mathrm{Zn}$ inclusion also increased the magnitude of the change in shear modulus, $\Delta G$, and mismatch parameter, $\epsilon$, between the precipitate and matrix, thus increasing the contribution of modulus mismatch and coherency strengthening to the peak strength of the alloy. The steep microhardness decline of $3.5 \mathrm{Zn} 0.2 \mathrm{Zr}$ relative to $0.2 \mathrm{Zr}$, observed during overaging (isochronal aging) was due to the combination of enhanced precipitate coarsening and dissolution of $\mathrm{Zn}$ from precipitate phase after long exposure to high temperature.

Results from electrical conductivity and microhardness measurements show that adding $\mathrm{Zn}$ to the Al-Zr alloy had no significant impact on the volume fraction of the precipitates formed. This conclusion was made because both alloys displayed similar increases in electrical conductivity (mean value $\sim+1.8 \mathrm{MS} / \mathrm{m}$ ) and microhardness (mean value $\sim+138$ $\mathrm{MPa}$ ) from as-cast to peak-aged conditions.

The tensile strengths of "AA+CW" and " $\mathrm{CW}$ " specimens come from dislocationprecipitate and dislocation-solute interactions, because coherent precipitates and solutes generate strain fields that obstruct the movement of dislocations. The strength difference between $0.2 \mathrm{Zr}$ and $3.5 \mathrm{Zn} 0.2 \mathrm{Zr}$ wire specimens in the " $\mathrm{CW}$ " condition was $26 \mathrm{MPa}$. This difference was possibly due to dislocation- $\mathrm{Zn}$ solute interaction in $3.5 \mathrm{Zn} 0.2 \mathrm{Zr}$, which is non-existent in $0.2 \mathrm{Zr}$. In the case of "AA+CW", the tensile strength of $3.5 \mathrm{Zn} 0.2 \mathrm{Zr}$ was 41 $\mathrm{MPa}$ more than $0.2 \mathrm{Zr}$. Which is an additional $15 \mathrm{MPa}$ increase from the "CW" condition. This indicates that prior aging was slightly more effective in improving the strength of $3.5 \mathrm{Zn} 0.2 \mathrm{Zr}$ relative to $0.2 \mathrm{Zr}$. Since it is now established that the addition of $\mathrm{Zn}$ to $\mathrm{Al}-\mathrm{Zr}$ 
does not increase precipitate volume fraction, it could therefore be concluded that $\mathrm{Al}_{(3-}$ x) $\mathrm{Zn} \times \mathrm{Zr}$ generated an improved dislocation-precipitate interaction due to its increased precipitate/matrix lattice mismatch and coherency strengthening relative to $\mathrm{Al}_{3} \mathrm{Zr}$. After thermal aging at $600{ }^{\circ} \mathrm{C}$ for $5 \mathrm{~h}, 0.2 \mathrm{Zr}$ retained $95 \%$ of its as-wiredrawn strength, while $3.5 \mathrm{Zn} 0.2 \mathrm{Zr}$ retained $84 \%$. The strength of the specimens remained almost constant after thermal aging for $15 \mathrm{~h}$. Thus, the initial softening observed was due to dislocation annihilation.

The microstructures of $0.2 \mathrm{Zr}$ and $3.5 \mathrm{Zn} 0.2 \mathrm{Zr}$ specimens were characterized by microsegregation of the $\mathrm{Zr}$ solute species after solidification. This led to regions of varying number density of precipitates formed as well as precipitate size gradients across the specimen. This segregation caused the formation of dendritic core/interdendritic channels in the microstructure[30]. At $450^{\circ} \mathrm{C}$, the larger $\mathrm{L}_{2}$ precipitates were formed in the interdendritic channels while smaller ones were situated in the rich dendritic region. Previous studies of Al-Zr alloy have shown that some of the $\mathrm{L} 1_{2}$ precipitates transform to $\mathrm{D} 0_{23}$ during isochronal and isothermal aging at temperatures $>475^{\circ} \mathrm{C}$. This transformation was observed in $0.2 \mathrm{Zr}$ and $3.5 \mathrm{Zn} 0.2 \mathrm{Zr}$ at 500 and $600^{\circ} \mathrm{C}$. EDX data shows that the $\mathrm{Zn}$ composition in the $\mathrm{Al}_{(3-\mathrm{x})} \mathrm{Zn}_{\mathrm{x}} \mathrm{Zr}$ particles was higher at $450{ }^{\circ} \mathrm{C}$ relative to 500 and $600{ }^{\circ} \mathrm{C}$. This confirms the dissolution of $\mathrm{Zn}$ between these temperatures, which partly explains why a steeper microhardness reduction was observed in $3.5 \mathrm{Zn} 0.2 \mathrm{Zr}$ with respect to $0.2 \mathrm{Zr}$. 


\section{Chapter 6: Influence of $\mathrm{Zn}$ on ductility and creep rate of precipitation hardened $\mathrm{Al}$ alloys}

\subsection{Abstract and Introduction}

\subsubsection{Abstract}

Generally, the enhancement of alloy strength leads to reduced ductility. However, the addition of $\mathrm{Zn}$ to $\mathrm{Al}-\mathrm{Zr}$ is shown to have the potential to increase the ductility of the alloy before and after thermal aging experiments. This is determined from percent elongation (\%EL) data of $\mathrm{Al}-\mathrm{Zr}$ and $\mathrm{Al}-\mathrm{Zn}-\mathrm{Zr}$, when the alloy specimens are cold worked after aging $(\mathrm{AA}+\mathrm{CW})$ and as-cast $(\mathrm{CW})$. The cold worked alloys are annealed at $300^{\circ} \mathrm{C}$ for 5 and $15 \mathrm{~h}$.

Finally, \%EL results from the thermally aged alloys also show similar enhanced ductility due to $\mathrm{Zn}$ addition. However, $\mathrm{Zn}$ reduces the creep resistance of Al- $\mathrm{Zr}$ alloy.

\subsubsection{Introduction}

Aluminum alloys are most widely used for aircrafts and automobiles due to their low mass and density. Though, these alloys are known to have lower strength relative to steel, which limits their applications in the transportation industry. Due to low strength, mechanism such as precipitation and work hardening have been employed to make them stronger. $\mathrm{Zr}$ solute offers one of the highest strengthening potential in precipitation strengthened $\mathrm{Al}-\mathrm{Zr}$ relative to other transition metals.

The strength of the precipitation-strengthened alloy improves as solute concentration is increased, making the alloy more brittle. The enhanced strength is due to increased dislocation retardation from higher precipitate volume fraction. Hence, the process of increasing the strength of $\mathrm{Al}-\mathrm{Zr}$ results in reduced ductility. The reduced ductility of the precipitation-strengthened alloy make it less reliable for transportation and minor structural applications. Thus, the challenge is to develop an alloy with simultaneous improvement of strength and ductility. 
Several studies have shown that enhanced ductility of Al alloys can be achieved through $\mathrm{Zn}$ addition. $\mathrm{Hu}$ et al. reported that increasing the $\mathrm{Zn}$ content from $0-15$ wt.\%, can effectively enhance tensile elongation of the alloy from 10 to $30 \%$. This was due to increased rate of work hardening and the presence of several fine slip bands[88].

The objective of this study is to investigate the influence of $\mathrm{Zn}$ addition to $\mathrm{Al}-\mathrm{Zr}$ on the ductility and creep resistance.

\subsection{Experimental design for $\% \mathrm{EL}$}

The \%EL experiment was performed in conjunction with the tensile test experiment, using the Instron tensile test instrument and Futek maximum load capacity of 10,000 lbs, as detailed in sub-sections 3.4.3 and 5.2. In this study, ductility measurements were taken on the $\mathrm{CW}$ and $\mathrm{AA}+\mathrm{CW}$ alloy specimens simultaneously while performing tensile test. During the tensile tests experiment described in section 5.2, a $25.4 \mathrm{~mm}$ (1-inch) Epsilon extensometer with sharp knife-edge contact was clamped to the $38.1 \mathrm{~mm}$ gage length of each alloy tensile specimen (design B tensile bar). The diameter of the gage length region of the specimens is $3.8 \mathrm{~mm}$. The extensometer readings represent stain to failure. Using a uniform diameter tensile bar led to inconsistent ductility measurements, hence, the need to use design $\mathrm{B}$ tensile bar specimens.

Creep test was performed on $203 \mathrm{~mm}$ ( 8 inches) long, as-wiredrawn-AA+CW ( $0.2 \mathrm{Zr}$ and $3.5 \mathrm{Zn} 0.2 \mathrm{Zr}$ ) specimens, before and after thermal aging (at $300^{\circ} \mathrm{C}$ for $5 \mathrm{~h}$ ), using an Instron screw-driven tensile testing frame. For all creep experiments, a gage length, constant stress, constant temperature and duration of $101.6 \mathrm{~mm}$ (4 inches), $40 \mathrm{MPa}, 250^{\circ} \mathrm{C}$ and $2.5 \mathrm{~h}$ were used.

\subsection{Results and discussion}

Comparing the $\% \mathrm{EL}$ of $0.2 \mathrm{Zr}$ and $3.5 \mathrm{Zn} 0.2 \mathrm{Zr}$ specimens in $\mathrm{CW}$ to their corresponding $\mathrm{AA}+\mathrm{CW}$ condition (as-wiredrawn) indicates that heat treatment of the alloys before cold work makes them slightly less ductile, Figure 43(a). For instance, at as-wiredrawn condition, $0.2 \mathrm{Zr}$ and $3.5 \mathrm{Zn} 0.2 \mathrm{Zr}$ specimens have ductility of 4.7 and $6.3 \% \mathrm{EL}$ after $\mathrm{CW}$, respectively. After $\mathrm{AA}+\mathrm{CW}$, these values reduced to 3.5 and $5.5 \% \mathrm{EL}$ respectively. This 
result also indicates that the addition of $\mathrm{Zn}$ enhanced the ductility of $\mathrm{Al}-\mathrm{Zr}$ at as-wiredrawn condition. The addition of $3.5 \mathrm{wt} . \% \mathrm{Zn}$ enhanced the \%EL of $0.2 \mathrm{Zr}$ from 4.7 and $3.5 \% \mathrm{EL}$ to 6.3 and $5.5 \% \mathrm{EL}$ for $3.5 \mathrm{Zn} 0.2 \mathrm{Zr}$ at $\mathrm{CW}$ and $\mathrm{AA}+\mathrm{CW}$ respectively.
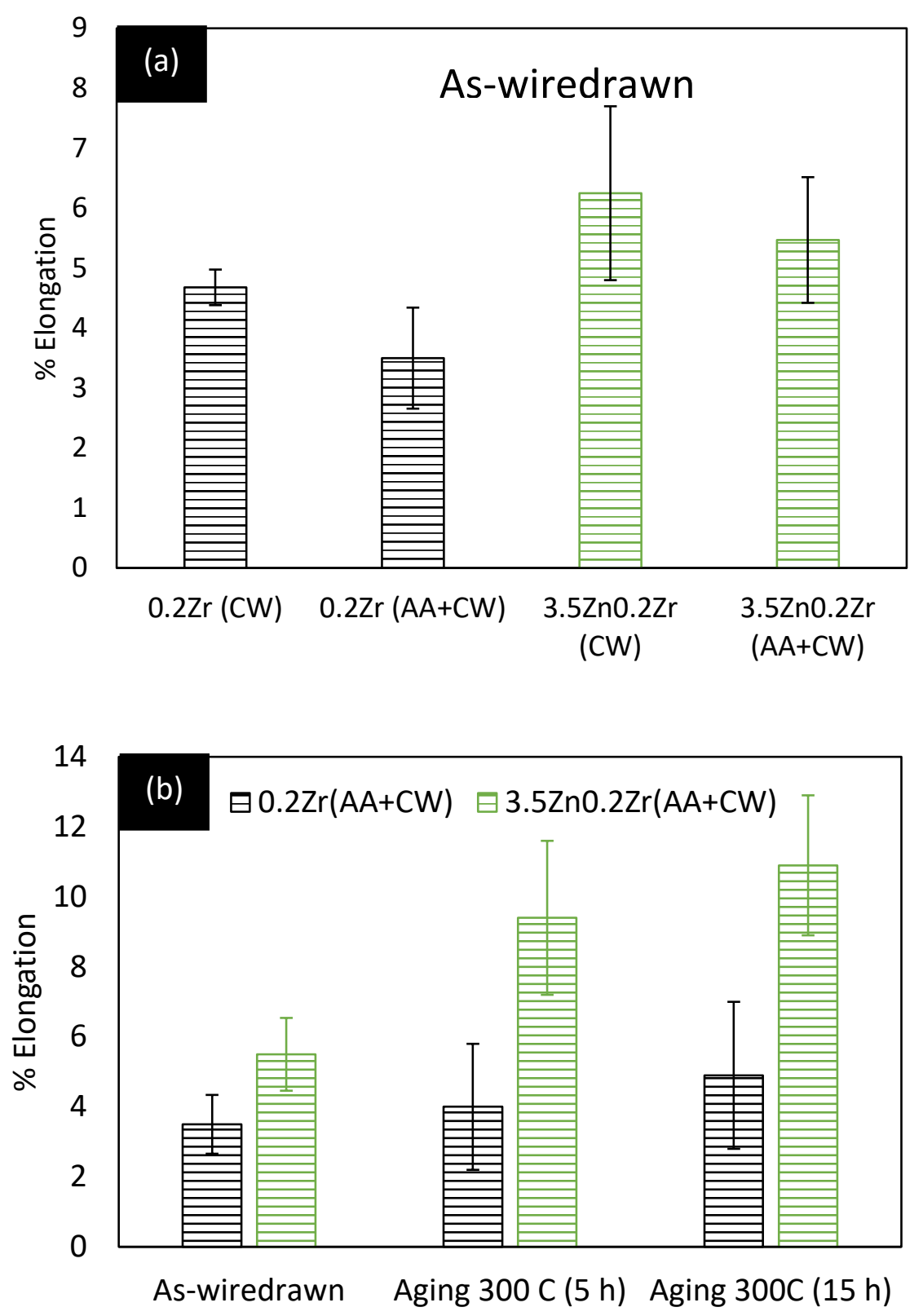

Figure 43. \% Elongation measurement of $0.2 \mathrm{Zr}$ and $3.5 \mathrm{Zn} 0.2 \mathrm{Zr}$ at $\mathrm{CW}$ and $\mathrm{AA}+\mathrm{CW}$ conditions, (a) as-wiredrawn (b) After thermal aging experiment at $300^{\circ} \mathrm{C}$ for 5 and $15 \mathrm{~h}$. 
According to Figure 43(b), annealing the AA $+\mathrm{CW}$ alloys during thermal aging, widens the difference in $\% \mathrm{EL}$ between $0.2 \mathrm{Zr}$ and $3.5 \mathrm{Zn} 0.2 \mathrm{Zr}$. The difference in strain to failure $(\% \mathrm{EL} / 100$ ), between both $\mathrm{AA}+\mathrm{CW}$ alloys increased from 0.02 (as-wiredrawn) to 0.054 and 0.06 after thermal aging for 5 and $15 \mathrm{~h}$, respectively.

Creep test was performed on $0.2 \mathrm{Zr}$ and $3.5 \mathrm{Zn} 0.2 \mathrm{Zr}$ before and after thermal aging, to determine the impact of adding $\mathrm{Zn}$ on the creep rate of Al-Zr alloy. According to the data in Table 10 and Figure 44, the inclusion of $3.5 \mathrm{wt} . \% \mathrm{Zn}$ to $0.2 \mathrm{Zr}$ increased the creep rate in as-wiredrawn condition, from $2.9 \times 10^{-6}$ to $5.4 \times 10^{-6}$. The annealed wires increased from $1.7 \times 10^{-6}$ in $0.2 \mathrm{Zr}$ to $5.1 \times 10^{-6}$ in $3.5 \mathrm{Zn} 0.2 \mathrm{Zr}$.

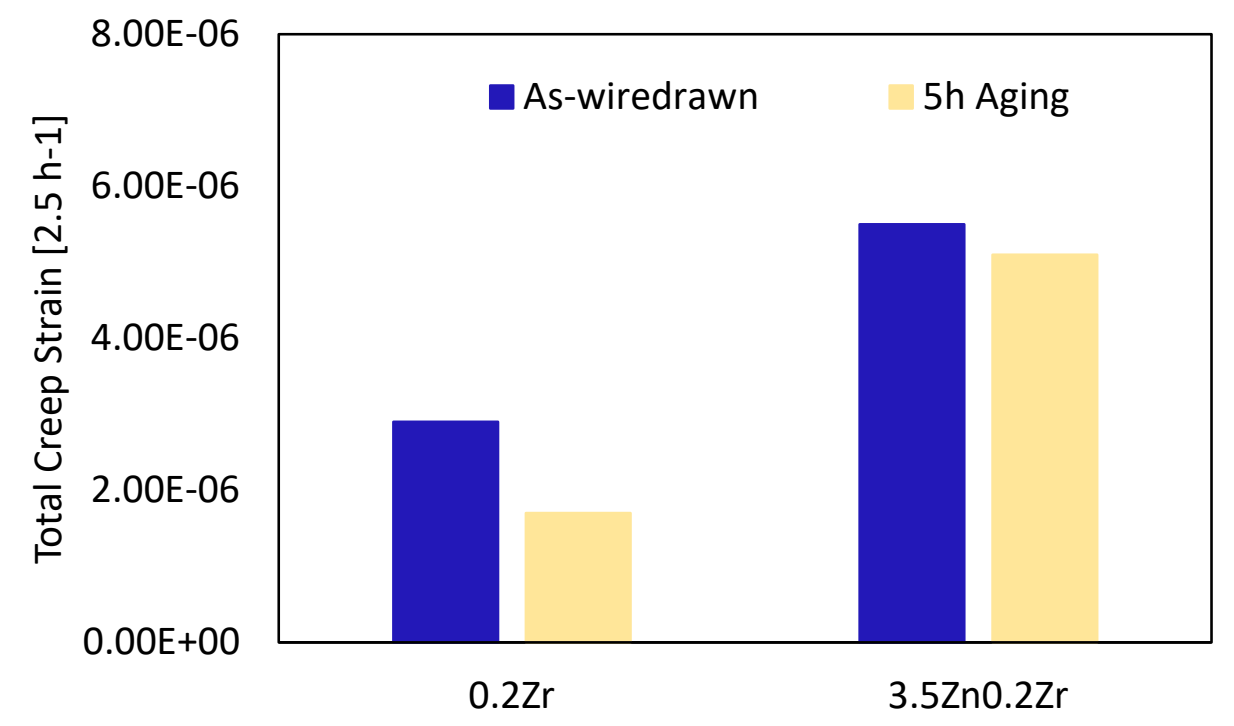

Figure 44. Total creep strain of $0.2 \mathrm{Zr}$ and $3.5 \mathrm{Zn} 0.2 \mathrm{Zr}$ at as-wiredrawn and after $5 \mathrm{~h}$ thermal aging. The creep test was performed at constant stress, temperature and duration of 40 $\mathrm{MPa}, 250^{\circ} \mathrm{C}$ and $2.5 \mathrm{~h}$. 
Table 10. Creep strain rate of $0.2 \mathrm{Zr}$ and $3.5 \mathrm{Zn} 0.2 \mathrm{Zr}$ alloys

\begin{tabular}{ccc}
\hline & \multicolumn{2}{c}{ Creep strain rate $s^{-1}\left(40 \mathrm{MPa}, 250^{\circ} \mathrm{C}\right)$} \\
\hline $0.2 \mathrm{Zr}$ & As-wiredrawn & After $5 \mathrm{~h}$ aging \\
$3.5 \mathrm{Zn} 0.2 \mathrm{Zr}$ & $2.9 \times 10^{-6}$ & $1.7 \times 10^{-6}$ \\
& $5.4 \times 10^{-6}$ & $5.1 \times 10^{-6}$ \\
\hline
\end{tabular}

$02 \mathrm{Zr}$, at overaging temperature, $>450^{\circ} \mathrm{C}$. However, significant deformation of the alloys could have led to coarsening at a much lower temperature $\left(250^{\circ} \mathrm{C}\right)$, during the creep test experiment, especially in $3.5 \mathrm{Zn} 0.02 \mathrm{Zr}$, because of the high diffusivity of $\mathrm{Zn}$ in $\mathrm{Al}$.

\subsection{Summary and conclusions}

Comparing $\mathrm{CW}$ and $\mathrm{AA}+\mathrm{CW}$ alloys showed that aging the alloys before cold work raised the tensile strength of $0.2 \mathrm{Zr}$ and $3.5 \mathrm{Zn} 0.2 \mathrm{Zr}$. The increased strength from precipitation led to reduced ductility of the alloys.

3.5Zn0.2Zr experienced slightly higher ductility than $0.2 \mathrm{Zr}$ after as-wiredrawn and thermal aging conditions, even though it has a better strength. This indicates that the addition of $\mathrm{Zn}$ could be responsible for the enhanced ductility as a result of reduced stacking fault energy of the alloy.

A higher total creep strain was observed in $3.5 \mathrm{Zn} 0.2 \mathrm{Zr}$ relative to $0.2 \mathrm{Zr}$. This could be attributed to enhanced precipitate coarsening in $3.5 \mathrm{Zn} 0.2 \mathrm{Zr}$ compared to $0.2 \mathrm{Zr}$, at such low temperature, $250^{\circ} \mathrm{C}$. The high diffusivity of $\mathrm{Zn}$ in $\mathrm{Al}$ could be responsible for the enhanced coarsening in $3.5 \mathrm{Zn} 0.2 \mathrm{Zr}$ relative to $0.2 \mathrm{Zr}$. 


\section{Chapter 7: Performance summary of Al-Zn- $\mathrm{Zr}$ and $\mathrm{Al}-\mathrm{Zn}-\mathrm{Ni}$ and $\mathrm{AA} 1350$}

\subsection{Introduction}

The electrical conductivity of Al alloy 1350 (AA1350) currently used for power transmission is between 34.9 (extra hard H-19) and $35.7 \mathrm{MS} / \mathrm{m}$ (annealed), which is very close to that of pure $\mathrm{Al}(36.9 \mathrm{MS} / \mathrm{m})$. This leaves little room for developing an $\mathrm{Al}$ alloy with improved electrical conductivity, while subsequently increasing strength. Al-Zn-Zr is an alternate Al alloy with excellent thermal resistance, creep and strength but a lower electrical conductivity relative to Al-Zn-Ni and AA1350. Al-Zn-Ni has a slightly better strength and thermal resistance than AA1350 but similar electrical conductivity. In this chapter the performance of the two new alloys are compared to AA1350.

To make direct comparison between the potential of the new alloys and AA1350, some of the $25 \mathrm{lbs}$ commercial AA1350 rods received from General Cable were cut, re-casted and prepared using similar melting, polishing and cold work procedures used for $\mathrm{Al}-\mathrm{Zn}-\mathrm{Zr}$ and Al-Zn-Ni alloys (detailed in chapter 4 and 5). Therefore, the AA1350 detailed in this chapter is not considered extra hard-H19 alloy. Where available, data for AA1350-H19 and AA1350-O were also included in the plot for comparison with currently used electrical conductors.

\subsection{Mechanical and electrical properties}

\subsubsection{Microhardness and eddy current}

According to Figure 45, the microhardness of AA1350 is $248 \mathrm{MPa}$ at as-cast. It gradually reduced during isochronal aging to 235 and $221 \mathrm{MPa}$ at 250 and $450{ }^{\circ} \mathrm{C}$, respectively. This shows that AA1350 does not form any strengthening phase hence no precipitation hardening was observed. Henceforth, most of its strength was derived from solid solution 
strengthening via impurities and cold work. The microhardness of $0.2 \mathrm{Zr}$ (403 $\mathrm{MPa})$, 3.5Zn0.1 Ni (356 MPa) and 3.5Zn0.2Zr (459 MPa) were much higher at their respective peak strength. Both alloys are capable of forming secondary strengthening phases responsible for the enhanced microhardness during aging. As expected, there are no microhardness data for as-cast AA1350-H19 and AA1350-O alloys, since these alloys are cold worked wires.

Similarly, increased eddy current conductivity was observed for all the alloys in this study at their respective peak condition. Though, only a slight increase was observed for $3.5 \mathrm{Zn} 0.1 \mathrm{Zr}$. As expected, these eddy current conductivity values were much lesser than AA1350. For instance, at peak condition, $0.2 \mathrm{Zr}, 2.5 \mathrm{Zn} 0.2 \mathrm{Zr}, 3.5 \mathrm{Zn} 0.2 \mathrm{Zr}$ and $3.5 \mathrm{Zn} 0.1 \mathrm{Ni}$ experienced a peak eddy current conductivity of $34,32,30$ and $33 \mathrm{MS} / \mathrm{m}$, respectively, relative to $36 \mathrm{MS} / \mathrm{m}$ for AA1350. The slight increase in eddy current conductivity of AA1350 was due to annealing and not precipitation. 

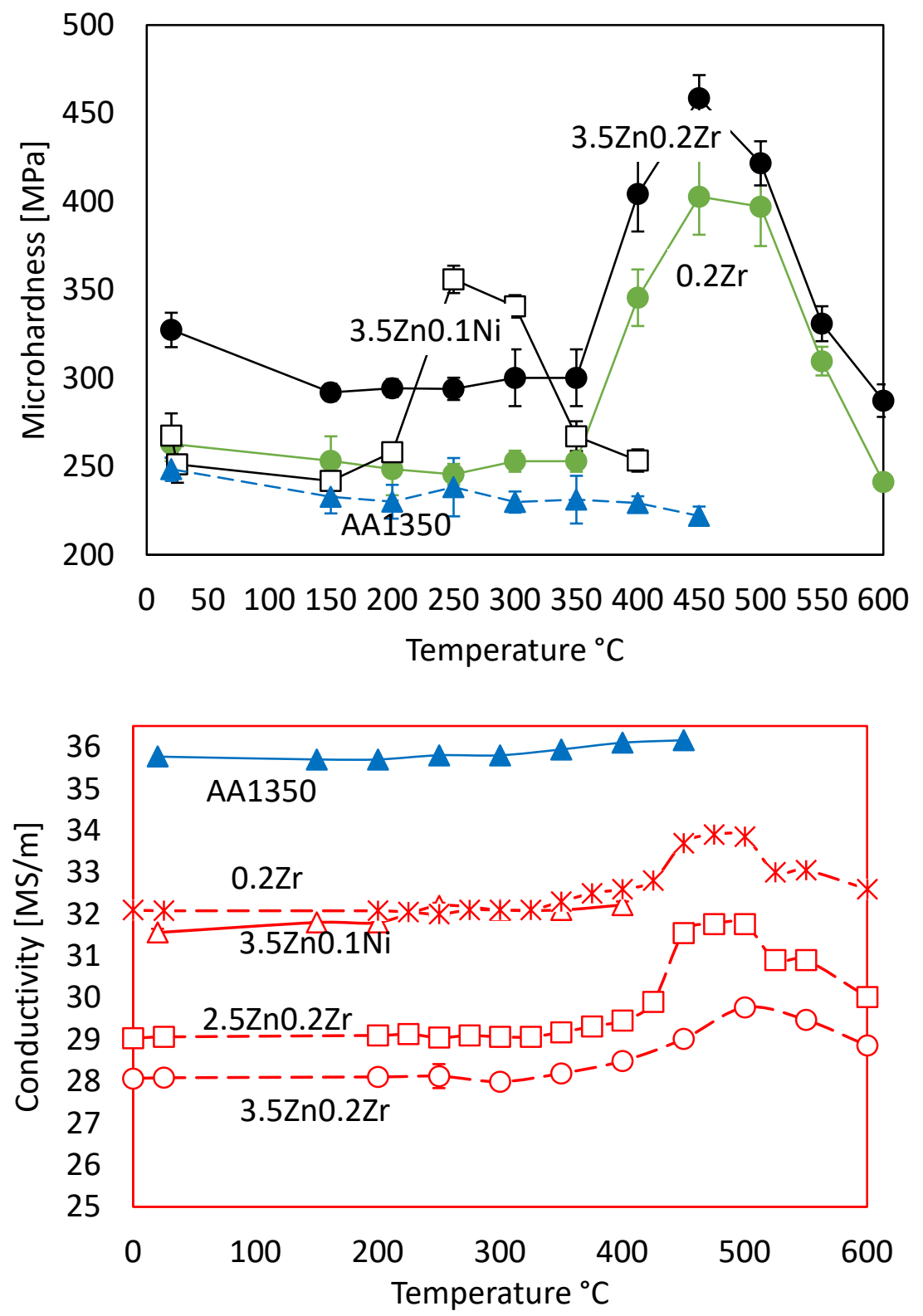

Figure 45. Microhardness and conductivity comparison of Al-Zn-Ni and Al-Zn-Zr to AA1350. Highest peak strength was observed for Al-Zn-Zr, followed by Al-Zn-Ni and AA1350. No peak strength was observed for AA1350 due to lack of strengthening phase formation during aging. As predicted by DFT, Al-Zn-Zr alloy experiences the lowest conductivity. 


\subsubsection{Tensile strength and conductivity}

The tensile strengths and electrical conductivities of several compositions of Al-Zn-Ni and Al-Zn-Zr alloy wires were plotted together with AA1350 (re-casted in the laboratory) to observe how the strength gained compares to electrical conductivity lost by each alloy. The alloy composition of $\mathrm{Al}-\mathrm{Zn}-\mathrm{Ni}$ were varied from $0.5-3.5 \mathrm{wt} . \% \mathrm{Zn}$, while Ni composition was kept constant at $0.1 \mathrm{wt} . \%$. The $0.2 \mathrm{Zr}$ and $3.5 \mathrm{Zn} 0.2 \mathrm{Zr}$ alloys were fabricated for $\mathrm{Al}-$ $\mathrm{Zn}-\mathrm{Zr}$ alloys. Online data for currently used AA1350-H19 and -O alloys was also included in the plot, to show that additional increased strength can be achieved for the new alloys if they were extra hardened.

From Figure 46, the Al-Zn-Ni alloys have better strengthening potential but slightly lower electrical conductivity relative to AA1350. However, the percent tensile strength gained is more than $3 \times$ the percent electrical conductivity lost, relative to AA1350. For instance, the tensile strengths of $0.5 \mathrm{Zn} 0.1 \mathrm{Ni}, 2.5 \mathrm{Zn} 0.1 \mathrm{Ni}$ and $3.5 \mathrm{Zn} 0.1 \mathrm{Ni}$ are 6,13 and $27 \%$ higher than AA1350, respectively. The electrical conductivity of AA1350 is $0,3,6 \%$ higher than that of $0.5 \mathrm{Zn} 0.1 \mathrm{Ni}, 2.5 \mathrm{Zn} 0.1 \mathrm{Ni}$ and $3.5 \mathrm{Zn} 0.1 \mathrm{Ni}$. This confirms DFT data which indicates that $\mathrm{Zn}$ and Ni have very minimal effect on electrical conductivity of Al, Figure 18.

Figure 46 shows that $\mathrm{Zr}$ has a better precipitation strengthening potential relative to $\mathrm{Ni}$. However, due to the greater negative impact of $\mathrm{Zr}$ on electrical conductivity, higher electrical conductivity was lost relative to AA1350. The tensile strength and electrical conductivity of $3.5 \mathrm{Zn} 0.2 \mathrm{Zr}$ is $62 \%$ higher and $14 \%$ lower than AA1350. The percent tensile strength gained is more than $4 \times$ the percent electrical conductivity lost, relative to AA1350.

By comparing AA1350-H19, AA1350-O to the AA1350 re-casted in the laboratory, it can be shown that extra hardening of the AA1350 would yield additional tensile strength of 35 $\mathrm{MPa}$ with only $\sim 0.4 \mathrm{MS} / \mathrm{m}$ electrical conductivity lost. This indicates that if the new Al$\mathrm{Zn}-\mathrm{Zr}$ and Al-Zn-Ni alloys were extra hardened, higher strength would have been recorded. It will however be expected that great reduction in the existing \%EL would occur. On the 
other hand, AA1350-O has a much lower tensile strength relative to AA1350-H19 and AA1350, due to annealing.

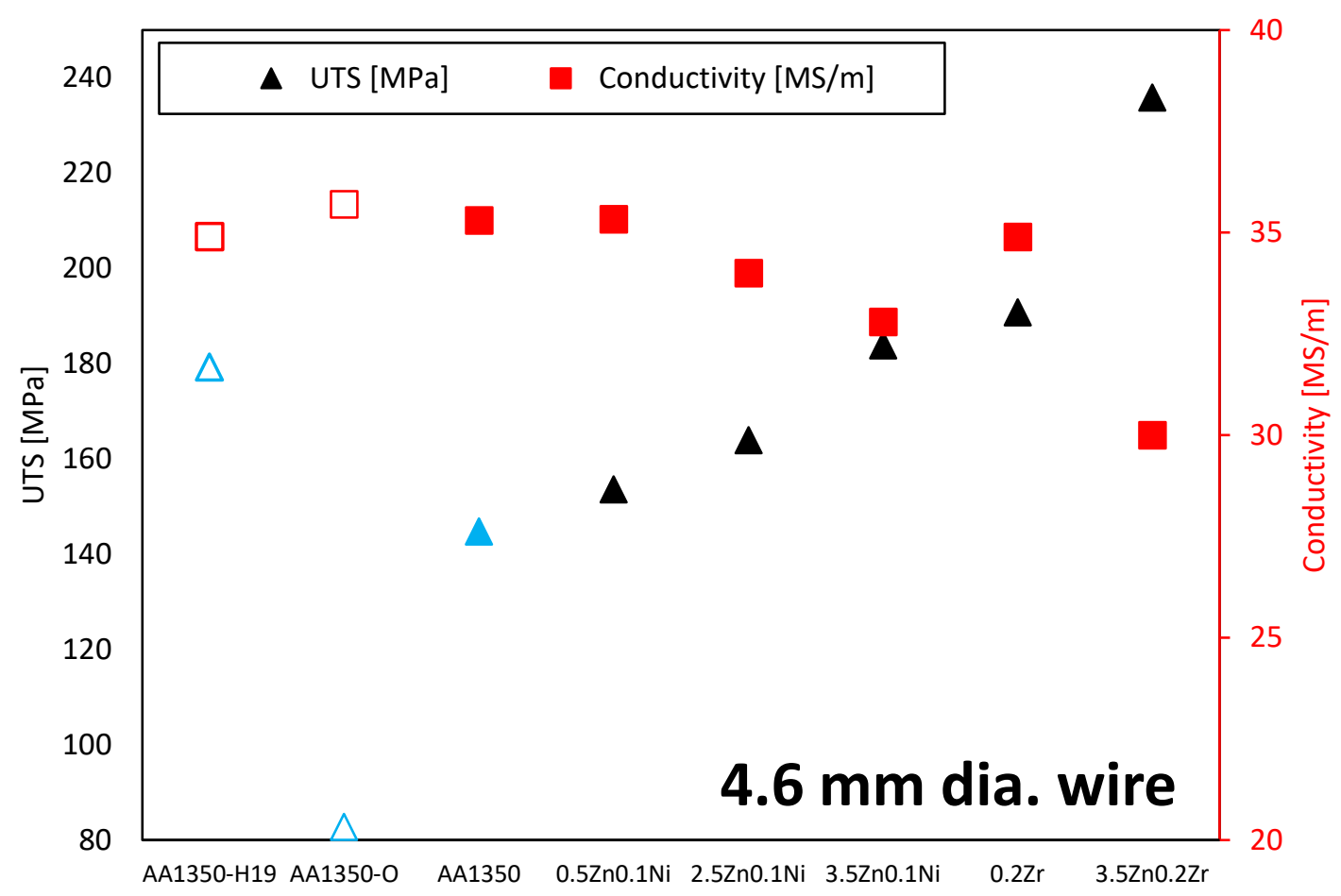

Figure 46. Tensile strength and electrical conductivity plot comparison. Al-Zn-Zr containing alloys show greater strengthening potential relative to Al-Zn-Ni and AA1350 alloys but lower electrical conductivity. The data also shows that the new alloys have improved strength relative to AA1350 and currently used AA1350-H19 and -O.

\subsection{Summary and conclusions}

Unlike Al-Zn-Ni and Al-Zn-Zr, AA1350 does not respond to aging, because it does not form any strengthening phase. Fe is the major impurity composition $(\sim 0.4 \mathrm{wt} . \%)$ present in AA1350 and it does not form secondary phase in Al.

The additional strengthening achieved in Al-Zn-Ni and Al-Zn-Zr is $3 \times$ and $4 \times$ electrical conductivity lost, relative to AA1350. 


\section{References}

1. Aluminum to replace copper as a conductor in on-board power systems. 2011 Retrieved October 29, 2018; Available from: www.sciencedaily.com/releases/2011/02/110207124035.htm.

2. Djukanovic, G. Copper vs Aluminium - substitution slows but continues. 2016 Retrieved October 29, 2018; Available from: https://aluminiuminsider.com/copper-vs-aluminium-substitution-slows-butcontinues/.

3. Hasnip, P.J., et al., Density functional theory in the solid state. Royal Society Publishing, 2014.

4. Shi, D., et al., First-principles studies of Al-Ni intermetallic compounds. Journal of solid state chemistry, 2009. 182(10): p. 2664-2669.

5. Aluminum Conductor Steel Supported (ACSS). Retrieved October 29, 2018; Available from: https://www.southwire.com/ProductCatalog/proddetail.jsp?htmlpreview=true\&to ken $=29 \& \operatorname{desc}=\mathrm{A}$.

6. K.E. Kniplng, D.C.D., D.N. Seidman, Precipitation evolution in Al-Zr and Al-ZrTi alloys during aging at $450^{\circ} \mathrm{C}$ compared to $600{ }^{\circ} \mathrm{C}$. Acta Materialia, 2008. 58: p. 1182-1195.

7. K.E. Knipling, D.C.D., D.N.Seidman Precipitation evolution in Al-Zr and Al-Zr-Ti alloys during isothermal aging at $375-425{ }^{\circ} \mathrm{C}$. Acta Materialia, 2008. 56: p. 114 $-127$. 
8. K.E. Knipling, R.A.K., C.P. Lee, D.C. Dunand, D.N. Seidman, Precipitation evolution in Al-0.1Sc, Al-0.1Zr and Al-0.1Sc-0.1Zr (at. \%) alloy during isochronal aging. Acta Materialia, 2010. 58: p. 5184-5195.

9. K.E. Knipling, D.C.D.a.D.N.S., Nucleation and Precipitation Strengthening in Dilute Al-Ti and Al-Zr Alloys. The Minerals, Metals and Materials Society and ASM International, 2007. 38A: p. $2552-2563$.

10. K. Knipling, D.D., D. Seidman, Criteria for developing castable creep resistant aluminum-based alloys. 2006: p. 246-265.

11. Chemicool Periodic Table. 2012 Retrieved October 30, 2018; Available from: https://www.chemicool.com/elements.

12. Fadayomi, O., et al., Investigation of Al-Zn-Zr and Al-Zn-Ni alloys for high electrical conductivity and strength application. Materials Science and Engineering A, 2019. 743: p. 785-797.

13. Hatch, J.E., Aluminum: Properties and Physical Metallurgy. American Society for Metals, 1984.

14. G. Ghosh, A.v.d.W., M. Astra, First principles phase stability calculations of L12, D022 and D023 structures in Al-TM (=Ti,Zr,Hf)-Zn systems. Proceedings of an International Conference on Solid-Solid Phase Transformation in Inorganic Materials, 2005.

15. G. Ghosh, A.v.d.W., M. Astra, First principles phase stability calculations of pseudobinary alloys of (Al,Zn)3Ti with L12, D022 and D023 structures.

16. Greenwood, D., The Boltzmann equation in the theory of electrical conduction in metals. Proceedings of the Physical Society, 1958. 71(4): p. 585. 
17. Kubo, R., Statistical-mechanical theory of irreversible processes. I. General theory and simple applications to magnetic and conduction problems. Journal of the Physical Society of Japan, 1957. 12(6): p. 570-586.

18. Ghosh, G., A. Van De Walle, and M. Asta, First-Principles Phase Stability Calculations of Pseudobinary Alloys of (Al, Zn) 3 Ti with L1 2, DO 22, and DO 23 Structures. Journal of phase equilibria diffusion, 2007. 28(1): p. 9-22.

19. Sholl, D. and J.A. Steckel, Density functional theory: a practical introduction. 2011: John Wiley \& Sons.

20. Pelleg, J., Mechanical properties of materials. Vol. 190. 2012: Springer Science \& Business Media.

21. Lu, L., et al., Ultrahigh strength and high electrical conductivity in copper. Science, 2004. 304(5669): p. 422-426.

22. Gladman, T., Precipitation hardening in metals. Materials Science and Technology, 1999. 15(1): p. 30-36.

23. Gladman, T., Precipitation hardening in metals. Materials Science Technology, 1999. 15(1): p. 30-36.

24. Allison, J., Integrated computational materials engineering: A perspective on progress and future steps. JOM, 2011. 63(4): p. 15-18.

25. Ghosh, G. and M. Asta, First-principles calculation of structural energetics of Al$T M(T M=T i, Z r, H f)$ intermetallics. Acta Materialia, 2005. 53(11): p. 3225-3252.

26. Wang, J., et al., First-principles calculations of binary Al compounds: Enthalpies of formation and elastic properties. Calphad, 2011. 35(4): p. 562-573.

27. Chrifi-Alaoui, F., et al., Enthalpies of formation of the Al-Ni intermetallic compounds. Journal of Alloys Compounds, 2004. 364(1-2): p. 121-126. 
28. Yuan, X.-L., et al., The first-principles calculations for the elastic properties of Zr2Al under compression. Journal of Alloys Compounds

2011. 509(3): p. 769-774.

29. Knipling, K.E., D.C. Dunand, and D.N. Seidman, Criteria for developing castable, creep-resistant aluminum-based alloys-A review. Zeitschrift für Metallkunde, 2006. 97(3): p. 246-265.

30. Knipling, K.E., D.C. Dunand, and D.N. Seidman, Precipitation evolution in Al-Zr and Al-Zr-Ti alloys during aging at 450-600 C. Acta Materialia, 2008. 56(6): p. 1182-1195.

31. Knipling, K.E., D.C. Dunand, and D.N. Seidman, Precipitation evolution in Al-Zr and Al-Zr-Ti alloys during isothermal aging at 375-425 C. Acta Materialia, 2008. 56(1): p. 114-127.

32. Cubiotti, G., et al., The electronic structure of Al3Ni. Journal of Physics: Condensed Matter, 1995. 7(25): p. 4865.

33. Knipling, K.E., et al., Precipitation evolution in Al-0.1 Sc, Al-0.1 $\mathrm{Zr}$ and Al-0.1 Sc-0.1 Zr (at.\%) alloys during isochronal aging. Acta Materialia, 2010. 58(15): p. 5184-5195.

34. Fine, M.E., et al., Alloy Design of Nanoscale Precipitation Strengthened Alloys: Design of a Heat Treatable Aluminum Alloy Useful to 400C, in Final Report for Department of Energy Grant No. DE-FG02-02ER45997," 2006, Northwestern University.

35. Fleischer, R. High Temperature Ordered Intermetallic Alloys III, CT Liu, AI Taub, NS Stoloff, and CC Koch, eds. in Materials Research Society Symposia Proceedings, Materials Research Society. 1989. Pittsburgh, PA. 
36. Zhang, S., J. Nic, and D. Mikkola, New cubic phases formed by alloying Al3Ti with Mn and Cr. Scripta Metallurgica et Materialia, 1990. 24(1): p. 57-62.

37. Carlsson, A. and P. Meschter, Relative stability of LI 2, DO 22, and DO 23 structures in MAl 3 compounds. Journal of Materials Research, 1989. 4(5): p. 10601063.

38. Kresse, G., M. Marsman, and J. Furthmüller, Vienna Ab initio Simulation Package (VASP), the guide Computational Materials Physics. Faculty of Physics, Universität Wien, Vienna, Austria, 2014.

39. Madsen, G.K. and D.J. Singh, BoltzTraP. A code for calculating band-structure dependent quantities. Computer Physics Communications, 2006. 175(1): p. 67-71.

40. Reshak, A. and S. Auluck, Thermoelectric properties of Nowotny-Juza NaZnX $(X=$ P, As and Sb) compounds. Computational Materials Science, 2015. 96: p. 90-95.

41. Reshak, A., S.A. Khan, and S. Auluck, Thermoelectric properties of a single graphene sheet and its derivatives. Journal of Materials Chemistry C, 2014. 2(13): p. 2346-2352.

42. Reshak, A.H., Fe 2 MnSix Ge 1-x: influence thermoelectric properties of varying the germanium content. RSC Advances, 2014. 4(74): p. 39565-39571.

43. Shojaei, A.R., Electrical conductivity plus probability of superconductivity in $\alpha-$ cuse/klockmannite; bulk and nano-layers. Journal of Alloys Compounds, 2015. 632: p. 568-574.

44. Thermo-Calc Software TCAL5: Al-Alloys v5.0 database. $2017 \mathrm{~b} 16$ January, 2018.

45. Pal, H., S.K. Pradhan, and M. De, Microstructure and mechanical property of $\alpha$ Al-Zn-Cu alloys aged at room temperature. Materials Transactions, JIM, 1995. 36(4): p. 490-495. 
46. Fujikawa, S.-I. Impurity diffusion of scandium in aluminium. in Defect and Diffusion Forum. 1997. Trans Tech Publ.

47. Marumo, T., S. Fujikawa, and K.-i. Hirano, Diffusion of zirconium in aluminum. J. Jap. Inst. Light Met., 1973. 23(1): p. 17-25.

48. S. Dias, R.M., A. Seeger, Mater. Sci. Forum, 1987. 15 - 18: p. 419.

49. Erdelyi, G., et al., Determination of diffusion coefficients of $\mathrm{Zn}$, Co and Ni in aluminium by a resistometric method. Philosophical Magazine B, 1978. 38(5): p. 445-462.

50. Peterson, N. and S. Rothman, Impurity diffusion in aluminum. Physical Review B, 1970. 1(8): p. 3264.

51. Prabhu, T.R., Effects of ageing time on the mechanical and conductivity properties for various round bar diameters of AA 2219 Al alloy. Engineering Science Technology, an International Journal, 2017. 20(1): p. 133-142.

52. Raghavan, V., Al-C-Co (Aluminum-Carbon-Cobalt). Journal of Phase Equilibria Diffusion, 2008. 29(1): p. 46-48.

53. Wadhwa, A.S. and E.H.S. Dhaliwal, A Textbook of Engineering Material and Metallurgy. 2008: Firewall Media.

54. Wang, C., et al., Phase alignment and crystal orientation of Al3Ni in Al-Ni alloy by imposition of a uniform high magnetic field. Journal of Crystal Growth, 2008. 310(6): p. 1256-1263.

55. Marquis, E.A., D.N. Seidman, and D.C. Dunand, Precipitation strengthening at ambient and elevated temperatures of heat-treatable Al (Sc) alloys [Acta Materialia 50 (16), pp. 4021-4035]. Acta Materialia, 2003. 51(1): p. 285. 
56. Tabor, D., The physical meaning of indentation and scratch hardness. British Journal of Applied Physics, 1956. 7(5): p. 159.

57. Wang, Z., et al., Effect of coherent L12 nanoprecipitates on the tensile behavior of a fcc-based high-entropy alloy. Materials Science Engineering: A, 2017. 696: p. 503-510.

58. Meyers, M.A. and K.K. Chawla, Mechanical metallurgy: principles and applications. Vol. 761. 1984: Prentice-Hall Englewood Cliffs, NJ.

59. Gaillac, R., P. Pullumbi, and F.-X. Coudert, ELATE: an open-source online application for analysis and visualization of elastic tensors. Journal of Physics: Condensed Matter, 2016. 28(27): p. 275201.

60. Shi, D., et al., First-principles studies of Al-Ni intermetallic compounds. Journal of solid state chemistry, 2009. 182(10): p. 2664-2669.

61. Bi-Yu, W.N.a.T., Structural, elastic and electronic properties of L12 aluminum phases from first principles calculation. Acta Phys. Sin., 2009. 58: p. 230-234.

62. Fu, L., et al., Mechanical properties of L12 type Al3X (X=Mg, Sc, Zr) from firstprinciples study. physica status solidi, 2012. 249(8): p. 1510-1516.

63. Z. Wei, S.T., B. Wu, K. Bai, First principles investigation of crystal lattice structure, thermodynamics and mechanical properties in ZnZrAl2 intermetallic compound. Solid State Communications, 2016. 247: p. 82-87.

64. Ardell, A.J., Ch 12: Intermetallics as precipitates and dispersoids in high-strength alloys, in Intermetallic compounds: principles and practice, F.R. Westbrook JH, Editor. 1994, Chichester: John Wiley \& Sons. p. 257.

65. H.J. Frost, M.F.A., Deformation-mechanism maps: the plasticity and creep of metals and ceramics. 1982: New York: Pergamon Press. 
66. Makhlouf, Y.F.a.M.M., The Al-Al3Ni Eutectic Reaction: Crystallography and Mechanism of Formation. Metallurgical and Materials Transactions A, 2015. 46A: p. 3808-3812.

67. P.H.L. Souza, C.A.S.d.O., J.M.V. Quaresma, Precipitation hardening in dilute AlZr alloys. J Mater Res Technol., 2018. 7(1): p. 66-72.

68. W. Lefebvre, e.a., Tracking the path of dislocations across ordered Al3Zr nanoprecipitates in three dimensions. Scripta Materialia, 2014. 70: p. 43- 46.

69. R. Hyland, e.a., Al ( $f c c):$ Al3Sc (L12) interphase boundary energy calculations. Acta materialia, 1998. 46(10): p. 3667-3678.

70. X. Gao, J.W., X. Wu, R. Wang and Z. Jia, Effects of Alloying Atoms on Antiphase Boundary Energy and Yield Stress Anomaly of L12 Intermetallics : First-Principles Study. Crystals, 2018. 8: p. 96.

71. M.A. Phillips, B.M.C., and W.D. Nix, A model for dislocation behavior during deformation of Al/Al3Sc (fcc/L12) metallic multilayers. Acta Materialia, 2003. 51(11): p. 3157-3170.

72. Freeman, T.H.a.A.J., Effect of antiphase boundaries on the electronic structure and bonding character of intermetallic systems: NiAl. Physical Review B, 1991. 43: p. 8.

73. O. I. Gorbatov, e.a., Effect of composition on antiphase boundary energy in Ni3Al based alloys: Ab initio calculations. Physical Review B, 2016. 93: p. 224106.

74. C.B. Fuller, D.N.S.a.D.C.D., Mechanical properties of Al(Sc,Zr) alloys at ambient and elevated temperatures. Acta Materialia, 2003. 51: p. 4803-4814.

75. X. Sauvage, E.V.B., M. Yu.Murashkin, Y. Nasedkina, N.A. Enikeev, R.Z. Valiev, Optimization of electrical conductivity and strength combination by structure design at the nanoscale in Al-Mg-Si alloys. Acta Materialia, 2015. 98: p. 355-366. 
76. A.K. Guptaa, D.J.L., S.A. Court, Precipitation hardening in Al-Mg-Si alloys with and without excess Si. Materials Science and Engineering: A, 2001. 316: p. 11-17.

77. Guo, Z. and W. Sha, Quantification of precipitation hardening and evolution of precipitates. Materials Transaction, 2002. 43(6): p. 1273-1282.

78. Desch, P., R. Schwarz, and P. Nash, Formation of metastable L12 phases in Al3Zr and $\mathrm{Al}-12.5 \% \mathrm{X}-25 \% \mathrm{Zr}(\mathrm{X} \equiv \mathrm{Li}, \mathrm{Cr}, \mathrm{Fe}, \mathrm{Ni}, \mathrm{Cu}$ ). Journal of the Less Common Metals, 1991. 168(1): p. 69-80.

79. Virk, I. and R. Varin, Structure of as cast L12 compounds in Al3Zr-Base alloys containing $\mathrm{Cu}$ and $\mathrm{Mn}$. Scripta metallurgica et materialia, 1991. 25(1): p. 85-88.

80. Commission, I.E., Thermal-resistant Aluminium Alloy Wire for Overhead Line Conductor IEC 62004. 2007: IEC.

81. Knipling, K.E., D.N. Seidman, and D.C. Dunand, Ambient-and high-temperature mechanical properties of isochronally aged Al-0.06 Sc, Al-0.06 $\mathrm{Zr}$ and Al-0.06 Sc-0.06 Zr (at.\%) alloys. Acta Materialia, 2011. 59(3): p. 943-954.

82. Souza, P.H.L., J.M.d.V. Quaresma, and C.A.S. Oliveira, Precipitation Evolution and Modeling of Growth Kinetics of L12-structured Al3Zr Particles in Al-0.22 Zr and Al-0.32 Zr (wt.) Alloys Isothermally Aged. Materials Research, 2017(AHEAD): p. $0-0$.

83. Litynska, L., et al., TEM and HREM study of Al3Zr precipitates in an Al-Mg-Si-Zr alloy. Journal of Microscopy, 2006. 223(3): p. 182-184.

84. Tsau, C.-H. and Y.-C. Chen, The coarsening of the precipitates in melt-spun AlTi-Zr ribbons. Materials Chemistry Physics, 2002. 73(2-3): p. 111-117.

85. Skoko, Ž., S. Popović, and G. Štefanić, Microstructure of Al-Zn and Zn-Al Alloys. Croatica chemica acta, 2009. 82(2): p. 405-420. 
86. Ardell, A., Precipitation hardening. Metallurgical Transactions A, 1985. 16(12): p. 2131-2165.

87. Zedalis, M. and M. Fine, Precipitation and ostwald ripening in dilute AI Base-ZrV alloys. Metallurgical Transactions A, 1986. 17(12): p. 2187-2198.

88. Hu, C.M., et al., Enhanced tensile plasticity in ultrafine-grained metallic composite fabricated by friction stir process. Scripta Materialia, 2008. 59: p. 1163-1166. 


\section{Appendix A}

\section{A.1 VASP-DFT input files}

\section{A.1.1 INCAR}

INCAR file contains the codes utilized for running each simulation. It is the central input file. The INCAR files used for this study were similar since all the alloys included $\mathrm{Al}$ and transition metals. Most of these parameters also have default values that were not necessary to change. The sample of a typical INCAR file used for the cluster and disperse alloy systems follows the format below:

SYSTEM $=$ Al107Zn crystal

LPLANE $=$.TRUE. \#Reduces the amount of communication needed

LSCALU $=$. FALSE.

$\mathrm{NSIM}=4$

$\mathrm{NPAR}=4$

LOPTICS $=$.TRUE. \#VASP calculates the frequency dependent dielectric matrix

ISIF $=3$ \#Allows the cell and ions to fully relax

ISMEAR $=1 \quad$ \#Methfessel-Paxton scheme for partial occupancies

SIGMA $=0.2 \quad \#$ Smearing width in $\mathrm{eV}$

PREC $=$ high $\quad$ \#Precision high

$\mathrm{EDIFF}=1 \mathrm{E}-06 \quad \# \mathrm{SCF}$ convergence criteria

EDIFFG $=-0.0001$

LREAL $=$ Auto \#Uses reciprocal projection operators

$\mathrm{NSW}=5 \quad$ \#Number of ionic steps

IBRION $=1 \quad$ \#RMM-DIIS algorithm for ion relaxation

ENCUT $=550 \quad$ \#Energy cut-off

NELMIN $=4$ 


\section{A.1.2 POSCAR}

This file is used to develop the alloy crystal lattice geometry. Here the atom positions in direct (fractional) coordinates and lattice vectors are detailed.
Al107Zn
1.0

$\begin{array}{rrr}12.0000000000 & 0.0000000000 & 0.0000000000 \\ 0.0000000000 & 12.0000000000 & 0.0000000000 \\ 0.0000000000 & 0.0000000000 & 12.0000000000\end{array}$

Al Zn

$107 \quad 1$

Direct

$\begin{array}{lll}0.000000000 & 0.000000000 & 0.333333343 \\ 0.000000000 & 0.000000000 & 0.666666687 \\ 0.000000000 & 0.333333343 & 0.000000000 \\ 0.000000000 & 0.333333343 & 0.333333343 \\ 0.000000000 & 0.333333343 & 0.666666687 \\ 0.000000000 & 0.666666687 & 0.000000000 \\ 0.000000000 & 0.666666687 & 0.333333343 \\ 0.000000000 & 0.666666687 & 0.666666687 \\ 0.333333343 & 0.000000000 & 0.000000000 \\ 0.333333343 & 0.000000000 & 0.333333343 \\ 0.333333343 & 0.000000000 & 0.666666687 \\ 0.333333343 & 0.333333343 & 0.000000000 \\ 0.333333343 & 0.333333343 & 0.333333343 \\ 0.333333343 & 0.333333343 & 0.666666687 \\ 0.333333343 & 0.666666687 & 0.000000000 \\ 0.333333343 & 0.666666687 & 0.333333343\end{array}$




\begin{tabular}{|c|c|c|}
\hline 0.333333343 & 0.666666687 & 0.666666687 \\
\hline 0.6666666887 & 0.000000000 & 0.000000000 \\
\hline 0.6666666687 & 0.000000000 & 0.333333343 \\
\hline 0.6666666687 & 0.333333343 & 0.000000000 \\
\hline 0.666666687 & 0.333333343 & 0.666666687 \\
\hline 0.6666666687 & 0.666666687 & 0.000000000 \\
\hline 0.666666687 & 0.6666666887 & 0.333333343 \\
\hline 0.6666666887 & 0.000000000 & 0.6666666687 \\
\hline 0.166666672 & 0.000000000 & 0.166666672 \\
\hline 0.166666672 & 0.000000000 & 0.500000000 \\
\hline 0.166666672 & 0.000000000 & 0.833333313 \\
\hline 0.166666672 & 0.333333343 & 0.166666672 \\
\hline 0.166666672 & 0.333333343 & 0.500000000 \\
\hline 0.166666672 & 0.333333343 & 0.833333313 \\
\hline 0.166666672 & 0.666666687 & 0.166666672 \\
\hline 0.166666672 & 0.666666687 & 0.500000000 \\
\hline 0.166666672 & 0.666666687 & 0.833333313 \\
\hline 0.500000000 & 0.000000000 & 0.166666672 \\
\hline 0.500000000 & 0.000000000 & 0.500000000 \\
\hline 0.500000000 & 0.000000000 & 0.833333313 \\
\hline 0.500000000 & 0.333333343 & 0.166666672 \\
\hline 0.500000000 & 0.333333343 & 0.500000000 \\
\hline 0.500000000 & 0.333333343 & 0.833333313 \\
\hline 0.500000000 & 0.6666666887 & 0.166666672 \\
\hline 0.500000000 & 0.666666687 & 0.500000000 \\
\hline 0.500000000 & 0.666666687 & 0.833333313 \\
\hline 0.833333313 & 0.000000000 & 0.166666672 \\
\hline 0.833333313 & 0.000000000 & 0.500000000 \\
\hline
\end{tabular}




\begin{tabular}{|c|c|c|}
\hline 0.833333313 & 0.000000000 & 0.833333313 \\
\hline 0.833333313 & 0.333333343 & 0.166666672 \\
\hline 0.833333313 & 0.333333343 & 0.500000000 \\
\hline 0.833333313 & 0.333333343 & 0.833333313 \\
\hline 0.833333313 & 0.666666687 & 0.166666672 \\
\hline 0.833333313 & 0.666666687 & 0.500000000 \\
\hline 0.833333313 & 0.666666687 & 0.833333313 \\
\hline 0.166666672 & 0.166666672 & 0.000000000 \\
\hline 0.166666672 & 0.166666672 & 0.333333343 \\
\hline 0.166666672 & 0.166666672 & 0.666666687 \\
\hline 0.166666672 & 0.500000000 & 0.000000000 \\
\hline 0.166666672 & 0.500000000 & 0.333333343 \\
\hline 0.166666672 & 0.500000000 & 0.666666687 \\
\hline 0.166666672 & 0.833333313 & 0.000000000 \\
\hline 0.166666672 & 0.833333313 & 0.333333343 \\
\hline 0.166666672 & 0.833333313 & 0.6666666887 \\
\hline 0.500000000 & 0.166666672 & 0.000000000 \\
\hline 0.500000000 & 0.166666672 & 0.333333343 \\
\hline 0.500000000 & 0.166666672 & 0.666666687 \\
\hline 0.500000000 & 0.500000000 & 0.000000000 \\
\hline 0.500000000 & 0.500000000 & 0.333333343 \\
\hline 0.500000000 & 0.500000000 & 0.666666687 \\
\hline 0.500000000 & 0.833333313 & 0.000000000 \\
\hline 0.500000000 & 0.833333313 & 0.333333343 \\
\hline 0.500000000 & 0.833333313 & 0.666666687 \\
\hline 0.833333313 & 0.166666672 & 0.000000000 \\
\hline 0.833333313 & 0.166666672 & 0.333333343 \\
\hline 0.833333313 & 0.166666672 & 0.666666687 \\
\hline
\end{tabular}




\begin{tabular}{lll}
0.833333313 & 0.500000000 & 0.000000000 \\
0.833333313 & 0.500000000 & 0.333333343 \\
0.833333313 & 0.500000000 & 0.666666687 \\
0.833333313 & 0.833333313 & 0.000000000 \\
0.833333313 & 0.833333313 & 0.333333343 \\
0.000000000 & 0.166666672 & 0.166666672 \\
0.000000000 & 0.166666672 & 0.500000000 \\
0.000000000 & 0.166666672 & 0.833333313 \\
0.000000000 & 0.500000000 & 0.166666672 \\
0.000000000 & 0.500000000 & 0.500000000 \\
0.000000000 & 0.500000000 & 0.833333313 \\
0.000000000 & 0.833333313 & 0.166666672 \\
0.000000000 & 0.833333313 & 0.500000000 \\
0.000000000 & 0.833333313 & 0.833333313 \\
0.333333343 & 0.166666672 & 0.166666672 \\
0.333333343 & 0.166666672 & 0.500000000 \\
0.333333343 & 0.166666672 & 0.833333313 \\
0.333333343 & 0.500000000 & 0.166666672 \\
0.333333343 & 0.500000000 & 0.500000000 \\
0.333333343 & 0.500000000 & 0.833333313 \\
0.333333343 & 0.833333313 & 0.166666672 \\
0.333333343 & 0.833333313 & 0.500000000 \\
0.333333343 & 0.833333313 & 0.833333313 \\
0.666666687 & 0.166666672 & 0.166666672 \\
0.666666687 & 0.166666672 & 0.500000000 \\
0.666666687 & 0.166666672 & 0.833333313 \\
0.56666687 & 0.500000000 & 0.166666672 \\
\hline 0.500007 & 0.50000000 & 0.50000
\end{tabular}




$\begin{array}{lll}0.666666687 & 0.500000000 & 0.833333313 \\ 0.666666687 & 0.833333313 & 0.166666672 \\ 0.666666687 & 0.833333313 & 0.500000000 \\ 0.666666687 & 0.833333313 & 0.833333313 \\ 0.833333313 & 0.833333313 & 0.666666687 \\ 0.666666687 & 0.666666687 & 0.666666687 \\ 0.666666687 & 0.333333343 & 0.333333343 \\ 0.000000000 & 0.000000000 & 0.000000000\end{array}$

\section{A.1.3 POTCAR}

It contains the pseudopotential for each atom present in a system used in the computation. If the number of atoms in an alloy system is more than one, their pseudopotentials POTCAR files were simply concatenated into one single file using BASH script. A typical pseudopotential file is too long to be included here. Several POTCAR files are available online for download. There are also various categories of POTCAR for each element. Therefore, it is important to first test each of them to see which category works best for the system. In this study most of the POTCAR files used were selected from PAW-PBE_52 category. The beginning section of a typical POTCAR file is detailed below for Al.

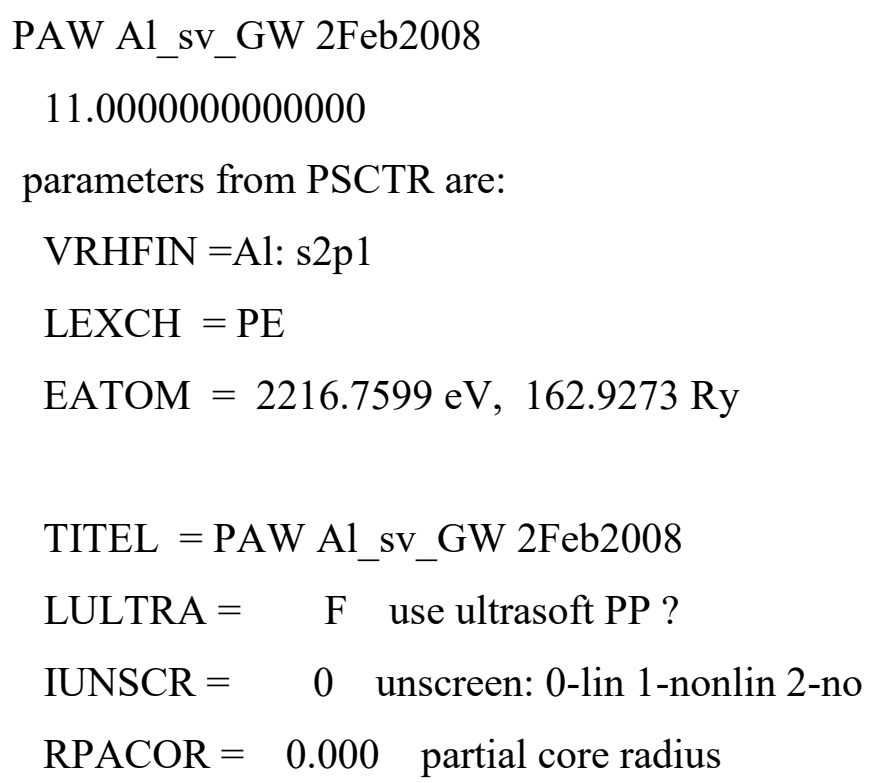




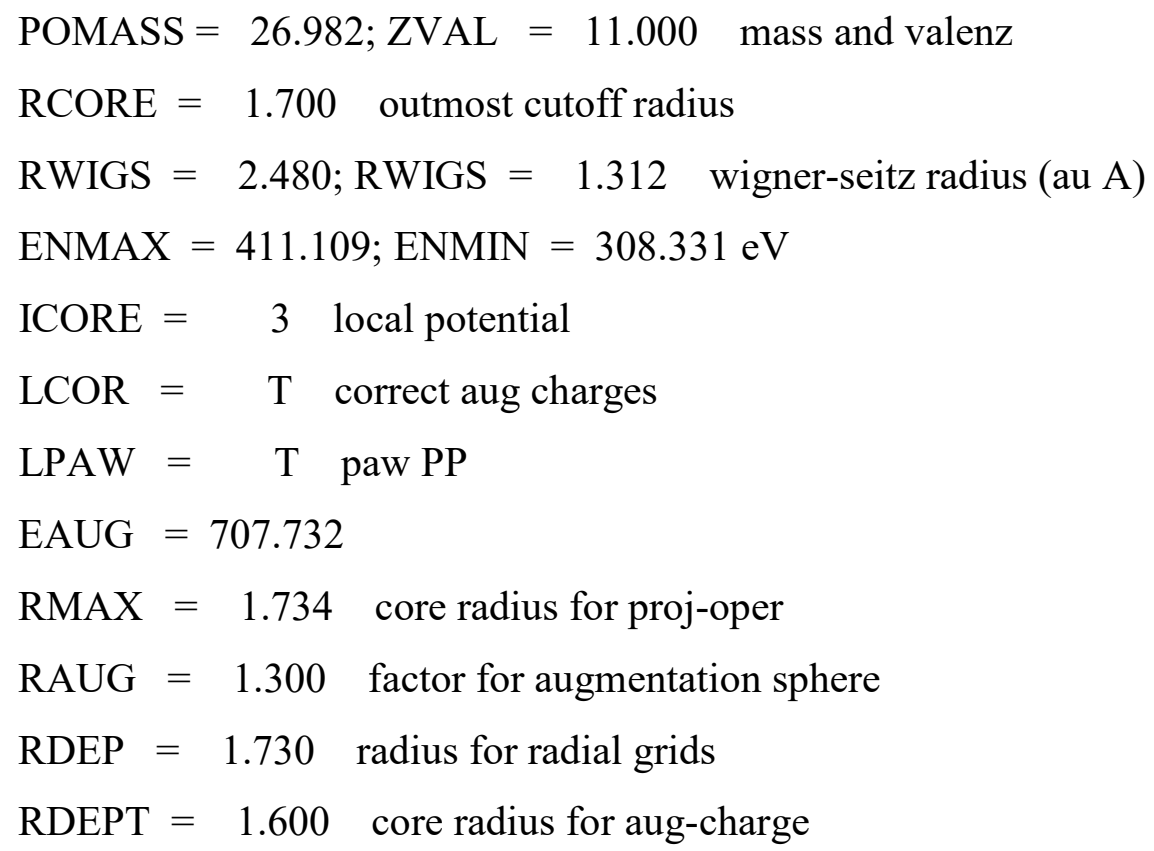




$$
\begin{array}{cccc}
1 & -69.6401625 & 23 & 1.600 \\
1 & -68.0291300 & 23 & 1.600 \\
1 & -2.7120682 & 23 & 1.700 \\
2 & -5.4423304 & 23 & 1.700 \\
2 & 81.6349560 & 23 & 1.700 \\
3 & 13.6058260 & 23 & 1.700
\end{array}
$$

Error from kinetic energy argument $(\mathrm{eV})$

NDATA $=100$

STEP $=20.0001 .050$

172. 171. 171. 170. 169. 168. 167.166.

164. 163. 162. 160. 158.156 .154 .152$.

150. 147. 145. 141. 138. 135. 131. 128.

125. 120. 115. 112. $107 . \quad 102.96 .7 \quad 91.6$

$\begin{array}{llllllll}86.6 & 81.6 & 76.7 & 71.9 & 65.7 & 61.2 & 55.4 & 51.2\end{array}$

$\begin{array}{llllllll}45.9 & 41.0 & 36.3 & 32.0 & 28.1 & 24.5 & 21.2 & 17.5\end{array}$

$\begin{array}{llllllll}15.0 & 12.1 & 9.74 & 8.10 & 6.35 & 4.91 & 3.54 & 2.64\end{array}$

$\begin{array}{llllllll}1.94 & 1.31 & 0.859 & 0.548 & 0.342 & 0.210 & 0.132 & 0.829 \mathrm{E}-01\end{array}$

0.632E-01 0.539E-01 0.510E-01 0.494E-01 0.463E-01 0.419E-01 0.354E-01 0.283E-01 0.216E-01 0.160E-01 0.113E-01 0.845E-02 0.648E-02 0.536E-02 0.464E-02 0.415E-02 0.362E-02 0.307E-02 0.254E-02 0.203E-02 0.164E-02 0.137E-02 0.116E-02 0.964E-03 0.787E-03 0.628E-03 0.492E-03 0.411E-03 0.362E-03 0.335E-03 0.302E-03 0.253E-03 0.192E-03 0.144E-03 0.113E-03 0.104E-03

END of PSCTR-controll parameters

local part

109.604107337578

$0.54237223 \mathrm{E}+02 \quad 0.54226690 \mathrm{E}+02 \quad 0.54200652 \mathrm{E}+02 \quad 0.54157311 \mathrm{E}+02$

$0.54096753 \mathrm{E}+02$

$0.54019091 \mathrm{E}+02 \quad 0.53924471 \mathrm{E}+02 \quad 0.53813066 \mathrm{E}+02 \quad 0.53685074 \mathrm{E}+02$

$0.53540717 \mathrm{E}+02$ 


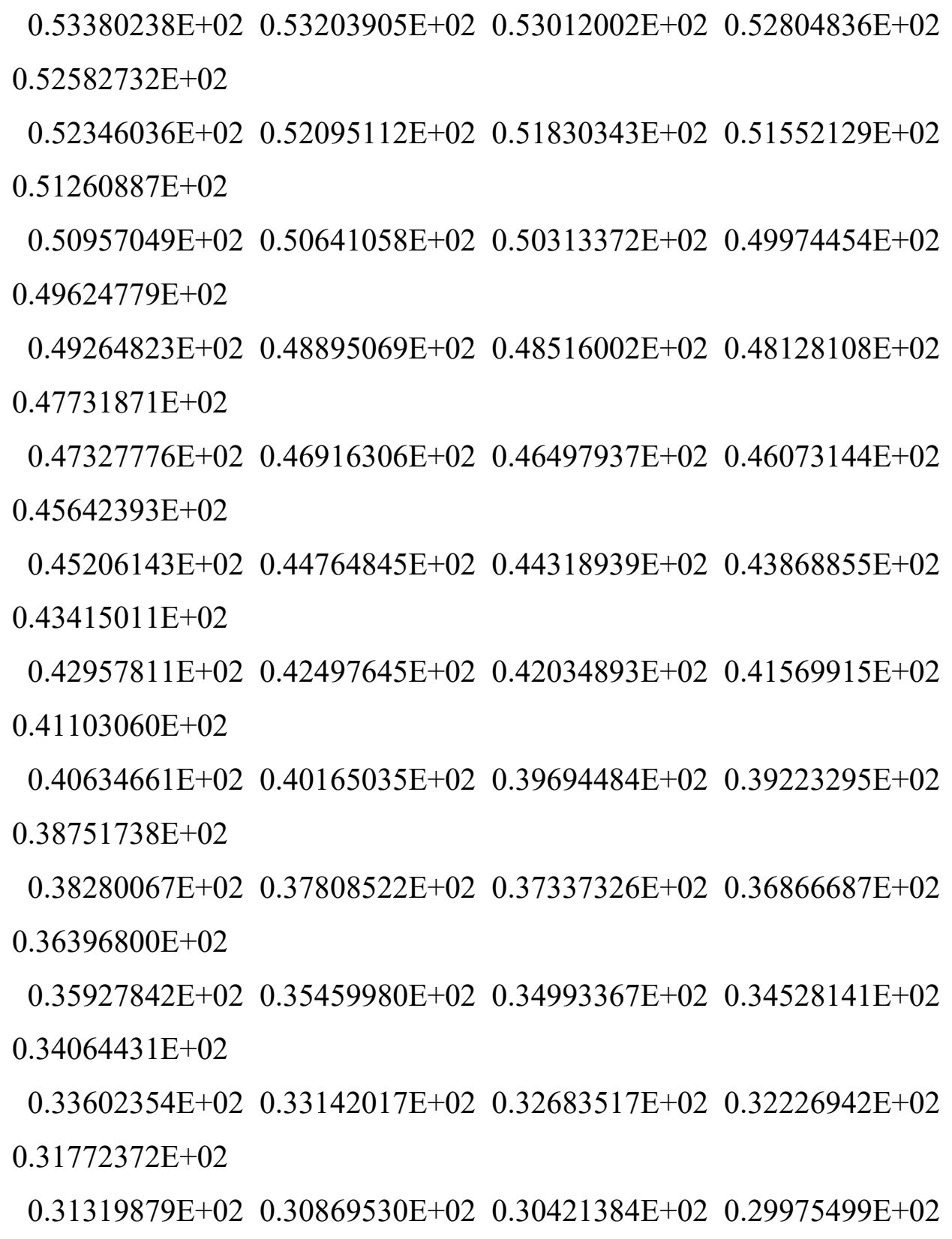

\section{A.1.4 KPOINTS}

It contains the k-point coordinates and mesh size for creating the k-point grid. These kpoints could be entered explicitly or the automatic k-mesh generation could be used. In this study the automatic k-mesh was used. 
Automatic mesh

$0 \quad$ ! automatic generation scheme

Auto ! fully automatic

$70 \quad$ ! length (1)

\section{A.2 VASP-DFT output files}

There are many files the VAST-DFT outputs for a single simulation, though, only a few of the most important files are detailed in this study. They include the OSZICAR, CONTCAR and OUTCAR files.

\section{A.2.1 CONTCAR}

This file is very similar to the POSCAR file. The only difference is the CONTCAR file represents the final (lowest energy) crystal lattice geometry of the alloy system after all the atoms/ions and crystal cell have been relaxed. It contains the atomic positions of the last ionic step of the relaxation until convergence occurs. A typical CONTCAR file for Al unit cell is detailed below.
$\mathrm{Al}$
1.00000000000000
$\begin{array}{llll}4.0187845410749867 & 0.0000000000000000 & -0.0000000000000000\end{array}$
$\begin{array}{llll}0.0000000000000000 & 4.0187845410749867 & 0.0000000000000000\end{array}$
$\begin{array}{llll}0.0000000000000000 & 0.0000000000000000 & 4.0187845410749867\end{array}$
$\mathrm{Al}$
4
Direct
$0.0000000000000000 \quad 0.0000000000000000-0.0000000000000000$
$0.5000000000000000-0.00000000000000000 .5000000000000000$
$\begin{array}{llll}0.5000000000000000 & 0.5000000000000000 & 0.0000000000000000\end{array}$
$\begin{array}{llll}0.0000000000000000 & 0.5000000000000000 & 0.5000000000000000\end{array}$ 
$0.00000000 \mathrm{E}+00 \quad 0.00000000 \mathrm{E}+00 \quad 0.00000000 \mathrm{E}+00$

$0.00000000 \mathrm{E}+00 \quad 0.00000000 \mathrm{E}+00 \quad 0.00000000 \mathrm{E}+00$

$0.00000000 \mathrm{E}+00 \quad 0.00000000 \mathrm{E}+00 \quad 0.00000000 \mathrm{E}+00$

$0.00000000 \mathrm{E}+00 \quad 0.00000000 \mathrm{E}+00 \quad 0.00000000 \mathrm{E}+00$

\section{A.2.2 OSZICAR}

This includes the free energy for each electronic step, where $\mathrm{N}$ is the number of electronic steps, $\mathrm{E}$ is the current free energy, $\mathrm{dE}$ is change in free energy between the last and current free energy. $5 \mathrm{~F}$ represents the final free energy after convergence occurs for the fifth ionic step. The last section of an OSZICAR file is detailed below.

$\mathrm{N} \quad \mathrm{E} \quad \mathrm{dE} \quad \mathrm{deps}$ ncg $\mathrm{rms} \quad \mathrm{rms}(\mathrm{c})$

DAV: $1 \quad-0.401502795801 \mathrm{E}+03 \quad 0.17239 \mathrm{E}-02 \quad-0.18031 \mathrm{E}-0253672 \quad 0.255 \mathrm{E}+00$

$0.221 \mathrm{E}-01$

DAV: $2 \quad-0.401504383900 \mathrm{E}+03 \quad-0.15881 \mathrm{E}-02 \quad-0.17568 \mathrm{E}-0247608 \quad 0.375 \mathrm{E}-01$ $0.127 \mathrm{E}-01$

DAV: $3 \quad-0.401504657332 \mathrm{E}+03 \quad-0.27343 \mathrm{E}-03 \quad-0.22635 \mathrm{E}-0351000 \quad 0.237 \mathrm{E}-01$ $0.115 \mathrm{E}-01$

DAV: $4 \quad-0.401504698951 \mathrm{E}+03 \quad-0.41619 \mathrm{E}-04 \quad-0.39631 \mathrm{E}-0452792 \quad 0.104 \mathrm{E}-01$ $0.978 \mathrm{E}-02$

DAV: $5 \quad-0.401504689634 \mathrm{E}+03 \quad 0.93170 \mathrm{E}-05 \quad-0.65127 \mathrm{E}-0549192 \quad 0.429 \mathrm{E}-02$ $0.100 \mathrm{E}-01$

DAV: $6 \quad-0.401504682709 \mathrm{E}+03 \quad 0.69251 \mathrm{E}-05 \quad-0.16285 \mathrm{E}-0538272 \quad 0.179 \mathrm{E}-02$ $0.102 \mathrm{E}-01$

DAV: $7 \quad-0.401504673349 \mathrm{E}+03 \quad 0.93598 \mathrm{E}-05 \quad-0.19199 \mathrm{E}-06 \quad 18312 \quad 0.946 \mathrm{E}-03$ $0.981 \mathrm{E}-02$

DAV: $8 \quad-0.401504552759 \mathrm{E}+03 \quad 0.12059 \mathrm{E}-03 \quad-0.22889 \mathrm{E}-06 \quad 18512 \quad 0.499 \mathrm{E}-02$ $0.375 \mathrm{E}-02$

DAV: $9 \quad-0.401504173158 \mathrm{E}+03 \quad 0.37960 \mathrm{E}-03 \quad-0.71947 \mathrm{E}-0546256 \quad 0.108 \mathrm{E}-01$ $0.246 \mathrm{E}-01$ 
DAV: $10 \quad-0.401504192861 \mathrm{E}+03 \quad-0.19703 \mathrm{E}-04 \quad-0.50227 \mathrm{E}-0551176 \quad 0.304 \mathrm{E}-02$ $0.253 \mathrm{E}-01$

DAV: $11 \quad-0.401504198040 \mathrm{E}+03 \quad-0.51791 \mathrm{E}-05 \quad-0.37283 \mathrm{E}-0620928 \quad 0.872 \mathrm{E}-03$ $0.249 \mathrm{E}-01$

DAV: $12 \quad-0.401504223205 \mathrm{E}+03 \quad-0.25165 \mathrm{E}-04 \quad-0.31809 \mathrm{E}-07 \quad 15280 \quad 0.662 \mathrm{E}-03$ $0.235 \mathrm{E}-01$

DAV: $13 \quad-0.401504308492 \mathrm{E}+03 \quad-0.85286 \mathrm{E}-04 \quad-0.49261 \mathrm{E}-07$ 15696 $\quad 0.214 \mathrm{E}-02$ 0.195E-01

DAV: $14 \quad-0.401504345387 \mathrm{E}+03 \quad-0.36896 \mathrm{E}-04 \quad-0.16512 \mathrm{E}-06 \quad 16544 \quad 0.442 \mathrm{E}-02$ $0.202 \mathrm{E}-01$

DAV: $15 \quad-0.401504332576 \mathrm{E}+03 \quad 0.12811 \mathrm{E}-04 \quad-0.78803 \mathrm{E}-0631408 \quad 0.515 \mathrm{E}-02$ $0.255 \mathrm{E}-01$

DAV: $16-0.401504382106 \mathrm{E}+03 \quad-0.49530 \mathrm{E}-04 \quad-0.15681 \mathrm{E}-0544472 \quad 0.181 \mathrm{E}-02$ $0.236 \mathrm{E}-01$

DAV: $17 \quad-0.401504357514 \mathrm{E}+03 \quad 0.24592 \mathrm{E}-04 \quad-0.21255 \mathrm{E}-06 \quad 17272 \quad 0.165 \mathrm{E}-02$ $0.240 \mathrm{E}-01$

DAV: $18 \quad-0.401504364701 \mathrm{E}+03 \quad-0.71878 \mathrm{E}-05 \quad-0.46060 \mathrm{E}-07$ 14976 $0.124 \mathrm{E}-02$ $0.226 \mathrm{E}-01$

DAV: $19-0.401504481088 \mathrm{E}+03 \quad-0.11639 \mathrm{E}-03 \quad-0.29493 \mathrm{E}-0546040 \quad 0.896 \mathrm{E}-02$ $0.733 \mathrm{E}-02$

DAV: $20 \quad-0.401504522386 \mathrm{E}+03 \quad-0.41299 \mathrm{E}-04 \quad-0.24834 \mathrm{E}-0541808 \quad 0.915 \mathrm{E}-02$ $0.174 \mathrm{E}-02$

DAV: $21 \quad-0.401504526024 \mathrm{E}+03 \quad-0.36376 \mathrm{E}-05 \quad-0.19927 \mathrm{E}-0540072 \quad 0.318 \mathrm{E}-02$ $0.138 \mathrm{E}-02$

DAV: $22 \quad-0.401504521701 \mathrm{E}+03 \quad 0.43235 \mathrm{E}-05 \quad-0.26492 \mathrm{E}-0617768 \quad 0.866 \mathrm{E}-03$ $0.158 \mathrm{E}-02$

DAV: $23 \quad-0.401504531226 \mathrm{E}+03 \quad-0.95253 \mathrm{E}-05 \quad-0.55396 \mathrm{E}-07 \quad 15008 \quad 0.114 \mathrm{E}-02$ $0.137 \mathrm{E}-02$

DAV: $24 \quad-0.401504529763 \mathrm{E}+03 \quad 0.14633 \mathrm{E}-05 \quad-0.62587 \mathrm{E}-0714976 \quad 0.316 \mathrm{E}-03$ $0.140 \mathrm{E}-02$ 
DAV: $25 \quad-0.401504533246 \mathrm{E}+03 \quad-0.34831 \mathrm{E}-05 \quad-0.20371 \mathrm{E}-0714976 \quad 0.901 \mathrm{E}-03$

$0.141 \mathrm{E}-02$

DAV: $26 \quad-0.401504540646 \mathrm{E}+03 \quad-0.74006 \mathrm{E}-05 \quad-0.23519 \mathrm{E}-07$ 14928 $0.371 \mathrm{E}-02$

$0.172 \mathrm{E}-02$

DAV: $27 \quad-0.401504576367 \mathrm{E}+03 \quad-0.35721 \mathrm{E}-04 \quad-0.30987 \mathrm{E}-0620976 \quad 0.109 \mathrm{E}-01$

$0.274 \mathrm{E}-02$

DAV: $28 \quad-0.401504560871 \mathrm{E}+03 \quad 0.15496 \mathrm{E}-04 \quad-0.62616 \mathrm{E}-07 \quad 15080 \quad 0.268 \mathrm{E}-02$

$0.134 \mathrm{E}-02$

DAV: $29 \quad-0.401504557892 \mathrm{E}+03 \quad 0.29794 \mathrm{E}-05 \quad-0.77154 \mathrm{E}-07$ 15064 $0.555 \mathrm{E}-03$

$0.103 \mathrm{E}-02$

DAV: $30 \quad-0.401504557468 \mathrm{E}+03 \quad 0.42396 \mathrm{E}-06 \quad-0.37330 \mathrm{E}-0714968 \quad 0.336 \mathrm{E}-03$

$$
5 \mathrm{~F}=-.40150456 \mathrm{E}+03 \mathrm{E} 0=-.40150361 \mathrm{E}+03 \mathrm{~d} \mathrm{E}=-.369697 \mathrm{E}-04
$$

imaginary and real dielectric function

\section{A.2.3 OUTCAR}

This is the most important output file in this study, because it contains a detail of all the computational output. A typical OUTCAR file is too long to be included in this paper, however a few important sections are detailed below.

\section{COMPUTATION PARAMETERS SUMMARY}

vasp.5.3.5 31Mar14 (build May 102014 09:33:21) complex

executed on HPConROCKSatMTU date 2015.10.23 10:58:00

running on 32 total cores

distrk: each k-point on 32 cores, 1 groups

distr: one band on NCORES_PER_BAND $=8$ cores, 4 groups 
INCAR:

POTCAR: PAW Al_sv_GW 2Feb2008

POTCAR: PAW Zn_sv_GW 01Dec2010

POTCAR: PAW Al_sv_GW 2Feb2008

$\mathrm{VRHFIN}=\mathrm{Al}: \mathrm{s} 2 \mathrm{p} 1$

$\mathrm{LEXCH}=\mathrm{PE}$

EATOM $=2216.7599 \mathrm{eV}, 162.9273 \mathrm{Ry}$

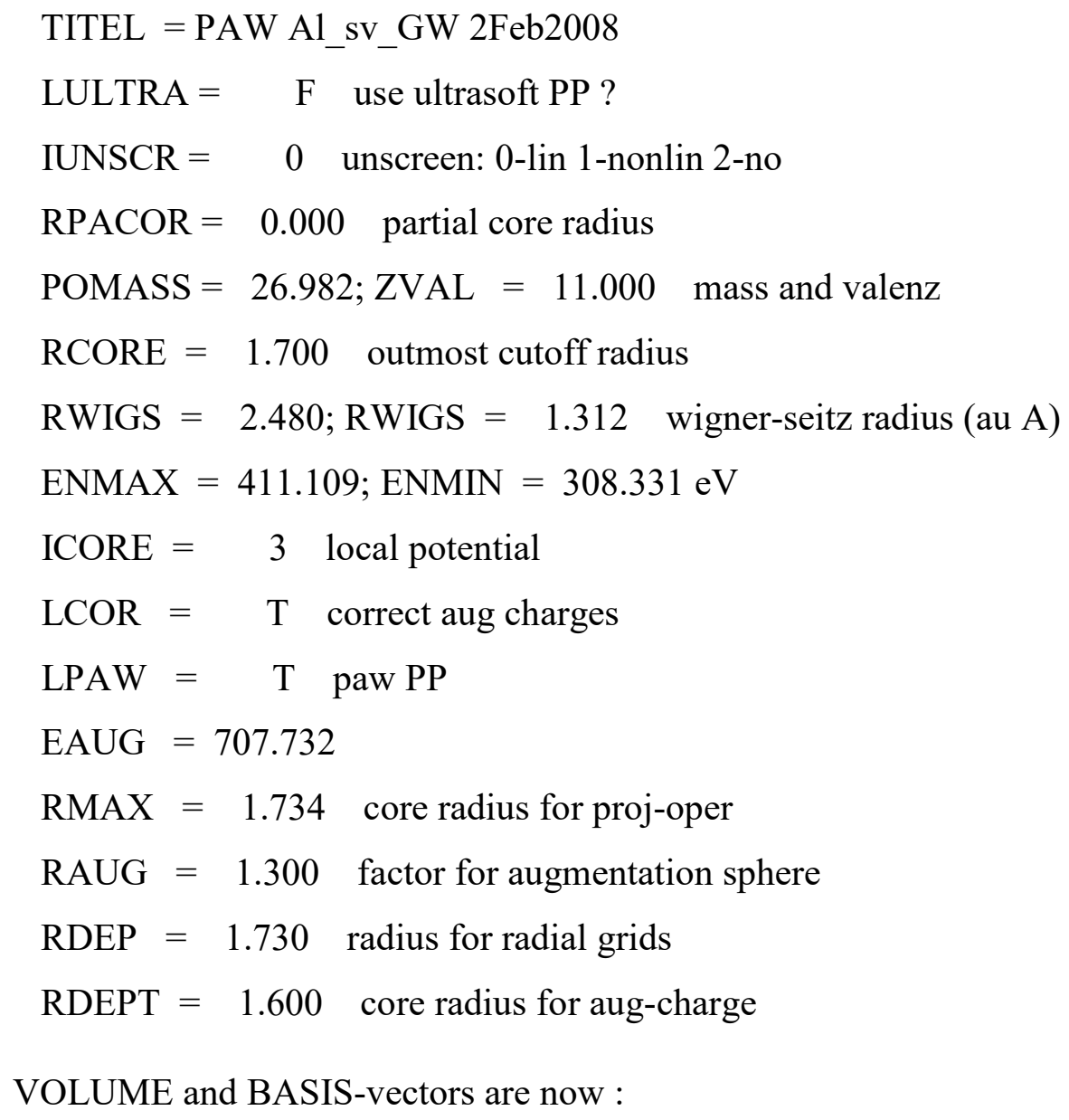




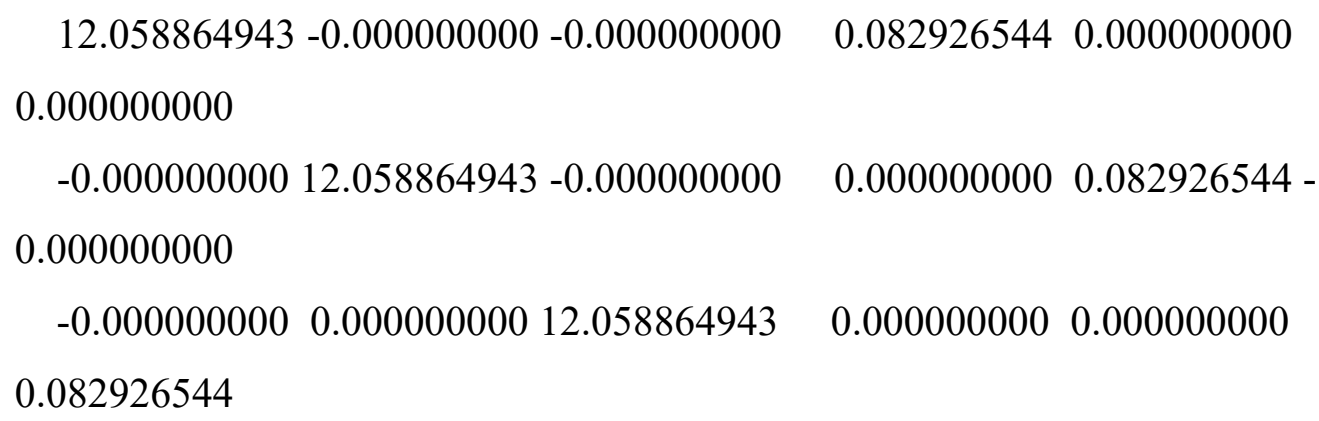

\section{ELECTRICAL CONDUCTIVITY}

electrical conductivity sigma (Mega S m-1) (frequency dependency in vasprun.xml)

$\begin{array}{lll}0.177 & 0.000 & 0.000 \\ 0.000 & 0.177 & 0.000 \\ 0.000 & 0.000 & 0.177\end{array}$

\section{VASP COMPUTATION COST, TIME AND MEMORY}

OPTICS: CPU time 202.38: Wall time 232.70

4ORBIT: CPU time 0.00: Wall time 0.00

total amount of memory used by VASP on root node 469708 . kBytes 


$$
\begin{array}{lc}
\text { base : } & 30000 . \text { kBytes } \\
\text { nonlr-proj: } & 11669 . \text { kBytes } \\
\text { fftplans : } & 18522 . \text { kBytes } \\
\text { grid : } & 24772 . \text { kBytes } \\
\text { one-center: } & 1129 . \text { kBytes } \\
\text { wavefun : } & 383616 . \text { kBytes }
\end{array}
$$

General timing and accounting informations for this job:

Total CPU time used (sec): 68395.719

User time (sec): $\quad 65783.439$

System time (sec): $\quad 2612.280$

Elapsed time (sec): $\quad 94499.464$

Maximum memory used (kb): 1594244.

Average memory used (kb): $\quad 0$.

Minor page faults: 128220

Major page faults: 5

Voluntary context switches: 275599073 


\section{Appendix B}

\section{B.1 Automated bash submission (ABS) scripts}

This script was written to dynamically submit multiple simulation files with one code. It checks all the folders containing the input files to see if the POTCAR files requires concatenation and performs concatenation before submitting using the qgenscript. It is useful for single, binary and ternary alloy systems; it can be expanded to access more than ternary systems. For this code to function properly a few guidelines must be followed:

- For multiple element alloy system, label the non-concatenated POTCAR files of each element as AIPOTCAR and POTCARTM (replace TM with the specific element e.g $\mathrm{Zn}, \mathrm{Zr}, \mathrm{Ni})$.

- Each alloy system folder must include all input files with the appropriately.

- The qgenscript and this ABS script must be in the same folder containing all alloy system folders.

The ABS script is detailed below

\#!/bin/bash

\# Variable for number of files in folder

\# imax is the max number of directories

\# EDITABLE

$\operatorname{imax}=0$

\# Arrange all directories into an array

shopt -s nullglob

array $=(*)$ 
shopt -u nullglob

\#echo $\$\{$ array[i] $\}$

\#echo \$ \{\#array[@]\}

\# Start loop all through all directories present

\# EDITABLE

for $((\mathrm{i}=0 ; \mathrm{i}<=\mathrm{imax} ; \mathrm{i}++))$;

do

\# Assign current array element to a

$\mathrm{a}=($ " $\{$ array $[\mathrm{i}]\} ")$

echo \$a

\# Open current working folder path and copy vasp_535p.sh into it

\# Enter into current working folder

\# EDITABLE

cp vasp_535p.sh /home/otfadayo/research/\$a

$\mathrm{cd} /$ home/otfadayo/research/\$a

\# if to check if POTCAR files need concatenation into one file then removes pieces

\# if POTCAR file existing is already concartenated it submits

if [ -f AlPOTCAR ] \&\& [ -f POTCARZn ] \&\& [ -f POTCARTM ]

then

cat AIPOTCAR POTCARZn POTCARTM > POTCAR

rm -rf AIPOTCAR POTCARZn POTCARTM

qsub vasp_535p.sh

elif [ -f AlPOTCAR ] \&\& [ -f POTCARTM ]

then

cat AIPOTCAR POTCARTM $>$ POTCAR 


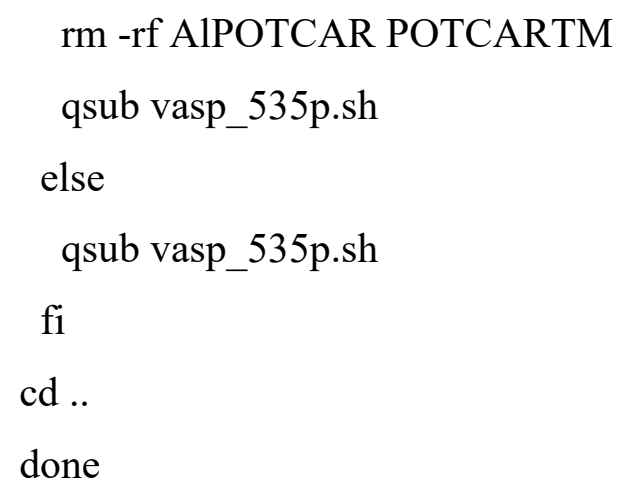

\section{B.2 VASP submission scripts}

Submission scripts for VASP simulations are generated using qgenscript, an in-house utility developed at and unique to Michigan Tech University. Its typical submission script is detailed below. Though, technical aspects of the scripts can occasionally change to reflect the changes in queuing system configuration. As such, users are strongly encouraged to not edit the script and generate a new one for each simulation. Furthermore, users can consult the HPC administrator to generate such scripts in bulk, whenever necessary to save time.

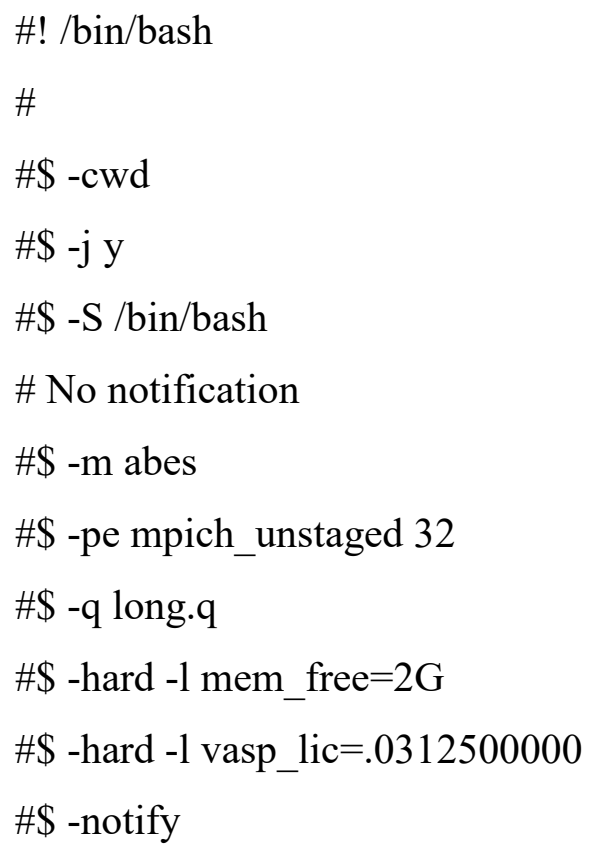


\# Necessary variables

source /share/apps/bin/bashrc

module load intel/2013.0.028

module load vasp/5.3.3

module list

\# Input/Output files

export INPUT_FOLDER="\$ $\{\mathrm{PWD}\} "$

export ARRAY_JOB="'"

\# Run VASP 5.3.3 (standard; parallel)

mpirun -n $\$\{$ NSLOTS $\}$-machine $\$\{$ TMP $\} /$ machines $\$\{$ VASP $\} /$ vasp

\# Unload modules

module unload vasp/5.3.3

module unload intel/2013.0.028

module list 


\section{B.3 Computational cost}

Below is a summary of the computation cost for the various project types worked on.

\begin{tabular}{cc}
\hline Project type: & Binary $\mathrm{Al}_{107} \mathrm{TM}$ \\
\hline Number of ionic steps (NSW) & 5 \\
Number of simulations: & 100 \\
Average total cores per simulation: & 32 \\
NPAR & 4 \\
Average CPU time per simulation (s): & 261 \\
Average wall time (s): & 276 \\
\hline
\end{tabular}

\begin{tabular}{cc}
\hline Project type: & Cluster ternary $\mathrm{Al}_{106} \mathrm{ZnTM}$ \\
\hline Number of ionic steps (NSW) & 5 \\
Number of simulations: & 25 \\
Average total cores per simulation: & 64 \\
NPAR & 4 \\
Average CPU time per simulation (s): & 553 \\
Average wall time (s): & 556 \\
\hline
\end{tabular}

\begin{tabular}{cc}
\hline Project type: & Disperse ternary $\mathrm{Al}_{106} \mathrm{ZnTM}$ \\
\hline Number of ionic steps (NSW) & 5 \\
Number of simulations: & 25 \\
Average total cores per simulation: & 64 \\
NPAR & 4 \\
Average CPU time per simulation (s): & 765 \\
Average wall time (s): & 768 \\
\hline
\end{tabular}




\title{
Appendix C: Reprint copyright permission
}

Copyright
$\begin{aligned} & \text { Clearance } \\ & \text { Center }\end{aligned}$

\begin{abstract}
Please note that, as the author of this Elsevier article, you retain the right to include it in a thesis or dissertation, provided it is not published commercially. Permission is not required, but please ensure that you reference the journal as the original source. For more information on this and on your other retained rights, please visit: httes://www.elsevier.com/about/our-business/policies/copvright=Authorriohts
\end{abstract}

\section{BACK}

CLOSE WINDOW

Cepyright 92018 Cegextight Clearance Center. Ins, All Rights Restrved. Privacy statement. Terms and Conditions. Comments? We would like to hear from you, E-mail us at sustomercareolegeuright.com 